Rhode Island College

Digital Commons @ RIC

\title{
The College Experience of Commuter Students and the Concepts of Place and Space
}

Marissa Weiss

Rhode Island College

Follow this and additional works at: https://digitalcommons.ric.edu/etd

Part of the Higher Education Commons

\section{Recommended Citation}

Weiss, Marissa, "The College Experience of Commuter Students and the Concepts of Place and Space" (2014). Master's Theses, Dissertations, Graduate Research and Major Papers Overview. 95.

https://digitalcommons.ric.edu/etd/95

This Dissertation is brought to you for free and open access by the Master's Theses, Dissertations, Graduate Research and Major Papers at Digital Commons @ RIC. It has been accepted for inclusion in Master's Theses, Dissertations, Graduate Research and Major Papers Overview by an authorized administrator of Digital Commons @ RIC. For more information, please contact digitalcommons@ric.edu. 
THE COLLEGE EXPERIENCE OF COMMUTER STUDENTS AND THE CONCEPTS OF PLACE AND

SPACE

BY

MARISSA WEISS

A DISSERTATION SUBMITTED IN PARTIAL FULFILLMENT OF THE REQUIREMENTS FOR THE DEGREE OF

DOCTOR OF PHILOSOPHY

IN

EDUCATION

UNIVERSITY OF RHODE ISLAND

AND

RHODE ISLAND COLLEGE

2014 
DOCTOR OF PHILOSOPHY OF EDUCATION DISSERTATION

$\mathrm{OF}$

MARISSA WEISS

APPROVED:

Dissertation Committee:

Major Professor Annemarie Vaccaro

Peter Adamy

Julie Horwitz

Roberta Sue Pearlmutter

RIC: $\quad$ Karen Castagno

Dean, Feinstein School of Education - RIC

URI: $\quad$ Nasser H. Zawia

Dean, The Graduate School - URI

UNIVERSITY OF RHODE ISLAND

AND

RHODE ISLAND COLLEGE

2014 


\begin{abstract}
The demographics of the college student population, the dearth of research on commuter students, and the pervasive negative stereotypes of commuters indicate that an appreciation of the commuter student experience is important for the future of higher education (Dugan et al., 2008; Jacoby, 1989; Krause, 2007). The Digest of Education Statistics 2011 reports that in academic years 2003-04 and 2007-08 85.8\% of all students enrolled at postsecondary institutions did not live in on-campus housing (Snyder \& Dillow, 2012). Despite their status as the numerical majority, commuter students are still considered nontraditional (Orgren, 2003). Due to the variations in commuter student populations, it is important for each institution to study its commuters, and to use that information to guide policy and programs, instead of basing decisions on data collected nationwide or at a particular institution (Dugan et al., 2008; Jacoby, 1989). As the vast majority of State College undergraduate students commute (Office of Institutional Research and Planning, 2012), it is necessary to have an understanding of the phenomenon of commuting. To gain this understanding, the theoretical frames of critical theory, campus ecology, and phenomenology were used to guide the exploration of two research questions:
\end{abstract}

1. How do commuter students make meaning of their college experience?

2. How do commuter students describe the role of campus space and place in their college experience?

For this study I interviewed ten participants, asked them to collect photos that represented their college lives, interviewed them about their photos (participant-driven photo elicitation), and conducted gallery walk focus groups in which the participants' photos were displayed and they had an opportunity to discuss the themes present in the 
photos. Through general inductive thematic analysis, as well as the trustworthiness measures of member checking, peer debriefing, and triangulation, three overarching themes emerged: commuter students and dorm people, "How difficult it is for commuters" (Victoria), but we're used to it, and finding a "second home" (Lindsay). These themes, along with a review of the findings through the lenses of the theoretical frameworks, were used to develop recommendations for both practice and research related to commuter students. 


\section{ACKNOWLEDGMENTS}

I would like to thank my Major Professor, Annemarie Vaccaro, for all of her encouragement, feedback, and guidance throughout the dissertation process. She helped me to see that my original idea of looking at event security practices at three different institutions would be a bit overwhelming for a dissertation (three IRB approval processes - yikes!) and could be a more appropriate project for future research. As she and many others in the $\mathrm{PhD}$ program remarked, the dissertation is not your life's work; it is the beginning of your research career. Annemarie gave me the autonomy to take ownership of my research and encouraged me to follow my own path and to trust my instincts. She said numerous times during the process, "you are on the right track!"

The members of my dissertation committee have been very helpful as well. Thanks to Julie for her expertise in Photovoice and visual research methodology. Thanks to Sue for her investment in student success and her ability to look at systems from a different perspective in order to effectively challenge and support students. Thanks to Pete for his encouragement of my efforts to sit with students in their cars to understand this specific aspect of commuter culture. It is from this pilot study that the idea for the dissertation research emerged. And thanks to Rebecca for agreeing to figure out how to sign the electronic signature forms (no easy feat!) and join us as the outside committee member.

I could not have done this study without my wonderful participants who were willing to share a piece of themselves, reflect on their experiences, and take the time to capture their college lives in photos. In addition to informing this research and shedding light on the commuter student experience, they helped me to reflect on my 
assumptions of what it means to attend college and to reexamine my role in Student Affairs and higher education.

Last, but not least, I would like to thank my family. My best friend and life partner, Phil, has been a supportive and loving presence - always there to listen when I had enough of the whole dissertation thing and just wanted the madness to end. My parents, Rosalie and Peter, encouraged me throughout the process, even when they did not quite understand all of the PhD requirements. Thanks to Doll Face (aka Grandma Rae) as she is our sunshine, our only sunshine, she makes us happy, when skies are grey. And thanks to Grandpa Jack, who turned 98 in June 2013; he is truly an inspiration and reminds us to value our relationships and to keep our memories alive. 


\section{TABLE OF CONTENTS}

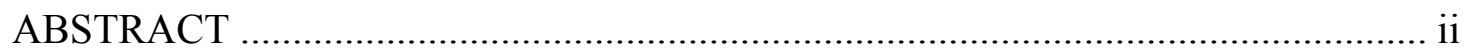

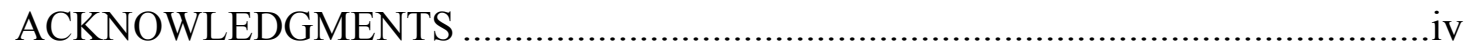

TABLE OF CONTENTS ...............................................................................

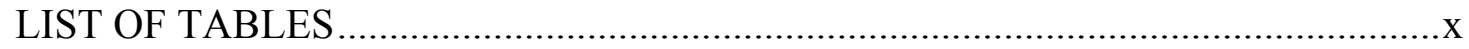

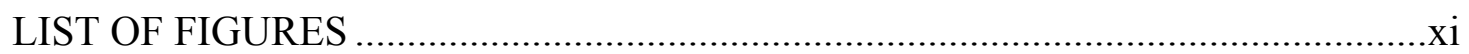

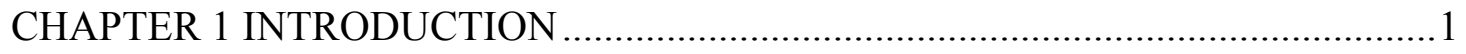

My Background and Interest in the Topic........................................................

Statement of the Problem .......................................................................................... 3

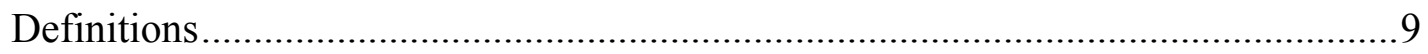

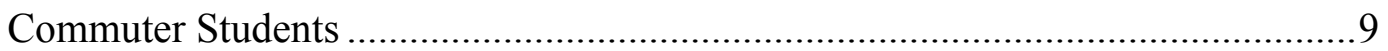

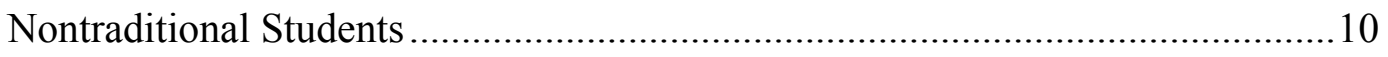

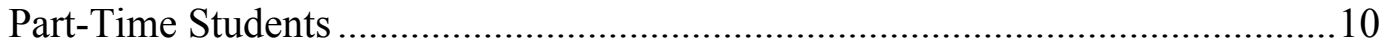

CHAPTER 2 REVIEW OF LITERATURE........................................................ 11

Residential Model of American Colleges ................................................................. 11

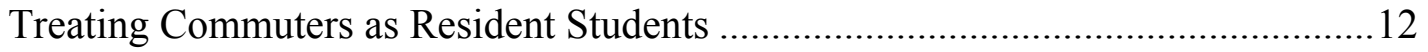

Comparing Commuters to Resident Students .................................................. 13

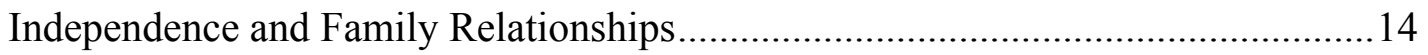

Fallacy of Assuming Commuter Population Homogeneity ................................... 15

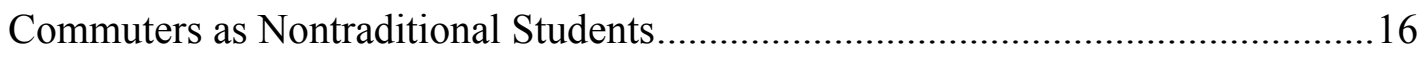

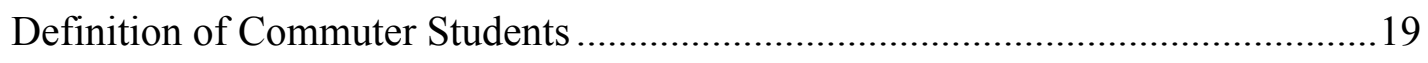

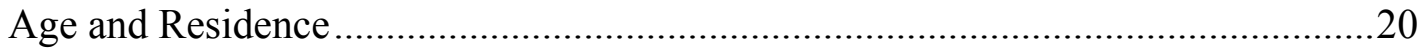

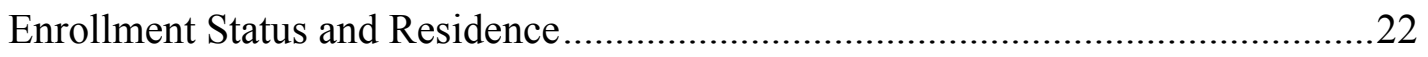

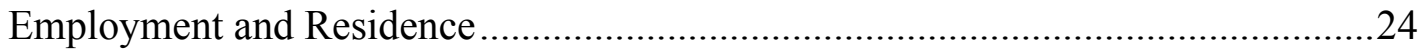

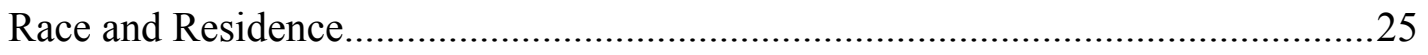

Challenging Traditional Student Development Paradigms...................................26

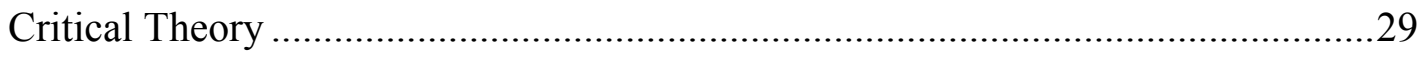

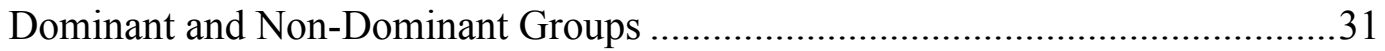




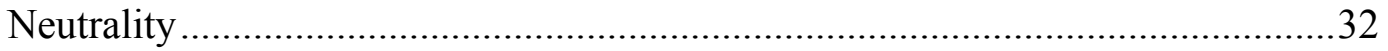

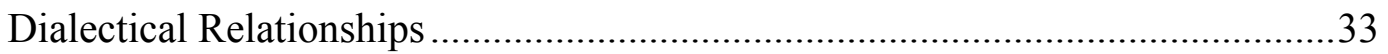

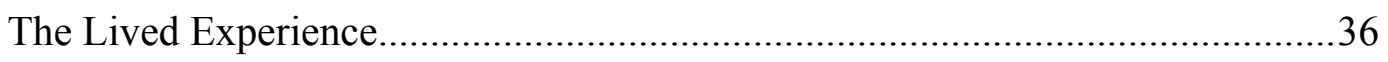

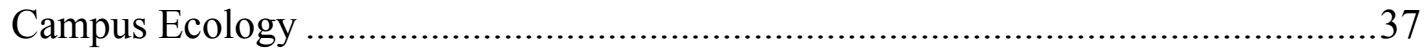

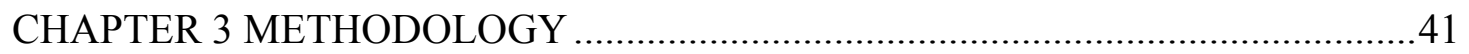

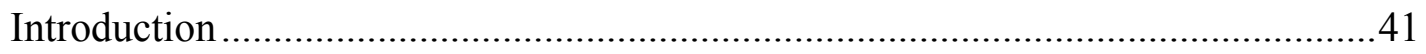

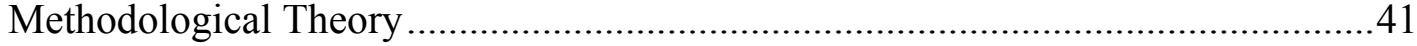

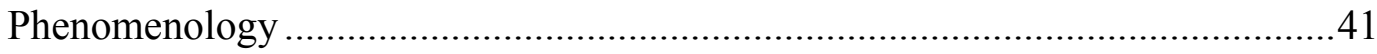

Phenomenologically Based Interviewing ..................................................45

Participant-Driven Photo-Elicitation ..............................................................4 47

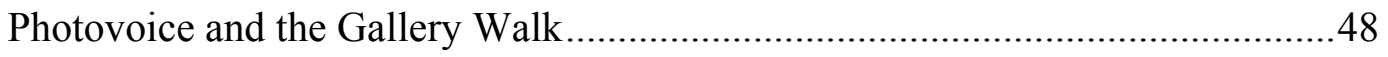

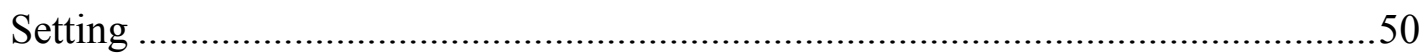

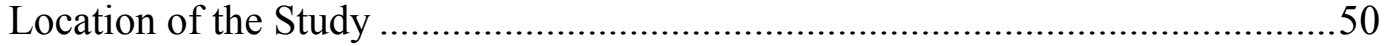

General Characteristics of the Study Population ..............................................50

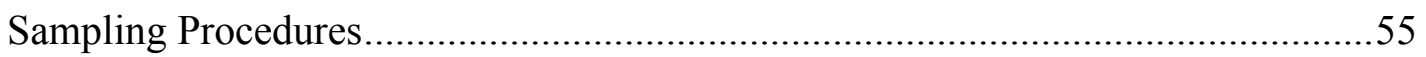

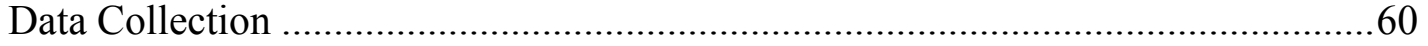

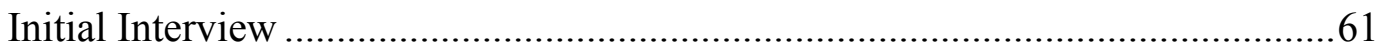

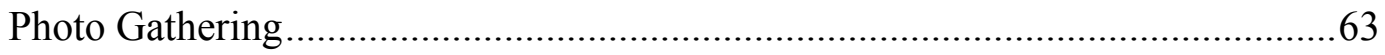

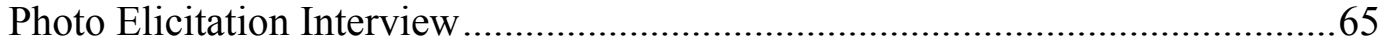

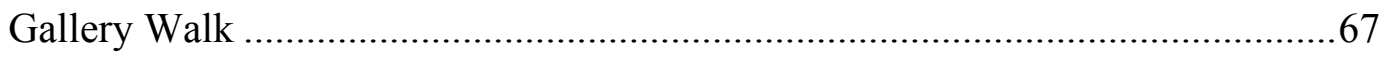

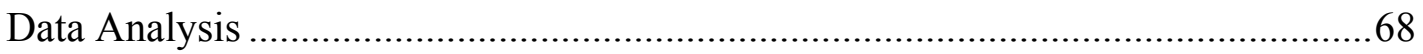

General Thematic Inductive Analysis ...............................................................69

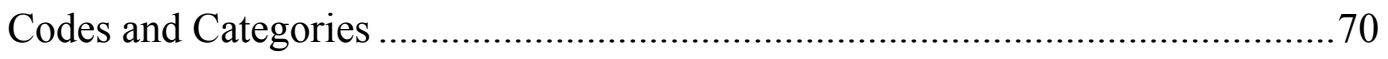

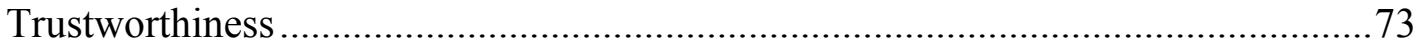

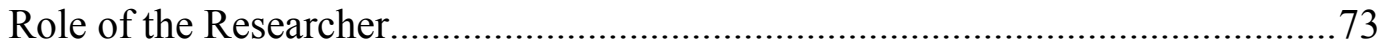

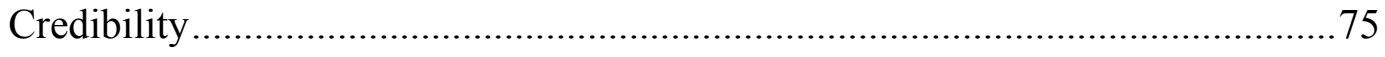

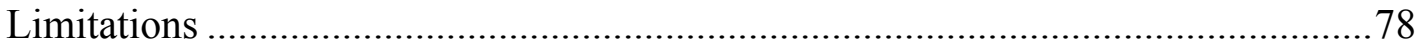

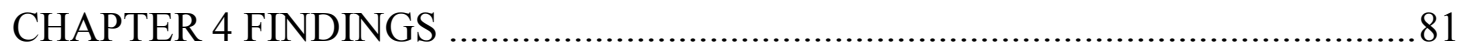

Commuter Students and Dorm People ............................................................. 81

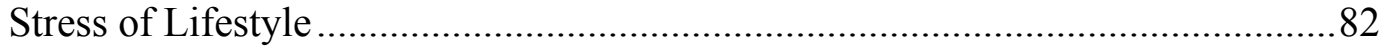




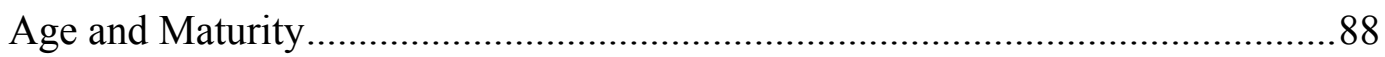

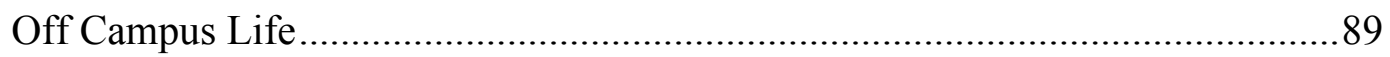

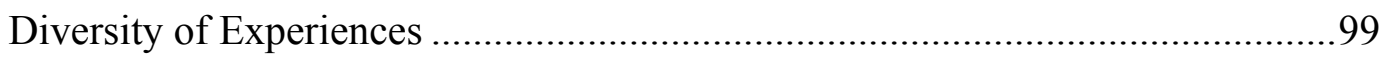

"How Difficult it is for Commuters" (Victoria), But We're Used to It ...................108

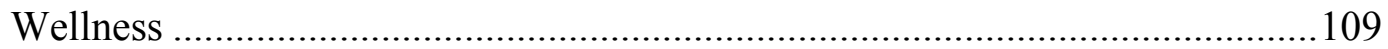

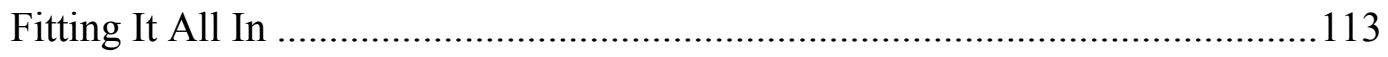

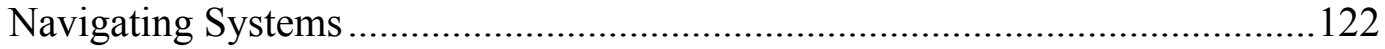

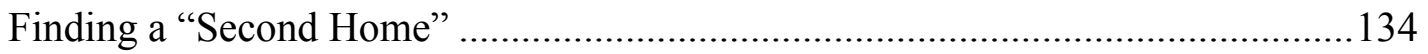

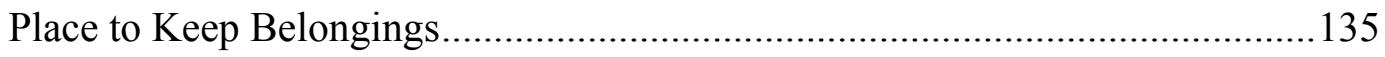

Place for Peace and Quiet...........................................................................136

Places for Social Interaction and Ownership......................................................145

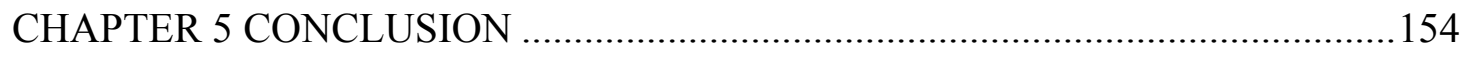

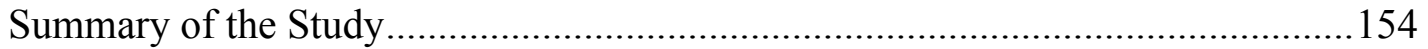

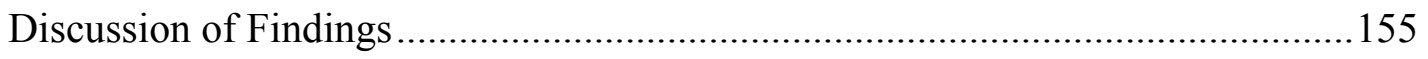

How Commuter Students Make Meaning of Their College Experience..............155

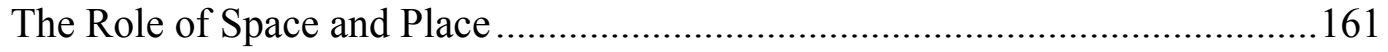

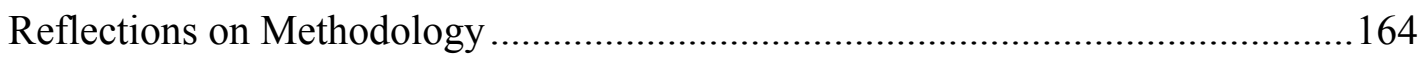

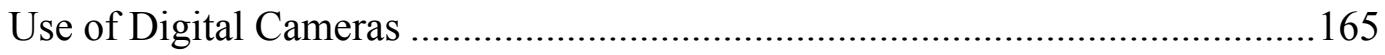

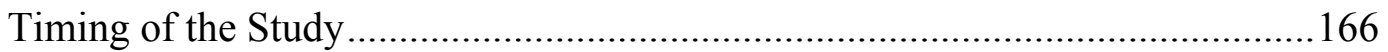

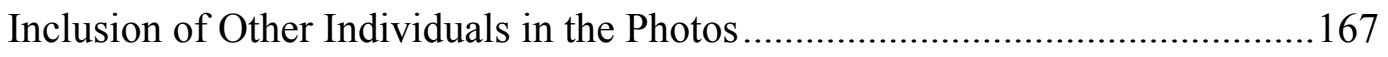

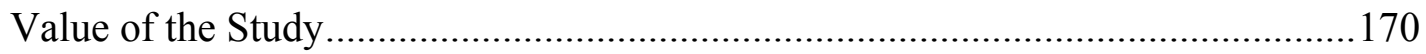

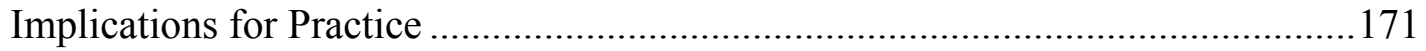

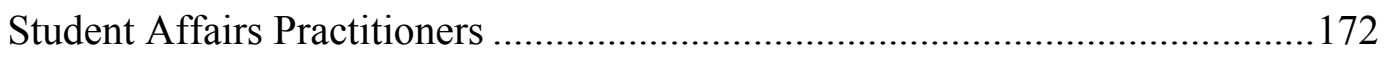

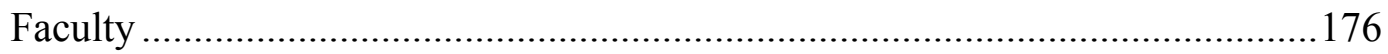

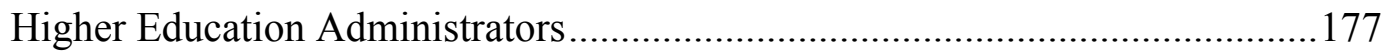

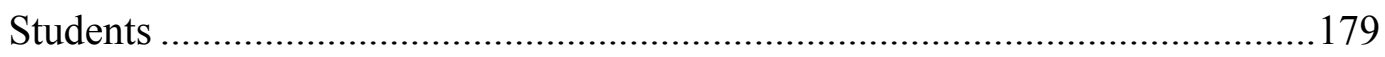

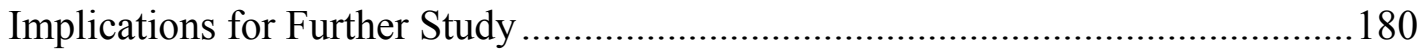

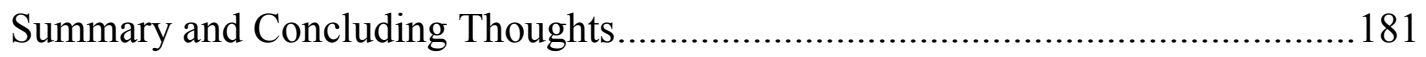

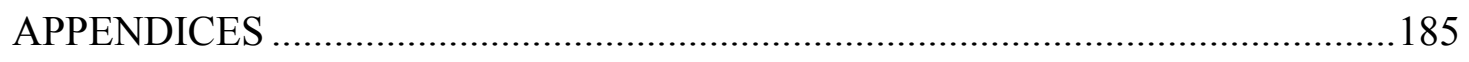

Appendix A: Data Collection Timeline …………………..................................185 


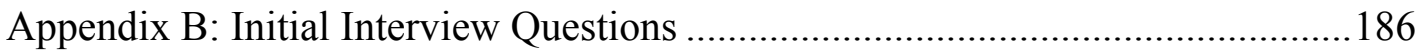

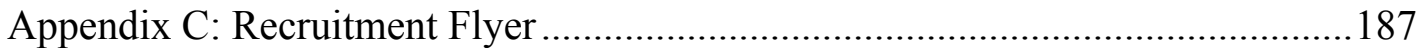

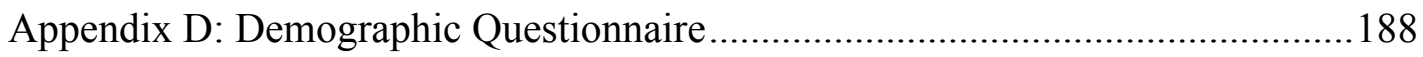

Appendix E: Photo Gathering Protocol ..............................................................189

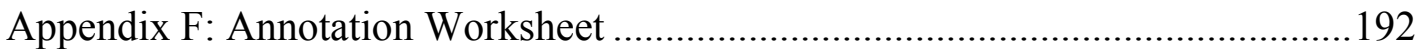

Appendix G: Photo Elicitation Interview Questions................................................193

Appendix H: Gallery Walk Prompt Questions: .....................................................195

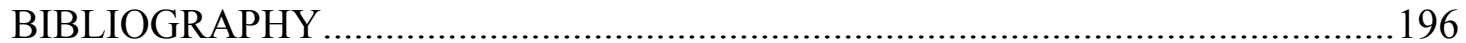




\section{LIST OF TABLES}

TABLE

PAGE

Table 1. Distribution of institutions and enrollments by classification category (Carnegie Foundation for the Advancement of Teaching, 2010)

Table 2. Four-year institutions by size and setting (Carnegie Foundation for the Advancement of Teaching, 2010) .5

Table 3. Percent of postsecondary institutions with campus housing and the mean percent of students living in campus housing at institutions with housing by institutional characteristics: 1996 (Lewis, Farris \& Greene, 1997, p. 7)

Table 4. Definitions of commuter students

Table 5. Fall 2012 Official Undergraduate Enrollment Data: Breakdowns by Commuter vs. Resident (State College Institutional Research and Planning, personal communication, July 31, 2013)

Table 6. Fall 2012 Racial Composition of Commuter and Residential Populations (calculated from data from State College Office of Institutional Research) (State College Institutional Research and Planning, personal communication, July 31, 2013)

Table 7. State College Student Census 2012: Commuter-Related Item Frequency Distributions (State College Institutional Research and Planning, personal communication, July 31, 2013)

Table 8. Study Participant Characteristics

Table 9. Evolution of Categories and Themes 


\section{LIST OF FIGURES}

FIGURE

PAGE

Figure 1. "Junk in the back." Photo taken and titled by Sasha to show how she carried around all of her stuff in the backseat of her car.

Figure 2. "Projects to help me out later in life." Photo taken and titled by Stephen to show his Technical Theater projects.

Figure 3. "The downside of commuting" - photo taken and titled by Sarah to show the price of gas and how expensive it can get.

Figure 4. "Having a photo of my son on my backpack keeps me motivated" - photo taken and titled by Annie to represent her relationship with her son.

Figure 5. "Family makes a crazy life worthwhile" - photo taken and titled by Angela of her niece to represent the important role of family in her life.

Figure 6. "Free dinner" - photo taken and titled by Sasha to show the meals prepared for her and her partner by her partner's parents.

Figure 7. "Magic gathered by first [State College] friend" - photo taken and titled by Stephen of his set of magic cards the represented his first friendship at State College

Figure 8. "InterVarsity Christian Fellowship is my spiritual home at [State College]" photo taken and titled by Annie of the on campus office space of the InterVarsity Christian Fellowship student organization

Figure 9. "Steph \& Sarah" - photo taken and titled by Victoria of her weekly lunch date at the Campus Dining Center with two of her friends.

Figure 10. "Where I spent a lot of my time with friends when I could" - photo taken and titled by Victoria of the "back of the dorms at [State College]....

Figure 11. "Beginning the day" - photo taken and titled by Patrick to show the view of the bay from his backyard. 101

Figure 12. "Every beginning has an end and every end starts a new beginning" - photo taken and titled by Kara of her community college diploma - whited out areas added to maintain confidentiality. 106

Figure 13. "Dinner on a busy night" - photo taken and titled by Angela to show her typical meal at the College's café 
Figure 14. "Hard at work by day, classes at night" - photo taken and titled by Angela of her desk at her off campus job.

Figure 15. "Will I go to the gym today?" - photo taken and titled by Sasha to show her attempts to go to the gym

Figure 16. "The daily struggle for parking spots" - photo taken and titled by Sarah of a very full campus parking lot used by students

Figure 17. "Walking outside in bad weather - photo taken and titled by Sarah to show a rainy day on campus

Figure 18. "Snow causes less parking spaces" - photo taken and titled by Victoria of snow piles taking up parking spaces.

Figure 19. "Where I would wait for the bus" - photo taken and titled by Patrick to show the pile of snow surrounding his bus stop

Figure 20. "Can't, no time" - photo taken and titled by Sasha of her unmade bed to represent her busy schedule

Figure 21. "I make $\$ 8.30$ an hour at the Dining Center" - photo taken and titled by Annie of her Dining Center uniform - name of the College blacked out on the hat to protect confidentiality

Figure 22. "It takes me an hour and fifteen minutes just to get to [the downtown bus depot]. Then it's another 20 minute ride to [State College]" - photo taken and titled by Annie to represent her long commute on the bus to campus

Figure 23. "The last leg home" - photo taken and titled by Patrick to show the walk from his bus stop to his home.

Figure 24. "I don't have the internet at home, so I type most of my work at school" photo taken and titled by Annie of text she had typed on a computer in one of the campus labs explaining her lack of access to the internet at home.

Figure 25. "Hallway of tours and time" - photo taken and titled by Stephen of the hallway in the performing arts building. As he would spend time waiting on these benches College tour guides would come by, sharing information about the College to prospective students and other visitors

Figure 26. "Waiting" - photo taken and titled by Stephen of the place where he would wait for the bus. 138

Figure 27. "Library Glass" - photo taken and titled by Marcela of the directory sign in 
the entrance of the Library

Figure 28. "The State College Library is my favorite building on campus. I like to hide in the basement and study" - photo taken and titled by Annie of a view of the Library from across the Quad.

Figure 29. "How the day is spent" - photo taken and titled by Sarah of the cubicle in the Library at which she spends a lot of time throughout the day - doing homework, eating meals, charging her devices, and relaxing

Figure 30. "My second home" - photo taken and titled by Lindsay of the inside of her car with her snacks, bag, and laptop, which was hooked up to her car's stereo system

Figure 31. "My sanctuary" - photo taken and titled by Lindsay of the College's dark room. As a photography major, she spent a lot of time there working on projects .. 143

Figure 32. "The Library has been very useful to me over the years" - photo taken and titled by Victoria of the front of the Library....

Figure 33. "It's more than just the politics" - photo taken and titled by Kara of the student government logo. Her involvement with student government helped her to make friends and get involved on campus.

Figure 34. "My hidden savior" - photo taken and titled by Sasha of her silver coffee mug on her desk at the campus computer lab.

Figure 35. "Cool art formation" - photo taken and titled by Victoria to show a place on campus where her and a friend would spend time.

Figure 36. "Back view of people - getting off bus 2 home" - photo taken and titled by Marcela of people sitting in front of her on her ride home on the bus

Figure 37. "Thank you" - photo taken and titled by Kara of her family at her Aunt's wedding 


\section{CHAPTER 1}

\section{INTRODUCTION}

\section{My Background and Interest in the Topic}

Before coming to work at State College (the name of the institution has been changed to protect participant confidentiality) I honestly did not pay much attention to commuter students. Aside from a semester at Mercer County Community College (MCCC) in New Jersey between my transition from Ithaca College to the University of Delaware, my entire undergraduate experience involved living on or very close to campus. It never occurred to me that commuting to a four-year institution was even an option. Of course "going to college" meant living on campus. These assumptions were reinforced through my employment as a Resident Assistant at the University of Delaware and as a Hall Director during my graduate studies at Colorado State University. Furthermore, my first professional position in Student Activities at Duke University allowed me to continue my ignorance of commuter students as Duke has a three year live in requirement, so virtually all students live on campus.

However, when I left Duke to work at State College, all of my assumptions were turned upside down. In contrast to Duke's highly residential environment, $85 \%$ of State College undergraduate students commute (Office of Institutional Research, 2012). So I needed to completely rethink my approach to students and my work in student affairs. Drawing on my limited commuter experience at MCCC, my interactions with State College students, and research published by scholars studying nontraditional and commuter students, I began to challenge my assumptions in order to find a more appropriate philosophy and practice. Instead of assuming that students 
would come to any program I planned if I offered free pizza, I organized events around class times and considered that events needed to be worthwhile enough for students to either come from off camps or stay after their classes to attend.

Furthermore, co-curricular programming competed not just with homework and other on campus events, but with opportunities to earn money at off campus jobs, family responsibilities, and spending time with friends from the neighborhood. I needed to come to terms with the fact that the College students were managing multiple roles and responsibilities. If I was lucky, State College and Student Activities came somewhere after work and family on students' list of priorities.

While the changes I made in my approach to Student Activities were helpful, they still fell short of truly embracing the distinct lifestyle, needs, and views of commuter students. I was operating under assumptions based on what I believed that these students valued, as opposed to hearing them share their perspective. Though it would have been easy for me to focus solely on the individual and blame these students for "not making the most of their college experience," "not understanding the importance of college and getting involved on campus," and "not being 'real' college students" - all myths of commuter students identified by Rhatigan (1986) - that approach would have been both ignorant and unethical. Instead of trying to fit these students into a socially acceptable mold of the traditional college student, I sought to broaden my understanding of the college experience by putting the oft-ignored voices of commuter students in the forefront. As noted throughout this dissertation, commuter students are the majority of college-going individuals (Snyder \& Dillow, 2012, p. 342) and that population is set to continue to increase due to the rise in 
nontraditional student enrollment (Choy, 2002), thus the perpetual focus on residential students as the traditional and more desirable population is outdated.

\section{Statement of the Problem}

The demographics of the college student population, the dearth of research on commuter students, and the pervasive negative stereotypes of commuters indicate that an appreciation of the commuter student experience is important for the future of higher education. In regards to demographics, though State College has a high percentage of commuter students at $85 \%$ (Office of Institutional Research and Planning, 2012), the Digest of Education Statistics 2011 reports that in academic years 2003-04 and 2007-08 85.8\% of all students enrolled at postsecondary institutions did not live in on-campus housing (Snyder \& Dillow, 2012). It is important to note that this percentage includes students at all types of higher education institutions - twoyear, four-year, public, private, and for profit. Furthermore, finding this piece of data was very difficult as NCES does not include any tables devoted specifically to student housing status in the Condition of Education Report (Aud et al., 2010; Aud et al., 2011; Aud et al., 2012; Planty et al., 2009; U.S. Department of Education, 2013), the central publication of the U.S. Department of Education for reporting enrollment statistics at educational institutions in the United States, or the Digest of Education Statistics (Snyder \& Dillow, 2011, 2012) - a clearinghouse of data from both government and private entities on the American education system, prekindergarten through graduate school. The $85.8 \%$ statistic came from a table entitled "Number and percentage of students enrolled in postsecondary institutions, by level, disability status, and selected student characteristics: 2003-04 and 2007-08" (Snyder \& Dillow, 
2011, p. 342). It appears that the purpose of including student housing status in this table is to compare the living arrangements of all students with those of students with disabilities.

In order to situate State College in the context of similar institutions, data from the Carnegie Foundation for the Advancement of Teaching (2010) are helpful.

According to the Carnegie Classifications (Carnegie Foundation for the Advacement of Teaching, n.d.) State College is considered medium (3,000 to 9,999 students), fouryear, primarily nonresidential (less than $25 \%$ of degree-seeking undergraduates living on campus) - coded as M4/NR. M4/NR make up 3.8\% of all institutions and enroll $6.7 \%$ of all students, as seen in Table 1.

Table 1

Distribution of institutions and enrollments by classification category (Carnegie Foundation for the Advancement of Teaching, 2010)

\begin{tabular}{|c|c|c|c|c|c|}
\hline Category & Institutions & Percent & Total Enrollment & Percent & Average Enrollment \\
\hline VS2: Very small two-year & 500 & $10.8 \%$ & 155,396 & $0.7 \%$ & 311 \\
\hline S2: Small two-year & 634 & $13.7 \%$ & 904,360 & $4.4 \%$ & 1,426 \\
\hline M2: Medium two-year & 389 & $8.4 \%$ & $2,038,857$ & $9.8 \%$ & 5,241 \\
\hline L2: Large two-year & 199 & $4.3 \%$ & $2,251,077$ & $10.9 \%$ & 11,312 \\
\hline VL2: Very large two-year & 99 & $2.1 \%$ & $2,435,454$ & $11.7 \%$ & 24,601 \\
\hline VS4/NR: Very small four-year, primarily nonresidential & 272 & $5.9 \%$ & 189,445 & $0.9 \%$ & 696 \\
\hline VS4/R: Very small four-year, primarily residential & 70 & $1.5 \%$ & 58,357 & $0.3 \%$ & 834 \\
\hline VS4/HR: Very small four-year, highly residential & 140 & $3.0 \%$ & 94,047 & $0.5 \%$ & 672 \\
\hline S4/NR: Small four-year, primarily nonresidential & 200 & $4.3 \%$ & 510,944 & $2.5 \%$ & 2,555 \\
\hline S4/R: Small four-year, primarily residential & 164 & $3.5 \%$ & 397,967 & $1.9 \%$ & 2,427 \\
\hline S4/HR: Small four-year, highly residential & 321 & $6.9 \%$ & 652,537 & $3.1 \%$ & 2,033 \\
\hline M4/NR: Medium four-year, primarily nonresidential & 175 & $3.8 \%$ & $1,382,152$ & $6.7 \%$ & 7,898 \\
\hline M4/R: Medium four-year, primarily residential & 172 & $3.7 \%$ & $1,230,094$ & $5.9 \%$ & 7,152 \\
\hline M4/HR: Medium four-year, highly residential & 132 & $2.8 \%$ & 721,755 & $3.5 \%$ & 5,468 \\
\hline L4/NR: Large four-year, primarily nonresidential & 134 & $2.9 \%$ & $3,843,134$ & $18.5 \%$ & 28,680 \\
\hline L4/R: Large four-year, primarily residential & 103 & $2.2 \%$ & $2,419,563$ & $11.7 \%$ & 23,491 \\
\hline L4/HR: Large four-year, highly residential & 41 & $0.9 \%$ & 770,900 & $3.7 \%$ & 18,802 \\
\hline ExGP: Exclusively graduate/professional & 23 & $0.5 \%$ & 19,032 & $0.1 \%$ & 827 \\
\hline (Special focus institution) & 850 & $18.3 \%$ & 652,589 & $3.1 \%$ & 768 \\
\hline (Not classified) & 16 & $0.3 \%$ & 0 & $0.0 \%$ & NA \\
\hline All Institutions & 4,634 & $100.0 \%$ & $20,727,660$ & $100.0 \%$ & 4,473 \\
\hline \multicolumn{6}{|c|}{ SOURCE: 2010 Carnegie Classification; National Center for Educations Statistics, IPEDS Fall Enrollment (2009). } \\
\hline \multicolumn{6}{|l|}{ NOTES } \\
\hline e counted separately if reporte & over the co & $f_{0}$ & & & \\
\hline
\end{tabular}

When the scope of the data is redefined to include only four-year institutions, as shown in Table 2 (calculated from using the downloaded data from Table 1), M4/NR make up $9.1 \%$ of institutions and enroll $11.26 \%$ of students. Furthermore, when 
combining all primarily nonresidential four-year institutions (VS4/NR, S4/NR, M4/NR, and L4/NR), 40.6\% of four-year institutions are primarily nonresidential and enroll $48.28 \%$ of students attending four-year institutions.

Table 2

Four-year institutions by size and setting (Carnegie Foundation for the Advancement of Teaching, 2010)

\begin{tabular}{|c|c|c|c|c|}
\hline Category & Institutions & Percent & $\begin{array}{l}\text { Total } \\
\text { Enrollment }\end{array}$ & Percent \\
\hline $\begin{array}{l}\text { VS4/NR: Very small four-year, primarily } \\
\text { nonresidential }\end{array}$ & 272 & $14.14 \%$ & 189,445 & $1.54 \%$ \\
\hline $\begin{array}{l}\text { VS4/R: Very small four-year, primarily } \\
\text { residential }\end{array}$ & 70 & $3.64 \%$ & 58,357 & $0.48 \%$ \\
\hline $\begin{array}{l}\text { VS4/HR: Very small four-year, highly } \\
\text { residential }\end{array}$ & 140 & $7.28 \%$ & 94,047 & $0.77 \%$ \\
\hline $\begin{array}{l}\text { S4/NR: Small four-year, primarily } \\
\text { nonresidential }\end{array}$ & 200 & $10.40 \%$ & 510,944 & $4.16 \%$ \\
\hline S4/R: Small four-year, primarily residential & 164 & $8.52 \%$ & 397,967 & $3.24 \%$ \\
\hline S4/HR: Small four-year, highly residential & 321 & $16.68 \%$ & 652,537 & $5.32 \%$ \\
\hline $\begin{array}{l}\text { M4/NR: Medium four-year, primarily } \\
\text { nonresidential }\end{array}$ & 175 & $9.10 \%$ & $1,382,152$ & $11.26 \%$ \\
\hline $\begin{array}{l}\text { M4/R: Medium four-year, primarily } \\
\text { residential }\end{array}$ & 172 & $8.94 \%$ & $1,230,094$ & $10.02 \%$ \\
\hline $\begin{array}{l}\text { M4/HR: Medium four-year, highly } \\
\text { residential }\end{array}$ & 132 & $6.86 \%$ & 721,755 & $5.88 \%$ \\
\hline $\begin{array}{l}\text { L4/NR: Large four-year, primarily } \\
\text { nonresidential }\end{array}$ & 134 & $6.96 \%$ & $3,843,134$ & $31.32 \%$ \\
\hline L4/R: Large four-year, primarily residential & 103 & $5.35 \%$ & $2,419,563$ & $19.72 \%$ \\
\hline L4/HR: Large four-year, highly residential & 41 & $2.13 \%$ & 770,900 & $6.28 \%$ \\
\hline All Four-Year Institutions & 1,924 & $100.00 \%$ & $12,270,895$ & $100.00 \%$ \\
\hline
\end{tabular}

This data clearly show that nearly half of all four-year institutions are predominantly commuter campuses.

The limitation of the Carnegie data is that it does not show how many students at these institutions actually commute. The Digest of Education Statistics 2011 (Snyder \& Dillow, 2012) mentioned earlier noted that $85.8 \%$ of students at all postsecondary institutions commute, but that data is a bit misleading as it includes two-year institutions, which often do not provide campus housing, as is indicated by 
Stated alternatively, the mean percent of students not living on campus at public fouryear institutions was $74 \%$. While this data are a bit outdated, they do give a snapshot of the magnitude of the number of students at four-year institutions that commute.

Though this data are helpful in showing the size of the commuter student population, it is also beneficial to briefly discuss the characteristics of students who are more likely to commute. Since the end of World War II and the introduction of the GI Bill, the student body has been shifting from the traditional White upper or middleclass male, 18-22 years old, who lives on campus and attends college full time (with no outside family or work obligations) (Pascarella, 2006) to students "who are older than typical college students, work because of financial necessity, belong to the first generation in their family to attend college, do not live on campus, attend part-time, or are members of minority racial groups" (Ogren, 2003, p. 640). The magnitude of this shift can be seen in a special report focusing on nontraditional students (Choy, 2002) issued by NCES as an addendum to the Condition of Education 2002. The report notes that "almost three-quarters of undergraduates are in some way "nontraditional"" (Choy, 2002, p. 26). NCES defines nontraditional status as students who display any of the following characteristics: financial independence, part time enrollment, not attending college directly after high school graduation, full time employment, single parenthood, claiming dependents, and having a GED (as opposed to a high school diploma) (Choy, 2002). While commuting to campus is not included in this list, the research discussed in Chapter 2 suggests that there is an intersection between student living arrangement and many of these nontraditional characteristics - most notably the markers of age, enrollment status, race, and employment. 
As the current college student population is increasingly nontraditional and composed of a large number of commuter students, research is necessary to ensure that the policies and procedures at higher education institutions are addressing the needs of these students. Unfortunately there appears to be a lack of research on commuter students. For example, a quick ERIC search of academic journal articles using the key term "commuter student" yielded 91 results. A similar search using the key term "residential student" yielded 331 results. More specifically, it is noted throughout the literature on commuter students that there is a distinct lack of research on these students and their college experience (Dugan et al., 2008; Jacoby, 1989; Krause, 2007). Furthermore, as expanded upon in Chapter 2, much of the research focuses on comparing commuter students to resident students (Banning \& Hughes, 1986; Dugan, Garland, Jacoby \& Gasiorski, 2008; Jacoby, 1989), which sets up a dichotomy that fundamentally limits the ability to fully appreciate the depth and complexity of the commuter student experience.

Lastly, an authentic understanding of the commuter student experience is hampered by pervasive negative stereotypes of commuters as apathetic (Jacoby, 2000; Krause, 2007; Ortman, 1995), disengaged (Dugan et al., 2008; Kuh, Gonyea, \& Palmer, 2001), inferior (Holdsworth, 2006; Ortman, 1995), and immature due to continued ties to family members (Ortman, 1995). Thus, research that makes a concerted effort to avoid these biases and give voice to the commuter student perspective is an important contribution to promoting an appreciation for the commuter experience.

\section{Significance of the Study}


Due to the variations in commuter student populations, it is important for each institution to study its commuters, and to use that information to guide policy and programs, instead of basing decisions on data collected nationwide or at a particular institution (Dugan et al., 2008; Jacoby, 1989). As the vast majority of State College undergraduate students commute (Office of Institutional Research and Planning, 2012), it is necessary to have an understanding of the phenomenon of commuting. In addition, due to the prevalence of commuter student myths and the tendency to view college from a residential-dominated perspective, using a phenomenological qualitative approach is especially appropriate as it helps to keep preconceived notions in check (Groenewald, 2004) by concentrating on the essence of the commuter experience from the perspective of the students.

\section{Research Questions}

To keep with the phenomenological underpinnings of the study, the research questions focus on how participants make meaning of their experiences (Gibson \& Hanes, 2003) and how they view their existence in the world.

1. How do commuter students make meaning of their college experience?

2. How do commuter students describe the role of campus space and place in their college experience?

\section{Definitions}

\section{Commuter Students}

Students who are not living in college-owned housing (Dugan et al., 2008; Ortman, 1995; Jacoby, 2000). 


\section{Nontraditional Students}

Bean \& Metzner (1985), who are cited by many other researchers (Gilardi \& Guglielmetti, 2011; NCES, 2002; Ogren, 2003; Tan \& Pope, 2005; Wolfe, 1993) identify age, enrollment status, and residence as the three key markers of nontraditional students. As such, they define a nontraditional student as "older than 24, or does not live in a campus residence (e.g. is a commuter), or is a part-time student, or some combination of these three factors" (p. 489).

\section{Part-Time Students}

Undergraduate students enrolled in less than twelve credits for a given semester or quarter (U.S. Department of Education, Integrated Postsecondary Data System, n.d.) 


\section{CHAPTER 2}

\section{REVIEW OF LITERATURE}

In an effort to explore the paradox between the actual student population and the outdated myths of traditional college students, the review of related literature will address five central themes: the residential model of the American college system, the manifestation of the residential model in policies and procedures, nontraditional student identity, the heterogeneity of the commuter student population, and the limited applicability of widely used student development frameworks. Building on this discussion, the second half of the review of literature will focus on the theoretical frameworks of critical theory and campus ecology.

\section{Residential Model of American Colleges}

From the very beginning of the establishment of the higher education system in the United States, commuter students were not included as the target population (Jacoby, 1989; Likins, 1986). The American system is based on the residential college model of British institutions, most notably Oxford and Cambridge. The most prestigious American universities, Harvard, Yale, and Princeton, all incorporate the residential philosophy into their educational mission (Jacoby, 1989). However, the residential view of college as both home and academic center does not reflect the actual experience of the vast majority of American college students who do not live on campus (Dugan et al., 2008; Jacoby, 2000; Wilson, 2003). Furthermore, as Pascarella (2006) notes, the stereotype of the typical college student as a White middle-class

male, 18-22 years old, who lives on campus and attends college full time (with no outside family or work obligations), is an outdated myth. Since the end of World War 
II, there has been a continual increase in the number of veterans, older students (above the traditional college age of 18-22), students of color, and students from lower socioeconomic backgrounds attending college; these students are much more likely to commute to campus due to a variety of issues (Chickering, 1974; Choy, 2002; Jacoby, 1989), including family responsibilities, marital status, financial concerns, and employment.

\section{Treating Commuters as Resident Students}

Despite the increase in numbers, colleges have not adapted their approach or services to address these changes (Likins, 1986). Dugan et al. (2008) note that colleges continue to utilize "programs and interventions designed for residential students with commuter student populations under the assumption that the effect on learning will be equivalent" (p. 283). The practice of ignoring or misunderstanding the unique needs of the commuter student "silent majority" (Wilson, 2003) is evident in a series of myths about commuters identified by Rhatigan (1986). These myths include the belief that commuters are "less committed to their education" (p. 4), "are less able academically" (p. 5), and "have no interest in the campus beyond their classes" (p. 5). Despite the lack of empirical evidence to support these claims, colleges continue to function under these assumptions (Dugan et al., 2008; Inman \& Pascarella, 1997).

Nontraditional students are at risk of feeling unsafe and unwelcome on campus (Griffin et al., 2008; Munoz, 2009; Museus \& Quaye, 2009; Pope et al., 2009). Even though the vast majority of current college students do not fit the mold of a "typical college student," colleges continue to base their physical design and services on a mythical concept of universal student development (Pope et al., 2009) that excludes 
many of their students. To compound the problem, instead of examining the defects in their assumptions and the structures based on those assumptions (McLauren, 2003), colleges continually view students from non-dominant groups as operating at a deficit (Davies, Safarik, \& Banning, 2003; Villalpando, 2003) and in need of adjusting to the institution (Strange \& Banning, 2001; Museus, 2008) - as opposed to the institution adjusting to them.

\section{Comparing Commuters to Resident Students}

This negative perception is further strengthened by the fact that most of the existing research is focused on comparing residential and commuter students (Banning \& Hughes, 1986; Dugan et al., 2008; Jacoby, 1989). Chickering (1974) published the first major study of commuter students, Commuting Versus Resident Students, which has shaped and reinforced the misperceptions and negative stereotypes of commuters (Jacoby, 1989) and the myths identified by Rhatigan (1986). Chickering's view of commuters as "the have nots" and resident students as "the haves" (p. 49) on the basis of pre-college characteristics of lower socio-economic status, limited past achievements, and less educated parents supports the view that commuters are functioning at a deficit, instead of simply experiencing college from a unique and valid perspective (Jacoby, 1989). The entire explanation for the lower levels of commuter satisfaction, engagement, and academic success found in Chickering's (1974) quantitative comparison of commuter and resident students is focused on the influence of pre-college student characteristics, and ignores the role of the institution in creating and perpetuating these trends (Banning \& Hughes, 1986). In other words, commuter student disengagement is assumed to result from students' disadvantaged 
backgrounds, instead of the institution's failure to acknowledge and accommodate the unique needs of commuter students. Furthermore, Jacoby (1989) challenges the validity of Chickering's findings on the basis that "in this work, the residential college experience is the benchmark against which all others should be measured. In it, the academic goals and developmental tasks of resident students remain unchallenged as the 'correct' ones" (p. 22). The commuter student experience is thus seen as nonnormative and marginal.

\section{Independence and Family Relationships}

In following in this vein of the residential experience as the "correct" one, some of the literature operates under the assumption that students need to leave home and break their ties with their families in order to successfully transition into the role of an independent, successful college student (Smith, 1989). Holdsworth (2006) comments on this assumption, noting that "popular discourses about students leaving home for the first time illustrate how going to university is recognized as an important rite of passage for young people" (p. 496). This notion is problematic as it makes three major assumptions: 1) all students are "young people"; 2) students who do not live on campus reside with their parents; and 3) living on campus is the only path for students to gain independence.

Furthermore, this line of reasoning ignores the central role that family and home community often play in the lives of commuters. Unfortunately, this role is not typically acknowledged or appreciated by institutions of higher education (Alfond, 1998; Holdsworth, 2006; Torres, Gross \& Dadashova, 2010). Commuter students, especially those in urban areas, often need to help provide financial support for their 
families (Alfond, 1998; Torres, Gross \& Dadashova, 2010), so severing ties to their relatives is not an option. In her study of inner-city commuter students, Alfond (1998) found that these students ended up feeling marginalized by both their home and school communities in that the individuals in these two environments did not realize the conflicting demands being placed on the students. The college sees responsibility and independence as spending time on campus, attending class, and completing assignments, while the family sees responsibility and independence as providing financial and emotional support. Broadening the target population of college activities to include home friends and family members, and placing a higher value on students' community activities could help to bridge the gap (Alfond, 1998).

\section{Fallacy of Assuming Commuter Population Homogeneity}

Along with varying degrees of connection to their families and home communities, commuter students are a highly diverse group, with significant differences according to living situation, employment status, educational goals, age, enrollment status (full time versus part time), and other factors (Rhatigan, 1986). Unfortunately NCES does not gather data that cross-reference living arrangement with employment status, race, age, sex, or enrollment status (A. D'Amico, personal communication, October 28, 2013), therefore national data is not available. However, research on commuter students often emphasizes the population's diversity (Jacoby, 2000; Kuh, Gonyea, \& Palmer, 2001; Newbold, Mehta, \& Forbus, 2011; Ortman, 1995; Rhatigan, 1986). The significance of this diversity is emphasized by Banning and Hughes (1986), who note that "commuting students represent the largest and most complex and diverse aggregation of students in higher education" (p. 23). 
Unfortunately, there are few studies that acknowledge the complexity of the commuter student population (Dugan et al., 2008). In one of these rare studies, Dugan et al. (2008) found significant differences between independent (living on their own) commuters and dependent (living with parents) commuters in relation to their leadership efficacy.

\section{Commuters as Nontraditional Students}

The diversity of the commuter student population is related to its overlap with students deemed "nontraditional." In the report Nontraditional Undergraduates (Choy, 2002), NCES noted that $73 \%$ of students in 1999-2000 met one of the following criteria for nontraditional status: financial independence, part time enrollment, not attending college directly after high school graduation, full time employment, single parenthood, claiming dependents, and having a GED (as opposed to a high school diploma). However, the report goes on to explain that the term "nontraditional" is imprecise (Choy, 2002). To illustrate this point, a series of articles

on nontraditional students were reviewed (Bean \& Metzner, 1985; Christie \& Dinham, 1991; Choy, 2002; Gilardi \& Guglielmetti, 2011; Gilman et al., 2006; Ogren, 2003; Tan \& Pope, 2005; Taniguchi \& Kaufman, 2005; Westbrook \& Sedlacek, 1991; Wolfe, 1993; Wyatt, 2011) to get a sense for the variations in definitions. Bean \& Metzner (1985), who are cited by many other researchers (Choy, 2002; Christie \& Dinham, 1991; Gilardi \& Guglielmetti, 2011; Ogren, 2003; Tan \& Pope, 2005; Wolfe, 1993) identify age, enrollment status, and residence as the three key markers of nontraditional students. As such, they define a nontraditional student as "older than 24, or does not live in a campus residence (e.g. is a commuter), or is a part-time student, 
or some combination of these three factors" (p. 489). As this definition appears to have the most agreement amongst researchers, it is the definition utilized in this study. However, it is important to explore the other aspects of the various definitions to make a point about the social construction of nontraditional identity and the difficulty of providing appropriate services for students.

The five most common components of definitions of nontraditional students are employment, age, residence, enrollment status, and race. As will be discussed later in the review, these components are somewhat interrelated. It is interesting to note that there is disagreement over the exact age for inclusion; some studies vaguely note that nontraditional students are "older than typical college students" (Ogren, 2003). Setting up this dichotomy of typical versus atypical appears to reinforce the notion that "older" students are outside of the norm. Most studies use the general guideline of 25 years of age and older (Christie \& Dinham, 1991; Gilardi \& Guglielmetti, 2011; Gilman et al., 2006; Tan \& Pope, 2005; Westbrook \& Sedlacek, 1991; Wyatt, 2011), except for Taniguchi \& Kaufman (2005) who include students ages 21 and older. To explain this decision, Taniguchi \& Kaufman (2005) note that "although researchers often use the cut-off age of 25 to define nontraditional students, this would result in the exclusion of men and women who become parents and go on to college in their early 20s" (p. 918). This attention to students who have children in their early 20 s incorporates the belief that childbearing is a nontraditional student experience and, furthermore, does not address students who may have had children before the age of 21. 
In terms of family status, the Nontraditional Undergraduates report (Choy, 2002) is the only study to identify single parenthood and dependents as nontraditional indicators. Furthermore, it is also the only study to include high school diploma and timing of college entry as components. The discrepancies between the NCES definition and those of other studies are significant in that it is the way that the U.S. Department of Education identifies nontraditional students. Thus, it is curious that the NCES definition does not incorporate one of Bean \& Metzner's (1985) key factors: residence.

The lack of one unifying definition is problematic in that a characteristic that one institution views as nontraditional, might be seen as traditional by another institution. Therefore, there is little consistency regarding best practices, demographic information, research, support personnel, and necessary resources. For example, the Rhode Island College Vision 2015 Strategic Plan (2010) mentions nontraditional students under the section on facilities, noting that "consideration of issues of accessibility will promote the College's service to nontraditional students" (p. 7). In this sense, it appears that nontraditional students are students with physical disabilities. The School of Arts and Sciences at Rutgers University provides support services for nontraditional students, which includes "returning adults whose formal education has been interrupted, students needing to pursue higher education on a part-time basis, postbaccalaureate students pursuing a second undergraduate degree or major, nonmatriculating students, international students, and veterans" $(2011$, ๆ 1). At Western Oregon University, Non-Traditional Student Services supports students who "are over the age of 25 , are returning to school after an extended break, or have 
children" (n.d., @ 1). Thus, the conversations, policies, and programs surrounding nontraditional students would be markedly different at Rhode Island College, Rutgers University, and Western Oregon University as a result of the differing definitions.

\section{Definition of Commuter Students}

While not as complicated as the definition of nontraditional students, there is also some disagreement over the definition of commuter students. As illustrated in Table 4, not living in college-owned housing appears to be the main definition, however, there is no consensus as to if students who live in temporary off-campus residences for the purposes of attending college are considered commuter students. Again this lack of agreement can create issues for consistency in policies, best practices, services, and resources related to commuter students.

Table 4

Definitions of commuter students

\begin{tabular}{|l|l|}
\hline Sources & Definitions \\
\hline Dugan et al (2008) & Not living in college-owned housing \\
\hline Ortman (1995) & Not living in college-owned housing \\
\hline Jacoby (2000) & Not living in college-owned housing \\
\hline $\begin{array}{l}\text { Newbold, Mehta, \& } \\
\text { Forbus (2011) }\end{array}$ & $\begin{array}{l}\text { "Commuting students are considered to be living outside } \\
\text { of the county where the school operates and have not } \\
\text { relocated to attend the school" (p. 147). }\end{array}$ \\
\hline $\begin{array}{l}\text { Inman \& Pascarella } \\
\text { (1997) }\end{array}$ & $\begin{array}{l}\text { Not living in university residence halls (excluding } \\
\text { students who live in off-campus apartments and sorority } \\
\text { and fraternity houses) }\end{array}$ \\
\hline Aud et al. (2011) & $\begin{array}{l}\text { Living off campus without family members and living } \\
\text { off campus with family members (derived from data } \\
\text { collected through the Free Application for Federal } \\
\text { Student Aid (FAFSA)) }\end{array}$ \\
\hline
\end{tabular}

For example, Commuter Student Services at the University of California, San Diego seems to view commuter students predominantly as those who live in off-campus apartments, as their programs center on finding housing, being a renter, and 
information for landlords (2011). Commuter Student Services at the University of Memphis defines a commuter student as "one who DOES NOT live on campus or in any University-owned property, and must utilize various modes of transportation to travel to and from classes" - emphasis included in original citation - $(2011, \mathbb{\uparrow} 1)$ and seems to focus their services around transportation and lounge space (though they do also host an off-campus housing fair). So, as with the myriad of definitions of nontraditional students, the disagreement over which students are considered commuters has important implications for how these students are perceived and served.

\section{Age and Residence}

While all of the aspects of a student's nontraditional status are individually important, a student's identity as a commuter is central in that it is highly related to the other aspects of nontraditional status and that it represents a disconnect from the residential college model. With the exception of a small number of universities that offer family housing or have a few older students who decide to live in the residence halls, most older students (those above the age of 25) are commuters. Some universities have specific policies that address the age of students in the residence halls:

- Harris-Stowe State University: "Harris-Stowe State University does not offer undergraduate housing in the residence halls to married undergraduates or undergraduates with families. The age limit is 25 . The residence hall is set up for traditional students. At this time, we do not offer nontraditional student housing" (n.d., $\mathbb{\| 1 8 )}$ 
- Lincoln University: “All unmarried students under 21 years of age, whose primary domicile is beyond a 60-mile radius of Lincoln University, are required to live in the University residence halls for four consecutive semesters" $(2011$, ๆ 1$)$.

- Piedmont College: "Though there is no official age limit to our residence hall students we do ask that all residential students be at least 18 years old and under 25 years old" $(2012$, \11).

- Nazareth College: "Visitation in residence halls are interpreted as a social visit of relatively short duration. A guest is defined as an individual, age 18-25, who is not a Nazareth College student. A visitor is defined as an individual, age 1825, who is a student at Nazareth College, but might live off campus or in another room, suite or apartment" $(2011, \mathbb{\uparrow} 1)$.

- Luther College: "All full-time students are required to live in college-owned housing unless married, of nontraditional age (23 years or older), or commuting from their legal guardians’ homes” $(2011, \uparrow 3)$.

- College of Charleston: "Presently we do not provide housing for married or graduate students. Our priority is undergraduate students because of the demand for on-campus housing. Is there an age limit for living on-campus? Yes. The age limit is 24 . The residence halls are set up for traditional students. At this time, we do not offer older student housing" $(2011, \mathbb{\Upsilon}$ \20).

According to these policies older students are not afforded the opportunity to live on campus, forbidden to visit fellow students who live on campus, or exempt from the traditional policy of requiring students to live on campus. 
Furthermore, even when there are no age restrictions for living in the residence halls, aspects of traditional college housing may not be accommodating to the needs of older students, and thus make it unrealistic for older students to live on campus. For example, Framingham State University (2012) does not allow any students to remain in the residence halls during school breaks, nor are students allowed to move in early. While this policy may sound reasonable, it could be a major issue for students for whom college housing is their permanent residence - as opposed to a student who returns to his/her family's home when not at school.

Another issue is related to transportation. Both the Massachusetts College of Liberal Arts (2012) and Salem State University (2012) prohibit freshman students from having cars on campus, so an adult student with an off campus job and other off campus responsibilities would have to find alternative transportation. Lastly, the guest policies of college residential life departments can create difficulties for students with families, even if they are not allowed to live with them on campus. At the University of Massachusetts - Lowell (2009) students must seek special permission from the Resident Director at least 48 hours in advance in order to have guests under the age of 18 stay overnight. So, if a student would like to have his/her children spend the night with him/her on campus this policy could be a hassle. In total, these policies can make living on campus an unattractive option for older students.

\section{Enrollment Status and Residence}

As with older students, there is a disconnect between residential life policies and part-time students. For Fall 2010, 36.7\% of undergraduate students enrolled in postsecondary institutions in the United States attended part-time (Aud et al., 2012, p. 
162). Over the last 40 years this percentage has fluctuated from a low of $28.3 \%$ in 1970 to a high of $42.2 \%$ in 1992 (Aud et al., 2012, p. 162). It is important to note that these figures include both four-year and two-year institutions. For Fall 2010, 22.2\% of undergraduate students enrolled at four-year institutions attended part time (Aud et al., 2012, p. 164). While this figure is lower than the percentage for students at all postsecondary institutions, it is still almost a quarter of four-year college students. This percentage has remained somewhat constant over the past 40 years, with a low of $19.8 \%$ in 1970 and 2005, and a high of 24.2\% in 1990 (Aud et al., 2012, p. 164).

Data on the numbers of part-time students are related to the discussion of commuter students as most universities require full-time enrollment in order to live on campus, which eliminates the opportunity for part-time students to live in the residence halls. Examples of policies reflecting enrollment requirements are listed below:

- University of New Haven: "To be eligible for on-campus housing, you must be a full-time undergraduate student making normal progress toward a degree" (n.d., ๆ 3).

- University of Virginia: Housing Division General Provisions state that the University is authorized to "give priority to a full-time enrolled student over a part-time student” (2011, ๆ 5).

- Fairleigh Dickinson University: "If a resident fails to enroll or maintain full time status, or fails to pay fees, the resident agrees to vacate the premises within 24 hours after original notification. Failure to do so will result in room and board charges accruing and disciplinary action being taken” $(2009$, ๆ 3$)$. 
- Valparaiso University: "Part-time, graduate, and law students are welcome to apply to live on-campus, however first priority for housing is given to full-time undergraduates. The University reserves the right to deny housing to individuals who are not full-time undergraduate students” (n.d., ๆ 3).

As seen in these examples, part-time students are either completely barred from living on campus or allowed to apply, but are given lower priority. Thus, part-time students are typically commuter students (Bean \& Metzner, 1985; Ogren, 2003).

\section{Employment and Residence}

Though not all students who are employed while attending college are commuters, there is some evidence that commuters generally work at least one job and/or commute in order to save money. Bozick (2007) confirms this relationship, commenting that "two options for partially defraying the costs of college are to work while enrolled and to live at home" (p. 263). Ogren (2003), in discussing the history of normal schools, which have a long tradition of educating commuter students to enter the field of teaching, stresses that "present-day students attend part-time and commute because they cannot afford to attend full-time or live on campus and/or their family or

life commitments prohibit them from devoting themselves exclusively to the pursuit of higher education" (p. 646). Furthermore, employment is often listed as one of the main demands drawing students' time and attention away from academic pursuits (Gilardi \& Guglielmetti, 2011; Stage, 2008; Wolfe, 1993). Gilman et al (2006) even include employment as part of their definition of a commuter campus: "Commuter campuses have a large number of part-time, older, married, and working students who reside off campus" (p. 19). Unfortunately, with rising tuition costs (and room and board fees), 
decreasing grant funding, and accumulating debt through student loans, many students have no other choice than to work while attending college (Bozick, 2007; Deil-Amen \& Turley, 2007).

\section{Race and Residence}

There is a general lack of research (Koch, 1999) and data (D'Amico, personal communication, October 28, 2013) related to race and residence. However, some of the literature on commuter students, campus climate, and students of color note a connection to living arrangement. For example, Braxton, Hirschy, and McClendon (2004) note that "minority students who attend commuter institutions often have jobs, live away from campus, and have demanding family responsibilities" (p. 49). This sentiment is echoed by Turley (2009), who explains that "the ability to attend college close to home is often among the most important factors that U.S. high school students, especially minorities and the socioeconomically disadvantaged, consider" (p. 126). Students of color also seem to be working more hours than their White counterparts. According to the Condition of Education 2010 (NCES, 2011) of fulltime undergraduate students, $5.4 \%$ of White students, $6.5 \%$ of Black students, and $8.5 \%$ of Hispanic students work more than 35 hours each week. So, while no national data is available on the racial identity of commuter students (D'Amico, personal communication, October 28, 2013), the relationship between race and the tendency to work while in college and to undertake significant family responsibilities implies that many students of color commute.

In addition, the realities of racism may discourage students of color from living on campus. Student perceptions of campus climate, defined as "the current perceptions 
and attitudes of faculty, staff, and students regarding issues of diversity on a campus" (Rankin \& Reason, 2005), influences their sense of belonging (Johnson, et al., 2007). Numerous studies on campus climate (Cabrera, Nora, Terenzini, Pascarella \& Hagedorn, 1999; D’Augelli \& Hershberger, 1993; Hurtado, 1992; Jones, Castellanos, \& Cole, 2002; Locks, Hurtado, Bowman \& Oseguera, 2008; Rankin \& Reason, 2005; Reid \& Radhakrishnan, 2003; Suarez-Balcazar, Orellana-Damacela, Portillo, Rowan \& Andrews-Guillen, 2003) found negative effects of campus climate for students of color. These negative effects include social and academic withdrawal (Cabrera et al., 1999), disincentive to interact with Whites and become integrated into the majority dominant campus community (Cabrera et al., 1999), feeling unsafe on campus (D’Augelli \& Hershberger, 1993), perception of differential treatment based on race (Hurtado, 1992), not feeling of a sense of belonging (Locks et al., 2008), and a perceived lack of institutional support for diversity (Jones, Castellanos, \& Cole, 2002). In general, students of color perceived the campus climate as hostile, alienating, and unwelcoming. This negative perception of campus climate may influence their decision to live at home.

\section{Challenging Traditional Student Development Paradigms}

The limited understanding of the commuter student experience is exacerbated by the reliance on student development theory that is based on research conducted with residential students (Bean \& Metzner, 1985; Gilardi \& Guglielmetti, 2011), most notably Tinto's (1987) theory of student departure. Braxton, Hirschy, and McClendon (2004) discuss the immense influence of Tinto due to the paradigmatic stature of his work. More specifically, they explain that "paradigmatic status connotes the 
considerable consensus among scholars of college student departure concerning the potential validity of Tinto's theory" (p. 7). Tinto's (1987) synthesis of the existing research on college student retention, including the National Longitudinal Study of high school data, and looking at that data through the lens of Emile Durkheim's study of suicide resulting from social isolation, led to the development of the theory of student departure. This theory centers on the notion that "some degree of social and intellectual integration must exist as a condition for continued persistence" (Tinto, 1987, p. 119). Simply put, if a student does not feel connected to the campus community he or she is more likely to drop out. While this concept might seem like common sense, it counters the belief that students drop out solely due to poor classroom performance. While there are students for whom this statement is true, "less than $15 \%$ of all institutional departures on the national average take the form of academic dismissal" (Tinto, 1987, p. 53).

Though this data is a bit outdated, Tinto's theory continues to serve as the basis for much of the current student involvement research (Baker, 2007; Cabrera et al., 1999; D’Augelli \& Hershberger, 1993; Guiffrida, 2003; Harper \& Quaye, 2007; Locks et al., 2008; Museus, 2008). Baker (2007) criticizes Tinto's generalization that all students, regardless of race, assimilate to the dominant campus culture using the same process, noting that "his theory does not adequately account for the experiences of minority college students” (p. 276). Yosso, Smith, Ceja, and Solórzano (2009) are also critical of Tinto's theory, taking issue with his insistence that students need to separate themselves from their home communities and leave "behind their previous attitudes and behaviors" (p. 677) in order to become integrated into the campus community and 
graduate. To the contrary, students of color often find strength in the support of their families (Turley, 2009) and need the counterspaces of cultural centers and ethnic student organizations to maintain their sanity and sense of self (Guiffrida, 2003). It is through these counterspaces that many students of color form connections to the campus community and achieve a sense of integration.

Tinto's central proposition that social integration is positively related to persistence is a valuable contribution to student development theory (Tinto, 1987). However, it is seriously limited by the conceptualization of appropriate pathways to integration, which is based on dominant White ideology. This ideology assumes that leaving one's old life behind and concentrating one's efforts on adopting new attitudes that align with the cultural norms of the institution is correlated to college success.

The focus on social integration is also limited by its basis in the residential social system. Karp, Hughes, and O'Gara (2010-2011), through their work with community college students, propose a reframing of Tinto's theory to better address the development and retention of commuter students. Through their qualitative study of matriculated community college students, they found that some of the students were able to attain a level of integration, which they define as "having a sense of belonging on campus" (p. 75), through information networks that they formed in the classroom. Thus, Tinto's separation of academic and social integration does not seem to be applicable to commuter students for whom class meetings are usually the only time that they spend on campus, therefore these academic encounters are their main opportunity for social integration. Other research supports the idea of the centrality of academic encounters; Braxton, Hirschy, and McClendon (2004) found that "the 
probability of student departure from a commuter college or university decreases for students who participate in communities of learning” (p. 40). Similarly, Braxton, Milem, and Sullivan (2000) found that the college classroom "functions as a gateway for student involvement in the academic and social communities of a college" (p. 1, ף 4). Instead of lamenting the lack of commuter student involvement in traditional cocurricular and extracurricular activities, it could be more useful to focus on the relationships that they form in the classroom and how to utilize these relationships to foster a vibrant college community in which commuter students feel as if they are first-class citizens.

\section{Critical Theory}

Critical theory is an appropriate lens through which to study commuter students as it centers on the conflict between dominant and non-dominant groups. In a nutshell, critical theorists argue that the dominant group maintains the status quo through institutionalization of systems that produce and reproduce dominant ideology (Apple, 1995). Through this institutionalization they define which types of knowledge and behavior are legitimate and valued, which is a process of social construction (Apple, 1995; Freire, 2000).

The non-dominant group does not merely passively accept the dictation of how they should behave in society. They either actively reject the dominant culture and develop alternative ways to "work the system" (Apple, 1995); or they obey the rules in the hopes that this behavior will allow them some personal freedom and control and help them to become more like the dominant group, whose superiority they have learned to idealize through internalized oppression (Freire, 2000). In either scenario, 
they are trapped by the limited possibilities of accepted identities, which have been constructed by the dominant group. In order to liberate themselves from these prescribed existences, there needs to be a movement to legitimate an experience that is free from these constraints.

To elaborate on this summary of critical theory, I have identified the following central themes that flow through the work of Freire (2000), Apple (1995), hooks (1994), and Giroux (1989), and inform this research.

- Institutions systemically reproduce dominant ideology and produce processes that further the interests of the dominant group (Apple, 1995; Giroux, 1989).

- Nothing is neutral (Apple, 1995; hooks, 1994). Legitimacy is socially constructed by the dominant group to define what is valued by society.

- Society is based on dialectal relationships - individuals are both shaping and being shaped by the environment (Apple, 1995; Freire, 2000; hooks, 1994).

- Individuals are viewed as whole beings; attempts to compartmentalize and/or commodify them are dehumanizing acts (Apple, 1995; hooks, 1994).

- Emphasis is placed on the lived experience and the value of individuals telling their stories (Giroux, 1989; hooks, 1994).

- Consciousness-raising is a key element in the struggle against inequities (Freire, 2000). Once consciousness is raised, there is a responsibility to take action to confront the disparities (Freire, 2000). 


\section{Dominant and Non-Dominant Groups}

In the discussion of commuter students, dominant and non-dominant groups can be likened to traditional and nontraditional students. As noted earlier in this chapter, the prohibition of nontraditional students from opportunities to live on campus (Bean \& Metzner, 1985; Ogren, 2003), the failure to address the characteristics of nontraditional students within student development theories (Baker, 2007; Cabrera et al., 1999; D’Augelli \& Hershberger, 1993; Guiffrida, 2003; Harper \& Quaye, 2007; Locks et al., 2008; Museus, 2008), and the stereotypes of commuter students as apathetic and less able (Jacoby, 2000; Krause, 2007; Ortman, 1995; Rhatigan, 1986) casts them as an inferior group within institutions of higher education. The maintenance of the status quo of focusing on traditional students is related to the fundamental shift in our understanding of the college experience that would be necessary in order to adequately address the needs of nontraditional students (Bean \& Metzner, 1985; Keith, 2007; Scheuer Senter \& Senter, 1998). As Scheuer Senter and Senter (1998) note, "many campuses are reluctant to make greater efforts to meet the needs of nontraditional students more fully" (p. 271).

The dominant ideology focuses on the traditional college student as a heterosexual White male who attends full time, lives on campus, does not have any outside obligations, is able-boded, and graduates in four years (Ogren, 2003). However, as previously noted, this traditional student is a rarity on many college campuses as almost $75 \%$ of undergraduate students at postsecondary institutions display some nontraditional characteristics (Choy, 2002). Abandoning the image of the traditional college student represents a challenge to the comfort with and control of 
the system of higher education by the dominant group. As bell hooks (1994) notes in her discussion of the resistance of dominant faculty to fully embrace multicultural education, the dominant group is supportive only up until a point at which their expertise is not threatened. Once an institution acknowledges that the student body has changed, it would need to revise its curriculum, instructional methods, support services, operating hours, mission, values, etc. in order to come into alignment (Bean \& Metzner, 1985; Keith, 2007; Senter \& Senter, 1998). As these revisions could prove threatening to those in power through loss of jobs, devaluing of certain areas of expertise, and the need for different skill sets, it is often much more attractive to maintain the status quo, even if that maintenance does not embrace nontraditional students.

\section{Neutrality}

One of the key methods for maintaining the status quo is to control what is valued as legitimate (Apple, 1995). The dominant group argues that identification of legitimacy is a neutral process. For example, in regards to education, the content of courses is often assumed to be neutral. Teaching Shakespeare does not have an underlying agenda, or does it? By teaching one topic instead of another, the institution is legitimating the value of certain types of knowledge. As Giroux (1989) notes, school knowledge represents the dominant culture through a "selective process of emphases and exclusions ... imposition of a specific set of ruling-class codes and experiences" (p. 129), which "disconfirm the histories, experiences, and dreams of subordinate groups" (p. 129). While the decision of what to teach is not necessarily a 
conscious choice to devalue other topics, it nonetheless unintentionally reproduces dominant ideology.

This principle can be applied further to the discussion of commuter students through the value placed on participation in campus activities. As previously noted in relation to Tinto's (1987) theory of student departure, it is believed that students need to become integrated into the campus community in order to persist. While this proposition may be valid, it assumes that campus activities are accessible to all students (Keith, 2007) and are of equal interest and value. However, as Johnson et al. (2007) notes, if students do not feel as if the institution is welcoming and encourages a sense of belonging, it is more difficult for them to become integrated into the campus community. Integration can be most challenging for students of color; it requires them to sacrifice their home culture and accept the campus norms based on dominant ideology (Johnson et al., 2007). Thus, to these students, campus activities may not be seen as a neutral experience, but a threat to self-preservation (Yosso et al., 2009). Furthermore, to students who commute, campus activities may be seen as inaccessible due to scheduling conflicts, or irrelevant due to the students' focus on off campus responsibilities (Newbold, Mehta, \& Forbus, 2011; Ortman, 1995).

\section{Dialectical Relationships}

While the student plays an important role in determining his/her success, the ability to connect to the campus community and thrive in that environment is also influenced by the institution. Johnson et al. (2007) promote this view of shared accountability, explaining that "rather than expecting students to bear sole responsibility for success through their integration into existing institutional structures, 
sense of belonging illustrates the interplay between the individual and the institution" (p. 526). This view fits with critical theory's concept of dialectical relationships in which things and individuals are both shaping and being shaped by the environment, which includes other individuals, physical structures, policies, procedures, and institutions (Apple, 1995). With this point in mind, one can see that educational institutions are not merely centers for the unidirectional reproduction of dominant ideology. The individuals within these institutions - faculty, administrators, staff, and students - reinterpret information according to their worldview and decide whether to accept or reject this information. However, this reinterpretation is still couched within the larger context of the dominant ideology. So, choosing rejection can be a risk that is associated with disconformity, which is viewed with suspicion by the dominant group (hooks, 1994).

Specifically in regards to this research, the act of commuter students sitting in their cars instead of spending time in the Student Union, Library, or other campus spaces can be viewed as a form of rejection. I explored this phenomenon in a pilot study (Weiss, 2009) in which I approached students who were sitting in their cars and asked if I could join them and conduct a brief interview. I found that the students sat in their cars for different reasons and for varying amounts of time. For example, one student used her car as a gathering spot; friends often came and joined her in her car where they listened to music and chatted between classes. Another student considered her car as a place for solitary relaxation; she would spend four to five hours in a row doing homework, playing games on the computer, and napping. She explained that her friends did not have breaks at the same time as she did, so she spent the time between 
classes by herself in her car. So while these students displayed the seemingly similar behavior of sitting in their cars, they were actually exhibiting different reactions to the experience of commuting. Furthermore, they were reinterpreting the purpose of parking lots - the institution may have intended for parking lots to be used as a place to store vehicles, but these students saw these spaces as providing a home for their mobile lounges. As will be further explored in the section on campus ecology, the institution presents spaces, programs, and policies for certain purposes, and the members of the college community reshape those purposes to fit their circumstances (Strange \& Banning, 2001).

\section{Wholeness and Compartmentalization}

In addition to viewing individuals as active participants in the environment through their decisions, critical theory promotes the belief that individuals need to be seen and valued as whole human beings. Unfortunately, many institutions, including schools, serve to compartmentalize individuals through an emphasis on the separation between public and private life (hooks, 1994). In her discussion of engaged pedagogy, hooks (1994) observed that faculty are often uncomfortable with seeing students "as whole human beings with complex lives and experiences rather than simply as seekers after compartmentalized bits of knowledge" (p. 15). Compartmentalization discourages unity and promotes isolation amongst the non-dominant group (Freire, 2000), thus preventing them from attaining a level of consciousness of their situation.

As commuting students often travel individually to campus in their own vehicles and do not have common spaces in which to spend time together, their experience can be very isolating (Banning \& Hughes, 1986). Furthermore, if faculty 
members are uncomfortable with viewing students as whole individuals with lives outside of the classroom, an understanding of and respect for their life experiences is unlikely to develop (hooks, 1994). Thus the students are blamed for not placing a high enough priority on their education (Rhatigan, 1986), instead of applauded for managing so many responsibilities at once (Ortman, 1995).

\section{The Lived Experience}

A key method for changing the paradigm of devaluing non-dominant experiences is to give voice to those who are marginalized. As such, critical theorists support the legitimacy of each individual's personal story and his/her lived experiences (Giroux, 1989; hooks, 1994). Thus, the use of qualitative research methods are the strategies of choice for honoring personal histories and perceptions, as opposed to placing value only on aggregate figures and averages, which often eliminate extreme cases as "outliers." Through the seemingly neutral focus on the normal distribution under the bell curve, non-dominant individuals are pushed aside and disregarded.

While giving voice to the marginalized is of utmost importance, that movement alone will not work to ensure that the voice of the non-dominant group is heard. Another necessary ingredient is the consciousness of the non-dominant group of their situation, as well as the consciousness of the dominant group of their role in the perpetuation of inequities. The process of consciousness-raising is often painful. It can create an inner conflict for aware educators; "those who make the discovery face a difficult alternative: they feel the need to renounce invasion, but patterns of 
domination are so entrenched within them that this renunciation would become a threat to their own identities" (Freire, 2000, p. 156).

\section{Campus Ecology}

Campus ecology can be used as a complimentary framework to critical theory in that it emphasizes the active role that students play in navigating institutions of higher education, which are steeped in dominant ideology. The campus ecology model emphasizes the transactional relationship (Kuk, Banning \& Amey, 2012) between the student and the campus, and assumes "that student and campus are mutually shaping forces in the complex balance of institutional life" (Strange \& Banning, 2001). In other words, "the students shape the environment and are shaped by it" (Strange \& Banning, 2001), which fits with the dialectical relationships of critical theory (Apple, 1995). In using this model, Strange \& Banning (2000) identify four key components of human environments: "physical condition, design, and layout; characteristics of the people who inhabit them; organizational structures related to their purposes and goals; and inhabitants' collective perception or constructions of the context and culture of the setting" (p. 5). Each of these components is reflective of the institution's goals and values, which are, in turn, interpreted by the members of the community. For example, the institution builds sidewalks to suggest appropriate ways to access various campus buildings. These sidewalks imply that the institution is encouraging individuals to utilize certain buildings and spaces more than other areas with no clear paths (Strange \& Banning, 2001). The members of the community see these sidewalks and decide whether to use these designated walkways, or to create their own paths, often resulting in trails worn into grassy fields. So, in essence, the institution sets up the environment 
in which individuals make decisions of how to use that environment (Strange \& Banning, 2001). This overarching concept of the interaction between constructed environments and human behavior is related to the study of commuter students through three main constructs: territory and personal space, congruence between members of the community and the dominant group, and fit with qualitative inquiry.

This study concerns itself with the role of campus space and place in the college experience of commuter students, thus campus ecology's focus on territory and personal space is relevant to this research. Strange and Banning (2001) note the need for students to find "a place to call one's own [through] selection of favorite niches on campus, private places in the library, or a favorite chair in the classroom" ( $p$. 28). These places are central to a student's experience in that they encourage a sense of belonging, security, and ownership, which are necessary prerequisites for a student's connection to and involvement with the institution (Strange \& Banning, 2001). As commuter students do not have a residence hall room or lounge to return to throughout the day, finding this personal space can be challenging (Banning \& Hughes, 1986). Furthermore, it can be difficult to make these spaces truly personal as there are limited opportunities for "display of self" (Strange \& Banning, 2001, p. 25), which are ways that "the physical environment can be used to convey messages about individual and group ownership" (Strange \& Banning, 2001, p. 25). While a student may sit in the same library cubicle everyday, there are no signs or other physical markers that denote his/her ownership of the space.

Campus ecology does not place the burden of finding personal spaces, and accessing other campus resources, solely on the backs of commuter students. The 
framework insists that institutions have a major responsibility to create environments that are inclusive of all members of the campus community (Kuk, Banning \& Amey, 2012). This insistence is related to the understanding that a student's fit with the campus environment, which is created by the dominant group, influences his/her success (Strange \& Banning, 2001). The concept of fit between student and institution has similarities with Tinto's (1987) theory of student departure, but, in contrast, campus ecology believes that the institution must actively involve members of the campus community in guiding the design of the campus and avoid casting individuals from non-dominant groups as deficient or inferior (Strange \& Banning, 2001). There is an intentional emphasis on empowering non-dominant individuals and questioning the status quo.

Through involving members of the campus community in the decision-making process (Kuk, Banning \& Amey, 2012), campus ecology is seen as a framework devoted to understanding students' perceptions and hearing their stories (Strange \& Banning, 2001), which is highly congruent with qualitative methodology and critical theory's focus on the lived experience (Giroux, 1989; hooks, 1994). More specifically, campus ecology is a good fit for phenomenological research involving photographs. Within campus ecology there is a distinct interest in understanding the everyday experience of members of the campus community in order to bring the mundane and ignored into the forefront and highlight the effects of the environment (Strange \& Banning, 2001). Furthermore, using photographic research methods helps in capturing the environmental impact, as it focuses on the examination of images and their ability "to find nonverbal messages that [communicate] complex issues" (Banning et al., 
2008, p. 42). So, concentrating on the everyday experience of a phenomenon, which is the focus of phenomenology, by using qualitative methods like participant-driven photo elicitation, is research well-informed by campus ecology and critical theory. 


\section{CHAPTER 3}

\section{METHODOLOGY}

\section{Introduction}

As the lived experience of commuter students is the core of this research, it is essentially a qualitative phenomenological study (Patton, 2002). The overarching goal of this study is to gain a deeper understanding of the everyday experience of commuter students as viewed from their perspective. In order to achieve this goal, the study employed phenomenological methodology, including participant-driven photoelicitation and interviews. These methods were guided by two research questions:

1. How do commuter students make meaning of their college experience?

2. How do commuter students describe the role of campus space and place in their college experience?

To outline how the context for the study and the processes utilized, Chapter 3 details the methodological theory, setting, sampling procedures, data collection, data analysis, and credibility and trustworthiness.

\section{Methodological Theory}

\section{Phenomenology}

An understanding of the everyday experience of a phenomenon is the basic foundation of phenomenology (Ehrich, 2005; Gibson \& Hanes, 2003; Groenewald, 2004). Phenomenology is a research methodology grounded in a philosophical view of human existence, which is very applicable to explorations in the social sciences (Natanson, 1973). Edmund Husserl (1976), viewed as the founding father of phenomenology (Gibson \& Hanes, 2003; Groenewald, 2004; Natanson, 1973; Schutz, 
1973), looked to understand the world through a deep exploration of how ordinary people perceive their everyday lives. Many distinguished philosophers, including Heidegger, Merleau-Ponty, Sartre, and Schutz, continued Husserl's work - expanding phenomenology's reach into sociology, anthropology, and other fields (Groenewald, 2004; Natanson, 1973). Three of phenomenology's main concepts lend themselves to this research on commuter students: making meaning from experiences, the lifeworld, and bracketing.

Individuals' experiences of a specific phenomenon is at the center of phenomenological understanding of the world. Husserl (1976) notes that "natural knowledge begins with experience (Erfahrung) and remains within experience" (p. 51). However, merely having an experience does not automatically lead to an appreciation of an individual's worldview; he/she needs to have a level of consciousness, which is achieved by looking back and reflecting on the experience (Schutz, 1973). Schutz (1973) describes this concept:

While just living along, we live in our experiences, and, concentrated as we are upon their objects, we do not have in view the "acts of subjective experience" themselves. In order to reveal these acts of experience as such we must modify the naïve attitude in which we are oriented towards objects and we must turn ourselves, in a specific act of "reflection" towards our own experiences . . . (p. 58)

Thus, a major goal of phenomenological study is to raise an individual's consciousness in order to explore how he/she uses his/her experiences to create meaning (Groenewald, 2004). 
Consciousness raising is achieved through a focus on the mundane experiences of everyday life (Natanson, 1973). By recounting these experiences, individuals become aware of what Husserl calls the lifeworld (Gibson \& Hanes, 2003). The lifeworld incorporates a consciousness of how one exists both in the world and within the world. Husserl (1976) describes the lifeworld in this way:

When consciously awake, I find myself at all times, and without my ever being able to change this, set in relation to a world which, through its constant changes, remains one and ever the same. It is continually "present" for me, and I myself am a member of it. Therefore this world is not there for me as a mere world of facts and affairs, but, with the same immediacy, as a world of values, a world of goods, a practical world. (p. 103)

Schutz (1973) agrees with the focus on consciousness, noting that the lifeworld is "a 'world' in which a person is 'wide-awake', and which asserts itself as the 'paramount reality' of his life" (p. 320). Thus, the lifeworld is not a static place defined by objective scientific facts; it is a dynamic place, which is shaped by the subjective experiences of the individual (Schutz, 1973).

When applying phenomenology to social science research, the researcher seeks to inhabit the participants' lifeworlds - to see how they see themselves (Gibson \& Hanes, 2003). In order to get an authentic view of their lifeworlds the researcher needs to "bracket" his/her biases (Gibson \& Hanes, 2003) - a phenomenological concept akin to qualitative methodology's focus on reducing researcher bias (Patton, 2002). Phenomenology does not support the notion of neutrality and having researchers attempt the impossible feat of looking at the world objectively; instead 
phenomenology implores researchers to make a conscious effort to acknowledge their assumptions and to set them aside, as if in brackets (Schutz, 1973). Only when a researcher's assumptions are bracketed can he/she begin to see the "the things themselves" (Willis, 2001, p. 3), i.e. to see the phenomenon as the participant sees it as opposed to how it is interpreted by the researcher. Once the researcher has bracketed his/her assumptions and gained an understanding of the participants' worldviews, the goal is to translate this understanding into phenomenological description (Willis, 2001), which summarizes the essence of the phenomenon (Groenewald, 2004).

Throughout the process of conducting this study I made notes of my observations and shared my reflections with colleagues (while maintaining the confidentiality of the participants) in an effort to bracket my assumptions. These notes and reflective conversations helped me to remain open to points that the participants were making about the commuter student experience, which I had not previously considered. For example, after my initial interview with Sasha, I made the following note: "interesting comment about commuting affecting academics - guessing that was the intended focus of the study - form that into a question to ask future participants." In other words, Sasha interpreted the goal of the research as investigating the impact of commuting on student academic performance, which was not my original intent. I had never really considered that aspect of the commuter experience - I was always focused more on campus involvement and a sense of belonging, probably due to my background in Student Affairs. However, once Sasha mentioned this concept, I incorporated it into follow up questions with the other participants, which lead to significant conversations about difficulties reconciling academic procedures with the 
commuter student lifestyle (which is discussed in more detail in Chapter 4). Thus, if I had not bracketed my assumption of the salience of campus life with limited attention to academic life I would have missed an important piece of the participants' lifeworlds.

\section{Phenomenologically Based Interviewing}

This study used Seidman's (2006) process for phenomenologically based interviewing and participant-driven photo-elicitation to gain an understanding of the lived experience of commuter students. In utilizing these two qualitative methodologies, participants were able to orally and visually explore their experience as college students and name their own reality (Ladson-Billings, 1999). These methodologies fit with campus ecology's emphasis on the environment (Strange \& Banning, 2001) and critical theory's concepts of the lived experience (Giroux, 1989; hooks, 1994) and consciousness-raising (Freire, 2000).

The study loosely followed Seidman's (2006) process for phenomenologically based interviewing, which outlines a protocol for a series of three interviews: 1) "focused life history" (p. 17), 2) "the details of experience" (p. 18), and 3) "reflection on the meaning" (p. 18). This three interview sequence supports phenomenological philosophy by first focusing on awakening consciousness of one's experiences (Husserl, 1976), then keeping the emphasis on "the things themselves" (Willis, 2001, p. 3) and the details of the everyday lives of ordinary people (Gibson \& Hanes, 2003), and finally getting a sense for an individual's lifeworld (Schutz, 1973). Seidman's process helps the participants to bracket their assumptions by situating their experience of the phenomenon of commuting in the context of their life history and 
inviting them to share concrete details of their experience, as opposed to abstract generalizations (Willis, 2001). By putting their biases of commuting aside, participants gain a clearer sense of the phenomenon and what it means to them (Groenewald, 2004). Thus, bracketing is useful not just for the researcher, but also for the participants (Groenewald, 2004; Willis, 2001).

In order to encourage bracketing by the participants I intentionally asked questions that focused on the details of their lives as commuter students, then followed up with relevant probe questions to prompt reflection or clarification. For example, during the initial interview I asked each participant to take me through a typical day, describing, in detail, how they spent their time (see Appendix B). Responding to this question gave participants the opportunity to thoroughly consider the exact steps they took to get to campus, complete homework assignments, attend classes, and organize the time between classes. Through this careful consideration, many of the participants realized that much of their day was spent waiting - waiting for the next class to begin, waiting for the bus to come, or waiting for assignments to be posted - which, as discussed further in Chapter 4, seemed to be a key aspect of the commuter experience.

Instead of conducting three straightforward interviews with each participant, this study reinterpreted the protocol by incorporating participant-driven photoelicitation and gallery walks (focus groups). Seidman (1998) allows for and even encourages adaptation of the protocol, "as long as a structure is maintained that allows participants to reconstruct and reflect upon their experience within the context of their lives" (p. 21). An initial interview centering on how the participants became commuter students developed the life history of commuting; the participant-driven photo- 
elicitation (follow up interview) explored the participants' current experience of commuting; and the gallery walk (focus group) gave participants the opportunity to reflect on the meaning of that experience.

\section{Participant-Driven Photo-Elicitation}

Participant-driven photo-elicitation, which is grounded in the fields of visual sociology (Epstein et al., 2006; Harper, 2002) and visual anthropology (Banks, 1998;

Collier \& Collier, 1986; Schwartz, 1989), involves participants taking photographs, then using those photographs to guide the interview with the researcher (Carter \& Mankoff, 2005; Noland, 2006; Schratz \& Steiner-Loffler, 1998; Van Auken, Frisvoll \& Stewart, 2010). This methodology is appropriate for this study in that it is consistent with critical theory (Carspecken \& Apple, 1992) in its ability to empower the participants to take an active role in the research (Noland, 2006; Van Auken, Frisvoll \& Stewart, 2010); it integrates the students' physical environment; it fosters unexpected discoveries beyond the preconceived notions of the researcher (Carter \& Mankoff, 2005; Schwartz, 1989); it can be more accessible to marginalized individuals (Collier \& Collier, 1986; Noland, 2006); and it helps participants to express notions of identity and personal experience, which can be difficult to convey using words alone (Chalfen, 1998; Epstein et al., 2006; Harper, 2002; Prosser \& Schwartz, 1998).

At its core, photo-elicitation involves using photographs during research interviews to prompt discussion (Carter \& Mankoff, 2005; Harper, 2002; Schwartz, 1989; Van Auken, Frisvoll \& Stewart, 2010). However, the mere presence of photographs does not automatically lead to rich, meaningful data. Harper (2002) notes the need for the photographs to "break the frame" in order to yield significant 
responses from the participants. In other words, the pictures need to present things in a novel way, which encourages the participants to reflect and consider things from a different perspective. However, the pictures themselves do not need to be especially unique (Schwartz, 1989), or of particularly good photographic quality (Collier \& Collier, 1986); the researcher, through intentional questions, can help the participant to notice aspects of the photos that had previously been taken-for-granted, but actually represent deeper meaning. Examples of these questions are listed in Appendix B. Alternatively, it is possible for the participants to point out important aspects of the photos that were not obvious to the researcher, which allows for the discovery of new, interesting findings (Carter \& Mankoff, 2005; Schwartz, 1989).

During photo-elicitation interviews, the participant generally leads the process by going through and describing each photo and sharing experiences related to the images (Schwartz, 1989). Oftentimes the actual content of the photos is not directly discussed; instead, the content serves as a pointer or cue for the participant to share a related situation or story (Carter \& Mankoff, 2005; Noland, 2006). Photo-elicitation helps participants to express thoughts that they might not be able to access through traditional interviews and surveys (Collier \& Collier, 1986; Noland, 2006; Van Auken, Frisvoll \& Stewart, 2010), making it an especially useful methodology for studies of identity (Noland, 2006). The specifics of how this methodology was used in this study of commuter students are detailed in the section on data collection.

\section{Photovoice and the Gallery Walk}

Photovoice is a particular type of participant-driven photo-elicitation, which incorporates an action research group process designed to empower participants to use 
their photographs to encourage critical dialogue and to bring about change in their communities (Wang, 1999). While this study is not necessarily action research, the photovoice elements of participants defining and sharing their photographs, the SHOWeD question protocol for contextualization (with modifications), taking action by making the findings public through the gallery walk presentation of the photos, and discussions used to minimize potential risks in taking photographs are incorporated into this research, as they are established methods that add to trustworthiness and provide structure that can help to mitigate researcher bias.

A key aspect of photovoice is sharing the images with a wider audience typically community groups that are associated with the issue documented in the photographs (Nykiforuk, Vallianatos \& Nieuwendyk, 2011). As the research questions guiding this study focus on the meaning that the participants attribute to their college experience, as opposed to how they can influence the College community's perception of commuter students and related policy, the audience for the gallery walks were the other participants in the study. While I do hope to present the findings to the College community and others within the field of higher education, this future step is not specifically associated with this study.

While the gallery walk was not a presentation to the broader community, it did accomplish the goal of giving the participants an opportunity to reflect on the meaning of their college experience. As Wang (1999) notes, “photovoice entails people's discussing the images that they have produced, and by doing so, they give meaning to, or interpret their images" (p. 186). Thus, providing an intentional environment for the participants to share their stories with others, view their photos in in relation to the 
images presented by their peers, and gain a deeper understanding for their experience is the main intention of the gallery walk.

\section{Setting}

\section{Location of the Study}

State College is a suburban campus located on the outskirts of a capital city in New England. The College functions on a semester schedule (Academic Calendar, 2012).

\section{General Characteristics of the Study Population}

The study population encompassed undergraduate commuter students at State College; both part time and full time students were eligible to participate, as were students at any stage of progress toward a degree - non-matriculated students, as well as students in any class standing (freshman, sophomore, junior, senior), were all invited to participate.

According to the Official Fall 2012 Enrollment File (State College Office of Institutional Research and Planning, personal communication, 2013) listed in Table 5, the College has an enrollment 7,553 undergraduate students; 6,444 of those students, or $85.3 \%$, are commuters. The College has six residence halls, which can house a total of 1,198 students (State College Office of Residential Life \& Housing, 2013). Thus, at any one time, the College has the capacity to house up to $6.3 \%$ of undergraduate students. However, the number of students living on campus often fluctuates as students withdraw from the institution, drop to part time and are thus no longer eligible for on campus housing, or their financial situation changes and they can no longer afford to pay for on campus accommodations. Unlike other institutions at 
which there is a live in requirement, particularly for first year students, and thus the residential population is fairly stable, State College sees shifts in student living arrangements throughout the year.

Table 5

Fall 2012 Official Undergraduate Enrollment Data: Breakdowns by Commuter vs. Resident (State College Institutional Research and Planning, personal communication, July 31, 2013)

\begin{tabular}{lcc} 
Of All Undergraduates & $\mathbf{N}$ & $\mathbf{\%}$ \\
\hline Commuter & 6444 & $85.3 \%$ \\
Resident & 1109 & $14.7 \%$ \\
\hline Grand Total & $\mathbf{7 5 5 3}$ & $\mathbf{1 0 0 . 0 \%}$
\end{tabular}

\begin{tabular}{lcc} 
By Gender & $\mathbf{N}$ & $\mathbf{\%}$ \\
\hline Commuter & $\mathbf{6 4 4 4}$ & $\mathbf{8 5 . 3 \%}$ \\
\hline Male & 2235 & $29.6 \%$ \\
Female & 4209 & $55.7 \%$ \\
& & \\
\hline Resident & $\mathbf{1 1 0 9}$ & $\mathbf{1 4 . 7 \%}$ \\
\hline Male & 324 & $4.3 \%$ \\
Female & 785 & $10.4 \%$ \\
\hline Grand Total & $\mathbf{7 5 5 3}$ & $\mathbf{1 0 0 . 0 \%}$
\end{tabular}

\begin{tabular}{lcc} 
By Race/Ethnicity & $\mathbf{N}$ & $\mathbf{\%}$ \\
Commuter & $\mathbf{6 4 4 4}$ & $\mathbf{8 5 . 3 \%}$ \\
\hline Non-Resident Alien & - & - \\
Hispanic/Latino & 676 & $9.0 \%$ \\
American Indian/Alaskan Native & 13 & $0.2 \%$ \\
Asian & 165 & $2.2 \%$ \\
Black/African American & 432 & $5.7 \%$ \\
Native Hawaiian/Other Pacific Islander & - & - \\
White & 4243 & $56.2 \%$ \\
Two or More Races & 105 & $1.4 \%$ \\
Unknown & 802 & $10.6 \%$ \\
& & \\
\hline Resident & $\mathbf{1 1 0 9}$ & $\mathbf{1 4 . 7 \%}$ \\
\hline Hispanic/Latino & 134 & $1.8 \%$ \\
American Indian/Alaskan Native & 5 & $0.1 \%$ \\
Asian & 17 & $0.2 \%$ \\
Black/African American & 129 & $1.7 \%$
\end{tabular}




\begin{tabular}{lcc} 
White & 693 & $9.2 \%$ \\
Two or More Races & 35 & $0.5 \%$ \\
Unknown & 96 & $1.3 \%$ \\
\hline Grand Total & $\mathbf{7 5 5 3}$ & $\mathbf{1 0 0 . 0 \%}$
\end{tabular}

Categories with a dash (-) represent a student count of less than 5.

\begin{tabular}{lcc} 
By Full/Part-Time Status & $\mathbf{N}$ & $\mathbf{\%}$ \\
\hline Commuter & $\mathbf{6 4 4 4}$ & $\mathbf{8 5 . 3 \%}$ \\
\hline Full-Time & 4446 & $58.9 \%$ \\
Part-Time & 1998 & $26.5 \%$ \\
Resident & $\mathbf{1 1 0 9}$ & $\mathbf{1 4 . 7 \%}$ \\
\hline Full-Time & 1087 & $14.4 \%$ \\
Part-Time & 22 & $0.3 \%$ \\
\hline Grand Total & $\mathbf{7 5 5 3}$ & $\mathbf{1 0 0 . 0 \%}$
\end{tabular}

Other demographic trends can be seen in the data in Table 5. In Fall 2012, the majority $(55.7 \%)$ of students were female commuters. Racial data can be problematic as it forces individuals to identify themselves according to socially constructed notions of identity, which can be seen by the $8.4 \%$ of students who declined to identify their race (coded as "Unknown"). However, using the available data, White commuters $(56.2 \%)$ are the most common, followed by Unknown commuters $(10.6 \%)$, White residents (9.2\%), and Hispanic/Latino Commuters (9.0\%). Taking the data from Table 5 to compare the racial makeup of the commuter and resident populations (Table 6) it appears that they are somewhat similar, though there is a slightly higher percentage of Hispanic/Latino, American Indian/Alaskan Native, Black/African American, and Multiracial students living on campus, and a slightly higher percentage of White, Asian, and Unknown students commuting. The cause of these slight differences is unclear - they may be due to the live in requirement for students in a particular 
bridge/transition program for first generation students, which includes a higher number of students of color, but that cannot be concluded definitively.

Table 6

Fall 2012 Racial Composition of Commuter and Residential Populations (calculated from data from State College Office of Institutional Research) (State College

Institutional Research and Planning, personal communication, July 31, 2013)

\begin{tabular}{|l|l|r|l|r|}
\hline & \multicolumn{2}{|c|}{$\begin{array}{c}\text { Commuter Students } \\
\text { N=6444 }\end{array}$} & \multicolumn{2}{c|}{$\begin{array}{c}\text { Resident Students } \\
\text { N= 1109 }\end{array}$} \\
\hline Race & $\mathbf{N}$ & $\mathbf{\%}$ & $\mathbf{N}$ & $\%$ \\
\hline Hispanic/Latino & 676 & $10.5 \%$ & 135 & $.5 \%$ \\
\hline $\begin{array}{l}\text { American } \\
\text { Indian/Alaskan } \\
\text { Native }\end{array}$ & 13 & $.2 \%$ & 5 & $12.1 \%$ \\
\hline Asian & 165 & $2.6 \%$ & 17 & $11.6 \%$ \\
\hline $\begin{array}{l}\text { Black/African } \\
\text { American }\end{array}$ & 432 & $6.7 \%$ & 129 & $62.5 \%$ \\
\hline White & 4243 & $65.8 \%$ & 693 & $3.2 \%$ \\
\hline $\begin{array}{l}\text { Two or More } \\
\text { Races }\end{array}$ & 105 & $1.6 \%$ & 35 & $8.6 \%$ \\
\hline Unknown & 802 & $12.4 \%$ & 96 & \\
\hline
\end{tabular}

It is not surprising to note that only 22 resident students attend part time as

State College's Residential Life \& Housing policy states that students need to attend full time in order to live on campus (State College Office of Residential Life \& Housing, 2013). It appears that a few exceptions have been made, potentially in extenuating circumstances.

In addition to enrollment data, State College administers the Student Census Survey every other year (alternating with administration of the National Survey of Student Engagement), which was designed by the College to obtain a more holistic view of the student population and to receive feedback on College programs and services (State College Assessment, 2012). Table 7 features commuter-related items from the 2012 Student Census. 


\section{Table 7}

State College Student Census 2012: Commuter-Related Item Frequency Distributions (State College Institutional Research and Planning, personal communication, July 31, 2013)

\begin{tabular}{|c|c|c|c|c|c|c|}
\hline & \multirow[b]{3}{*}{ Question } & \multirow[b]{3}{*}{ Response Options } & \multicolumn{4}{|c|}{ Residency } \\
\hline & & & Com & iter & Resi & nt \\
\hline & & & Count & $\%$ & Count & $\%$ \\
\hline \multirow[t]{7}{*}{17.} & \multirow{7}{*}{$\begin{array}{l}\text { How do you commute to Rhode } \\
\text { Island College? }\end{array}$} & My own car & 561 & 84.0 & - & - \\
\hline & & Carpool & 7 & 1.0 & - & - \\
\hline & & Dropped off by relative/friend & 32 & 4.8 & - & - \\
\hline & & Public transportation & 34 & 5.1 & - & - \\
\hline & & $\begin{array}{l}\text { Public transportation for individuals with } \\
\text { disabilities }\end{array}$ & 8 & 1.2 & - & - \\
\hline & & Other & 26 & 3.9 & - & - \\
\hline & & Total & 668 & 100.0 & - & - \\
\hline \multirow[t]{6}{*}{18.} & \multirow{6}{*}{$\begin{array}{l}\text { Approximately how many miles } \\
\text { each way do you commute? }\end{array}$} & Less than 5 miles & 155 & 23.6 & - & - \\
\hline & & 5-10 miles & 187 & 28.5 & - & - \\
\hline & & 10-20 miles & 195 & 29.7 & - & - \\
\hline & & 20-50 miles & 112 & 17.1 & - & - \\
\hline & & More than 50 miles & 7 & 1.1 & - & - \\
\hline & & Total & 656 & 100.0 & - & - \\
\hline \multirow[t]{6}{*}{19.} & \multirow{6}{*}{$\begin{array}{l}\text { How many days per week do } \\
\text { you commute to campus? }\end{array}$} & 1 day & 22 & 3.4 & - & - \\
\hline & & 2 days & 101 & 15.4 & - & - \\
\hline & & 3 days & 86 & 13.1 & - & - \\
\hline & & 4 days & 284 & 43.4 & - & - \\
\hline & & 5 days & 161 & 24.6 & - & - \\
\hline & & Total & 654 & 100.0 & - & - \\
\hline \multirow[t]{4}{*}{30.} & \multirow[t]{4}{*}{ Are you working this semester? } & Yes & 503 & 76.6 & 111 & 68.9 \\
\hline & & No (by personal choice) & 94 & 14.3 & 38 & 23.6 \\
\hline & & Unemployed & 60 & 9.1 & 12 & 7.5 \\
\hline & & Total & 657 & 100.0 & 161 & 100.0 \\
\hline \multirow[t]{4}{*}{31.} & \multirow{4}{*}{$\begin{array}{l}\text { Where are you currently } \\
\text { working? }\end{array}$} & On campus & 45 & 9.0 & 41 & 37.3 \\
\hline & & Off campus & 409 & 81.5 & 42 & 38.2 \\
\hline & & Both on and off campus & 48 & 9.6 & 27 & 24.5 \\
\hline & & Total & 502 & 100.0 & 110 & 100.0 \\
\hline \multirow[t]{8}{*}{32.} & \multirow{8}{*}{$\begin{array}{c}\text { How many hours per week do } \\
\text { you usually work? }\end{array}$} & $1-10$ & 64 & 12.7 & 26 & 23.6 \\
\hline & & $11-15$ & 63 & 12.5 & 33 & 30.0 \\
\hline & & $16-20$ & 108 & 21.5 & 30 & 27.3 \\
\hline & & $21-25$ & 77 & 15.3 & 11 & 10.0 \\
\hline & & $26-30$ & 61 & 12.2 & 7 & 6.4 \\
\hline & & $31-35$ & 48 & 9.6 & 3 & 2.7 \\
\hline & & More than 35 & 81 & 16.1 & 0 & 0.0 \\
\hline & & Total & 502 & 100.0 & 110 & 100.0 \\
\hline \multirow[t]{5}{*}{33.} & \multirow{5}{*}{$\begin{array}{l}\text { How much of your earnings do } \\
\text { you spend on college-related } \\
\text { expenses (e.g. tuition, books, } \\
\text { transportation)? }\end{array}$} & Less than $25 \%$ & 148 & 29.8 & 32 & 29.4 \\
\hline & & $25 \%-49 \%$ & 183 & 36.8 & 38 & 34.9 \\
\hline & & $50 \%-74 \%$ & 111 & 22.3 & 27 & 24.8 \\
\hline & & More than $75 \%$ & 55 & 11.1 & 12 & 11.0 \\
\hline & & Total & 497 & 100.0 & 109 & 100.0 \\
\hline
\end{tabular}


As per the data in Table 7, the majority of commuters at State College drive their own cars to campus (84\%), though some students do use other means of transportation, including getting dropped off/picked up by a relative or friend and utilizing public transportation. The majority of commuters travel 20 miles or less (a combined $81.8 \%$ ), though a few students do travel more than 50 miles. Many of the commuters $(43.4 \%)$ come to campus four days per week, which is probably related to the College's tendency not to hold many classes on Fridays. Most courses are offered on a MondayWednesday or Tuesday-Thursday schedule.

Though having a job while attending college is not a phenomenon limited to commuter students, the literature notes that it is often a contributing factor to the decision to commute. Thus, it is not surprising that a campus with such a high percentage of commuter students would also have a high percentage of employed students ( $76 \%$ of commuters). The vast majority of commuter students who work have jobs off campus $(81.5 \%)$. While resident students also have jobs $(68.9 \%)$, they are more likely than commuter students to work on campus and to work less hours. The lower number of hours worked on campus can be related to College guidelines that prohibit students from getting paid for working more than 20 hours per week.

\section{Sampling Procedures}

As the focus of phenomenological qualitative research is to understand the daily lives of ordinary people experiencing a specific phenomenon (Schutz, 1970), as opposed to generalizing to a larger population, a small number of individuals were selected to participate to allow for in-depth exploration. Purposive sampling, a method of searching for "information-rich cases" (Patton, 2002, p. 46), was used to find 
commuter students who drive their own cars to campus, who get dropped off and picked up by a friend or family member, who ride public transportation to campus, and who walk or ride their bicycles to campus.

To find these students I used a variety of methods, mostly related to going to places associated with different means of transportation. As I usually take the public bus to campus a few times a week, I used this opportunity to hand out recruitment flyers (see Appendix C) for the study. On the ride to campus from the downtown bus depot I waited until we entered the campus, which is the last stop on the bus line, to hand out the flyers to ensure that everyone on the bus was going to State College. The College shares the bus route with a local high school so I wanted to avoid giving flyers to those students, or other community members who were not on their way to the College. I continued this method for two weeks (January 22, 2013 to February 5, 2013) in which time three of the students I met on the bus contacted me to participate in the study - Annie, Marcela, and Patrick (their names have been changed to protect their identities). I knew Patrick from a few bicycle advocacy meetings I had organized in Fall 2012; I had not previously met Annie or Marcela.

During this same two week time period I spent around two hours a day handing out recruitment flyers to students in the commuter parking lots. For this method I used two tactics; my first strategy involved walking through the parking lots and approaching students who were sitting in their cars. I knocked on the window and students would either roll down their window or open the car door, and I handed them a flyer. Alternately, I stationed myself in the path of where the parking lot leads into campus and handed flyers to students as they walked to and from their cars. This 
method was time consuming and not very successful - I did not get any participants using this method.

In a variation of the parking lot method, I spent around four hours during those two weeks standing in areas in which students are often dropped off and picked up (in front of the main administration building and in front of the Student Union) and handed out flyers to students who were waiting for their rides to come. One student, Stephen, was recruited using this method.

As I had been unsuccessful in recruiting any commuters who drove their own cars to campus, I resorted to two more general recruitment strategies: the weekly enewsletter sent to all students and the Psychology Department pool of participants. I had been so focused on using transportation type to recruit students that I ignored methods that advertised the study to all students. As $85 \%$ of students at State College are commuters (Office of Institutional Research, 2012), using recruitment methods that reached out to all students made sense. Thus, the February 8, 2013 edition of the Student Activities Briefs e-newsletter included the recruitment flyer for the study. It is important to note that though the e-newsletter is sponsored by my office, it is sent from a generic office email account. From this strategy I recruited five participants Lindsay, Kara, Victoria, Sarah, and Sasha.

I found the last participant, Angela, through the Psychology Department pool of participants. State College's introductory psychology courses require that students participate in at least one research study. The available studies, mostly sponsored by faculty members in the Department, are listed on a secure website; students are able to 
search through the studies and sign up to participate in one that fits their interests or their schedules.

Though recruitment flyers were also placed on campus bulletin boards none of the participants found out about the study through that advertisement. General characteristics of the ten study participants are listed in Table 8. While only two participants, Angela and Marcela, identified themselves as attending part time, other participants (Sasha, Patrick, and Annie) mentioned having attending on a part time basis in the past. As the commuter student population at State College is $65.3 \%$ female (calculated by using figures from Table 5) it is not surprising that only two of the participants were male. Two participants identified as people of color, which is a bit lower than the $34.2 \%$ (calculated by using figures from Table 6) of commuter students at State College who are of color. 
Table 8

Study Participant Characteristics

\begin{tabular}{|c|c|c|c|c|c|c|c|c|c|c|}
\hline 葛 & $\stackrel{\ddot{d}}{\ddot{\infty}}$ & 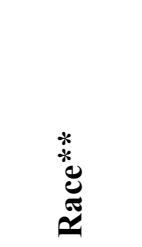 & $\overbrace{0}^{\infty}$ & 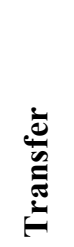 & 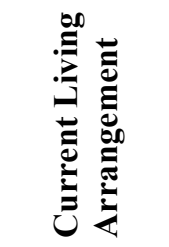 & 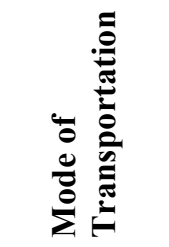 & 总 & 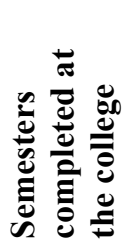 & 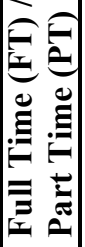 & 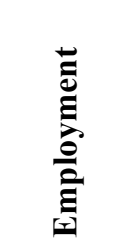 \\
\hline Lindsay & $\mathrm{F}$ & White & 20 & No & $\begin{array}{l}\text { With Dad } \\
\text { and } \\
\text { Stepmom }\end{array}$ & Own car & $\begin{array}{l}2014 / \\
2015\end{array}$ & 5.5 & FT & $\begin{array}{l}\text { Off } \\
\text { campus }\end{array}$ \\
\hline Kara & $\mathrm{F}$ & White & 21 & Yes & $\begin{array}{l}\text { With } \\
\text { roommates } \\
\text { - own } \\
\text { apartment }\end{array}$ & Own car & 2014 & 3 & FT & $\begin{array}{l}\text { On and } \\
\text { Off } \\
\text { Campus }\end{array}$ \\
\hline Stephen & M & White & 22 & No & With Mom & $\begin{array}{l}\text { Own car, } \\
\text { sometimes } \\
\text { bus or } \\
\text { dropped } \\
\text { off by } \\
\text { mom }\end{array}$ & 2014 & 3.5 & FT & $\begin{array}{l}\text { On } \\
\text { campus }\end{array}$ \\
\hline Victoria & $\mathrm{F}$ & White & 22 & No & $\begin{array}{l}\text { With Dad, } \\
\text { Aunt, and } \\
\text { Niece }\end{array}$ & Own car & 2013 & 10 & FT & $\begin{array}{l}\text { Off } \\
\text { campus }\end{array}$ \\
\hline Sarah & $\mathrm{F}$ & White & 22 & No & $\begin{array}{l}\text { With Mom } \\
\text { and Dad }\end{array}$ & Own car & 2013 & 8 & FT & $\begin{array}{l}\text { Off } \\
\text { campus }\end{array}$ \\
\hline Annie & $\mathrm{F}$ & White & 26 & Yes & $\begin{array}{l}\text { Own } \\
\text { apartment }\end{array}$ & Bus & 2014 & 3 & FT & $\begin{array}{l}\text { On } \\
\text { campus }\end{array}$ \\
\hline Angela & $\mathrm{F}$ & White & 27 & Yes & $\begin{array}{l}\text { With Mom } \\
\text { and Dad }\end{array}$ & Own car & 2014 & 0 & PT & $\begin{array}{l}\text { Off } \\
\text { campus }\end{array}$ \\
\hline Patrick & M & $\begin{array}{l}\text { Not } \\
\text { Available }\end{array}$ & 31 & No & $\begin{array}{l}\text { With } \\
\text { friend's } \\
\text { parents }\end{array}$ & Bus & 2014 & 6 & FT & $\begin{array}{l}\text { On } \\
\text { campus }\end{array}$ \\
\hline Sasha & $\mathrm{F}$ & Hispanic & 31 & Yes & $\begin{array}{l}\text { With } \\
\text { partner }\end{array}$ & Own car & 2016 & 6 & FT & $\begin{array}{l}\text { On } \\
\text { campus }\end{array}$ \\
\hline Marcela & $\mathrm{F}$ & Black & 44 & Yes & $\begin{array}{l}\text { Alone - } \\
\text { own } \\
\text { apartment }\end{array}$ & Bus & 2013 & 10 & PT & $\begin{array}{l}\text { Used to } \\
\text { work } \\
\text { on } \\
\text { campus }\end{array}$ \\
\hline
\end{tabular}

*Participants have been given pseudonyms to protect their identity.

**Racial data came from participants' self-identification through an open ended question on the demographic questionnaire (see Appendix D)

Participant recruitment ended after interviewing the tenth participant (Angela)

as I had reached data saturation, which occurs when no new information is likely to be gained from involving additional participants (Mason, 2010). The staggered

recruitment method was a key component in monitoring saturation. As opposed to 
predetermining the number of participants based on an arbitrary prediction, I continued to recruit participants until I began to notice a pattern of similar stories in the interviews. Recurring themes such as the effort it takes to get to campus, dealing with inconveniences, and spaces on campus in which students spend their time created a somewhat consistent image of the everyday experience of commuter students, which was the main clue that data saturation had been reached. I identified these emerging themes through listening to the interview recordings, beginning the transcription process, reviewing my memos, and conducting a preliminary thematic analysis.

While the number of participants was not predetermined, due to the practicality of handling the large amounts of data and the labor-intensive process of qualitative research (Mason, 2002), it was estimated that the study would involve less than ten participants. This estimate agrees with Wang's (1999) recommendation of utilizing seven to ten participants in photovoice research in order to allow enough time to deeply explore the participants' experiences. In exchange for their participation, the participants were given a choice of thank you gifts: a $\$ 15$ gas station gift card, public transportation pass ( $\$ 13$ value), or a $\$ 10$ Dunkin Donuts gift card; they were also given glossy prints of the photos they took for the study.

\section{Data Collection}

Data collection took place in four stages: initial interview, photo gathering, photo-elicitation interview, and gallery walk (focus group). It is important to note that participants entered the study at different times so I was conducting multiple stages simultaneously (see Appendix A for the data collection timeline). For example, while Patrick and Victoria were gathering photos, I was conducting initial interviews with 
Kara, Sasha, Sarah, and Lindsay. I operated under this "rolling admissions" framework in order to limit loss of subjects (Fraenkel \& Wallen, 2008) and to get a sense for when saturation was reached. If I had tried to start all of the participants at the same time, it would have been difficult to know how many participants to recruit. Furthermore, starting at the same time would have meant that Marcela, the first participant recruited, would have had to wait close to two months -until the time Angela joined the study - to meet for the initial interview. It appears that the staggered start was successful as all ten participants completed all of the data collection stages. This strategy also allowed participants who missed their scheduled gallery walk to attend the next gallery walk. For example, Patrick did not show up for the first gallery walk, which he was scheduled to attend, but was able to participate in the second gallery walk.

\section{Initial Interview}

In the initial interview, I began to develop a rapport with the participants and focused on discussing their life histories, which is consistent with the first stage in Seidman's (2006) process for phenomenologically based interviewing. I asked the participants to share how they came to be commuter students, to describe a typical school day, to highlight past experiences related to family life, employment, and schooling that had an influence on their current situation, and to reflect on which aspects of commuting work for them and which aspects do not work for them - the initial interview questions are listed in Appendix B. These questions were chosen intentionally to create a context for the participants' experience of commuting and 
begin to awaken their consciousness (Schutz, 1973) of the meaning they derive from commuting.

These interviews lasted an average of 30 minutes. Seidman (1998)

recommends that the interviews last 90 minutes; as a novice researcher, it was difficult to keep the conversation going for much more than 30 minutes. However, later stages in the data collection did last longer as the participants and I became more comfortable with each other and our conversations were informed by the photos. While my intention was to hold the interviews in a place of the participants' choosing, with a willingness to meet them off campus (if that arrangement was more convenient), participants preferred to meet on campus either during breaks between classes or after they had finished classes for the day. I met with eight of the participants in a quiet corner of the Library and two of the participants in a meeting room in the Student Union.

At the end of the initial interview, the participants were introduced to the photo gathering protocol (see Appendix E), reflected on the potential risks and ethical considerations in photographic research (Karlsson, 2007; Larkin, et al., 2007), and received the digital camera. The reflection on ethics was guided by Wang's (1999) work with photovoice. She recommends setting the stage for participant photo gathering with a discussion of appropriate ways to take pictures of others and a consideration of the future uses of the photos. In particular, the photo gathering protocol instructed the participants to ask others before taking their picture and offers the option of blurring the faces of individuals in order to protect their identities. Only a small number of photos taken by the participants involved others, which may have 
been related to the discussion of ethics - some of the participants were a bit worried about the possibility of taking unethical photos. None of the participants who took pictures of others requested to have the faces blurred.

\section{Photo Gathering}

The participants were given one week to take a minimum of 10 photos representing their "college life." Participants were encouraged to define their "college life" however they chose. When pushed for more clarification I often told participants that they should take pictures of anything that depicted their college experience. These instructions are based on common protocols used in auto-photography (another term for participant driven photo-elicitation) in which participants take

pictures of items in their environment that best described them . . [this method] allows participants the freedom to use their actual surroundings, to pick and choose the people who are important to their self-concepts, and to decide what issues and what objects are the most salient to their construction of self. (Noland, 2006, p. 3)

So the instructions were purposely vague in order to allow the participants the freedom to define the parameters of their college experience. They could take a maximum of 20 photos, but most participants took the minimum number of ten.

In keeping with Seidman's (2006) process for phenomenologically based interviewing, the photo gathering exercise took the place of an actual second interview. The timeframe was also based on Seidman's protocol; he recommends that interviews take place approximately one week apart from each other in order to allow "time for the participant to mull over the preceding interview but not enough time to 
lose the connection between the two" (p. 21). In addition to following Seidman's (1998) guidelines, research in participant-driven photo-elicitation also recommends giving participants one week to take their photos (Wang, 1999; Noland, 2006). Limiting the amount of time allotted for taking photographs helps to keep the participants focused (Noland, 2006) and increases the likelihood that participants will complete the study. However, this approach does not allow for participants to show growth or change in their perceptions. For example, some of the participants in this study noted wishing they could have had the opportunity to take pictures either throughout their time at State College or at least during the fall semester to capture experiences that are meaningful, but do not occur during the given week.

The exercise allowed the participants to explore their present experience as college students, which is consistent with the goal of Seidman's second interview: to discuss the participants' contemporary experience. Upon completion of the photo gathering exercise I met each participant to collect the camera and the Annotation Sheet (see Appendix F), which participants used to title their pictures and record the context of the photo (time, date, and location). I printed out the pictures in preparation for the photo elicitation interview.

It is important to note that the photo gathering process is not an inherently easy or safe assignment for participants. As Wang (1999) stresses, it is scary and risky to take pictures representing one's thoughts, identity, and experiences. In essence, it is an exercise involving a level of personal exposure. As such, some of the participants' claims of "forgetting the camera", discussed in more detail in the Reflections on Methodology in Chapter 4, may have been related to the risky nature of taking photos. 
To address this concern, questions used in the photo elicitation interview (Appendix G) asked participants to reflect on anything that was "missing" in their photos and their impressions of the level of difficulty in the taking pictures.

\section{Photo Elicitation Interview}

On the same day that I collected their cameras and photos I conducted a second interview with each participant - the photo-elicitation interview - in which the photographs were used to guide the discussion. General questions used to facilitate the conversation, including a modified version of the photovoice SHOWeD protocol (Wang, 1999), are listed in Appendix G. As this study is not action research, participants were not asked what steps they could take to improve the situation pictured in the photographs, which is usually a central aspect of photovoice research. However, Wang (1999) does note that photovoice methods can be adjusted, as long as participant identification of key photos (selection), an opportunity for participants to share the stories behind the photos (contextualization), and a systematic identification of issues and themes (codification) are included. Furthermore, the action component of this study centers on the consciousness raising of the participants during the gallery walk and future presentations of the findings.

Instead of focusing on action steps, the interviews revolved around the stories behind each photo, with prompts such as "what inspired you to take this photo?" and "what is happening here?" initiating the conversation. In addition, three questions asked during the initial interview were repeated during the photo-elicitation interview to get a sense for any changes in the level of consciousness (Schutz, 1973) of the commuter experience: what does it mean to you to be a commuter student, what about 
the commuter experience really works for you, and what aspects do not work for you. This interview served as the third stage in Seidman's (1998) process in which the participants reflected on the meaning of their past and current experiences, which created a context for understanding their existence, identity, and plans for the future.

These interviews lasted an average of 40 minutes and took place in the same locations as the initial interviews (quiet spots in the Library and a meeting room in the Student Union). At each interview I spread out the pictures on a table and asked the participants to go through each picture and share how they came to take the photo and its meaning. While the participants were instructed to come to the interview with the completed annotation sheet, about half of the participants did not do this step due to forgetting to carry the sheet around with them. In those cases I gave the participants a few minutes to write their titles on the back of each picture. It was very important for the participants to create titles as opposed to having me make up titles so that they reflected the meaning that the photo held for them (Noland, 2006; Van Auken, Frisvoll $\&$ Stewart, 2010).

During this interview the students selected five of the most meaningful photos to include in the gallery walk. This step was included to give the participants an opportunity to keep private any pictures that they considered too personal. In addition, photo selection is a key element of photovoice, in which "each participant may be asked to select and talk about one or two photographs she feels are most significant or that she likes best" (Wang, 1999, p. 188). This process also served as a way to encourage the participants to reflect on which of the photographs represented the core 
meaning of their college experience - the essence of the phenomenon (Gibson \& Hanes, 2003) of commuting.

\section{Gallery Walk}

All of the participants were invited to attend a gallery walk in which the five photos each participant had selected during his/her photo-elicitation interview were displayed. As participants were recruited throughout the spring 2013 semester, participants were grouped into three gallery walks according to when they joined the study. Initially I had envisioned holding one gallery walk for all of the participants, but that would left too much time between the interviews. For example, Marcela, who had the initial interview on January 28, 2013, would have had to wait until April 12, 2013 to attend the gallery walk. Thus, I grouped the participants into three gallery walks according to when they completed their photo-elicitation interviews. Sasha was initially supposed to attend the second gallery walk, but had a conflict, which is the reason she attended the third gallery walk with Angela. Patrick ended up missing the first gallery walk so he attended the second gallery walk instead.

The first gallery walk had three participants (Annie, Marcela, and Stephen); the second gallery walk had five participants (Kara, Victoria, Sarah, Lindsay, and Patrick); and the third gallery walk had two participants (Angela and Sasha). In order to maintain confidentiality, the photographer of the photos was not identified; the photos, with the participant-given titles, were hung up around the room. Participants were asked to view all of the photos and comment on any themes they saw in the images. More detailed prompt questions are included in Appendix H. The gallery 
walks took place in a conference room in an academic building and lasted an average of 75 minutes.

Photovoice often involves members of the public, especially key stateholders, in the sharing of photos, as a way to raise awareness of key issues facing the participants (Wang, 1999) and for other community members to add their comments (du Toit \& Gordon, 2007). As phenomenology (Gibson \& Hanes, 2003; Schutz, 1973), as well as critical theory (Apple 1995; Freire, 2000), is concerned with the consciousness raising of the individuals experiencing the specific phenomenon, the gallery walks only involved study participants. So, in a sense, the participants made their photos "public" to the other participants, and in that process had an opportunity to see their experience as commuter students in the context of their peers. To further the exploration of consciousness raising, three questions asked during the initial interview and photo-elicitation interview were repeated during the gallery walk to get a sense for any changes in the level of consciousness (Schutz, 1973) of the commuter experience: what does it mean to you to be a commuter student, what about the commuter experience really works for you, and what aspects do not work for you.

\section{Data Analysis}

I audiotaped all of the interviews using an iPod Touch Voice Memo application and transcribed the interviews using audio play back on the Finetunes Mac application and Excel spreadsheets. Data collection occurred on a fairly constant basis beginning January 28, 2013 until April 12, 2013 which made it difficult to attempt to do a true constant-comparative analysis in which data collection and analysis are conducted simultaneously in order to continuously develop, test, and refine theoretical 
propositions or potential themes (Fraenkel \& Wallen, 2010). However, I did transcribe some of the interviews during data collection and wrote regular memos to reflect on the recurring themes I was beginning to notice. I was then able to use the initial observations garnered through the transcripts and memos during later interviews, especially the gallery walks, to member check, which is described in more detail in the section on validity.

\section{General Thematic Inductive Analysis}

Instead of utilizing constant-comparative analysis, I followed the approach of a general thematic inductive analysis (Thomas, 2006; Boyatzis, 1998; Creswell, 2009) to get at the essence of the phenomenon (Gibson \& Hanes, 2003) of the college experience of commuting students. The general thematic inductive analysis included the following steps:

1. Read all of the transcripts and review all of the photographs

2. Develop a coding framework

3. Code the transcripts

4. Continuously refine the codes allowing for the emergence of new codes and for potential insignificance of initial codes

5. Copy and paste key segments of the transcripts into categories derived from the codes

6. Condense the categories into a few broad themes

7. Both at the end of this process and throughout the analysis, get feedback from study participants, experts, peers, and colleagues to check for trustworthiness and authenticity. 
Thus the beginning of the analysis involved reviewing all of the interview transcripts and the photos taken by the participants. It is important to note that the photos were not reviewed separately from the transcripts; they were included as they were described by the participants. As noted earlier, the images are made significant through the meaning and context provided by the participants (Carter \& Mankoff, 2005; Schwartz, 1989). The titles given to the images by the participants, their explanation for why they took these photographs, and the narratives that emerged when sharing the photographs are the central pieces of data. In Chapter 4 the photos are interspersed throughout the discussion of the findings, with the participant-given titles, as they are related to the specific themes under consideration.

\section{Codes and Categories}

In an effort to authentically represent the voices of the participants I focused on using data-driven codes based on the actual words of the participants and the specific connection to the photos. As Boyatzis (1998) notes, this method ensures that "previously silenced voices or perspectives inherent in the information can be brought forward and recognized" (p. 30). An initial review of the transcripts yielded 105 codes, generally organized into 16 categories. The 16 initial categories were the everyday, wellbeing, off campus, identity, residence halls, academics, driving, bus, social life, campus, spending the day, schedule, general college thoughts, photos, general transportation thoughts, and money.

Each of these categories incorporated a combination of relevant codes. For example, the category of spending the day consisted of the codes of packing and preparing, forgetting things at home, waiting, time spent alone, meals, carrying stuff 
around, knowledge of campus/navigating campus, use of resources, place to keep your things, time spent on campus, making the most of time spent on campus, "your own little space", and time spent in the car. In general, this category reflected how the participants described preparations to come to campus, where they spent time between classes, and their overall feelings toward being on campus for the day. It is important to note that I made a conscious effort not to insert my biases into the labeling of the codes and categories. For example, I could have given carrying stuff around a more negative connotation such as nowhere to store belongings, but I wanted to ensure that the participants' descriptions drove the analysis, not the meanings I attached to their experiences.

As key quotes from the transcripts were placed under the codes within the categories, new codes were added, while existing codes were sometimes merged or marked for potential elimination. For example, the category of general transportation thoughts originally included the codes of length of commute, (un)predictability of transportation, bicycle riding, impact of commuting on academics, commuting inconveniences, and giving rides to family members and friends. However, as I placed key quotes under the codes, I found that there were thoughts related to transportation that did not fit in the previously defined codes. Thus, I created the new codes of effort to get to campus, carpooling, driving vs. public transportation, and people who live really close to campus. These additional codes added a nuance to the discussion of transportation by highlighting the assumptions that the participants held regarding the requisite effort necessary for consideration as a "real" commuter. I began to get a sense that the participants believed that if a student lived really close to campus and 
did not need to either battle traffic or deal with inconvenient bus schedules his/her experience was somehow less valid.

The 16 categories were condensed into eight main categories: wellness, getting to campus, balancing multiple life roles, arranging one's schedule, inconveniences, finding a sense of community, institutional systems, identity, and place to spend time on campus. These categories were then formed into three overarching themes: commuter students and dorm people; "how difficult it is for commuters" (Victoria), but we're used to it; and finding a "second home" (Lindsay).

Table 9. Evolution of Categories and Themes

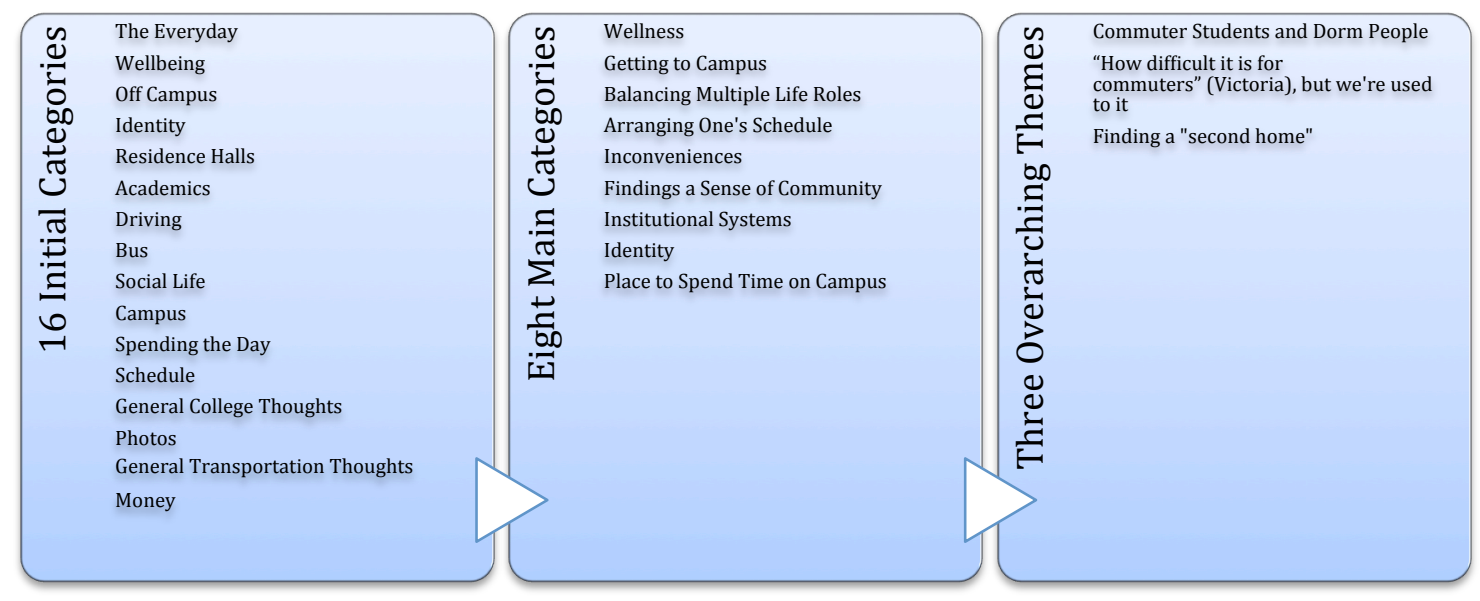

The three overarching themes also incorporated subthemes. Within commuter students and dorm people, the participants focused on four main areas of identity: stress of lifestyle, age and maturity, off campus life, and diversity of experiences. The difficulties for commuters included discussions of wellness, fitting it all in, and navigating systems. Finding "a second home" involved a search for storage, privacy, social interaction, and ownership. 


\section{Trustworthiness}

\section{Role of the Researcher}

In qualitative research, the researcher is the instrument (Creswell, 2009). In this sense, the researcher's biases, values, and personal background influence the data that is collected. While efforts are made to minimize these effects, it is acknowledged that these influences are inherent in the interactions and can never truly be avoided. Furthermore, in keeping with the philosophy of critical theory, the researcher's stance can never be neutral as she exists in an unequal society characterized by systematic advantages and disadvantages (Apple, 1995). This view is shared by phenomenology, which specifically encourages the researcher to bracket, or set aside, his/her assumptions (Gibson \& Hanes, 2003; Groenewald, 2004; Schutz, 1973) in order to obtain an open, conscious understanding of the phenomenon.

Thus, I, as the researcher, bring certain biases and viewpoints to my approach to the study. In particular, as a White, middle-class female who has witnessed instances of the marginalization of commuter students during my career in student affairs, I came to the study with a particular sense that commuter students were at a disadvantage and needed to be empowered. For example, time and again I would hear my colleagues at State College speak to incoming students at Orientation about homesickness and the challenge of leaving behind parents and loved ones to come to college, when the majority of incoming students were not concerned about these issues since they were living at home. My frustration at seeing the students so mischaracterized and misunderstood contributed to my desire to conduct this study. 
While this perspective can have some benefits - most notably that it fuels a dedication to promoting an understanding of the experience of commuter students - I needed to continually remind myself that this study is about the commuter student experience from the perspective of commuter students - not my preconceived notions of the commuter experience. To keep these preconceived notions in check, I kept memos of my reactions to the data and often debriefed these memos with members of the dissertation committee, peers from my $\mathrm{PhD}$ cohort, State College commuter students who were not in the study, and study participants. Maxwell (1998), in discussing the process for designing a qualitative study, highlights the importance of these memos for more than setting aside assumptions, but for examining these assumptions to see how they can lead to "unexpected insights and connections" (p. 225).

For example, the original title of the dissertation proposal was "Internalized Oppression of Commuter Students.” Through personal reflection and discussions with dissertation committee members, I realized that this title displayed a glaring assumption that commuter students felt oppressed and that they had internalized that oppression. Before I had even begun the study I had started to project my biases onto the participants! Thus, I changed the title to "The Commuter Student Experience and the Concepts of Space and Place." Furthermore, awareness of this bias made me especially attuned to the difference between perceiving an experience as an inconvenience, as opposed to a struggle, and how participants gave meaning to that experience. While I have a tendency to attribute the cause of a struggle to societal 
inequities and institutional systems, the participants were more apt to see commuting as an individual circumstance that they are proud of handling.

I was also careful to make note of the perspectives shared by the participants that had not occurred to me prior to conducting this research, including findings that did not confirm my preconceived notions. A detailed discussion of these efforts is included in Chapter 5. The methodological structure of the photovoice SHOWd protocol and the general guidelines of Seidman's phenomenologically based interviewing helped to provide consistency to the approach to the interviews, thus minimizing the opportunities for me to insert my biases and elements of a personal agenda.

\section{Credibility}

In order to maintain a high level of accuracy I member checked to allow interview participants to confirm that my findings truly reflected their feelings (Prosser \& Schwartz, 1989). Member checking occurred throughout the data collection and analysis process - as I transcribed the interviews and reflected in my memos I developed a general sense for recurring themes. In the photo-elicitation interviews and during the gallery walks I discussed these initial observations with the participants to get their feedback. For example, in their initial interviews, three of the participants noted that "commuters don't wear sweatpants" in answer to the question of whether they can tell if someone is a commuter student. This concept of perceiving commuter students as more prepared and mature was a pattern that was eventually incorporated into the theme of commuter students and dorm people, which is discussed in Chapter 4. 
I also shared a draft of the summary of the findings with all of the participants and asked for their feedback. Marcela responded to the summary, sharing that I "hit the nail on the head" (Marcela, personal communication, October 18, 2013) in capturing the essence of the commuter student experience.

In addition to member checking, I debriefed with commuter students not involved in the study and colleagues in the field of higher education to get their feedback on my findings. Peer debriefing and stakeholder checks (Thomas, 2006) help to establish a level of credibility and consistency in the data interpretation through the collection of feedback from individuals who are familiar with the phenomenon, but did not actually participate in the study. These debriefs took place during personal conversations, as well as formal presentations. I presented my initial findings at the New England Educational Research Organization (NEERO) Annual Meeting on April 1, 2013 and at the State College Graduate Student Symposium on May 8, 2013. At the Graduate Symposium, attended by peers in my $\mathrm{PhD}$ program, a few commuter students who did not participate in the study, and faculty members from State College, the commuter students often nodded their heads in agreement and shared after the presentation that the findings "totally made sense." At NEERO, attended by colleagues in education and higher education, as well as graduate students, the presentation was positively received, with feedback mostly centering on effective presentation of findings, i.e. including a table of key characteristics of the participants and showing the evolution of the codes.

I also debriefed with approximately 15 commuter students at State College who were not participants in the study. These students were participants in leadership 
programs sponsored by my office and students who worked in the Student Union. As I conducted the initial analysis I shared the emerging themes with the students and asked if these findings matched with their experiences. In general, they agreed with the findings and often commented that they were happy to hear that someone was interested in knowing more about the commuter experience. One student even remarked that discussing the study made her feel proud to be a commuter student - at one point she thought she was really missing out by not living on campus, but hearing about the findings made her see the legitimacy of her experience.

Lastly, the interview data and photographs allowed for triangulation, which utilizes multiple sources of data to confirm conclusions made from data analyses (Fraenkel \& Wallen, 2010). The images served as a type of triangulation to confirm or disconfirm the themes observed in the interviews. As noted earlier in Chapter 3, photographs provide unique data that can often not be collected through traditional interviews. Prosser and Schwartz (1998) discuss this concept in their review of the benefits of image-based research:

Photographs may not provide us with unbiased, objective documentation of the social and material world, but they can show characteristic attributes of people, objects, and events that often elude even the most skilled wordsmiths. Through out use of photographs we can discover and demonstrate relationships that may be subtle or easily overlooked. We can communicate the feeling or suggest the emotion imparted by activities, environments, and interactions. And we can provide a degree of tangible detail, a sense of being there and a way of 
knowing that may not readily translate into other symbolic modes of communication. (p. 116)

Thus, using photographs adds a deeper, nuanced understanding of a phenomenon. Furthermore, when viewed in relation to the stories told by the participants about the photographs, the researcher can identify discrepancies, as well as themes that are powerfully represented in both the images and interviews. For example, as shown in Chapter 4, Lindsay's photo of the inside of her car with all of her belongings (laptop, food, jacket, phone, etc.) on the front seat is highly congruent with her description of her car as her "second home." In contrast, Victoria's faraway view of the residence halls in one of her photos does not seem to match with the closeness that she feels with her friends who live on campus. Noting this discrepancy, I was able to probe a bit more during the photo-elicitation interview to find out that she does not feel as if she really belongs by the residence halls.

\section{Limitations}

The experience of commuting to college was the phenomenon under investigation, with individual students who commute as the unit of analysis. The focus of the interviews and gallery walks centered on the participants' subjective experience. For the purposes of providing a context for the identity of the participants, a brief demographic questionnaire was used (see Appendix D) to collect information on age, race, sex, number of semesters attended, expected graduation, major, and transfer status, i.e. if the participants had previously attended other institutions. This information was self-reported and taken at face value - it was not verified through the College's academic records system. This verification was not conducted as the soul of 
the research rests on the participants' perceptions as opposed to data listed on their transcripts. For example, how a participant identifies in terms of racial background is more important that the official classification listed in his/her academic record. Thus, while some accuracy might have been lost in relying on self-reports, it is a limitation that seems appropriate in working with critical phenomenology as the focus is on the socially constructed, subjective experience (Creswell, 2009).

In hindsight additional questions could have been added to the questionnaire in order to clearly establish the circumstances of each participants' current and past living arrangements and modes of transportation. I went into the study with the assumption that participants' living arrangements and modes of transportation did not change throughout their college careers. For example, I assumed that if a student currently lived with her parents, that living arrangement represented her entire college experience, which was often not the case. I asked the participants to describe their current living arrangement, but did not ask about prior living arrangements or their plans for the future unless they voluntarily shared that information. In making this assumption it is possible that I missed discussing some of the complexities of the commuter student experience, which are key aspects in the diversity of commuter student identity. To address this limitation I carefully reviewed the interview transcripts for clues of any changes in living arrangements and modes of transportation, though these efforts may not have been enough to mitigate the issue.

My prior assumptions also influenced my thoughts around sampling procedures. I may have missed out on the information that students I already knew could have provided as I made a concerted effort to find participants with whom I did 
not have a prior relationship. Thus, conducting research at the institution in which I work was a bit of a double-edged sword. I worried that if I interviewed students who I already knew we would have a level of familiarity that would make it difficult to ensure that the interviews would cover topics that we had already discussed in the course of our relationship. Furthermore, I was concerned that utilizing students with whom I had a prior relationship would make it difficult to defend my sampling procedures - was I just interviewing whoever was readily available instead of truly looking for information-rich participants? Lastly, I had a selfish interest in finding students who I did not know in order to broaden my understanding of commuter students. I was curious if my view was biased due to my tendency to work with students who are very involved on campus. I wondered if the unknown "average" student had a different experience than the involved student. I was very aware of these concerns going into the research and did my best to be methodical in my sampling procedures and use memos to reflect on those procedures. As it turned out, I ended up knowing two of the ten participants prior to the study, but I recruited them through the methods that I used for all of the other participants, as opposed to specifically reaching out to them to request their participation.

A more detailed review of the methodological limitations is included in

\section{Chapter 5.}




\section{CHAPTER 4}

\section{FINDINGS}

There are three main categories of themes that emerged from the data analysis outlined in Chapter 3: commuter students and dorm people; "how difficult it is for commuters" (Victoria), but we're used to it; and finding a "second home" (Lindsay). The first theme centers on how the participants seemed to form their identity in relation to "dorm people" ("dorm people" is their expression as opposed to the more formal term of "resident students"). As such they characterized themselves as more stressed, motivated and independent, more focused on off campus life, and representing a larger diversity of experiences. The second theme shows the pride the participants felt in continuing to work toward their degrees despite the various inconveniences related to commuting. In particular, they discussed circumstances related to wellness, fitting it all in, and navigating systems. The third theme explores the participants' searches for a sense of home and community as they spent their time on campus. They described a quest for places for keeping their things, peace and quiet, and social interaction.

To outline the data informing these themes, I weave together quotes from the interviews and gallery walks with the photos gathered by the participants. The photos are accompanied by the titles provided by the participants. Each theme and their corollary subthemes are described in detail, followed by summary remarks.

\section{Commuter Students and Dorm People}

The process of commuter students forming their identity in relation to dorm people makes sense as the non-dominant group is constantly compared to the 
dominant group (Apple, 1995). This view of "us" and "them" is related to the concept of "othering" in which the dominant group is considered the basis against which all groups and individuals are judged (Brantlinger, 2001). In the case of this study, it appears that in addition to feeling like the "other", the participants also attempted to take back some power by centering commuter student identity as the benchmark. In this sense the participants acknowledged some of the positive attributes of commuter students, most notably the dedication and effort involved in commuting.

It is important to note that this analysis is not meant as a superficial comparison to demonstrate the preferred type of student - in other words, the focus is not on perpetuating the tendency to compare resident and commuter students (Chickering, 1974; Jacoby, 1989). Instead, the differences in the perceptions of the two identities are discussed as they were an important and frequent topic of conversation during the interviews and directly relate to the first research question. Furthermore, the sometimes incongruent portrayals of commuter students by the participants point to the struggle of forming one's identity in relation to the dominant other, while maintaining a true sense of self that may not conform with dominant ideology (hooks, 1994). The participants focused on four main areas of identity: stress of lifestyle, age and maturity, off campus life, and diversity of experiences.

\section{Stress of Lifestyle}

In terms of stress of lifestyle, participants repeatedly characterized dorm students as enjoying an easy, stress-free existence. When asked if she could tell if a student lived on campus, Sasha explained that "when you're a dorm person ... not that it's less - not stressful, but - it's a little less than a commuter. You just walk to and 
from class - in your pajamas if you want [laughs].” This level of comfort and ease, displayed by dorm students through their general demeanor and choice of outfits, was echoed by other participants; Sarah explained that "when you see people who are like in their pajamas, kind of like you can tell that they just came from their dorm." It is interesting to note that none of the participants, including Sarah and Sasha, took a picture of resident students wearing pajamas. This omission may be due to the instructions of taking pictures that represented their college lives, and they did not see pajamas as included in their experience.

Dorm people also tended to carry less stuff around with them, which the participants seemed to think added to the more relaxed lifestyle of dorm people. According to Kara, dorm people were students who walked around campus "just carrying one book" because they could "leave a lot of their stuff like [in] a dorm" instead of carrying everything around with them. Stephen connected the residential experience to less of a need to come prepared to class, noting that "if you live here and you're like [mocking tone, imitating a dorm student] 'I forgot a text book or I forgot a book - I can just walk here I'll be back in like 30 minutes at the most' " it is not a big deal to forget things. A level of jealousy or resentment developed from looking at the easier life of dorm students; Patrick said, "everyday the bus comes up [the road into campus] and I see those College apartments and I think 'goddamn that'd be nice!"”

In contrast to the perceived less stressful life of dorm students, participants conceptualized commuting as very stressful. A lot of the stress is related to needing to be prepared. Sasha noted that "you gotta make sure you have everything in there with you because you can't keep going back and forth - like some people can just get up 
and go and you can tell that they're very relaxed - well I can tell." Sasha showed this concept of needing to "have everything in there with you" in her picture of the backseat of her car (Figure 1), which was had her gym clothes, school bag, and other items.

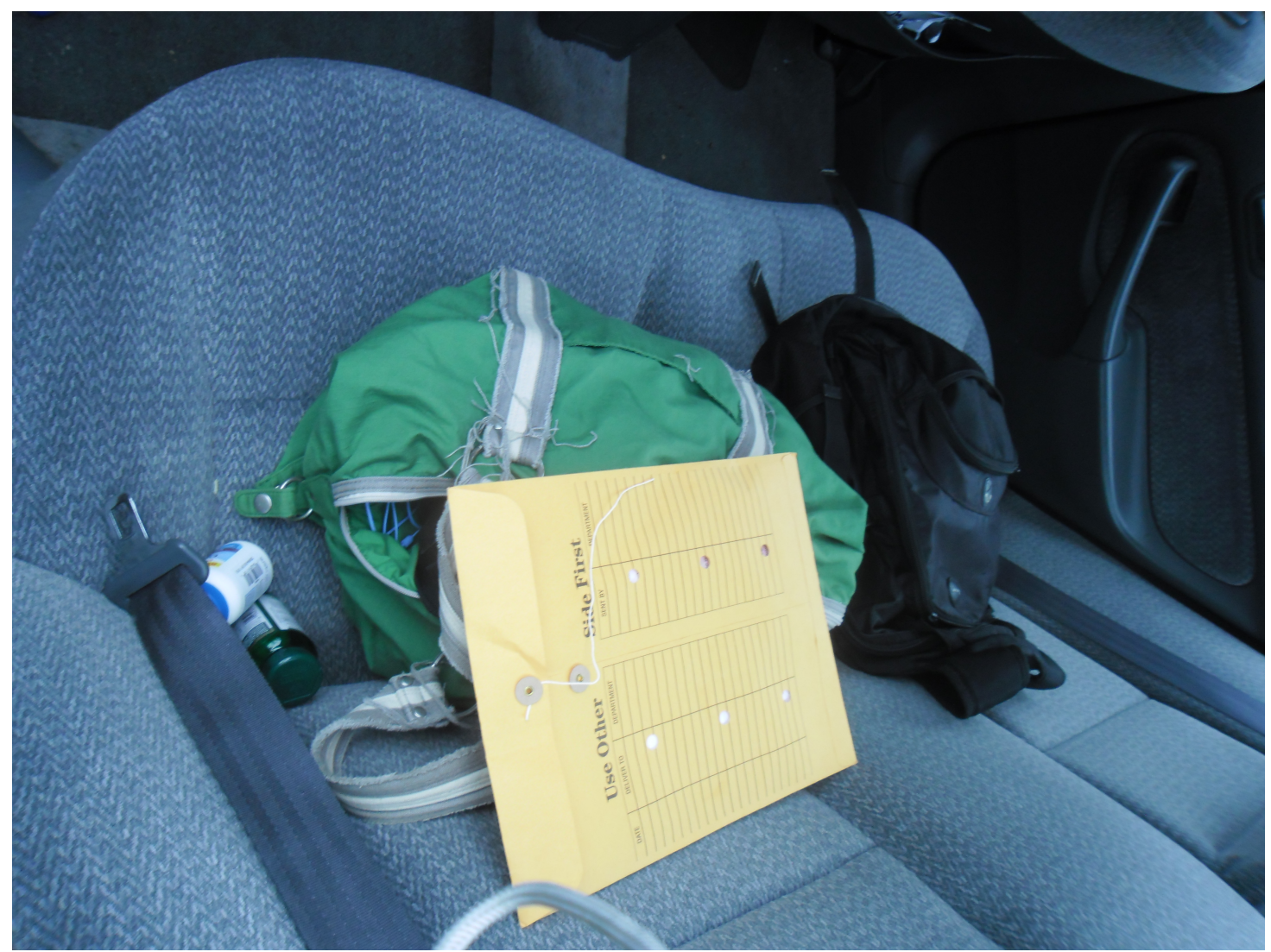

Figure 1. "Junk in the back." Photo taken and titled by Sasha to show how she carried around all of her stuff in the backseat of her car.

Despite this stressful lifestyle, the participants generally did not express a desire to live on campus. Stephen shared this point of view, noting "I don't really want to like live on campus because I hear some .. . horror stories." Lindsay agreed with this sentiment, explaining that "I've literally only been in the dorms maybe like three times total and I'm so glad I've never lived here - they're so ghetto - like so incredibly ghetto - like ew." While a dorm room would lend enough privacy for a daytime nap or a place to change clothes throughout the day to account for fluctuations in weather 
conditions, dorms were viewed as places that lacked privacy, were full of drama, cost a lot of money, and represented ghetto living conditions. It is interesting that dorm life was seen as so unsettling and tumultuous while the experience was also viewed as less stressful.

Some of the negative views of on campus living centered on the perception of roommates as inconsiderate. Stephen feared that a roommate would ruin his class projects; he explained, “[at home] I have my own room so I can keep my stuff without worrying about like my roommate like running in and like toppling everything or something." As a Technical Theater major, Stephen had a lot of class projects that involved building structures and designing costumes, which he displayed in Figure 2.

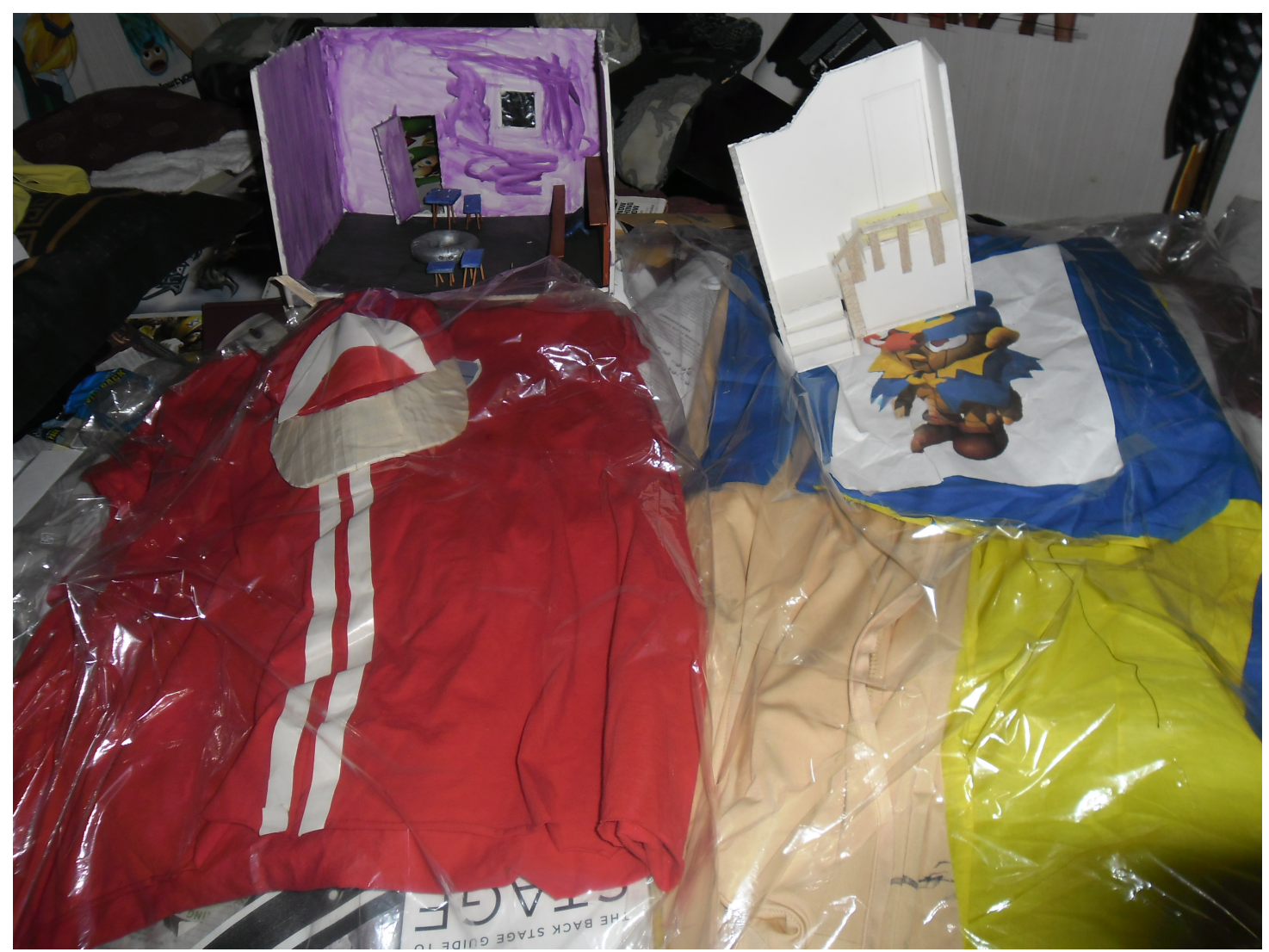

Figure 2. "Projects to help me out later in life." Photo taken and titled by Stephen to show his Technical Theater projects.

Stephen placed a lot of value on these projects so the possibility that someone would 
ruin them was very distressing to him.

Other participants feared that their roommates would put them in awkward situations. Victoria, who commented that "living [on campus] wouldn't be bad", still had reservations about potential roommate issues. To illustrate this concern she related a story about a friend who had an uncomfortable roommate situation:

my other friend like hated his roommate but he's like we're having lunch and I was like I thought you hated him and he was like I do but if I say no it's going to get all messed up and you know like the guy would sleep in his boxers and [my friend] would feel wicked uncomfortable and he would be like "dude can you just throw on some pants please" [laughs].

Her story has some undertones of homophobia - there is a possibility that living on campus could bring her into close contact with people with whom she would prefer not to associate or around whom she would feel uncomfortable. This point is related to the discussion in Chapter 2 of campus climate (Rankin \& Reason, 2005) and the perception of an unwelcoming campus environment. While Sasha, the one participant in the study who openly identified as gay, did not directly say that she found the residence halls unwelcoming, during the gallery walk she did characterize commuters as people who "most likely ... live off campus either with parents or with a partner so they might be a little bit older and independent." So, commuting gave Sasha the opportunity to live with her partner and "go home and feel comfortable" (Sasha) - in a place free of potentially judgmental roommates.

This view of home as a place of comfort was echoed by multiple participants. For example, Sarah explained, "living at home is pretty good - I mean the food is 
better and it's nice to sleep in your own bed." Participants also described living at home as more cost effective. Lindsay shared, "I could probably live on campus, but I just find it's easier and cheaper to not spend to like stay in a little room." To the participants, the amount of money it would cost to live on campus did not seem equivalent to the quality of the accommodations. Furthermore, Sarah was more willing to "pay for gas every week then to pay like the $\$ 3,000$ or whatever to live [on campus]." So even though the high price of gas was a downside of commuting, as seen in Sarah's photo in Figure 3, it was preferable to paying for a residence hall room.

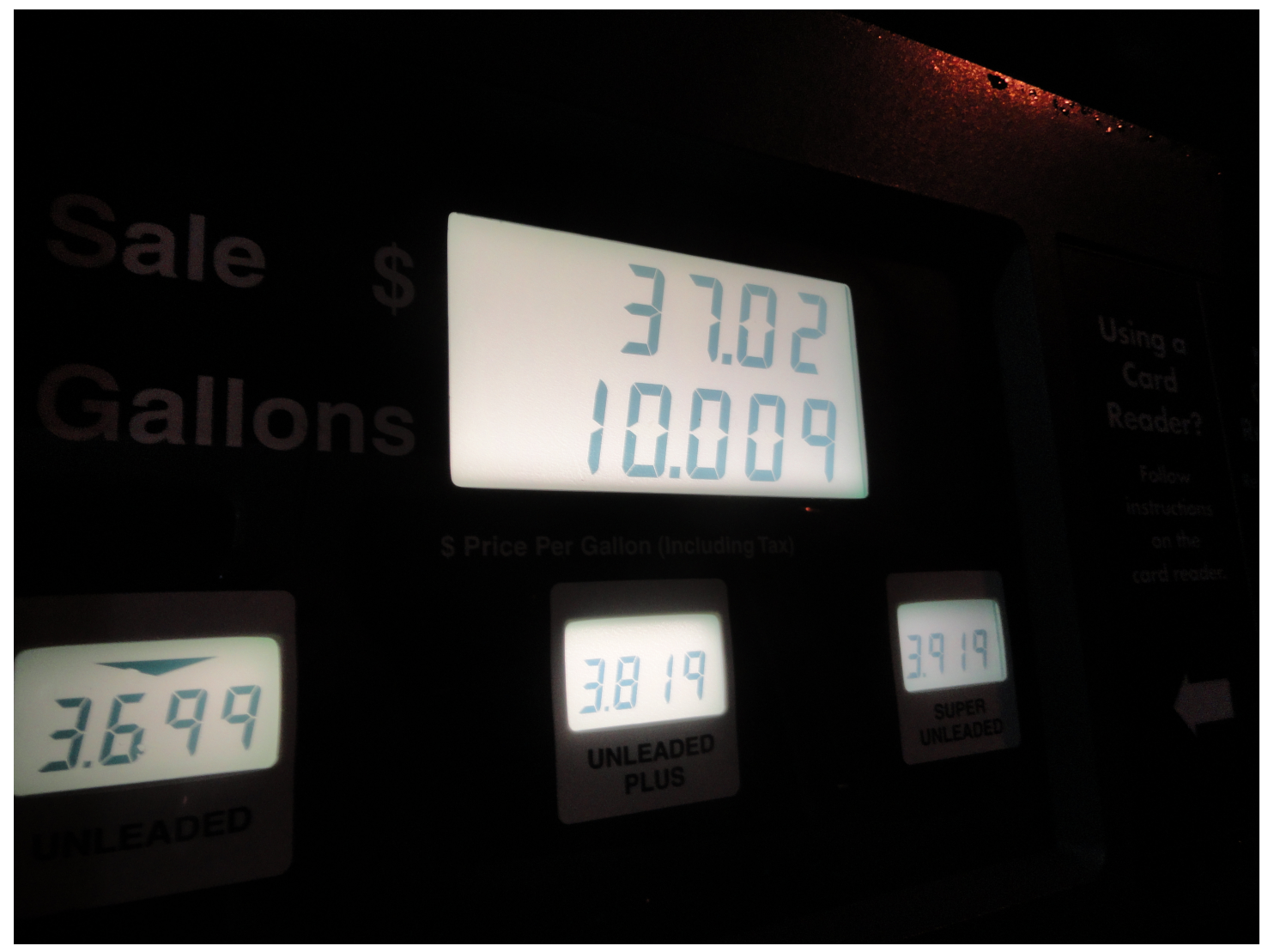

Figure 3. "The downside of commuting" - photo taken and titled by Sarah to show the price of gas and how expensive it can get.

Thus while dorm life appeared less stressful, participants seemed to think it was worth it to commute in order to enjoy the comforts of home and to avoid the drama of living on campus. This finding surprised me as I assumed that commuter students would 
harbor a deep-seated desire to live on campus and wish they could have the residential experience. Instead, the participants shared that they were willing to deal with the inconveniences of commuting in order to live at home.

\section{Age and Maturity}

Participants viewed dorm students as younger and less responsible and commuters as older and more mature. Contrary to the commonly held belief that living on campus is a more independent experience (Smith, 1989), the participants' saw campus living as restrictive. In noting the restrictions, Kara pointed out that "I don't even think they can have a water boiler in there - like in the dorms." Not having to abide by residence hall rules was perceived as a distinct advantage of living off campus. Avoiding these types of restrictions was seen as worth the sacrifices related to commuting. Lindsay explained, "I don't like driving but like I'll suck it up because then I can at least be home and do whatever I want basically - like [not] having restrictions [from] living on campus.”

Many of the participants never considered living on campus due to their age. Patrick shared, "I'm older so it never would have crossed my mind to live on campus." Annie agreed, noting "I'm an older student so I mean the dorm life is just not for me anymore - I'm really past the point in my life when that would be enjoyable [laughs] so I live off campus." Annie expanded on this concept, explaining that a typical commuter student at the college is:

Probably older um - you know - you didn't pick this college because your parents wanted you to go here or you're not going to college just because you can. I think if you're a commuter you feel like um maybe you're at a point in 
your life where you had jobs or sort of been out in this economy already and realized how central a college degree is. Um, so, I think there's that and I also feel like in a way um as a commuter I mean as much as I realize the importance of a college degree.

Even Lindsay, a somewhat more "traditional" age student, felt too old for living on

campus. She said, "I just don't think I'd ever want to do that - [live on campus] - now but I'm - I'm going to be 21 soon and I'm older and I have stuff going on at home.” Thus, in general, residential life was viewed as for younger students who have fewer responsibilities.

\section{Off Campus Life}

Lindsay's mention of "stuff going on at home" points to the more off campus focus of commuter students. In discussing his collection of photographs, Stephen noted "there's not really much I do socially, really - in here - because a lot of the friends I hang out with either aren't in college anymore or they go to like [the Community College]." He elaborated on this point during the focus group, sharing that "when you're a commuter you are less likely to have friends here because you don't live here so you don't have to go and like force yourself to meet people." Annie agreed with this off campus focus, commenting

I kind of like commuting because it allows me to have my own life outside of college. You know I . . hang out with a lot more people than I think I would if I lived on campus, um. I have a lot more time to explore the city. Um, yeah, commuting is - it's good. I like to have a life outside of school.

Adding to Annie's off campus focus was her son, whose picture she kept pinned to her 
backpack for motivation, as seen in Figure 4. She described the impact that her son has on her college experience, explaining that

I have a kid who's 7 so I always wanted to finish school because I have a child and I think it's important - you know - [you] should go to college no matter what um, you know, if that's something that you want to do - don't let things stand in your way - I want to do that and be a good role model.

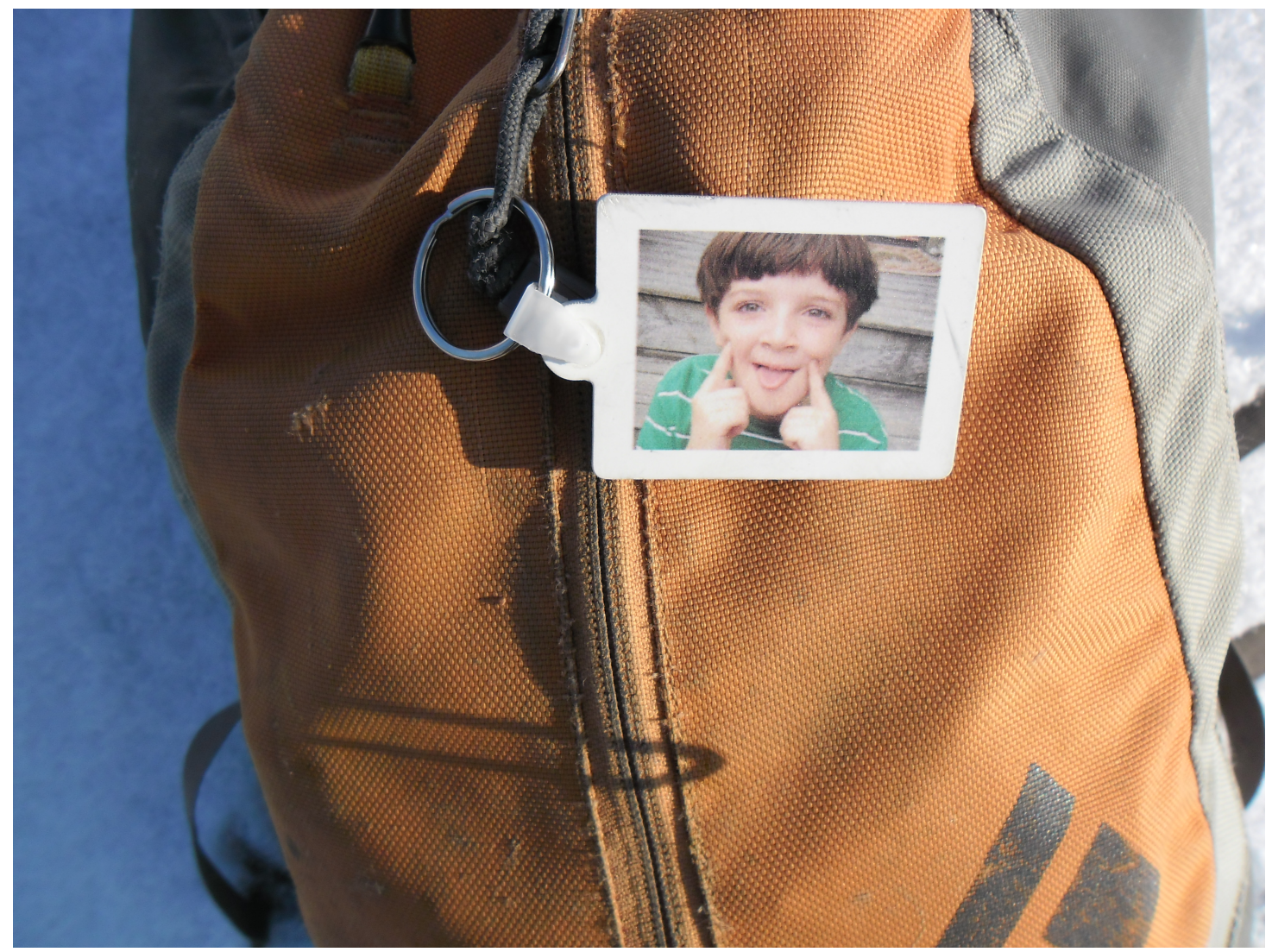

Figure 4. "Having a photo of my son on my backpack keeps me motivated" - photo taken and titled by Annie to represent her relationship with her son

Thus, Annie's off campus responsibilities actually impacted her drive to stay in school and continue towards a degree.

Participants purposefully chose to attend the College due to its proximity to their homes and families. Angela shared, "I've always commuted. I never wanted to live on campus. I don't think there's a particular reason why I just - I always want to 
be close to home." Along with working two jobs, Angela helped to take care of her baby niece so family was a significant part of her life. The value she placed on family can be seen in Figure 5 - a picture she took of her niece to represent her family.

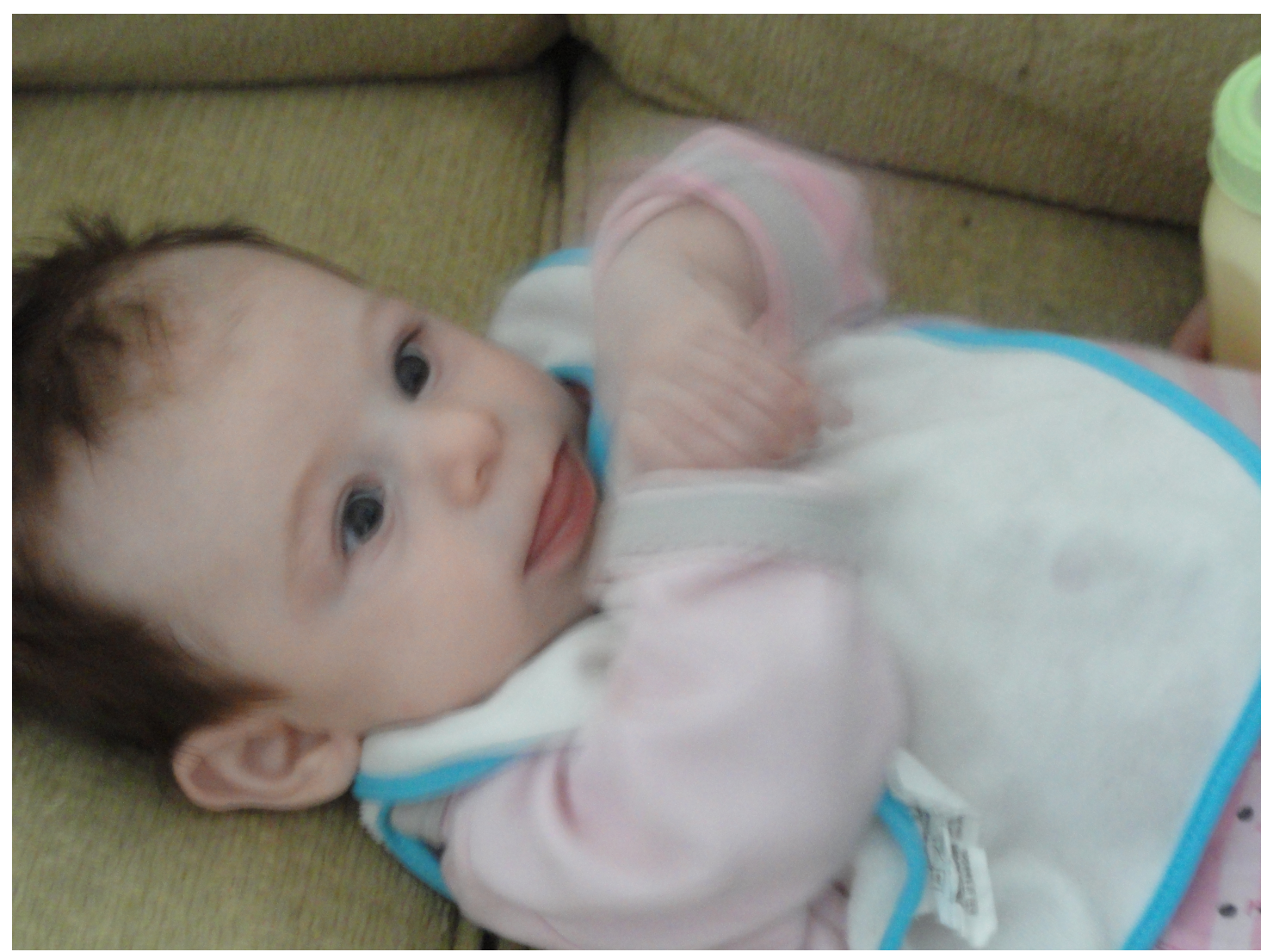

Figure 5. "Family makes a crazy life worthwhile" - photo taken and titled by Angela of her niece to represent the important role of family in her life

She explained that "without my family I probably wouldn't quite be as driven as I am - I like to think that they help push me."

For Sarah, proximity to home was one of the main reasons she chose to attend the College. She shared, "it's the only school I applied to when I was in high school . . . It's affordable, it's close by, like close enough that I can commute to it." Sasha considered herself "family-oriented" and featured her partner's family in Figure 6, which she titled "Free Dinner." The image showed the meal prepared for her and her partner by her partner's parents; they went to her partner's family's house a few times 
a week for dinner as their busy lifestyles did not always allow for time to cook. Sasha explained that "most of the time when we get out of school or work late we don't even go home - we go to her mom's house and she has all this prepared for us."

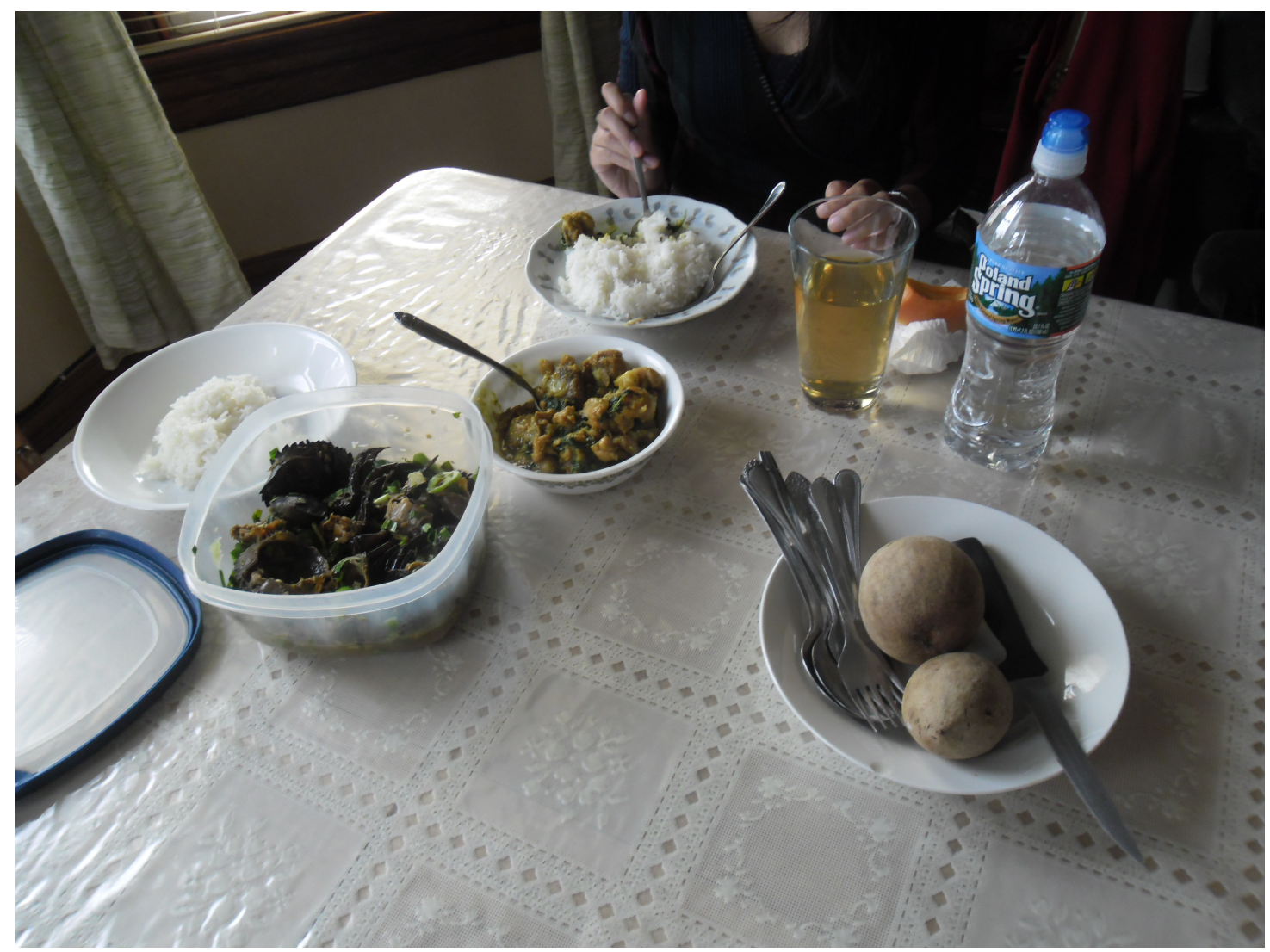

Figure 6. "Free dinner" - photo taken and titled by Sasha to show the meals prepared for her and her partner by her partner's parents

So many of the participants had close ties to their families, which they appeared to prioritize over on campus socializing.

In addition to family, off campus jobs also competed for their attention. Nine of the ten participants were employed at the time of the study, and the tenth participant, Marcela, had worked at the Campus Dining Center in the past. Of the nine participants reporting current employment, five of them were working off campus (Kara, Victoria, Sarah, Lindsay, and Angela). Patrick, Sasha, Stephen, and Annie all worked on campus; Kara also worked on campus in addition to her off campus job. 
Both Stephen and Sasha had worked off campus earlier in their college careers. While students living on campus may have also had off campus jobs and family responsibilities, the participants perceived dorm people as focusing more of their time on campus activities. Stephen viewed these activities as programs specifically geared toward dorm students, explaining that "there's all the random activities at the Student Union that an on campus student would probably go to.” To Sarah, campus activities were part of an idealized version of college. She shared, "I think that's like a stereotypical college thing - like people getting together and playing Frisbee [laughs] or like something like that." Campus events were also seen as activities for younger students. In explaining how she came to pick up a work shift at the on campus computer lab, Sasha noted that all of the younger students "were at that concert last night - so all the kiddies wanted to go see it. I was the only one who could work."

It is interesting that even participants who were involved in on campus activities still identified these activities and campus programs with dorm students. Stephen was a member of the Chess and Gaming Club and worked on campus; Victoria had a number of friends who lived on campus and had attended campus events; Kara was a member of Student Government; Annie was a member of the Christian Fellowship, wrote for the student newspaper, and worked on campus; Marcela had worked on campus in the past and had been a member of a multicultural student organization; and Sasha and Patrick both worked on campus. Even though seven of the ten participants were involved with campus programs, the participants still associated that type of experience with dorm students. 
There were a lot of contradictions in discussing the participants' social lives; they often described difficulties making friends and the relative unfriendliness of the campus, then would go on to discuss campus activities in which they were involved or people they had met. In reviewing the pictures he took for the study, Stephen explained that he did not have much of a campus social life, but later shared that he eventually got involved on campus: "I didn't like start going to like the school clubs and stuff until like a little bit after my - a little bit like after my sophomore year, and more toward my junior year." He continued this point by telling the story associated with his picture of his magic cards (Figure 7):

Um, this here - ah, during my sophomore year I met my - I'll say my first legit [State College] friend because there's a lot of people in my theater major that say "we're your friends, we're your friends" - I never hang out with them outside of college so I mean unless I work with them after college - I'm probably never going to see them again so I consider them close acquaintances. Um, but um, my friend showed me this club called the Chess and Game Club now it's only the Chess Club - but during when it was Chess and Game Club a lot of them played this game called Magic so I was like "Eh, I'll try it" - so I have magic cards now. 


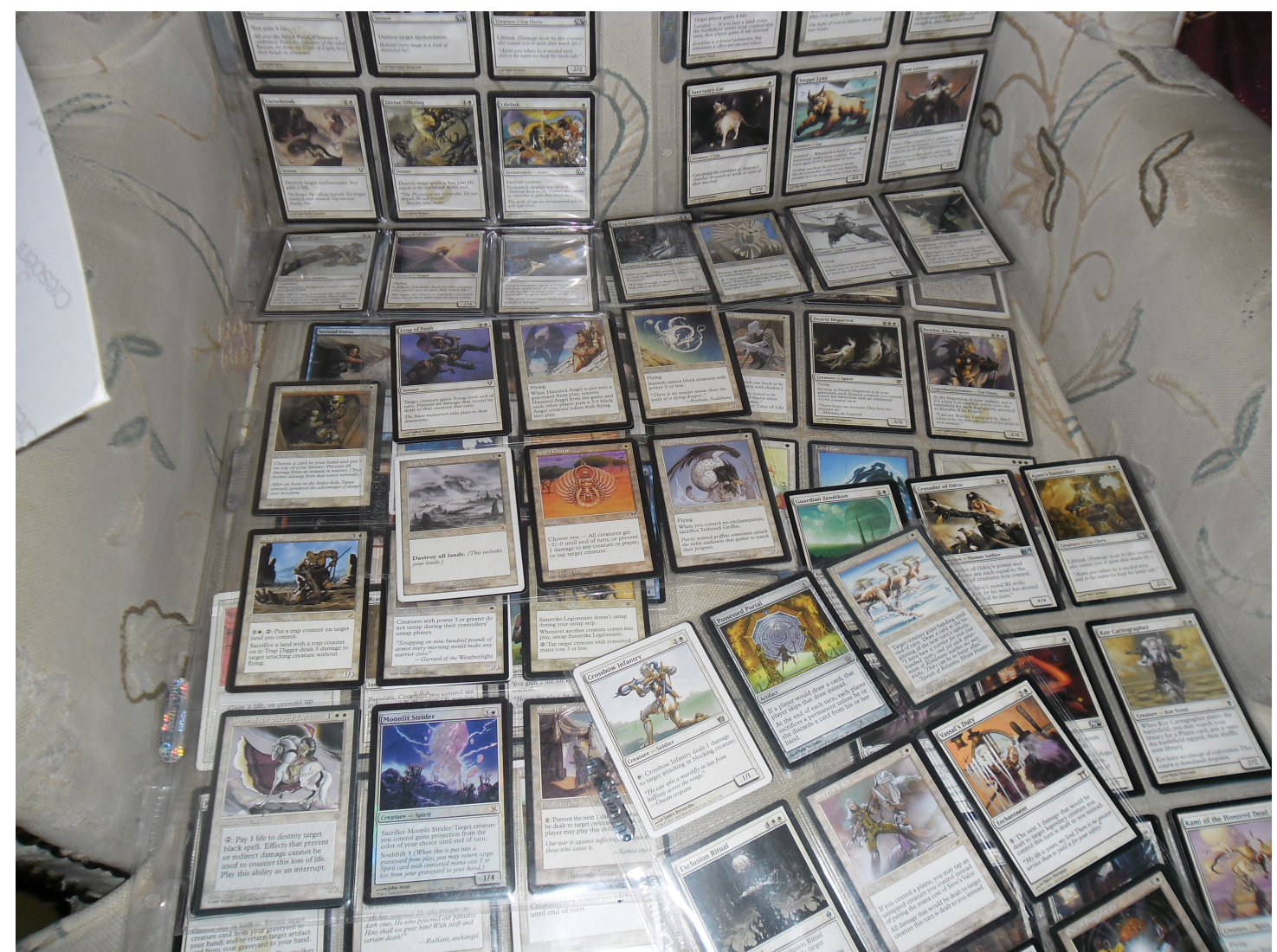

Figure 7. "Magic gathered by first [State College] friend" - photo taken and titled by Stephen of his set of magic cards the represented his first friendship at State College

Similarly, Annie initially described a non-existent social life, explaining “you can probably tell that I don't have the greatest social life here and I think that as a commuter it's hard to make connections with people." But she then went on to discuss her involvement with student organizations. In particular she discussed her participation with the InterVarsity Christian Fellowship, which is pictured in Figure 8:

This [picture] is the IV office - InterVarsity is a Christian group on campus it's kind of like a spiritual home for me - there's a lot of cool people there there's a meeting every Thursday night ... it's a really fun group of people to hang out with. They're often in the office ... Sometimes we'll like go out to a restaurant or something ... it's the only student group that I participate in, I just don't have time - like as a commuter student I just have to pick like one 
extra thing to do and that's what I do. Yeah. I've also written for the paper, but again it's too big of a time [commitment] for me to do anything except write the occasional article.

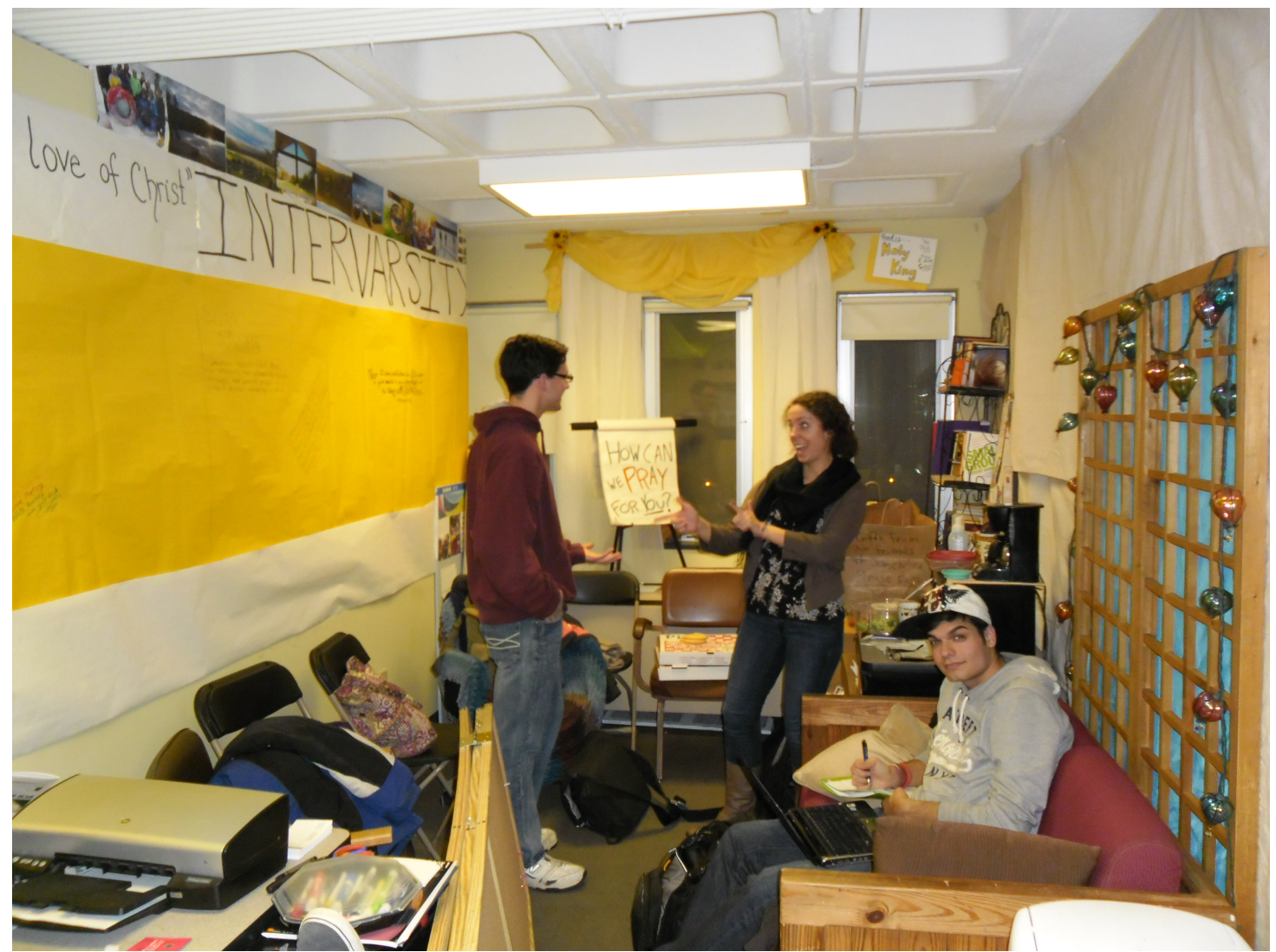

Figure 8. "InterVarsity Christian Fellowship is my spiritual home at [State College]"photo taken and titled by Annie of the on campus office space of the InterVarsity Christian Fellowship student organization

Similarly, Victoria felt that she "would have met more people if I lived here . . . because you're kind of forced to be thrown in more", but was pleased that she had been able to find a good group of friends. She said

It's a big adjustment going from you know high school where you pretty much grew up with everyone and your first day here and you know no one - you know - they tell you in orientation to try and like communicate with other 
people and make friends but like no one's really into that but I've been able to make my friends and stuff so I'm happy [laughs].

In particular, Victoria made some friends who lived on campus - pictured in Figure 9. She met them weekly for lunch in the Campus Dining Center.

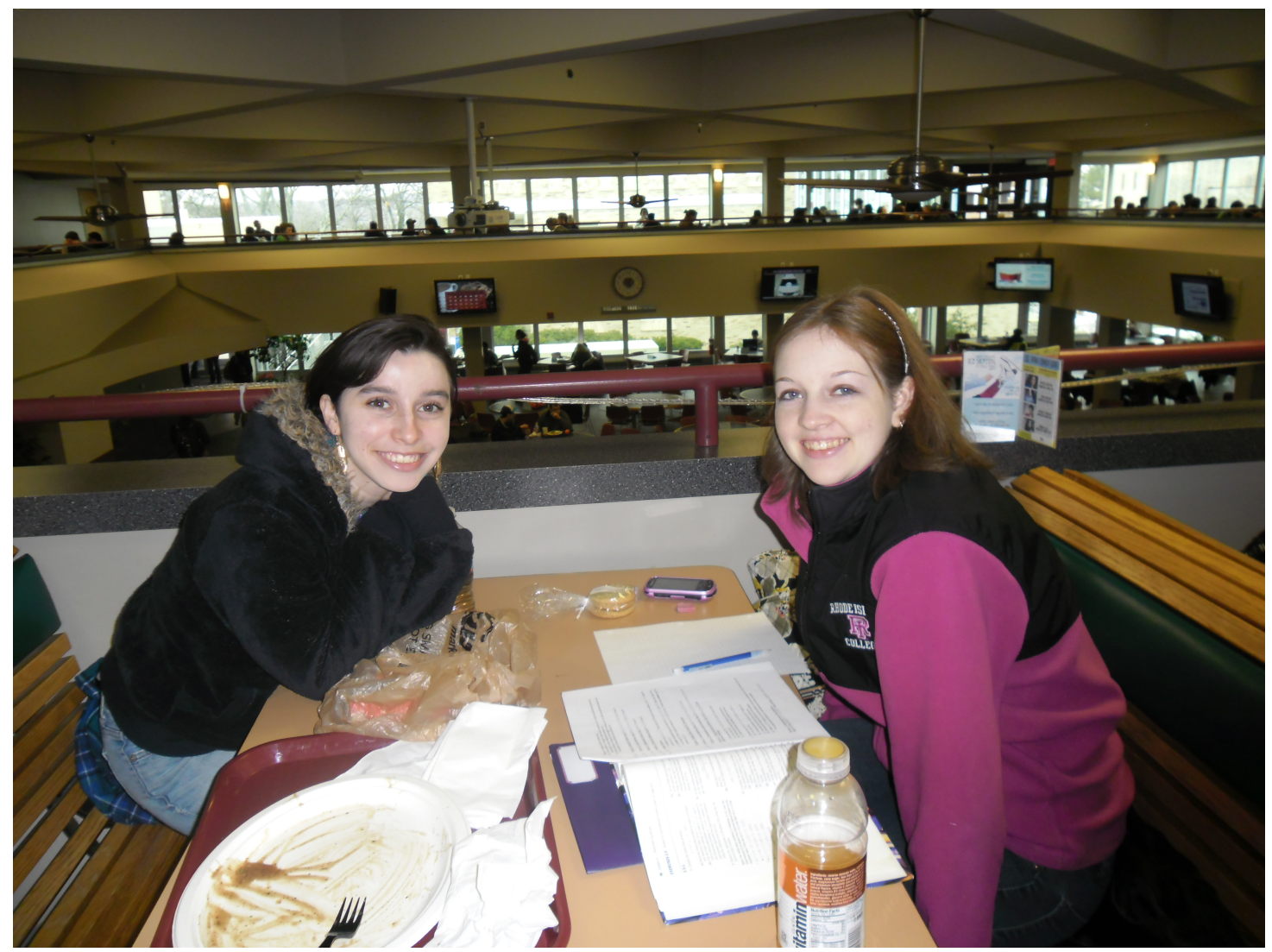

Figure 9. "Steph \& Sarah" - photo taken and titled by Victoria of her weekly lunch date at the Campus Dining Center with two of her friends

Despite feeling close to these friends, Victoria did not seem to feel completely comfortable in the residence halls, which can be seen in the picture she took of the residential side of campus to show where she spent time with her on campus friends (Figure 10). 


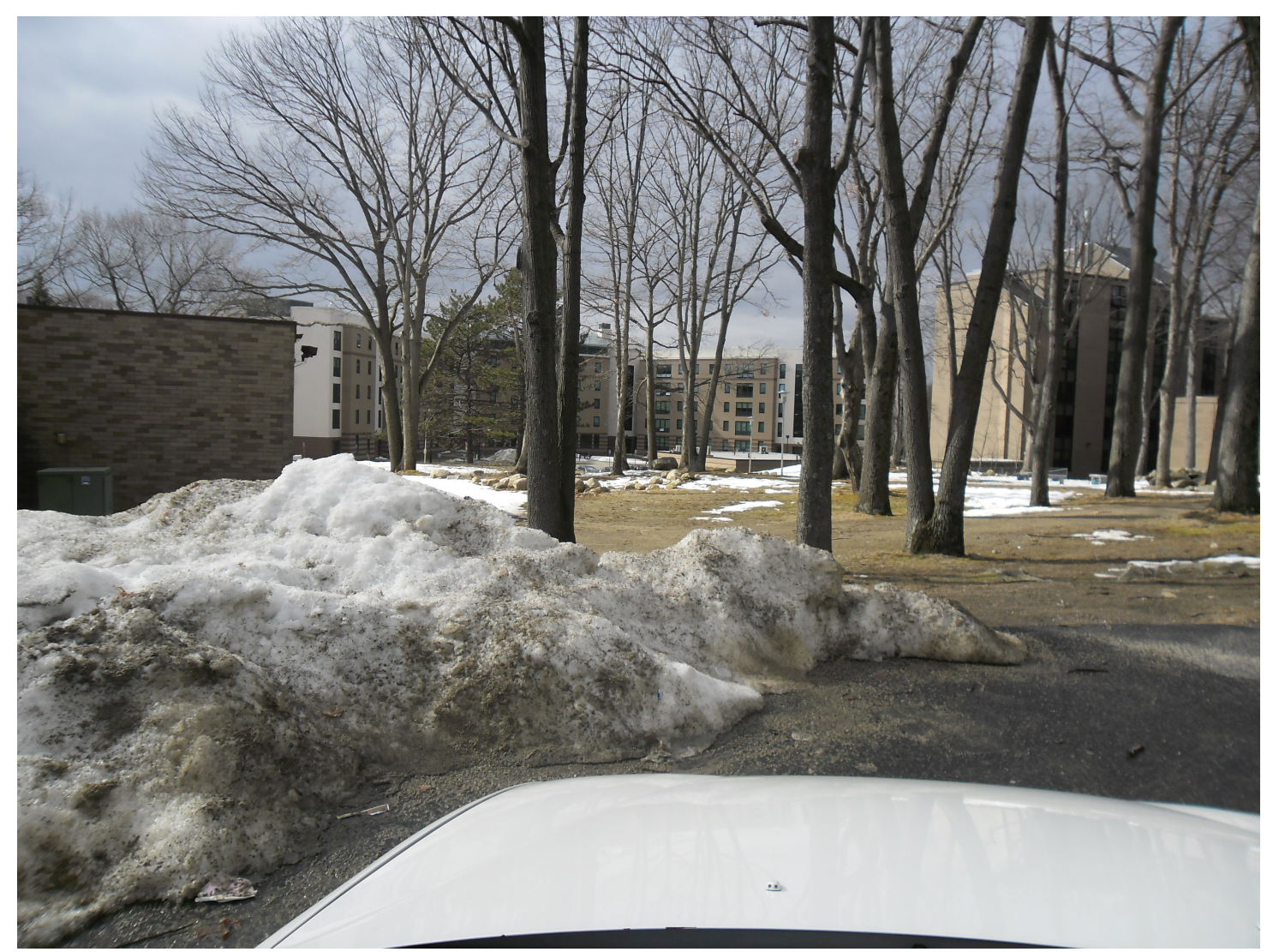

Figure 10. "Where I spent a lot of my time with friends when I could" - photo taken and titled by Victoria of the "back of the dorms at [State College]

When asked if there was anything she would change about her pictures, she commented that she would have liked to have taken a better picture of the dorms, but if she had driven closer she would have "been in the way". First, she did not feel as if it was okay for her to walk up to the dorms, and second, driving up to the entrance made her anxious at feeling out of place. Thus, though she said that she spent a lot of time there, her picture indicated a bit of apprehension, as if she did not truly belong there.

Again, in keeping with the trend in contradictions, Sasha initially noted "so that's my life. No time for extra friends." But, in discussing her on campus job, she mentioned her social connections. She explained "I like it - I like the student interaction - I interact with the professors - I get to know people - see people come 
and go [laughs]." Thus, in general, the participants characterized themselves as focused on family relationships and off campus employment, but, when their comments and pictures were reviewed more closely, they revealed a significant social connection to the campus. However, this connection was often minimized or not seen as the same type of on campus social life experienced by dorm students.

\section{Diversity of Experiences}

On campus socializing seemed to be the main priority of dorm students, according to the participants. In that respect, dorm students were viewed as a generally homogeneous group, while commuters perceived themselves as very diverse, varying in terms of living arrangement, mode of transportation, and entry to the college and progress toward graduation. A conversation during the first gallery walk summed up this concept of diversity amongst commuters:

Annie: It's like people here who live with their parents versus like people who live on their own.

Stephen: Yeah, that's also a thing, like I still live with my mom. But then I know a lot of . . commuter students - who live on their own and they're like only a year or two older than me, but they're like - their college experience is completely different from mine ... I don't have to worry about the mortgage, the electric bills, um insurance all that other good stuff . . . depending on your living situation it's very different for a commuter. There's other people who . . . are older than me and already have ... their own apartment or their own house and they don't have to like live with other people their experience is different too. So I think you can get a lot of different points of view that you can't get from campus students because they all talk about the same [thing] - 
no offense to the on campus students really because I know a lot of them, and they're pretty cool - but all of their stories are basically how bad their residence hall is.

Annie: [Laughs]

Stephen: Or their roommates - and so on and so forth. And you hear one you kind of hear them all.

Marcela: What about us - what's our story [laughs]?

Stephen: It's all different.

Marcela: Oh, so theirs is more uniform but ours is more varied.

Thus there is not one story that represents the experience of commuter students, according to the participants; there are multiple narratives.

These narratives include a variety of living situations. Annie, Patrick, Lindsay, Sasha, and Kara referenced more than one type of living arrangement experienced throughout their time in college. When asked to describe their living arrangements the participants often gave detailed stories. For example, Patrick explained

I've been living this past semester with my exes' mom and stepdad. She goes to school in Vermont so she's never down here. I just - I'm close friends with them ... the school year before this one I had my own apartment - and before that I rented a room. This school year I'm living out there. It would have been easier than finding a place.

He could have only shared that he lived with his ex-girlfriend's parents, but made it a point show where he had been and where he was headed. His story gives a glimpse into the frequent changes in his life. He included a picture of the view of the bay from the backyard of the house of his ex-girlfriend's parents (Figure 11) in his collection of 
photos.

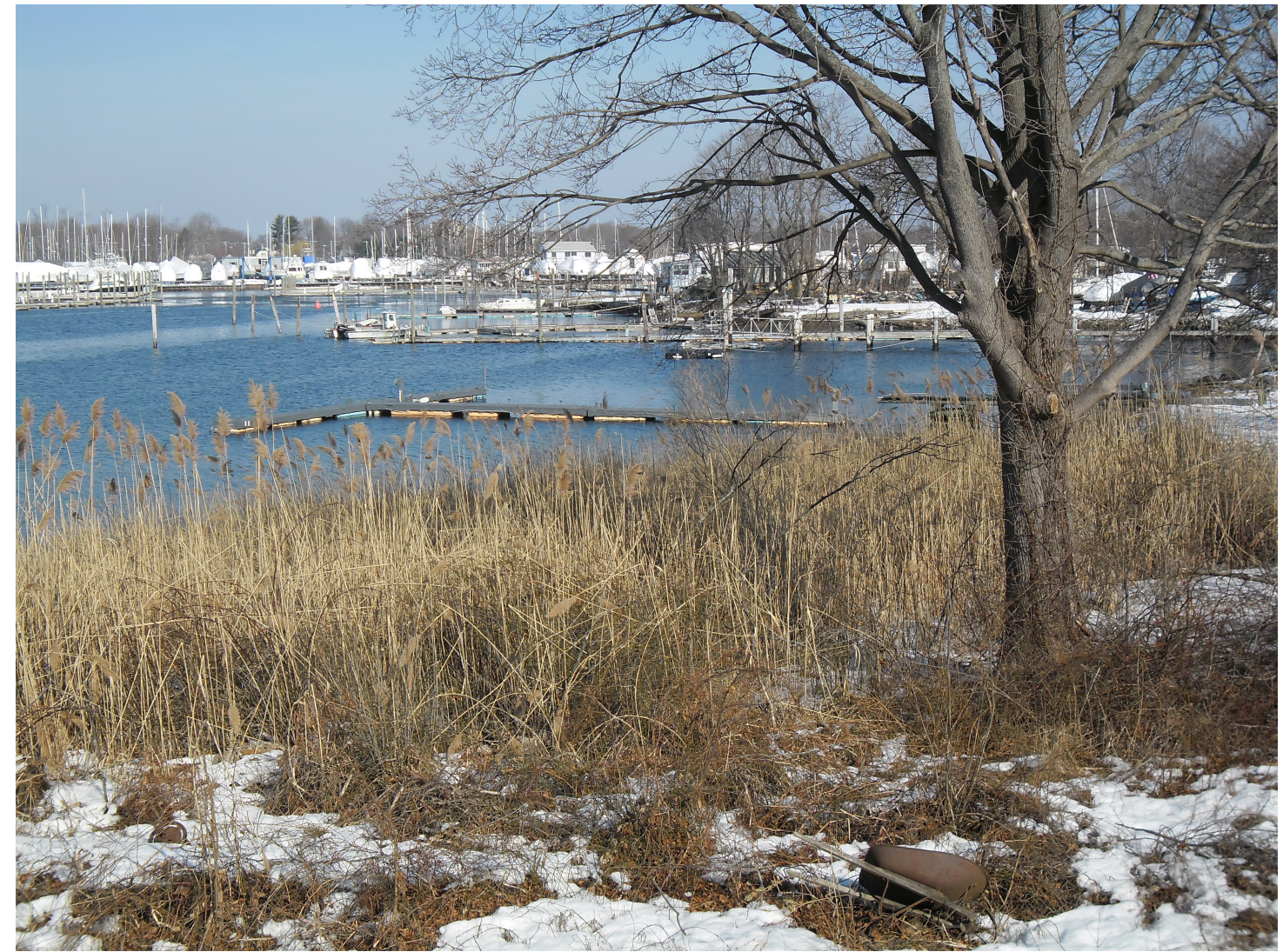

Figure 11. "Beginning the day" - photo taken and titled by Patrick to show the view of the bay from his backyard

Lindsay also had multiple living arrangements during her time at State College, which she described:

I actually did live in [the same state as State College] for a year and a half . . I was living with my friend's 85 year old great grandmother [laughs]. It was pretty interesting, but it was fun - helped her out a lot and she liked you know not being alone all the time and having someone else there to help her out. And then I don't know why I moved home really. I think I just missed like my family and stuff . . . So I just moved home. And plus my mom had moved away too so I kind of just moved home to be near my close family anyways.

This move allowed Lindsay to have two types of commuter experiences - living in an 
off campus apartment somewhat close to campus and living with her family whose home was around 45 minutes away in another state.

Other participants had one living arrangement during their time at State College. Sarah explained, "it's just me living with my parents. I do have brothers but they're long gone [laughs].” Similarly Stephen lived with his mom and Angela lived with her parents. It is interesting that a seemingly simple question about the participants' living arrangements would elicit such a diversity of responses. For easy categorization purposes one could say that Marcela and Annie lived alone, Patrick lived with another family, Kara lived with roommates, and Stephen, Victoria, Sasha, Sarah, Lindsay, and Angela lived with their families. For some of them, their current living situation is temporary as in Annie's sublet and Angela's future plans to move out. So it is possible for commuter students' living arrangements to vary from semester to semester, depending on family situations, finances, and other circumstances.

The participants' diversity was also seen in their different modes of transportation. Three participants took the bus (Marcela, Annie, and Patrick) and seven participants drove their own cars to campus (Stephen, Victoria, Andrea, Sasha, Kara, Sarah, and Lindsay). While this categorization reflects the participants' predominant mode of transportation, some of them utilized multiple ways to get to campus during their time at State College. For example, Stephen explained that

I usually - I go by car. Um, my car - it usually breaks down like twice a year, so I tend to either get dropped off by my mom or I take the bus. Or, if I am lucky enough to have class with a student I know personally I can get a ride. 
That's very rare, so it's usually like my mom or the bus.

Similarly, Lindsay and Sarah both mentioned briefly using other methods to get to campus. Lindsay shared that she "carpooled with my friend because she did live with me and her grandma for a little while so I think we both went together." Sarah's alternate mode of transportation was related to car issues. In describing her first day at State College, she said that "I didn't have my car yet - it was still like being registered [laughs] - so it was kind of funny - my parents dropped me off at college [laughs]." Thus the participants' mode of transportation sometimes changed throughout their time at the College due to car issues or finding others with whom to carpool, which adds another layer to the diversity and complexity of their experience.

There seemed to be a divide between the participants who drove and those who took the bus, which was most evident in the gallery walks. For example, during the first gallery walk, Marcela commented that "when you say commuter I forget drivers are commuters too - I'm just thinking about people who ride the bus - my perspective. I'm the commuter - not you drivers." Conversely, participants who drove were surprised that students took the bus. Sasha thought that taking the bus had "died out" since she had not "taken the bus in a long time." She summed up this assumption by sharing that she generally thought of commuters as people who were more likely to "be a little bit older and independent - not that someone who takes the bus isn't independent - they rely on outside transportation.” Thus, taking the bus did not fit with Sasha's image of a commuter student.

Other participants who drove expressed negative feelings toward the bus, which implied a lack of understanding of the experience of commuters who took 
public transportation. For example, Kara commented that "there's no like convenient bus [near my apartment] ... I guess I could take the bus, but it would be more of a hassle." This comment hints at a lack of consideration of the possibility that some commuter students do not have access to a personal vehicle and thus do not have the option to drive to campus.

This disconnect between the experience of bus riders and drivers was magnified in the gallery walk discussions of a recent stabbing on one of the bus routes. In gallery walk two, with all drivers (before Patrick arrived about halfway through the interview), the stabbing was seen as evidence that taking the bus was very dangerous. Sarah explained "I would never take the bus ... because the bus that comes to where I live [is the route on which the stabbing occurred] ... I'll drive my gas guzzler - it's fine!" Victoria agreed that the situation was "really scary" and expressed disbelief that "no one checks these people" - implying that individuals should be searched or patted down before riding the bus.

Conversely, in gallery walk one, with all bus riders, the stabbing was viewed as an isolated incident, which was not indicative of chronic violence. Annie, who often took the route on which the stabbing occurred, explained that "it wasn't a random act of violence - it was an act of domestic violence that happened to occur on the bus." Therefore, this unfortunate event did not discourage Annie from riding the bus; she said that the stabbing "doesn't make me feel like a freak to ride the bus or anything." She differentiated between the violent behavior of certain individuals and the general demeanor of people who take public transportation. 
The first gallery walk (comprised of all bus riders) seemed to help those participants to form a bond around their shared experience, which raised their consciousness of their commonalities. Upon learning that Annie and Marcela both took the bus, Stephen exclaimed "I'm a bus student too! My car breaks down at least twice a year - cheap parts - so I usually am a bus student at least once a semester at the very least." He was excited to meet other people who were also "bus students" because he assumed that "everyone who's going to be [at the gallery walk] . . . are going to be car people." Annie agreed, sharing "that's what I thought too." Seeing other bus students at the gallery walk was a confirmation that they were not alone. Thus two distinct communities surfaced, drivers and bus riders, which speaks to the variety of commuter experiences.

The participants also varied in regards to their entry to the College and progress toward graduation. One might expect that the question "how did you come to attend [State College]" would elicit fairly straightforward answers, but the opposite was true. Of the 10 participants, only three of them came to the College the semester immediately following high school graduation. Five of the participants were transfer students; this status seemed to influence their decision to commute. For example, Kara noted "when I transferred here I was already a junior so I didn't see much point in living on campus." Kara's identification as a transfer student can be seen in her picture of her community college diploma (Figure 12). 


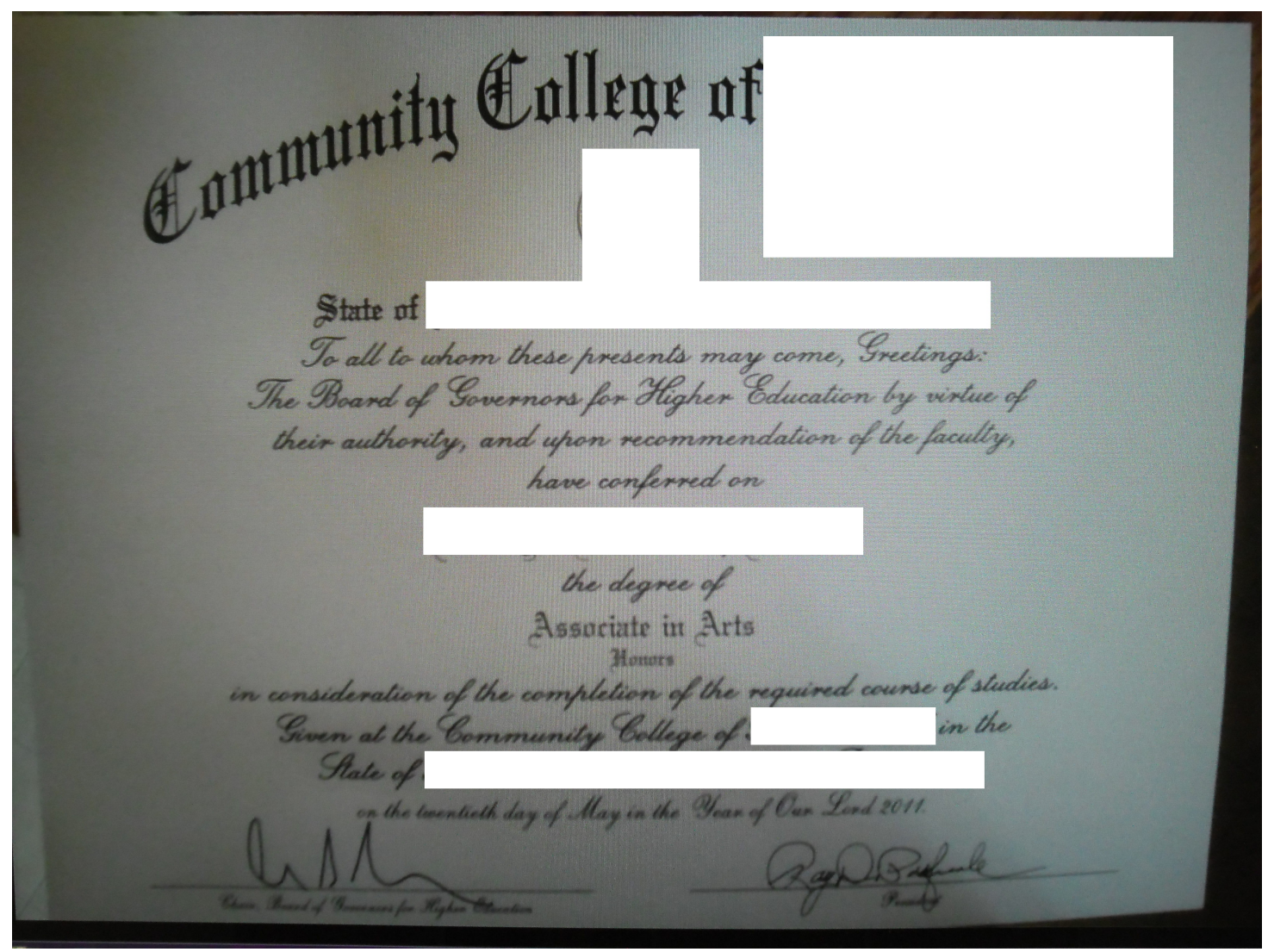

Figure 12. "Every beginning has an end and every end starts a new beginning" - photo taken and titled by Kara of her community college diploma - whited out areas added to maintain confidentiality

Thus, in addition to identifying as commuter students, half of the participants also identified as transfer students, which points to an intersectionality of these statuses. Transfer students are not the target population for living on campus, which can be seen in State College's Residential Life \& Housing policy: "because of limited housing space, we cannot guarantee housing for transfer students" (State College Residential Life \& Housing, 2013, ๆ 3). Even if transfer students wanted to live on campus it is likely that there would not be room for them.

Two of the participants, Marcela and Sasha, had taken time off between semesters due to a need to figure out their lives and academic goals. Marcela described herself as a "readmit, Communications" student. She explained that she had been 
“trying to finish my degree forever. I was supposed to graduate in '93, dot dot dot, so now this is my last chance... I came back because, you know, it's on your to do list when you don't finish something - it's stuck there." The "dot dot dot" is a reference to Marcela's experience in 1993 of attending the commencement ceremony and crossing the stage, only to find out that "I didn't get the [diploma] [nervous laugh] - I got the cardboard enclosure - and it was like anti-climatic for me. And I was like wow [whispers]. But I'm still trying!” Apparently she had not actually completed her coursework so could not graduate. Since then she has taken time off and come back to the College three separate times (in 1999, 2006, and 2013 - the time of the study) to try to finish.

Marcela and Sasha's circuitous paths towards graduation are related to the nondominant experience of commuting in that taking time off while working towards a degree does not fit with the traditional expectation of attending full time and graduating in four years (Pascarella, 2006). Furthermore, as students take time off they become older and more focused on their non-college lives, which, according to the participants, makes them less likely to want to live on campus.

This lack of fit with traditional expectations is central to the theme of commuter students and dorm people as it exposes the multiple narratives associated with the commuter experience and the complexities that emerge when individuals in the non-dominant group form their identities in relation to the dominant group. These complexities were often expressed by the participants through incongruous descriptions of their perceptions of the commuter and residential experiences. For example, dorm people appeared less stressed, but also lived in drama-filled, restricted 
environments. In contrast, commuters were seen as having hectic, busy lives, but enjoyed the comforts of home. Campus activities were seen as the domain of dorm students, even though the majority of the participants were involved in campus programs. It is as though the participants' involvement did not fit with their perception of actively engaged students.

Further adding to the complexities is the participants' tendency to experience multiple institutions of higher education, living arrangements, and modes of transportation during their time in college. These changes make it difficult to get a clear picture of the commuter experience - it is always in flux. There is a lack of a unified community within the commuter student population, with separations along the lines of bus riders and drivers, transfer students and those who began at the institution, and students who live with their families and those who live on their own. In addition, the participants often fell into different categories throughout their time in college. Thus, the picture of the commuter experience painted by the participants in relation to dorm people is one of incongruity, variety, and complexity. Despite this incongruous picture, the participants expressed somewhat unified views of the difficulty of the commuter experience and pride in their ability to continue to persevere towards graduation, which is explored in the next theme.

\section{"How Difficult it is for Commuters" (Victoria), But We're Used to It}

In the words of Stephen, the commuter experience was "not easy." Similarly, Victoria repeatedly noted "how difficult it is for commuters." Within the concept of the difficulty of the experience, the participants discussed three main aspects: wellness, fitting it all in, and navigating systems. However, the participants did more 
than just share their difficulties, they also showed that they were able to work through these tribulations in order to continue to attend State College.

\section{Wellness}

Related to the hectic nature of their schedules and large amounts of time spent away from home, it seemed difficult for the participants to find ways to eat meals - or to even eat at all - and to generally maintain healthy lifestyles. Marcela, who took the bus, did not seem to eat full meals. She explained "if I forget to bring food, like I did today, I'll buy a bottle of water. Instead of buying food I'll buy a bottle of water at [the Campus Dining Center]." Other participants exhibited similar habits; Annie shared "I usually bring snacks with me to eat because my schedule's pretty packed so I'll usually bring crackers and cheese - something to snack on during class." Victoria agreed, sharing "I bring snacks. Um, typically like just something small, but if not I try to eat like at my house prior to coming here." Angela who took a picture of a typical meal of granola bar and coffee (Figure 13), explained "I buy granola bars and just stick them in my bag and when I get hungry I eat something. It's usually on my way home or when I'm walking to my car. It's kind of insane [laughs]." 


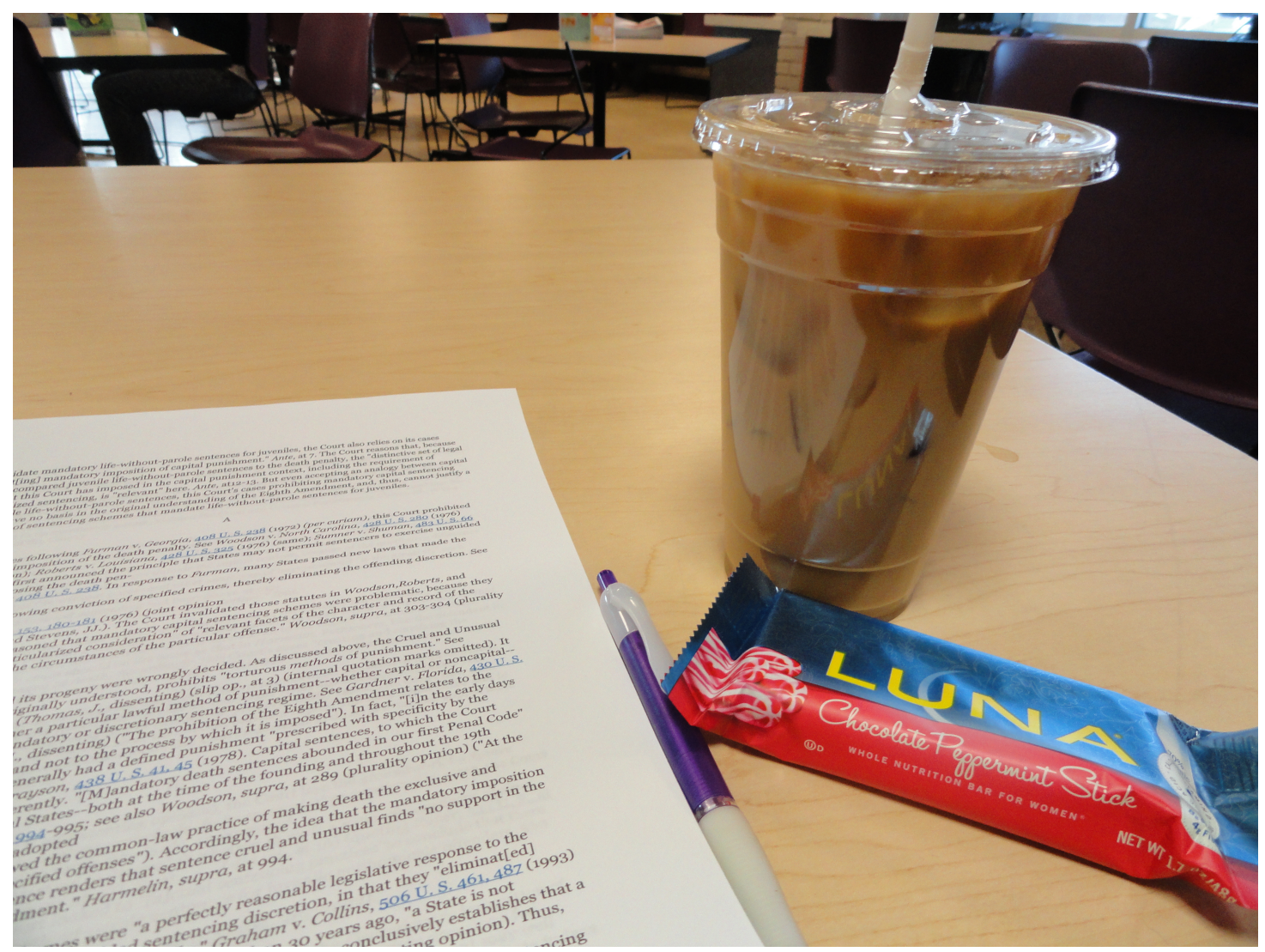

Figure 13. "Dinner on a busy night" - photo taken and titled by Angela to show her typical meal at the College's café

Some participants acknowledged the struggle to maintain a level of wellness and worked to use strategies to improve their health. Sasha, in discussing past difficult semesters, noted "this semester I'm not going to stress - I'm going to take it easy - I'm going to fix the schedule to my liking so two classes and make sure I'm home by 3.” Victoria and Angela also used strategies of rearranging their schedules to limit stress caused by off campus jobs. Victoria described her efforts to manage her job at a nursing home. She shared that she tries not to overwork myself because I have in the past and it causes me not to be able to study as much and my work isn't as good as I want it to be so I found if I limit myself to that many hours than I definitely have a lot more time to study, relax, and not be like exhausted - 24-7. 
Angela had a similar experience to Victoria in which she "had a really crazy schedule one time where I would go to work and then go to school and then go to work and it was too much." While Angela had cut down her work hours since that experience, her off campus employment was still a major part of her life, as can be seen in the picture of her workplace (Figure 14).

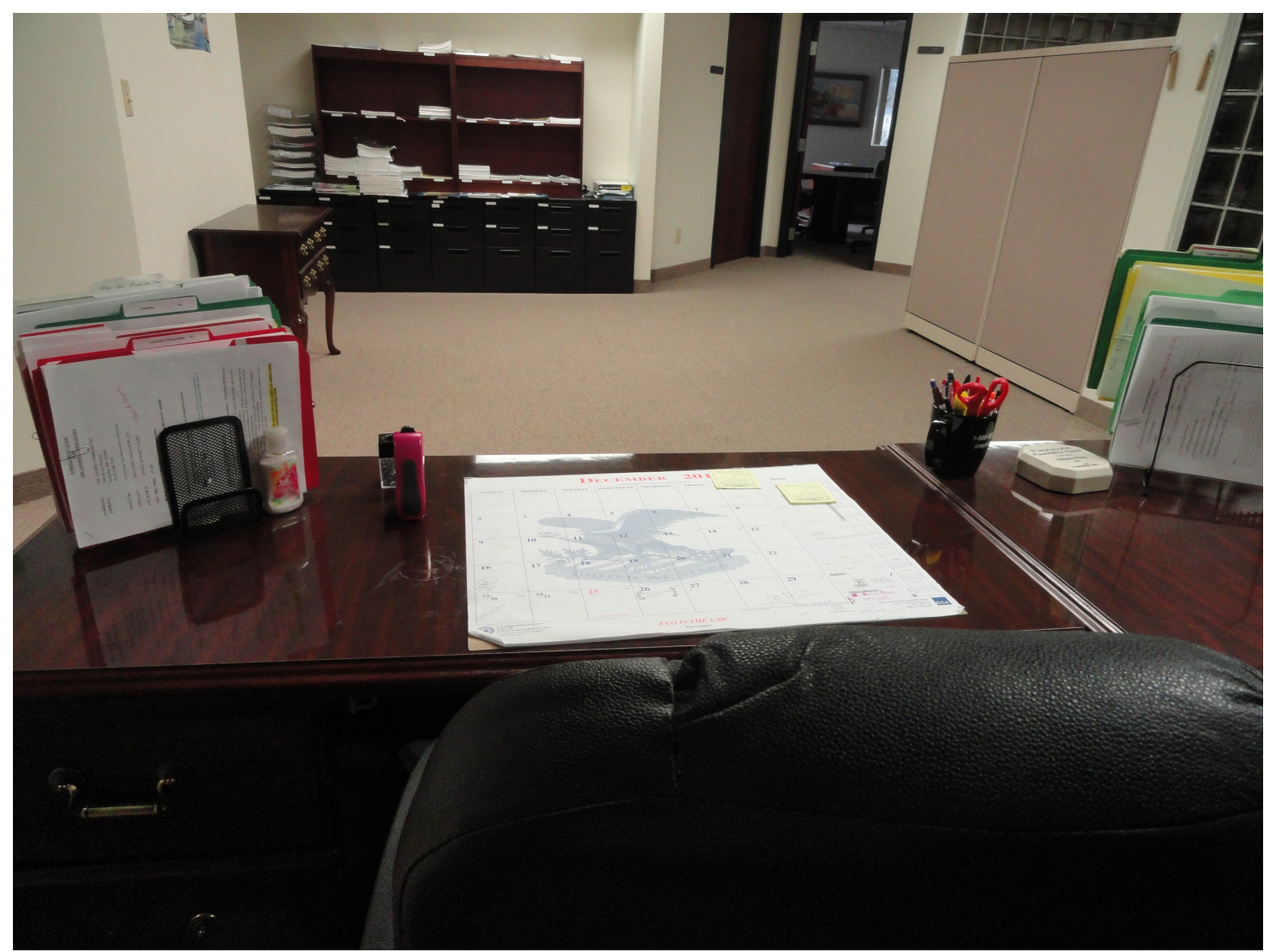

Figure 14. "Hard at work by day, classes at night" - photo taken and titled by Angela of her desk at her off campus job

She summed up the experience by sharing that "I was always eating like McDonald's and Burger King - it was like the worst time in my life - that's why now I can't afford to eat that stuff because it just makes me sick." Angela, Sasha, and Victoria made conscious efforts to rearrange their schedules in order to improve their health.

In addition, Sasha tried to find time for physical activity. She noted "I'm at the gym? Maybe twice a week. On a good week it's three or four times. It hasn't happened 
in a month [laughs]." This struggle to make it to the gym was shown in the picture she took of her gym bag (Figure 15), which she described as

[Laughs] That's this one - this is in my kitchen and uh sometimes I'll have my shoes out there and my clothes inside the bag so that if I do want to go to the gym I have it packed and ready to go. Right now it's in my trunk [laughs] - it was an attempt.

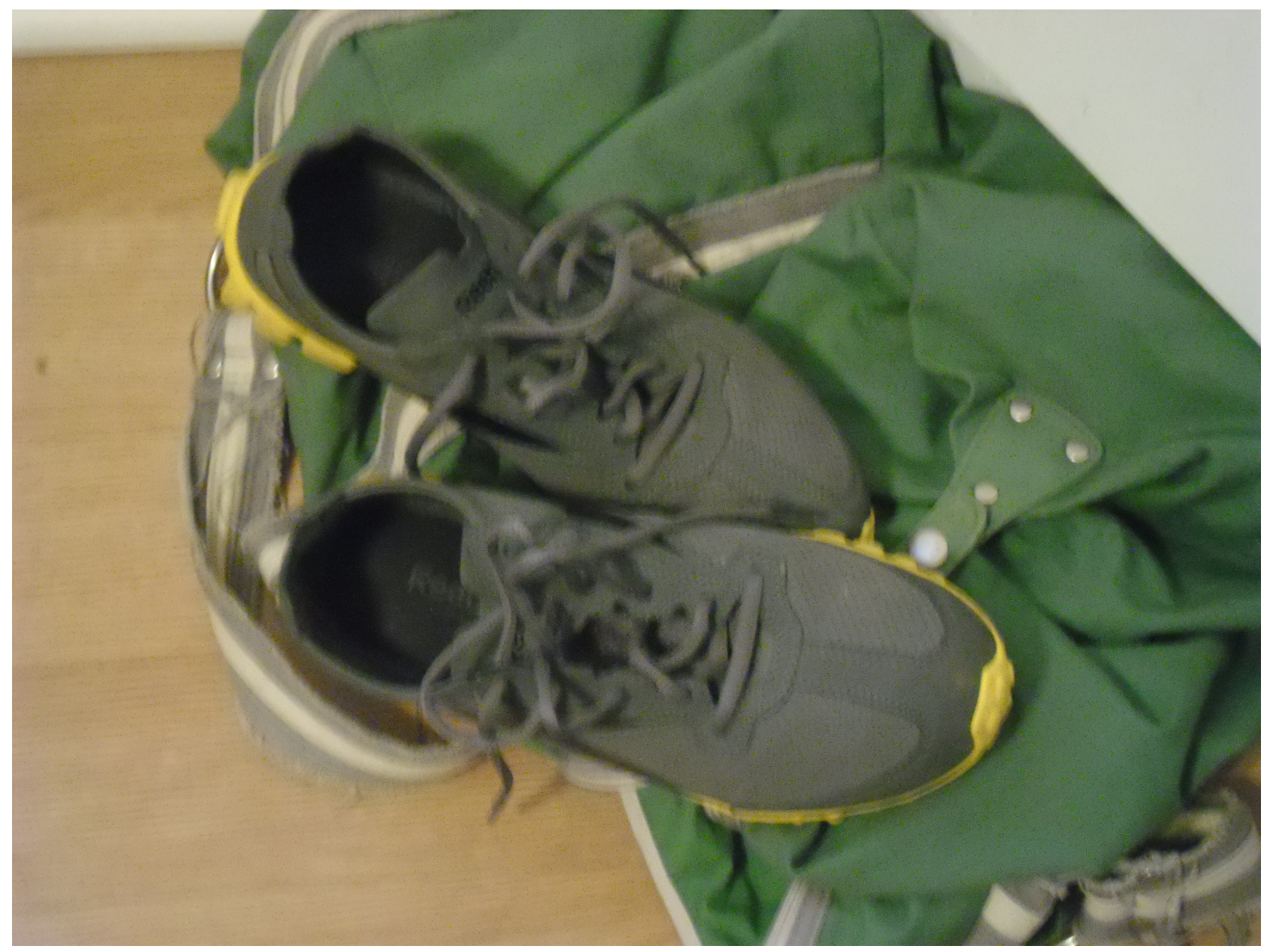

Figure 15. "Will I go to the gym today?" - photo taken and titled by Sasha to show her attempts to go to the gym

While some participants, mostly those who lived with their families, noted that home cooked meals were a benefit of commuting, they did not seem to be able to enjoy those meals often due to their schedules. Sarah expressed this discrepancy in describing the positive and negative aspects of commuting. She said 
Like literally I'd open the door and like the table is full of food so it's pretty awesome. Upside to commuting - there's another one. Um one downside is sometimes I'm driving home and I'm starving so I'll get like fast food or something.

Thus, while home cooked meals were an upside, Sarah was not always able to enjoy them as she would need to eat before arriving home. Similarly, Victoria's family is "Italian so [eating a] big dinner [is] kind of [a] thing," but this family meal was "on and off because if my aunt has time she'll cook dinner but everyone's usually eaten by the time I get home so I usually just like take a plate and then go do homework so it really depends." So the participants had a desire to eat home cooked meals, take care of their mental health, and exercise, but had to make an intentional effort to reach these goals.

\section{Fitting It All In}

Much of that effort was related to the level of organization necessary to fit it all in, i.e. to get to and from campus, take care of school-related tasks, and handle personal responsibilities. The effort required to get to campus was a frequent topic of conversation. While participants who took the bus experienced different challenges than those of drivers, there was a general consensus that getting to campus required significant effort. For participants who drove to campus, traffic was frequently cited as a cause of frustration. Traffic represented more than just wasted time - it negatively affected the academic experience. Kara explained this issue:

Another thing about driving to campus though is that I would be in such a bad mood half the time by the time I got to [the city in which State College is 
located] because people drive like idiots ... there's someone going like 55 in front of you - you can't do anything about it because you can't go anywhere because there's tons of traffic. By the time I get to class I'm like alright now that that's done do I really have to sit through three hours of class right now - I don't want anything to do with it and you're sometimes flustered because you're running late and it's just a mess. Commuting can be a mess.

Lindsay agreed with this sentiment: "It's hard to get out of that commuting mindset of like driving and then sit in class and have you know switch your brain right away to okay be smart now not just zoning out the whole time."

Along with the struggle to focus on schoolwork, traffic presented the challenge of timing and preparation. Angela explained that she usually left her house "an hour before [class] just because of traffic and you never know what might happen." Lindsay also experienced unpredictable traffic conditions; she noted that "sometimes it takes me almost a full hour and sometimes it takes me 40 minutes." Victoria summed up the drive to campus as "with traffic, time to get coffee, time to find a parking space, and actually like walk here it takes about 50 to 60 minutes just for all of that to happen.” Thus a certain amount of planning and anticipation of the unexpected was necessary to get to campus on time for class. Despite the "mess" of commuting the participants were dedicated to continuing to focus on their academics.

Once the participants arrived on campus they had to contend with the parking situation. Stephen explained, "I know the parking situation is really really bad so I usually try to get into my car an hour before my class starts this way if traffic happens I can at least get here in 30 minutes tops, then I have like another 15 to find a parking 
space.” Sarah echoed Stephens concern about parking in her picture (Figure 16) entitled, "the daily struggle for parking spots."

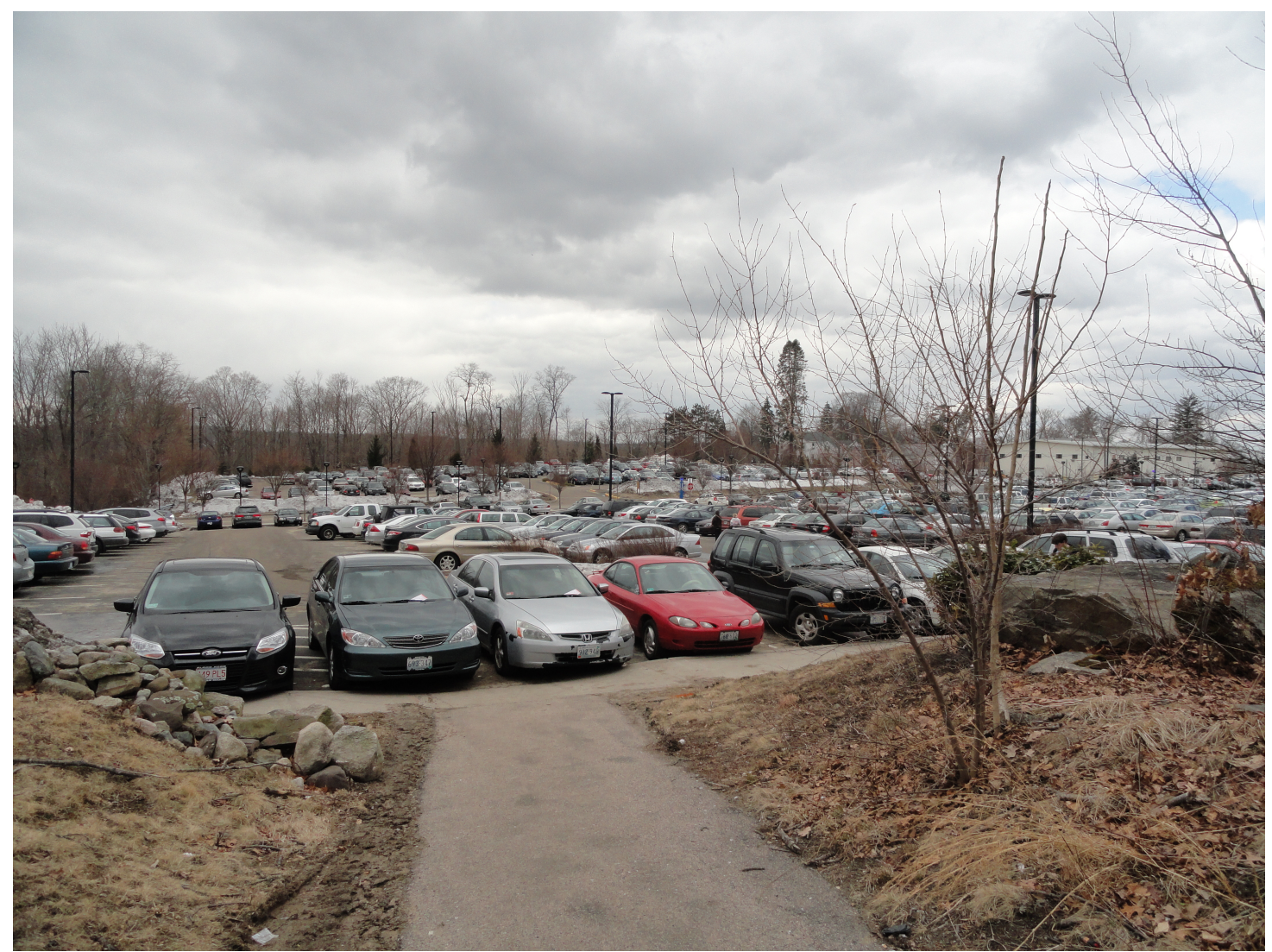

Figure 16. "The daily struggle for parking spots" - photo taken and titled by Sarah of a very full campus parking lot used by students

The amount of time it takes to get to campus is important as it influenced how participants felt when arriving on campus and created subpopulations of short-distance and long-distance commuters. People who live close to campus were seen as having a less stressful lifestyle. According to Stephen, "unless like your house is like only like five minutes away then I guess it's pretty easy for you." Stephen elaborated on this concept, noting, "I've met a couple of students here who actually just live very close here so they're a commuter but they're practically like an on campus student." So it is almost as if having a short commute illegitimates one's status as a commuter student as if making a long trek through a lot of traffic or multiple bus transfers is a necessary 
rite of passage to be considered a commuter.

However, all commuters, both bus riders and drivers, had to contend with the weather conditions. Kara described the impact that snow had on her commute, noting that

you have to get up and you have to clear your car, and then you have to account for like an extra 20 minutes in your commute . . . then you have to figure out like what you're doing to wear and how you're going to keep yourself warm while getting across campus - you can't just like go back to your dorm and change your clothes if your shoes get wet. You have to suck it up.

Sarah agreed with the annoyance of getting around campus in inclement weather, which she showed in her picture (Figure 17) of a rainy day on the campus quad. 


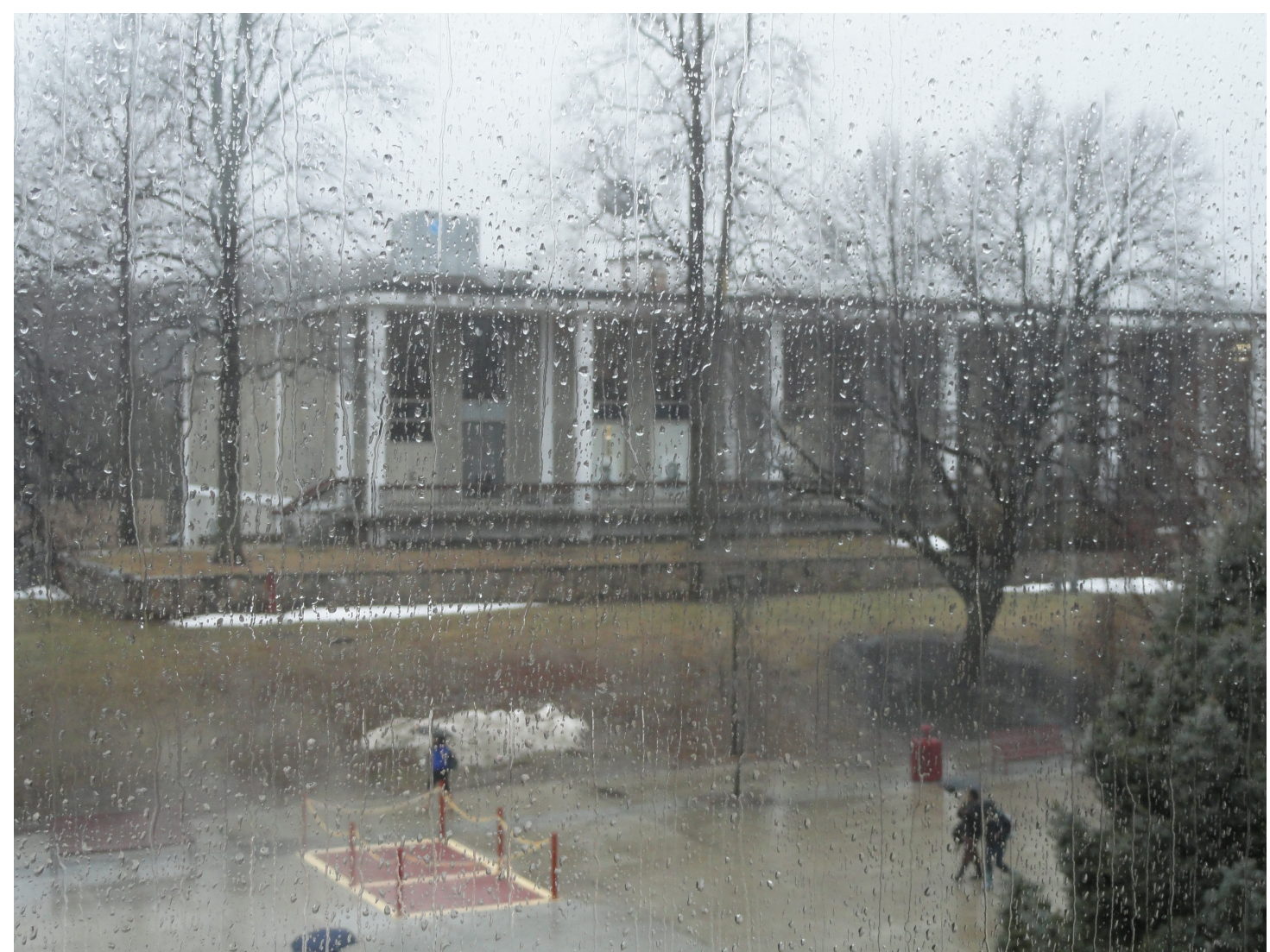

Figure 17. "Walking outside in bad weather - photo taken and titled by Sarah to show a rainy day on campus

In describing her picture, Sarah noted that if she "parked all the way over here and I have to get all the way over here I have to like put on like 12 coats and an umbrella." Thus, in her opinion, "a big part of college . . . is . . the environment . . like walking around in the rain - at least as a commuter." Victoria agreed with Sarah, commenting that "everyone can relate to the rain photos."

In particular, Victoria found that inclement weather negatively affected the parking situation on campus, which she showed in her picture of a parking spot, which was taken up by a pile of snow (Figure 18). She took this picture because I wanted to demonstrate how difficult it is for commuters when it snows outside because ... they pile the snow in horrible places - as you can see like this car had to park over [the line] because the snow's . . piling into 
the other parking space ... so that's one of the difficulties I've gone through here [laughs].

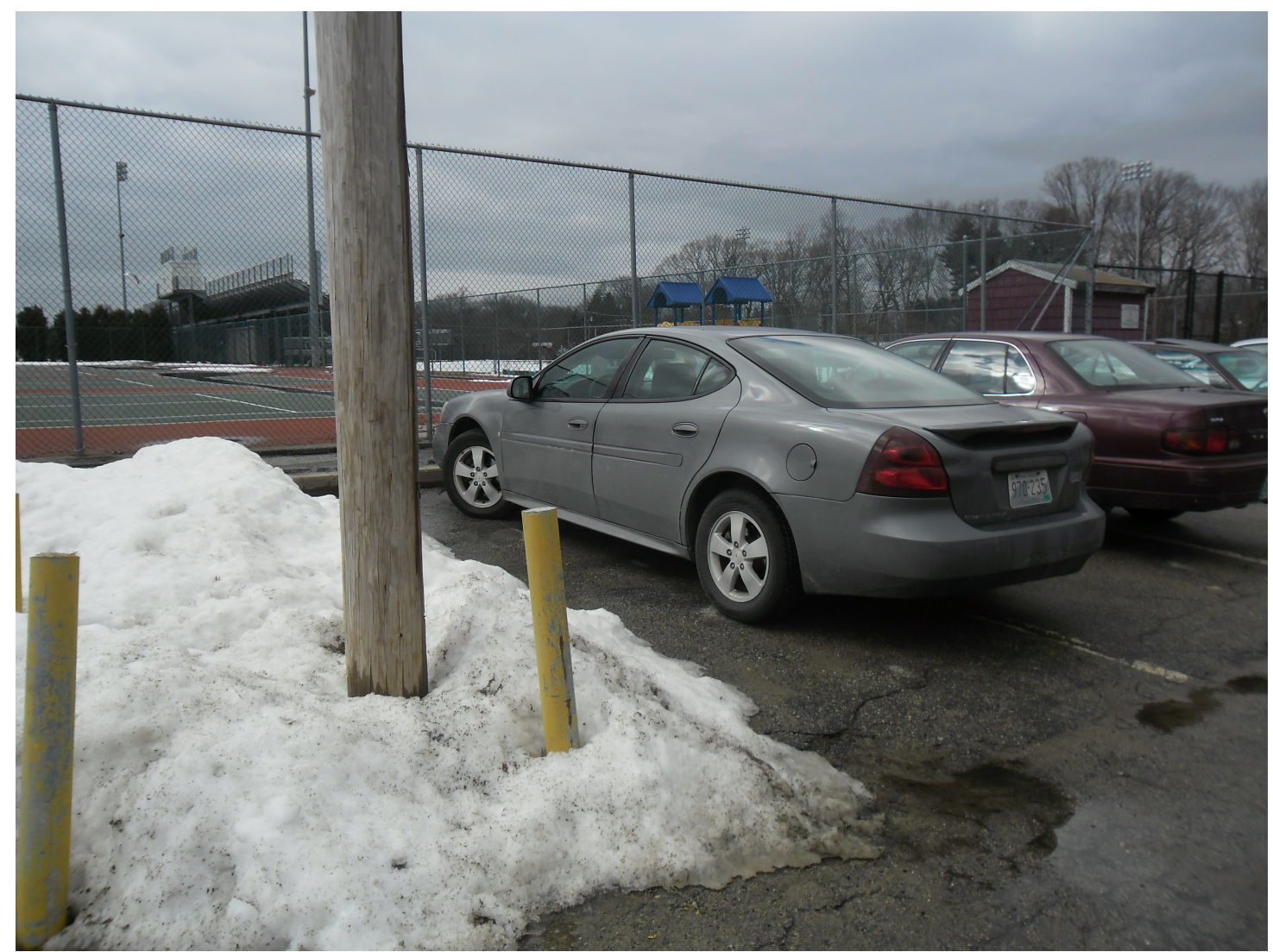

Figure 18. "Snow causes less parking spaces" - photo taken and titled by Victoria of snow piles taking up parking spaces

Weather also impacted participants who took the bus, as they spent more time outside getting to and waiting at bus stops. Patrick discussed this difficulty as he shared the picture (Figure 19) he took of his bus stop in the snow:

And this one - it didn't really pick up what I was trying - I had taken a walk down the street to try to get some perspective on how big a mound - they just took the front end - shoveled it into the parking lot and then dumped it - it wasn't even a push - it was a pick up and dump - so like there was like literally this mound that you had to go over to get from the parking lot to the bus stop. 


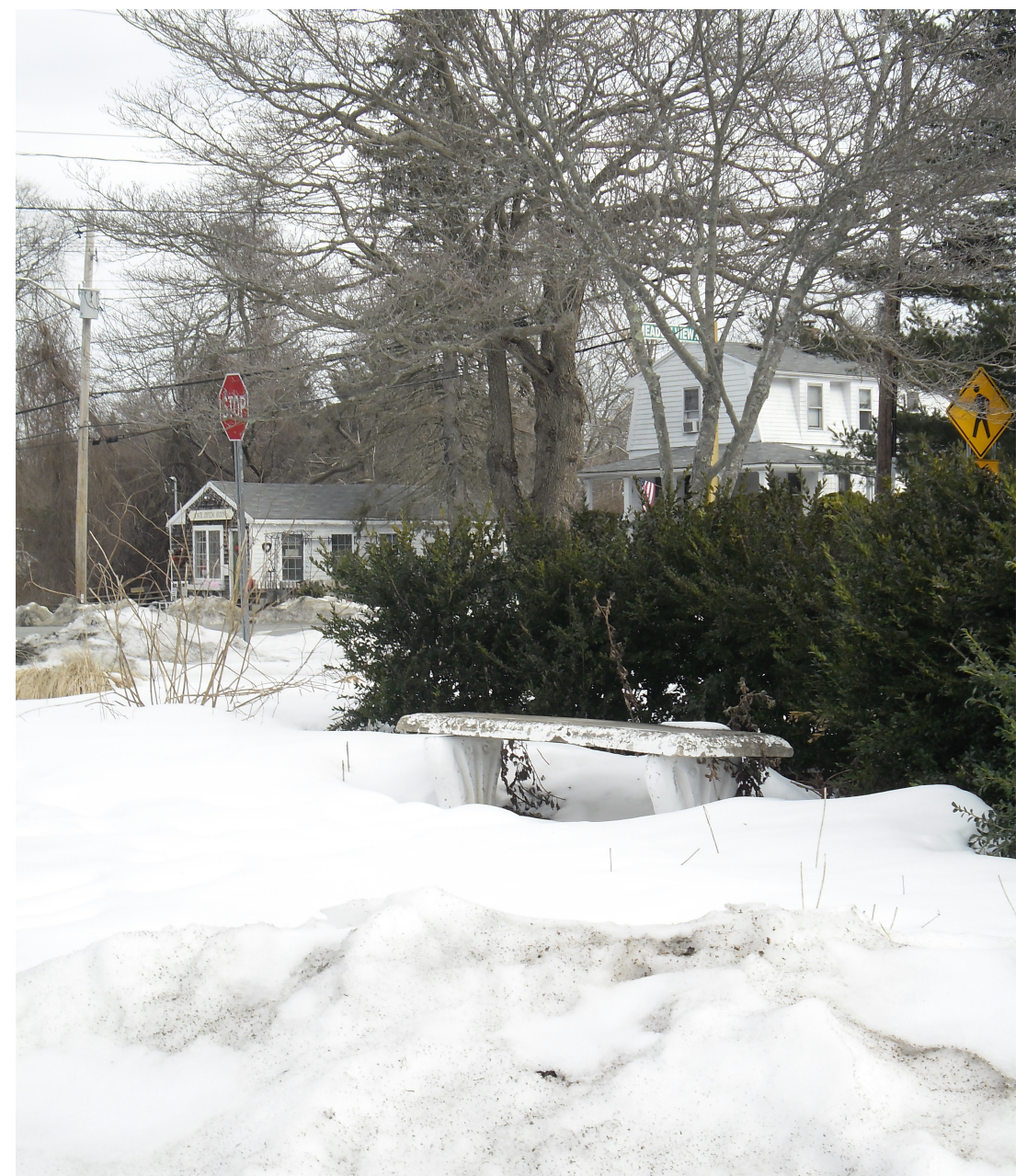

Figure 19. "Where I would wait for the bus" - photo taken and titled by Patrick to show the pile of snow surrounding his bus stop

Succinctly, Marcela summed up the difficulty of commuting in bad weather as "hanging out in the cold." Once again, as with traffic issues, inclement weather did not stop the participants from getting to campus or attending class. They braved the downpours, snowdrifts, and freezing temperatures to work toward their degrees.

To contend with the elements, anticipate the unexpected, and plan for the many hours spent away from home, the participants took great pains to prepare to come to campus each day. Sarah likened getting ready to come to campus with "packing up to 
go camping - like when I pack my bag in the morning I pack so many things - like chargers and food and water and like [laughs] because I'm here for so long it's like [sighs] it's crazy." By looking at the preparation level of her fellow students, Sarah could identify which students commuted. She described these students as "people that brought like Tupperware dishes of food and they have like the coffee tumbler like they look really prepared [laughs] you can definitely tell. Like they have the umbrella - it's not raining - but just in case." Kara summarized this experience as "it just can be an inconvenience - remembering everything what you need throughout the day - it's a lot." Thus, before leaving home and dealing with long bus commutes or traffic delays, the participants needed to be very meticulous about how they packed for the day.

Due to the amount of time it takes to get to campus, the participants did not typically leave and come back. Instead they often spent long stretches of time on campus between classes. Sarah shared,

I get here for my 8 am class so from 8 to $9: 50$ at my class and then I have a big break and I don't have class again until 5:00 [laughs] so I go to the Library and I do as much work as I can - maybe Netflix [laughs] - get incredibly bored and then I go to my class and then hopefully I don't hit 5:00 traffic - or 6:00ish - and then yeah.

Lindsay also explained,

I ended up having an actual six hour break in between classes which I would basically just do homework or sometimes ... I would just go to the mall or find something to do or sometimes I even actually drove all the way back to [my home in a neighboring state] and would just come back because 
sometimes it was like I don't have anything to do here - just go home - but I tried to minimize that as much as possible - I try to like make use of coming here so like I'm not like wasting gas.

Even though Sarah and Lindsay had a lot of time between classes they did not conceptualize that time as "free"; the breaks were basically time spent waiting for the next class to begin.

This time spent on campus is related to the discussion of finding a "second home," which is explored in greater detail in the discussion of the third theme. In contrast to the myth of apathy noted by Rhatigan (1985), the effort to get to campus indicates the exact opposite. Sasha viewed commuters as busy, dedicated people. For example, when asked what her pictures said about her, she said they showed "probably that I care about what I am - I'm probably too busy and I go to school and I'm family oriented." She showed her busy lifestyle in her picture (Figure 20) of her unmade bed, entitled "can't, no time". 


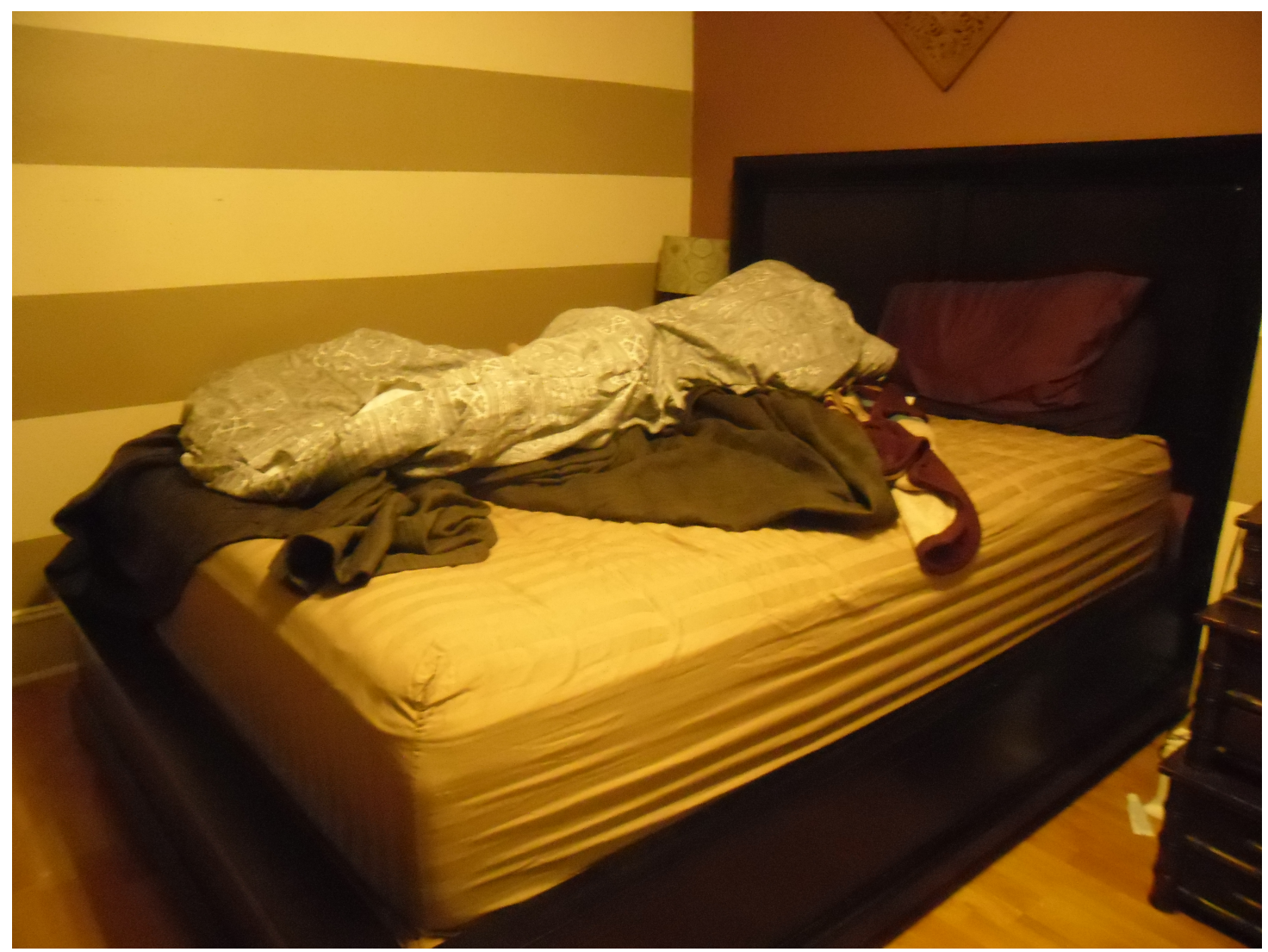

Figure 20. "Can't, no time" - photo taken and titled by Sasha of her unmade bed to represent her busy schedule

The participants definitely did not see commuters as apathetic; they perceived themselves as individuals who manage a various life roles and are pulled in a lot of different directions.

\section{Navigating Systems}

Fitting in jobs, time for homework, family responsibilities, a personal life, and classes, while allowing time for the commute required a lot of coordination and navigation of a variety of systems. In particular, the participants discussed their efforts in dealing with class schedules, technology, faculty expectations, and campus involvement. Two distinct issues related to schedules were mentioned: 1) the unpredictability of class schedules from semester to semester, and 2) the spacing of classes throughout the day. In terms of unpredictability, when being a college student 
is not an individual's sole, or even primary, life role, the change in class schedule from semester to semester can present many difficulties. Annie discussed this concern, explaining that unlike most colleges [at State College] ... you can't make a standardized schedule - you can't get a class only on Monday Wednesday or only on Tuesday Thursday - the classes are very randomly scheduled and um if you're a certain major you'll often find that classes ... tend to be clustered around certain days, but um it's not uniform across the board - I really wish that classes were like Monday Wednesday Friday or like Tuesday Thursday. As a result, she chose to get a job on as the unpredictability in class schedule makes also like working another job sort of difficult because you never know from semester to semester what days you're going to have classes. There might be a class that you have to take on days when you haven't had class before. So that's frustrating.

The importance of Annie's on campus employment is shown in her picture (Figure 21) of her uniform for her job with Campus Dining Services. 


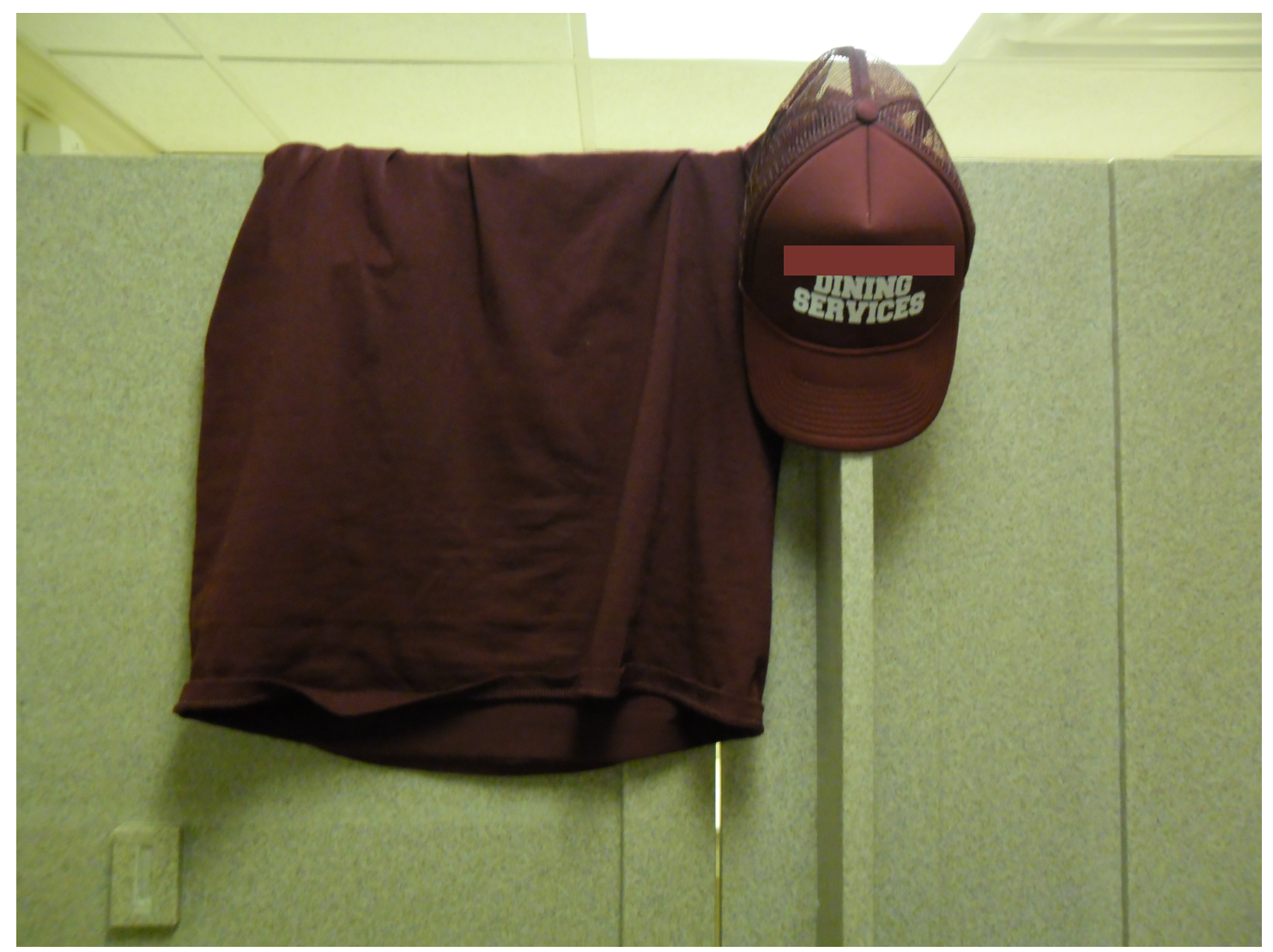

Figure 21. "I make $\$ 8.30$ an hour at the Dining Center" - photo taken and titled by Annie of her Dining Center uniform - name of the College blacked out on the hat to protect confidentiality

In order to minimize the amount of travel to and from campus, the participants tried to schedule their classes together - with varying levels of success. Kara discussed the difficulty of this process, noting that

making your schedule is always like a project because you want to have classes that are close to each other so ... you don't have that huge break and you want to come to campus as minimally as possible - the least amount of days that you have to so you can save on gas.

While the participants seemed to like having a lot of classes scheduled close together, this arrangement often led to long days. Patrick, was happy that he had "boxed" his schedule so 
that the majority of my classes are on Tuesday and Thursday and I work on campus Monday, Wednesday, Saturday. I have one class on Monday and Wednesday and it's right before I work on those days so it works out kind of like perfect. I spend you know - I'm on campus 12 hours a day sometimes like between studying here you know and working and the classes.

Despite the long days, Patrick's type of schedule was definitely preferable to one with a lot of long breaks, which Sarah called “the commuter's nightmare schedule."

Scheduling presented unique difficulties for students who took the bus as they worked to match the bus schedule to their class schedule and other needs. Annie found making these arrangements very frustrating as "the bus schedule is not in any way synced to the class times [laughs]." At the time of the study Annie was subletting an apartment in a town located around 45 minutes from State College, thus she had to take two buses to campus. She described this trip as "a really long commute" for which she needed to wake "up at like 7 something [in the] morning in order to get to school by 10. ." To show the significance of the bus in her commuting experience, Annie included a photo (Figure 22) of the bus parked at the campus bus shelter in her collection of pictures. 


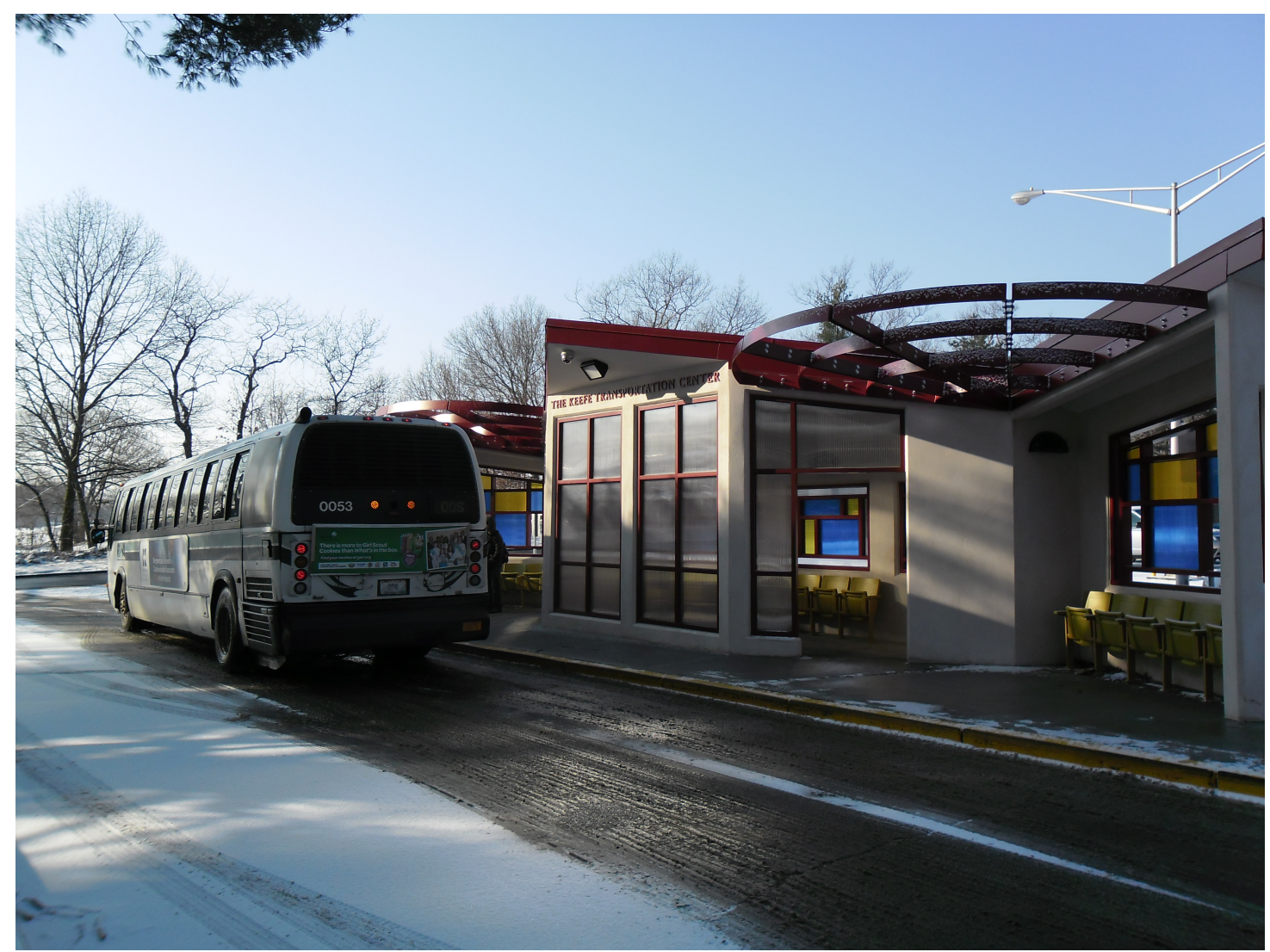

Figure 22. "It takes me an hour and fifteen minutes just to get to [the downtown bus depot]. Then it's another 20 minute ride to [State College]" - photo taken and titled by Annie to represent her long commute on the bus to campus

Patrick also took two buses to get to campus so he characterized the commute as "grueling" and shared that he lived at "the last bus stop on [the] route ... so ... that's 45 minutes to an hour trip into downtown and then another half an hour whatever to get up to school." Patrick showed the walk he needed to make from his bus stop to his home in the picture (Figure 23) he titled "the last leg home." 


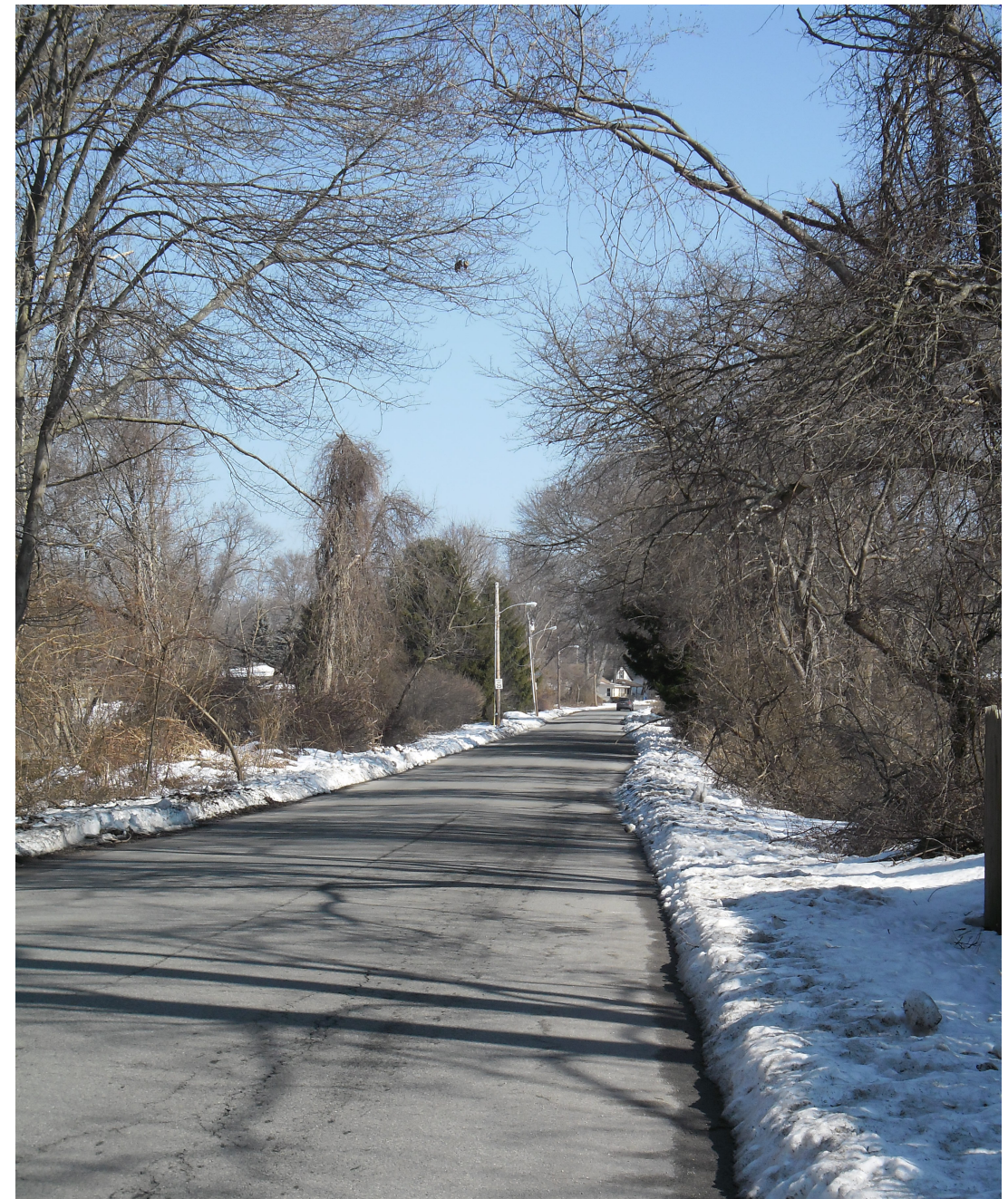

Figure 23. "The last leg home" - photo taken and titled by Patrick to show the walk from his bus stop to his home

Both Annie and Patrick traveled a significant amount of time to get to and from campus. While they stressed the difficulty of this experience, they also seemed to wear it as a type of badge of honor in that the length of their commute showed their dedication to attending State College.

Participants also discussed needing to navigate technological systems in terms of not having easy access to computers and printers, and faculty assuming that 
students were constantly checking their email and logging into the classroom management program. For example, Marcela discussed issues she had experienced with a professor who posted things online at the last minute. She said

last time was our first class - she hadn't given us the syllabus - she put it on Blackboard - and didn't finish it until - um Sunday morning, um, 4:00 in the morning, so I had to print my syllabus and all the other stuff for the class today [when I got to campus].

Victoria also experienced issues with late posting of assignments by faculty members, which made it difficult to complete classwork on time. She shared that sometimes the professor would post things very last minute ... it would be like late at night [when] they'd post and I couldn't get to school until the next morning to print it out and sometimes you don't have time to do that before the class, so sometimes it's definitely easier to be on campus.

The ability to complete assignments was also influenced by students' access to the internet at home. Annie's lack of internet at home, pictured in Figure 24, required that she do her homework ahead of time while on campus. She said

I don't have the internet at home so I do most of my work at school . . . I prefer to all of my work at school anyway, so that um when I leave - when I get home at 10:00 at night everything's already done and I don't have to worry about doing anything or ... [needing to get] to school earlier to print everything out if it's all done like the night before. So, that's that. I just can't really afford the extra cost of internet unless I live in a place that happens to have internet. 


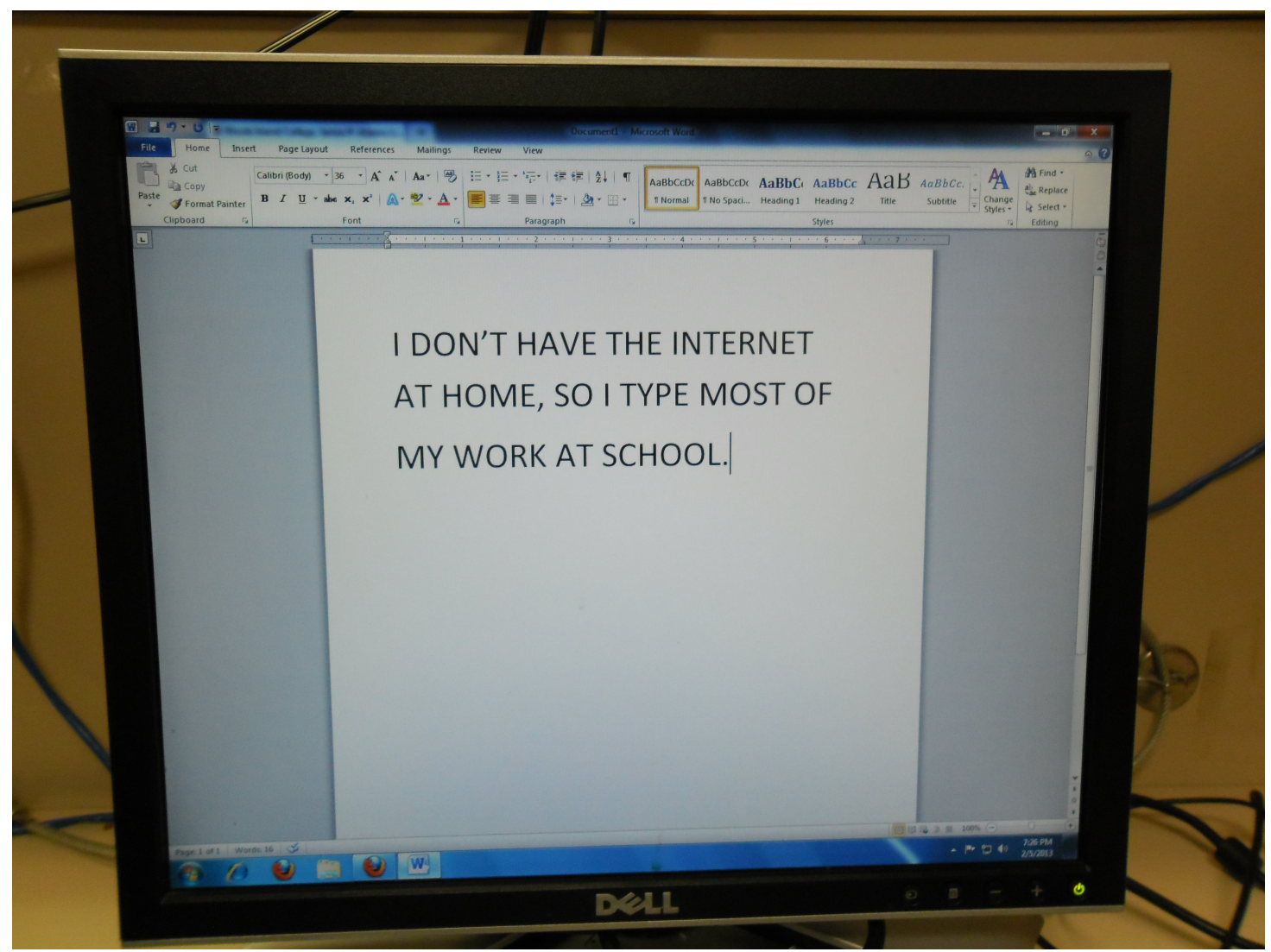

Figure 24. "I don't have the internet at home, so I type most of my work at school" photo taken and titled by Annie of text she had typed on a computer in one of the campus labs explaining her lack of access to the internet at home

The participants did not live in residence halls with automatic access to the internet through the campus network and nearby printing facilities in the computer labs, so they needed to plan ahead in order to keep up with their schoolwork, which was often complicated by faculty members who did not post assignments in a timely fashion.

Participants also viewed faculty members' last minute cancelation of classes as particularly inconvenient. Instead of stereotypically rejoicing when a class is canceled, the participants expressed frustration at making the trip to campus for nothing. Making the trip to campus meant spending money on gas, battling traffic, finding a parking spot, and missing out on a potential work shift for earning money, thus when class was 
canceled Lindsay wanted the professor to "pay me my gas back please." Similarly, Victoria saw class cancelations as "one of my biggest pet peeves."

Professors who arrived late or ended class too early also annoyed the participants. Lindsay explained this frustration, sharing that "you come into class and they're like oh we're going to leave an hour and a half early today and it's like I'm paying you - like thank you - and like sure it's nice but..." The participants displayed a feeling of having paid for their education so they felt entitled to receive it. Furthermore, since they made the trek to campus, they saw no reason why professors should not do the same. Sarah felt that there was "no excuse" for professors to arrive late to class - she "usually [gets] to class like 30 minutes early and it takes me like an hour to get here - like I wake up crazy early normally like I'm able to get here on time." The participants had little sympathy for professors who they believed did not put in as much effort as they did to be prepared and come to class. In general, they appeared to perceive the academic culture of the College as not fitting with commuter student culture - academic success depended on attending class and completing assignments in a timely fashion, which were made more difficult by systems that were unpredictable and seemingly unaware of the demands on commuter students.

Similarly, the participants found that the systems related to campus involvement were incompatible with commuter student culture. Kara, who was the most involved participant through her connection to student government, discussed the amount of dedication and planning that it took for her to get involved. She said that Living on campus ... you're here for all those events and activities and whereas I either have to stay and just go to them or leave and come back which 
is more convenient now that I moved, but I would find myself never wanting to come back to campus when I drove back to [my hometown] so.

Even though she noted the extra effort that it takes for commuter students to get involved, she did not see the connection between that effort and level of participation. Instead she implied that commuter students were just too busy or not interested in getting involved, which is seen through her explanation that most commuters have that mindset where I'm just coming to college to get my degree and get out and I come to school to go to class and either go to the Library and leave and it's not [that] they don't hang out here - for whatever reason it's that they work or they just don't have anyone to mingle with while they're on break [between classes] because no one else is around.

So, it is unclear - are students not socially connected to the college because their focus is on their off campus lives or because it is logistically difficult to participate? Furthermore, are they - despite their arguments to the contrary - actually socially connected to the college, but do not identify themselves as involved due to stereotypical notions of what it means to be an actively engaged student?

Some participants did see commuting as hindering the ability to more fully participate in college social life. Victoria perceived commuting as preventing her from being more involved, commenting that "because I commute [getting involved is] definitely not very doable with like all the time spent and everything else." She continued on this theme in her discussion of attending campus events.

I also feel that I would learn about more [State College-sponsored] trips and know about when they were going on and if they were sold out or not because 
there was a few times when I would hear about something late and then I would go to get tickets and they would be like "oh they're sold out and there's a waiting list" and then I'd be like "no, it doesn't say this in the email" [sighs].

Lindsay agreed with the idea that commuting made getting involved on campus more difficult, which she noted in her discussion of her attempt to join a sorority. She explained that

My sophomore year I tried doing some of the sorority rushes and trying to find out if I could get into that but I just really can't do it because I don't have the time to be here as much as they do stuff ... [the] sorority girls - they're all like extremely friendly - it's not what you think like it's going to be.

Thus the amount of time on campus required to join sororities and other student organizations seemed like an unrealistic commitment to the participants. They saw their inability to be more involved as a function of the incompatibility of their schedules and those of the organizations.

Furthermore, the decision to not be involved on campus showed a level of maturity and responsibility in prioritizing financial obligations. Lindsay explained that she

can't do any of that [club stuff] - like I need a job to get my gas money so when I go home I'm going to work ... I can't . . . come here on Wednesdays for like cool break and like hang out and like yeah the clubs - I can't be in the student club.

Lindsay's reference to "Wednesdays for like cool break" refers to the College's Free Period, which takes place on Wednesdays from 12:30pm to 2:00pm. During this time 
no classes meet in an effort to give students an opportunity to participate in clubs and organizations. As Lindsay noted, a flaw in this system is that students who are not already on campus for Free Period most likely do not come to campus just to enjoy that experience - they spend the free time working or taking care of other responsibilities.

In addition, the often long days full of classes, commute time, jobs, and other responsibilities made the participants exhausted and unable to participate in campus activities. Marcela described this feeling, sharing that you are just so tired when you have ... three classes in one day and you want to go to some of [the campus activities] but it's at 8:00 [at night] and you're so tired and it's like 3 or 5 [in the afternoon when you are done with classes] . . so you just go home.

Thus, it does not appear that the participants were uninterested in participating in clubs and events; they just did not see how these activities fit with their lifestyles and other commitments.

Despite the difficulties associated with achieving a level of wellness, fitting in all of their commitments, and navigating the systems of class schedules, technology, faculty expectations, and campus involvement, the participants continued to work toward their degrees. However, they perceived the amount of effort and commitment required to succeed at State College as especially onerous due to the particular demands of commuting. While they did not specifically articulate the lack of fit between commuter culture and college culture, they hinted at an underlying disconnect, which impacted them through a more acute need to be prepared, to 
intentionally schedule their time to promote personal wellbeing and allow for the management of multiple roles and responsibilities, and to make tough decisions when prioritizing classes, employment, and extracurricular involvement. Joining a student organization was not merely a function of attending meetings of organizations in which they were interested, to the participants making this commitment meant actively deciding not to work at a job or not to do homework, which can sometimes only be done while on campus, in order to attend. Thus, the participants appeared to be very particular about the amount of time they spent on campus, where they spent that time, and what they did in those spaces.

\section{Finding a "Second Home"}

As mentioned in the section on arranging one's schedule, the participants often spent long periods of time on campus waiting for the next class to begin, doing homework, or waiting for the bus. Thus, they needed to find a place (or places) to spend time. This need is related to Banning and Strange's (2000) concept of campus ecology in which there is a dialectical relationship between individuals and their environment - constructors of the environment create spaces for intended behaviors and individuals within that environment are both shaped by those intentions and reshape the environment to fit their purposes. The way that the participants adapted the campus environment to fit their needs is evident in a discussion between Stephen, Marcela, and Annie in the first gallery walk. When asked which themes they saw represented in the pictures, they had the following conversation:

Marissa: What stories or themes come out of looking at the pictures. What would you come up with? 
Stephen: Like the stories of buildings we go to. What it takes to get here.

Annie: Hmm ... yeah.

Stephen: I think like what relatively keeps us going through the rest of the day ...

Annie: Yeah.

Marcela: I think ... what is home ... for us on campus. Which buildings - like someone said [the] basement [of the Library] . . .

Stephen: Like [the picture of the InterVarsity office as a] spiritual home or whatever.

Marcela: Like for me, it's the Library [laughs].

Stephen: I'm a nomad on this campus - I sat a little bit someplace and then I move someplace else [laughs].

Marcela: So you don't have a campus home?

Stephen: Not really. I have campus spots.

Annie: Yeah.

Thus, the participants quickly zeroed in on the concept of "a campus home," which was also reflected in the pictures incorporated in the below analysis. In discussing these campus homes, the participants mentioned three main functions of home spaces: a place to keep their things, a place for peace and quiet, and a place for social interaction.

\section{Place to Keep Belongings}

As discussed in the prior themes, once the participants arrived on campus they often did not have a place to store their belongings, thus they had to deal with the inconvenience of carting things around. When asked what about the commuter experience does not work for her, Marcela replied, "heavy stuff. Carrying - lugging 
stuff. And especially if you're a bus commuter." Lindsay explained that she usually carried "two bags, and my purse, and my backpack - like my art bag and my purse because ... I don't have time to go back to my car so I just bring everything and lug it around to class." Stephen summed up the concept of lugging around one's stuff as "if you're a commuter you're more likely to have a backpack full of random junk."

To solve this problem, some of the participants used their cars as a "closet" or a home base to return to throughout the day. For example, Lindsay shared that she has "so much crap in my car." This "crap" included "napkins from places - I never throw them away", "my snack for after class - banana and water", "my laptop and my bags full of my photo paper, my binder for photo, [and] some ketchup packets." Victoria also used her car as a closet, explaining that she would "leave like half of my stuff in the car and then it's like 'okay I have 30 minutes before class' so I'll go back”, so throughout the day she needed to return to her car to get the rest of her things.

Kara was able to avoid needing to use her car as a closet and home base by keeping her things in the Student Government office where she worked. She was able to "leave my books [in the office] so I don't have to like run back out to my car." Thus the participants used different strategies in finding spaces in which to store their belongings - some could use their cars, one had an office space, while others never really found a specific space and therefore lugged their stuff around with them in type of nomadic existence.

\section{Place for Peace and Quiet}

In addition to needing a place to keep their things, the participants also noted a need for privacy, quiet, and comfort. These spaces for quiet and relaxation were 
important to the participants as they tended to spend a lot of time waiting around. As Kara noted, it could be awkward if one got to campus too early. When that happens "are you going to sit inside your class - are you going to sit in your car - are you going to go to ... the [Campus Café] - what are you going to do?” There is a sense of wanting a place where one felt comfortable just "being there" - a space where one could spend long periods of time relaxing or doing homework without being looked at as an intruder. Stephen agreed with the frequent experience of waiting, as he described of one of the salient themes of the pictures in the gallery walk as "a lot of waiting. Beginning the day. Ending the day. What do we do around campus." He showed his time spent waiting through his picture (Figure 25) of a hallway in the performing arts building where he frequently sat between classes.

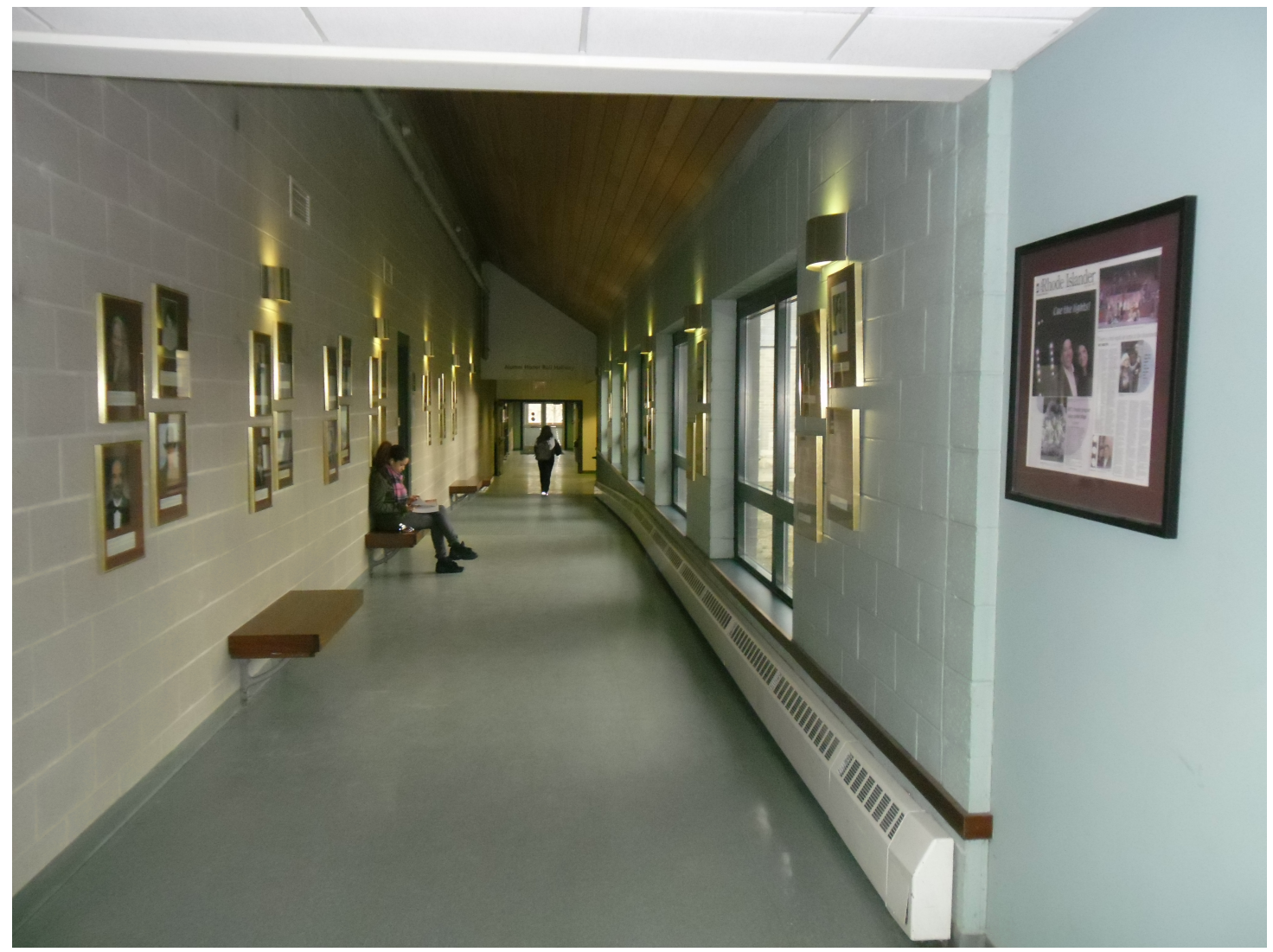

Figure 25. "Hallway of tours and time" - photo taken and titled by Stephen of the hallway in the performing arts building. As he would spend time waiting on these 
benches College tour guides would come by, sharing information about the College to prospective students and other visitors

Before his car was registered, Stephen also spent time in the front of the performing arts building waiting for the bus to arrive, which he featured in his picture entitled "Waiting" (Figure 26). He took this picture "because most of the time I'd usually be waiting for the bus around here ... so I saw this [view] a lot - for like a good portion of my freshman year."

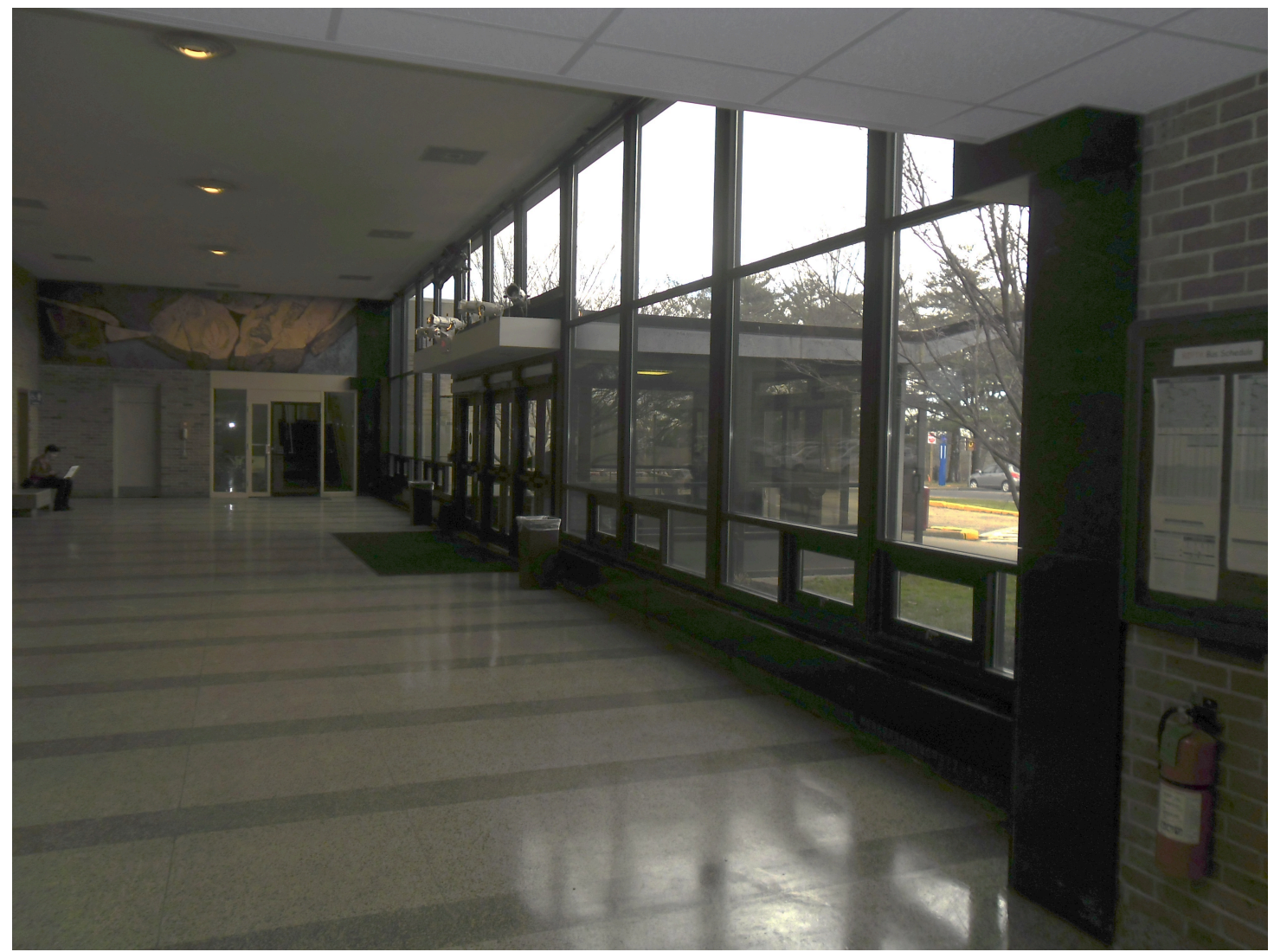

Figure 26. "Waiting" - photo taken and titled by Stephen of the place where he would wait for the bus

To make their time spent waiting feel more like hanging out at home or a favorite spot, the participants transformed a variety of spaces into "homes" or "sanctuaries" on campus, which included the Library, the car, and academic workspaces. Marcela, in describing the picture she took of the directory sign in the 
entrance to the Library (Figure 27), explained that the Library "is a nice place - for us commuters. When it's cold I go in there and go to the back room, sit down, look at the art."

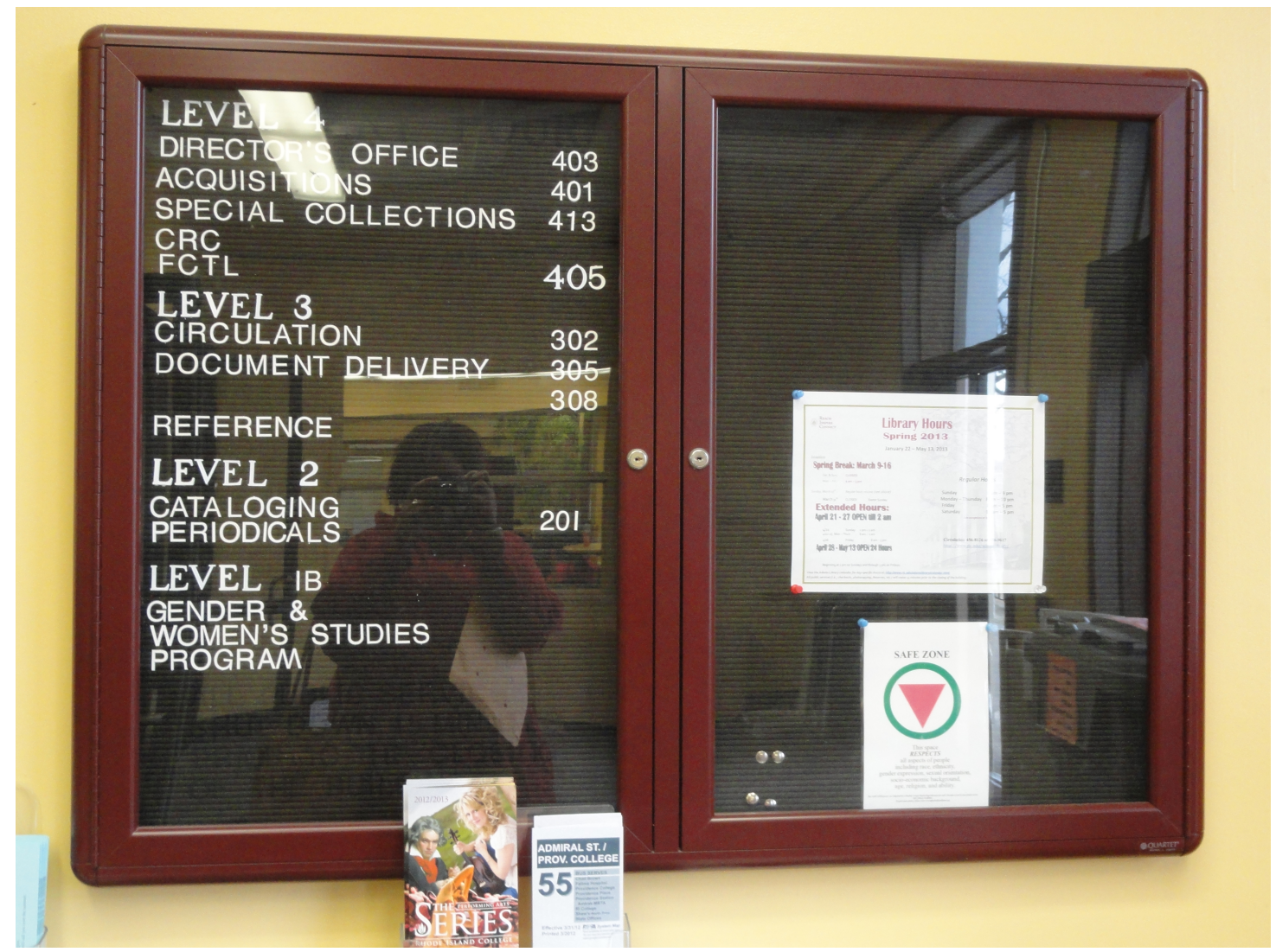

Figure 27. "Library Glass" - photo taken and titled by Marcela of the directory sign in the entrance of the Library

Annie also found a home in the Library, which she shared through her rationale for taking a picture of the Library (Figure 28). She said

this is a picture of the Library which is actually my favorite building on campus, um I like to do work there because the cubicles are much more private than the computer lab ... I spend a lot of time [there] ... I also like to read in the basement because hardly anyone is there ever so it's a good place to concentrate on reading something for class. 


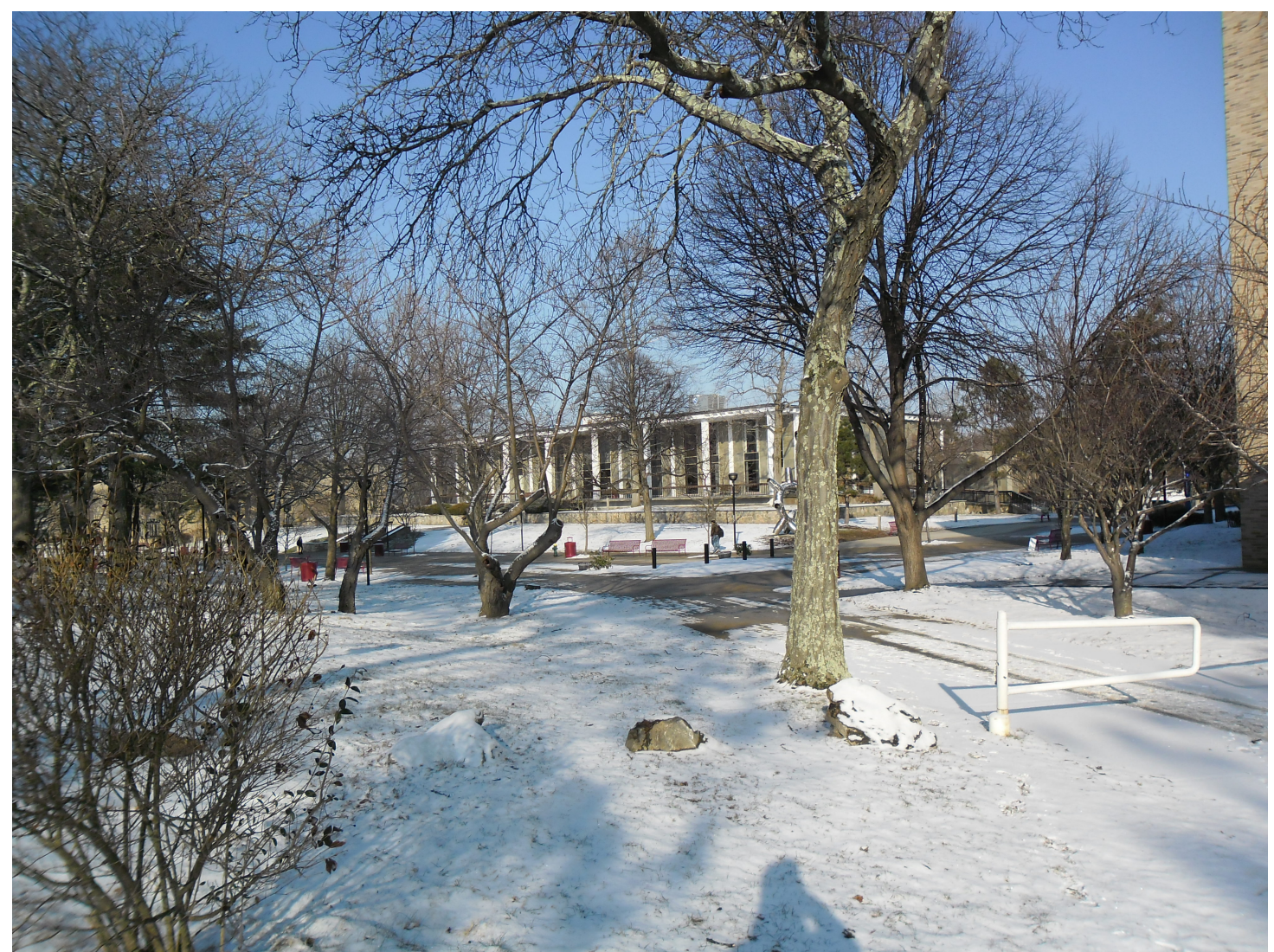

Figure 28. "The State College Library is my favorite building on campus. I like to hide in the basement and study" - photo taken and titled by Annie of a view of the Library from across the Quad

Similarly Sarah spent a lot of time in the Library, which she noted in her description of her picture of the cubicle she often inhabited while on campus (Figure 29). She explained

That's like the little cubby thing in the silent study section of the Library . . . basically I just unpack my entire bag ... I plug in all my things that need to be charged, get my notes out, my lunch, and stuff and then I just sit there for six hours [laughs]. 


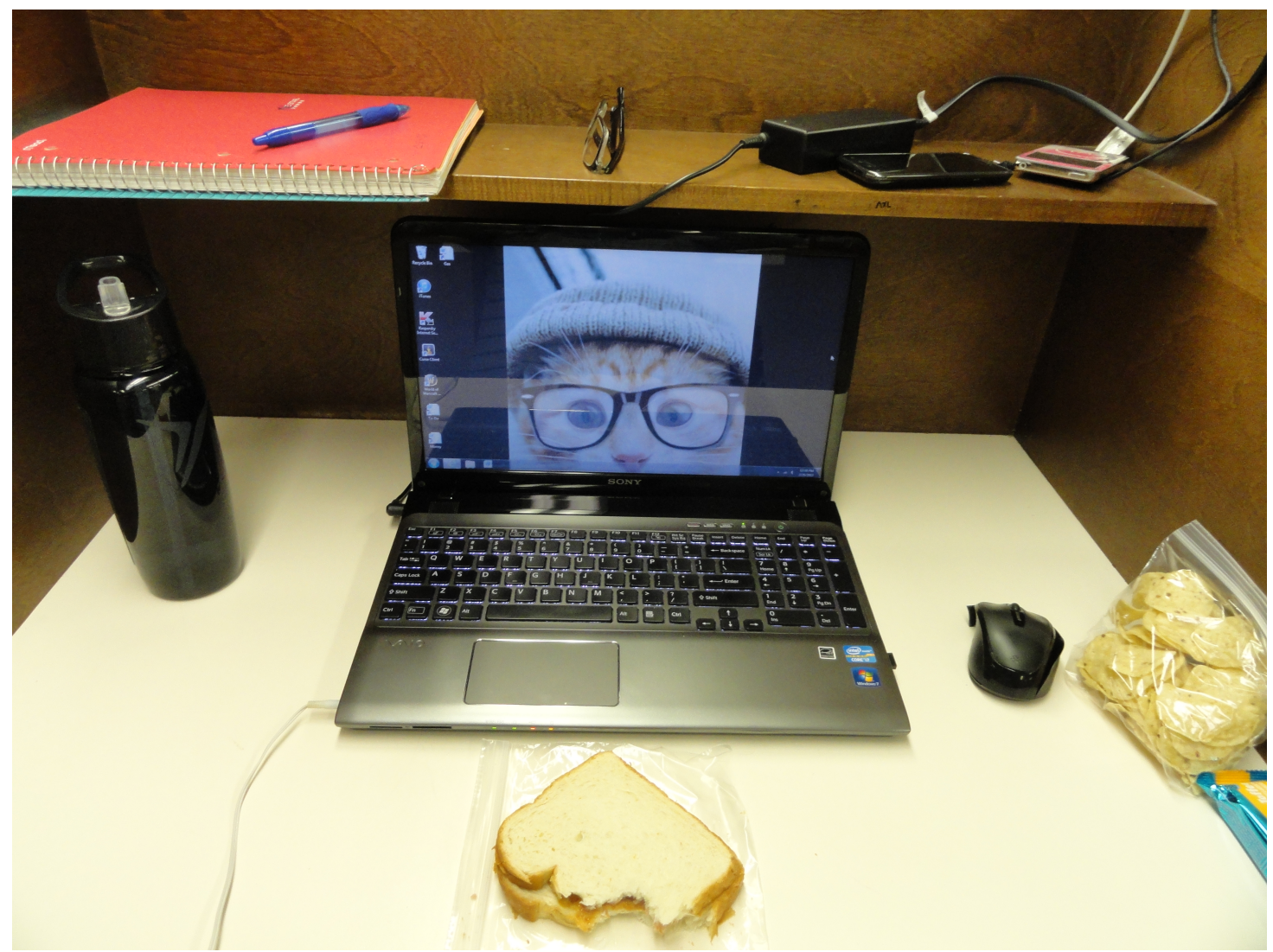

Figure 29. "How the day is spent" - photo taken and titled by Sarah of the cubicle in the Library at which she spends a lot of time throughout the day - doing homework, eating meals, charging her devices, and relaxing

Opportunities for "charging" were very important to Sarah. She shared that "getting a seat next to an outlet is like huge!" In particular she noted that while in class "a ton of people take notes on their laptops - have phones charging and things - so . . if you have a four hour class and . . you have a really bad laptop battery - getting the seat next to the outlet is like 'Yeah!' [Laughs]."

Along with using the Library as a charging station, the library cubicles were places to get homework done. Lindsay explained that she would lock myself in a library cubicle and be alone and get some work done - I find that's basically how I basically wrote all my really long papers from being here. 
While Lindsay mentioned spending time in the Library, she identified most closely with her car, which she called her "sanctuary" and "little house." In describing the picture she took of her car (Figure 30) she shared that when I'm on campus . . . I live in my car - I don't really . . . venture out and hang out in other places because I don't know I just like sitting in my car listen to my own music, kind of be by myself, eat lunch, and then go to my next class. It's comfortable, I nap in my car and people stare at me as they walk by, but I don't care - I like my car.

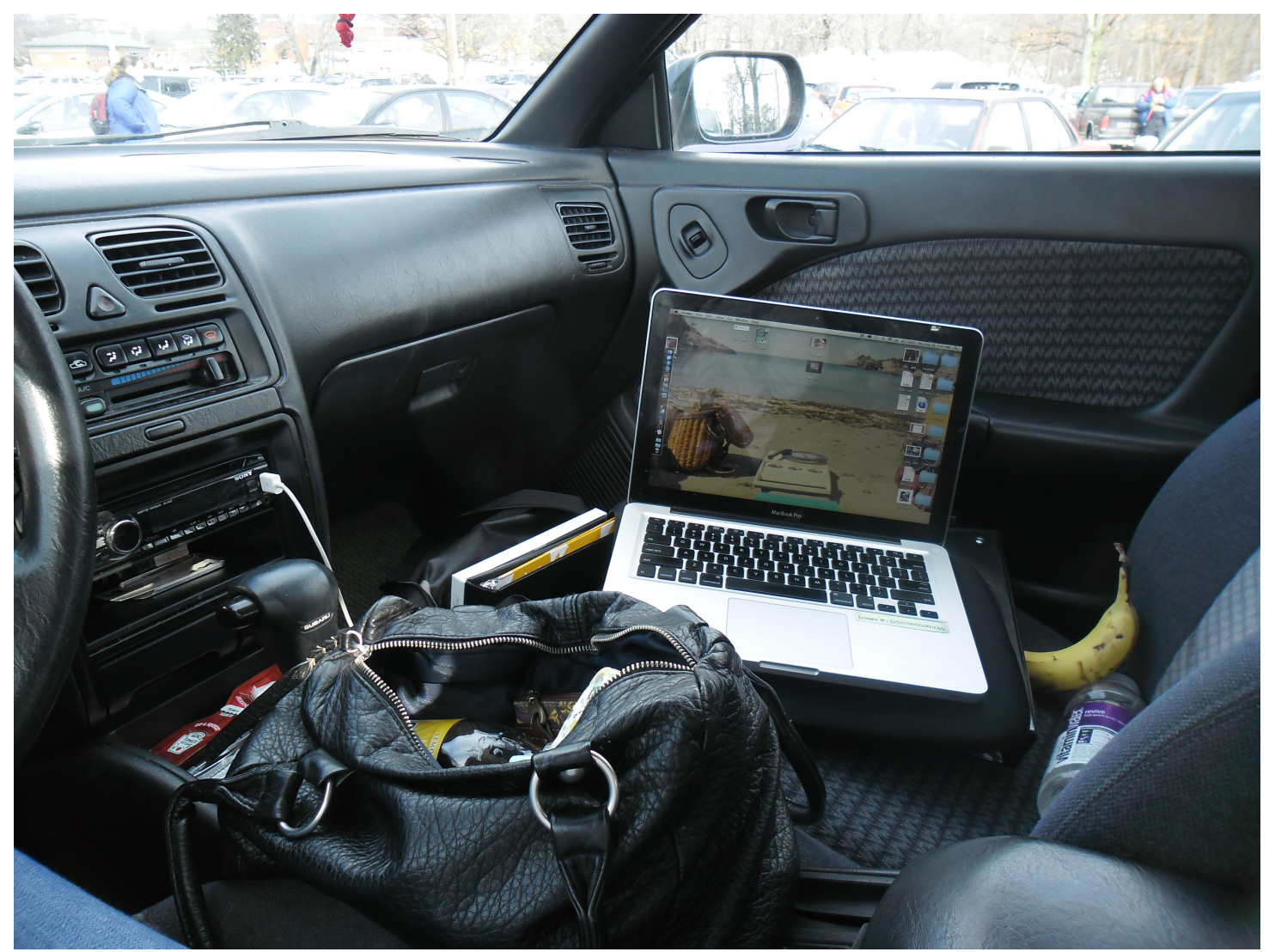

Figure 30. "My second home" - photo taken and titled by Lindsay of the inside of her car with her snacks, bag, and laptop, which was hooked up to her car's stereo system

Her car provided a level of safety and comfort. She said "when I'm in my car - [I] kind of just hang out and stay safe in there." In further describing the picture of her car, she noted how it also served as a mobile entertainment center. She pointed out that 
she plugs "in my laptop to my stereo so if I am watching like a movie or something I can hear it like in the whole car. I have like a little theater."

Other participants agreed with the view of the car as a home. In looking at Lindsay's picture during the gallery walk, Sarah commented "I really like the picture that's my second home - the car - I like that. Because I call my car my second home too - when I'm driving here and back. You get in there and take naps."

Lindsay also enjoyed the privacy of the College's dark room. She featured the dark room in one of her pictures (Figure 31) and described it as her "little sanctuary" and "our ghetto dark room." Despite the "horrible" conditions, she liked to go there and do her work when she knew no one else would be there.

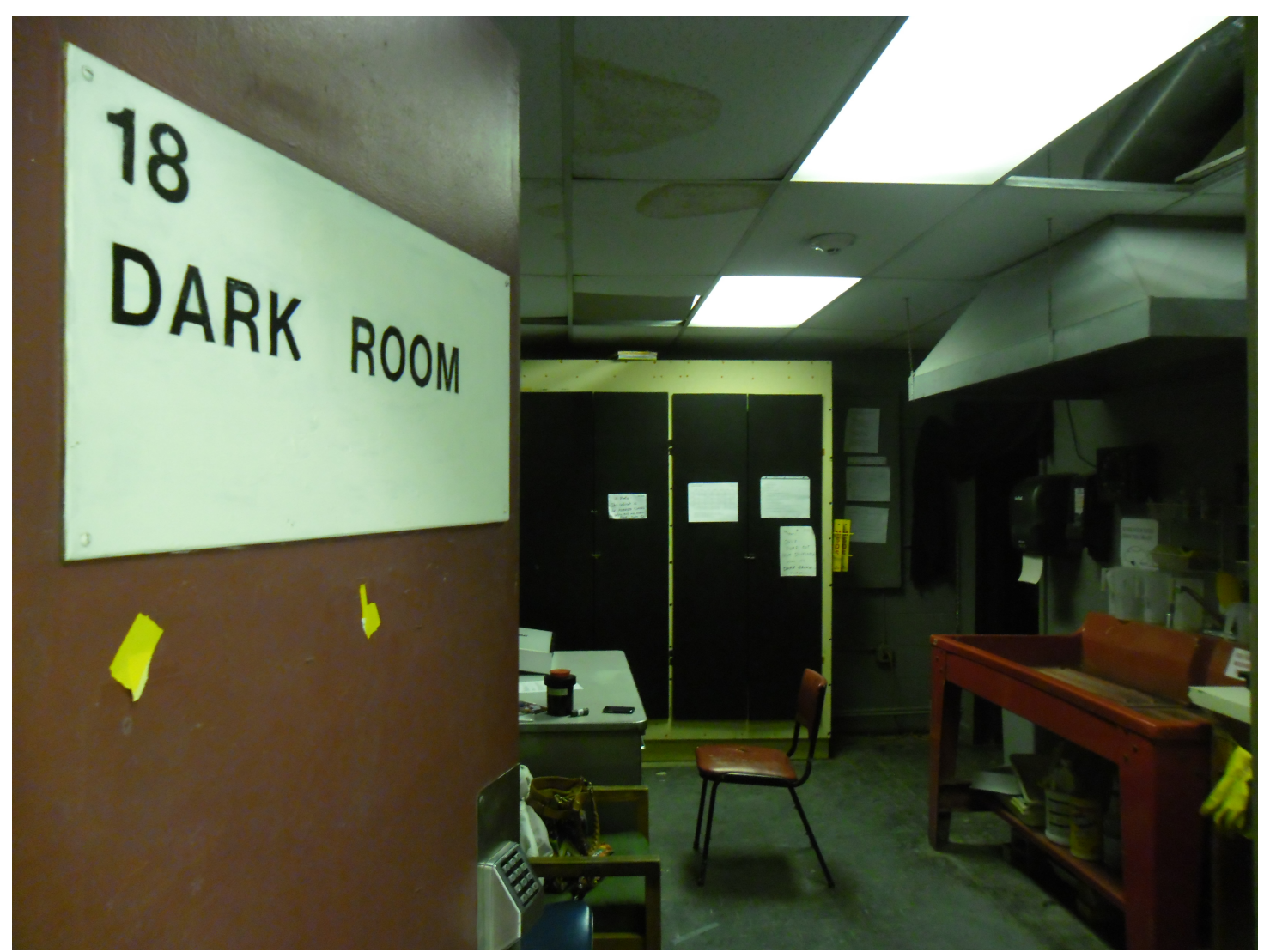

Figure 31. "My sanctuary" - photo taken and titled by Lindsay of the College's dark room. As a photography major, she spent a lot of time there working on projects 
She went on to describe the dark room and her time on campus in more detail, sharing that she felt "pretty peaceful in there ... it's nice and quiet you can be on your own and stuff."

Victoria found that kind of quiet and privacy in the Library, which she noted in her description of her picture (Figure 32) entitled "the Library has been very useful to me over the years." She said

the library's been very helpful for when I want to have some quiet time kind of thing I usually go downstairs find something in the back and kind of chill so that's been very helpful especially if I have a break between class and have work to do then it's always good to go to the library to kind of chill by yourself - [the Campus Dining Center] is too loud.

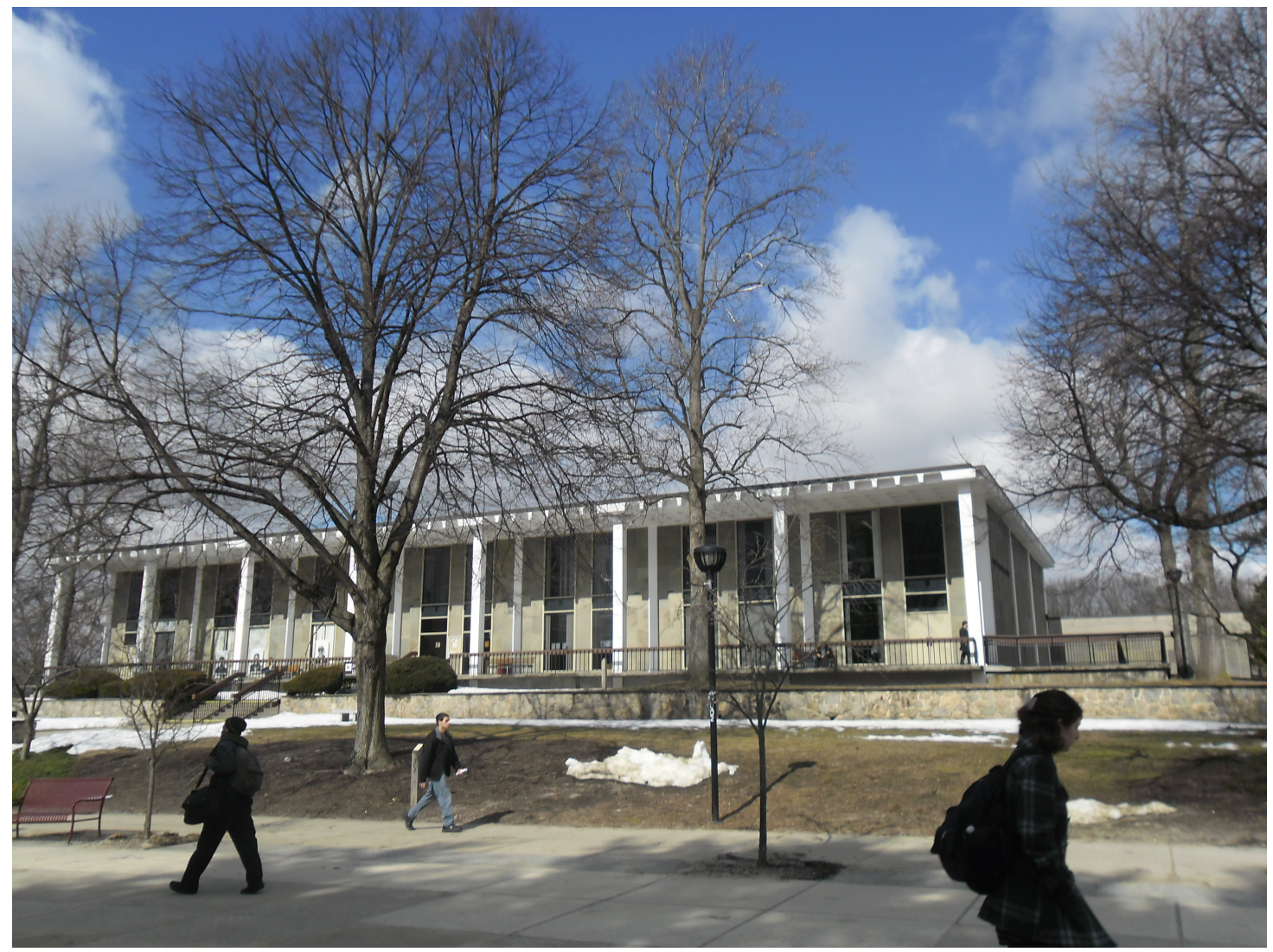

Figure 32. "The Library has been very useful to me over the years" - photo taken and titled by Victoria of the front of the Library 
While most of the participants were able to pinpoint at least one space that they considered a home, Angela did not strongly identify with any specific areas. She did discuss arriving early to class and waiting outside of the classroom for the class to begin. She characterized this time as "kind of nice" as it gave her the opportunity to "finish all my reading ... I can do it then because I have a little bit of time to finish things up so I don't feel as rushed." Despite the pleasure in using this time to complete homework, Angela did not describe the hallway space as a home. She was also the only participant not to mention time spent in the Library. Her lack of a campus home could be related to the fact that spring 2013 was her first semester at State College, she was the only participant who was non-matriculated, and she attended part time.

Overall she did not spend much time on campus. She did not have any long breaks throughout the day - she came to campus in the evenings specifically to attend a class, and then went home. However, aside from Angela, the other participants all seemed to spend so much time on campus, often with long breaks between classes, that they needed to find places in which they could wait in a private, quiet location. The Library, the car, benches in academic buildings, and academic workspaces like the dark room were used by the participants to fill this need.

\section{Places for Social Interaction and Ownership}

Along with needing space for peace and quiet, the participants also looked for places that allowed for social interaction. Social interaction is an important component of the home environment in that it represents a feeling of belonging and identification, i.e. there are people in my home who need me and make me feel like a member of a community. For example, Kara made a concerted effort to get involved on campus 
because during her time at the Community College there "wasn't really much to do so" as "[the Community College] doesn't really offer any" involvement opportunities, so when she "got [to State College she] wanted to get back to what [she] was doing in high school - being involved doing things." Student Government at State College was her place to make "a lot of friends" and earn "a really good building block for my resume." Kara utilized her office space in Student Government as a home. She said It's really nice having an office. Just because you have somewhere you can you just have your own little space without actually having to live on campus so it's a perk. But a lot of work goes with it so.

The significance of Student Government in her college experience is seen in her picture of the Student Government logo, which she (Figure 33) entitled "it's more than just the politics." 


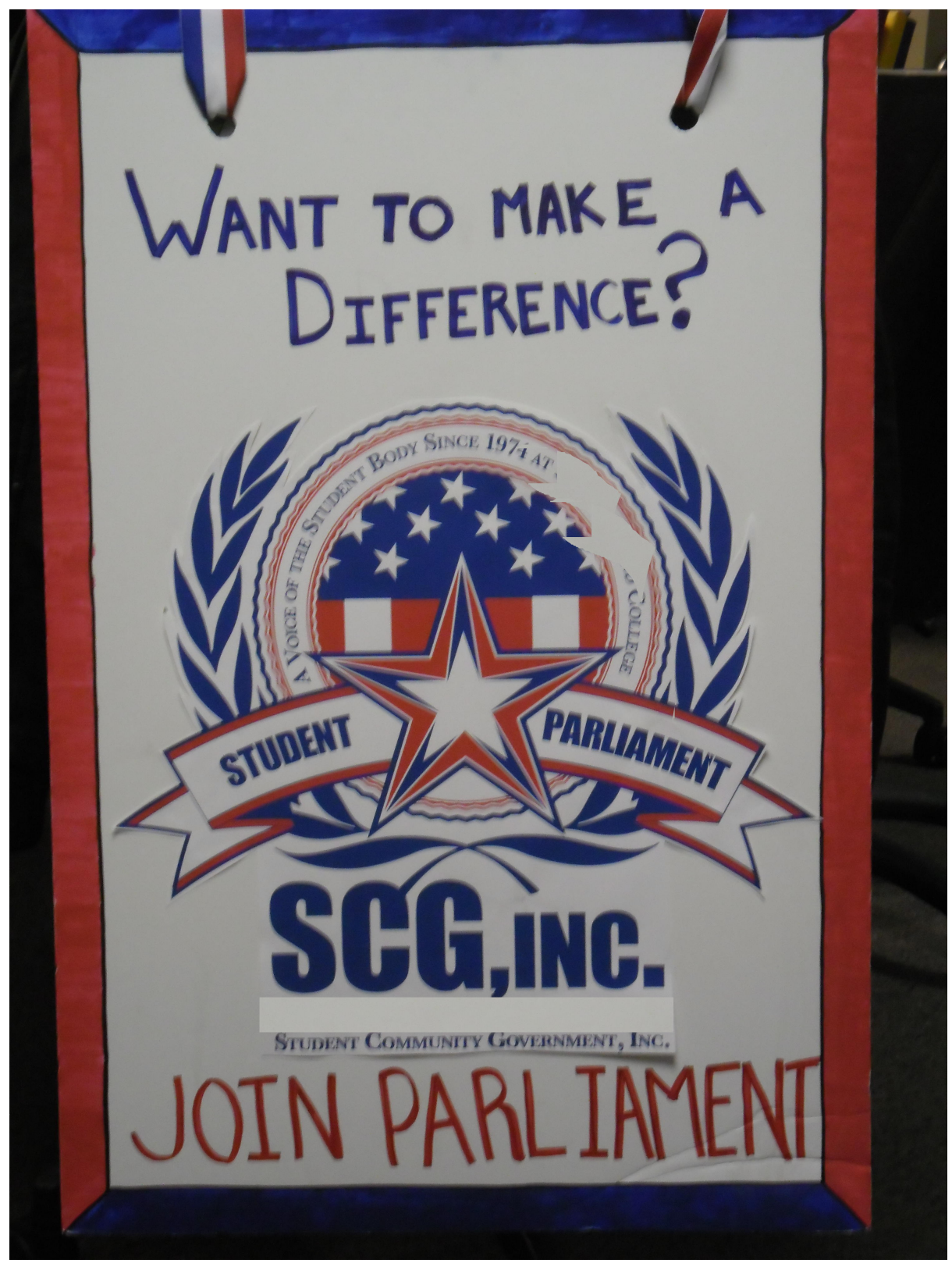

Figure 33. "It's more than just the politics" - photo taken and titled by Kara of the student government logo. Her involvement with student government helped her to make friends and get involved on campus.

She explained the benefits of the Student Government office space, commenting that "I don't have to go camp out in the Library and eat my sandwich like super quiet like I can spread myself out and have my own space." However, she did note that even though the office space was nice, it still did not take the place of actually living on campus. The office space, unlike a residence hall room, did not provide "a place on 
campus where I can have everything that I need and just go and get it or take a nap between classes whenever I feel like. I don't have ... that. Granted yes I have an office, but no ... place to ... relax or anything." While the office did not provide complete privacy, it was an environment in which Kara felt comfortable and connected to the college community - a kind of partial home.

For Sasha, her on campus job at the campus computer lab served as a place for social connections; these connections helped her to feel like a part of the College. She explained that "I need to work - I need to have that time away to do homework - have some interaction with other students - because if I just go to school and go home I'll go crazy." In other words, relationships with other students was a key component in helping Sasha to feel like school was more than just a place where she attended classes - it needed to be a place where she was a member of the community. Her picture of her desk at her job (Figure 34) showed a level of comfort with that environment as its title, "my hidden savior," referred to the silver coffee mug on her desk. Thus, she felt comfortable enough in this space to insert her personal belongings into the environment. 


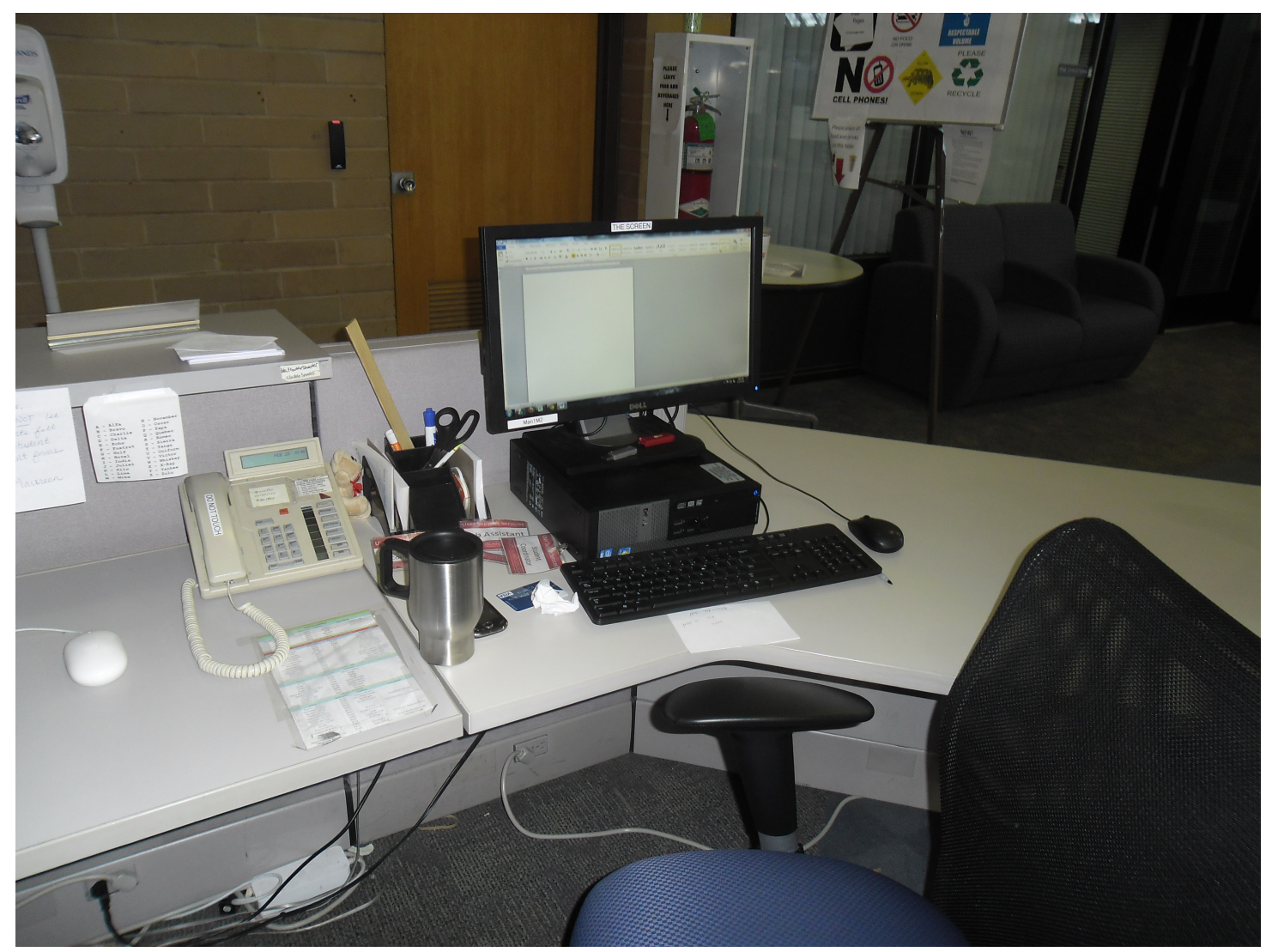

Figure 34. "My hidden savior" - photo taken and titled by Sasha of her silver coffee mug on her desk at the campus computer lab

Other participants found more informal spots for social interaction. Victoria discussed an outdoor space in which she would hang out with friends, which she featured in one of her pictures (Figure 35). To describe this picture she said this is [the science building] and one of me and my good friends - when he went here - used to hang out here on break all the time and we used to go there a lot and I think it's a nice little [place] to just kind of sit when it's spring - not winter. 


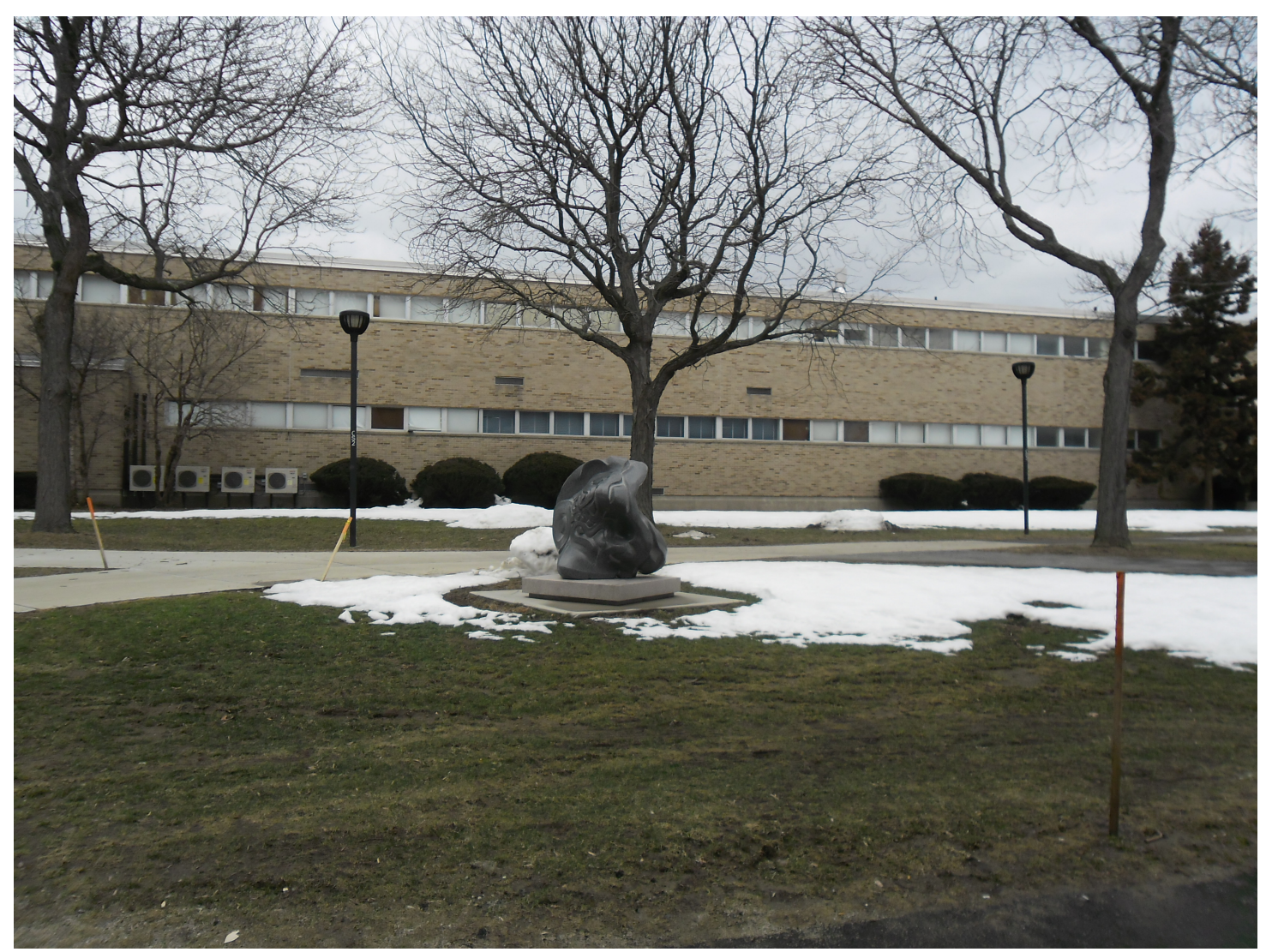

Figure 35. "Cool art formation" - photo taken and titled by Victoria to show a place on campus where her and a friend would spend time

Lindsay would even use her car as a social gathering space. She shared that "a couple of times I had a few friends that were walking by and they were like oh hey and they've jumped in and [hung] out in my car with me so funny." As a car and a courtyard with a campus art sculpture may not be considered spaces constructed for social interactions, Lindsay and Victoria repurposed these areas to suit their need for a place in which to spend time with friends.

The concept of repurposing campus spaces to fit their needs is a constant refrain underlying the theme of finding a "second home." Overall, it seemed as if the Library came the closest to providing a true home for the participants, however this space did not have a space for keeping one's belongings. Despite this shortcoming, the Library was seen as a comfortable, quiet location where the participants could safely 
spend long periods of time waiting, reading, eating, doing homework, and relaxing. While some of the participants enjoyed Lindsay's picture of her car and shared stories of how they used their cars as closets, only Lindsay seemed to spend a lot of time sitting in the car. To Lindsay, the car was a safe space where she could have easy access to all of her stuff and have control and ownership over the space as seen in her mention of her ability to play out loud whatever music and movies she wanted. She seemed to be the only participant for whom the car truly functioned as a home. The one other space, besides the car, that allowed for a certain level of ownership were the offices of some of the participants who worked on campus. Kara and Sasha were able to keep their belongings, form social connections, and personalize their spaces.

Personalization, ownership, privacy, social interaction, and storage were not inherently incorporated into campus spaces, but the participants made efforts to find these characteristics in different places - with varying levels of success.

\section{Summary}

In summarizing the findings, three overall themes emerged, including various subthemes. The first theme of commuter student identity in relation to dorm people represented the way in which the participants juxtaposed their experience in relation to that of the dominant group of dorm people. In comparison to dorm people, the participants viewed themselves as more stressed, older and more independent, more focused on off campus life, and representing a larger diversity of experiences. In regards to this diversity of experiences, the participants discussed a spectrum of different living arrangements, modes of transportation, entry to the institution, and progress toward graduation. The complexity of the participants' experiences was seen 
not just in the current categorization of where they lived and how they got to campus, but in how these and other attributes changed over the course of their college careers.

Further complicating the picture of the overall experience of commuting was the often incongruent views expressed by the participants. For example, they saw dorm students as less stressed, but conceptualized residence hall living as full of drama and substandard conditions. They saw campus involvement as the purview of dorm students, but went on to describe the various ways that they participated in campus activities. They identified themselves as commuter students, but did not include students who took certain modes of transportation or who commuted a short distance in that definition. Their self-perceptions were fraught with contradictions indicative of individuals from a non-dominant group trying to create an identity within a culture, which is predicated on the dominance of students who live on campus even though those students are not in the numerical majority.

Despite this lack of a unified identity, the participants seemed to agree that commuting was difficult. In particular they commented on their struggles to maintain a level of wellness, to fit in all of their responsibilities, and to navigate the systems of class schedules, technology, faculty expectations, and campus involvement. While these difficulties hinted at a lack of fit between college culture and commuter student culture, the participants did not necessarily see it in those terms. They were put off by the unpredictability of the class schedule, the difficulty of finding parking spots, the inconvenience of class cancelations, and the unrealistic requirements of campus involvement, but they viewed these annoyances as things that they were used to and just needed to deal with. In many instances they were proud of the extra effort they 
dedicated to making sure that they attended class, completed assignments, and made connections with some aspect of the campus community; they displayed a deep resiliency in continuing to persist toward graduation.

Their dedication to making the college experience work for them was evident in the way in which they reshaped the campus environment to create a home away from home. While they were not always successful in finding spaces to fit all of their needs, they utilized the Library, hallways, academic workspaces, the car, and campus offices to fulfill to their desire for places to store their belongings, to relax and do homework in a quiet, private environment, to make social connections, and to develop a sense of ownership. Finding these spaces seemed to take time - Angela, the participant who spent the least amount of time on campus and had been at the institution for only one semester, had not yet found a place (or places) to call home. Despite the incompleteness of the improvised home environments, the participants used these spaces to help spend the day and take care of their responsibilities.

In a nutshell, the participants viewed commuting as an effort, which required a decent amount of preparation and commitment. While it could be an isolating experience, the participants were often able to find somewhere on campus to serve as their home away from home. The significance of these findings, as well as their implications for research and practice, are discussed in Chapter Five. 


\section{CHAPTER 5}

\section{CONCLUSION}

\section{Summary of the Study}

A review of the research literature on commuter students and student

development theory shows that while commuter students are the numerical majority of college students in the United States (Snyder \& Dillow, 2012), their experience is still considered non-normative and nontraditional (Dugan et al., 2008; Krause, 2007). The intersection of age, race, employment status, and enrollment status often makes it either more difficult or impossible to live on campus (Jacoby, 1989; Ogren, 2003). Furthermore, paradigmatic student development theories cast the commuter student experience as the antithesis of a positive and successful time in college (Braxton, Hirschy \& McClendon, 2004; Karp, Hughes \& O’Gara, 2010-2011). This research, combined with my work at an institution with a large commuter population and Jacoby's (1989) recommendation that each institution study its commuter students to understand the unique needs of this population, influenced my interest in conducting a study designed to give voice to the commuter student experience at a mid-sized regional public four-year college in New England, referred to as "State College." For this study I interviewed ten participants, asked them to collect photos that represented their college lives, interviewed them about their photos (participant-driven photo elicitation), and conducted gallery walk focus groups in which the participants' photos were displayed and they had an opportunity to discuss the themes present in the photos. Through general inductive thematic analysis, as well as the validity measures of member checking, peer debriefing, and triangulation, three overarching themes 
emerged: commuter students and dorm people, "How difficult it is for commuters" (Victoria), but we're used to it, and finding a "second home" (Lindsay).

\section{Discussion of Findings}

\section{How Commuter Students Make Meaning of Their College Experience}

In taking the findings from Chapter 4 and reviewing them through the lenses of critical theory, campus ecology, and phenomenology, as well as the main arguments of the literature review, four key points emerge in relation to the first research question of how commuter students make meaning of their college experience: the social construction of which students are considered commuters; isolation and level of consciousness; the relationship between living arrangement and independence; and accessibility and relevance of campus involvement. While I define commuter students in Chapter 1 as students who are not living in college-owned housing (Dugan et al., 2008; Ortman, 1995; Jacoby, 2000), this definition is based on the research on commuter students, not on the perceptions of the students. As emphasized by critical theory, definitions and categorizations are socially constructed (Apple, 1995; Freire, 2000) - they are not neutral descriptions of concepts, but represent beliefs, which are influenced by dominant ideology and how individuals situate themselves in relationship to dominant society. In terms of this study, the participants expressed specific ideas about who they considered commuter students. Mode of transportation was one demarcation of commuter status - some bus commuters actually forgot about students who drove to campus or they figured that most people drove so their experience taking the bus was in the minority. Drivers often did not consider taking 
the bus as a viable option and only saw the struggles of commuting in terms of traffic and finding a parking spot.

Other aspects of commuting also showed a lack of agreement. Length of commute was a divisive concept - it seemed as if students who lived within walking distance were not considered commuter students as they could access their home as easily as a dorm student. Participants who lived with family members discussed the family-oriented nature of commuter students and their need to be close to home, while participants who did not live with family members saw other responsibilities as more central to the commuting experience. The one unifying characteristic of commuters was age; most of the participants perceived commuter students as generally older than students who lived on campus. As all of the participants were 20 years of age or older and had attended a college for at least two years, it is not surprising that they would hold this viewpoint.

Thus, it appears that the participants based their definitions of commuter students on their lifeworld (Schutz, 1973). For example, according to Marcela, commuters are students who take the bus and live on their own, as that conceptualization reflected her experience. Only after viewing the photos in the gallery walk and engaging in the focus group discussion did participants appear to gain an awareness of the experience of other commuter students, which will be discussed later in more detail. The variation in the participants' definitions shows the inadequacy and limitations of the commonly used terminology related to commuter students. Simply lumping all commuter students into one category ignores their 
diversity. As the participants noted, one of the most important and complex pieces of commuter student identity is their heterogeneity.

However, it is interesting to note that the participants did not concern themselves with the potential heterogeneity of dorm students - they were seen as a monolithic other who were preoccupied with their roommates and going to campus events. This other represented everything that commuter students were not - dorm students were seen as younger, less stressed, less prepared, more involved in campus life, and generally homogeneous. In forming their identity in relation to dorm students, it is as if the participants flipped the concept of othering (Brantlinger, 2001) on its head by casting the dominant group into a silenced, singular existence.

In sharing their lifeworlds and lived experiences, the participants exhibited a limited consciousness of variety within the dorm student community, as well as of aspects of commuting that were not part of their routine. This limited consciousness could be related to a level of isolation. As noted in Chapter 2, compartmentalization discourages unity and promotes isolation amongst the non-dominant group (Freire, 2000), thus preventing them from attaining a level of consciousness of their situation. The participants seemed to spend a lot of time alone while on campus; they were alone in their cars, in library cubicles, or on benches outside of classrooms. Furthermore, their commutes were often solitary experiences; aside from sporadic carpooling and driving significant others who did not attend State College to their jobs or schools, drivers made the commute alone. For bus riders, while they may have seen other students on the bus, they did not mention having any social interactions on the bus. The bus ride was a time for listening to music, relaxing, and getting some reading 
done. Thus, without a central space for social interaction the participants did not necessarily spend a lot of time interacting with many other commuter students, let alone dorm students. Very few of the participants had been in the residence halls, and those who went there seemed to feel a bit out of place.

As both phenomenology and critical theory call for consciousness-raising in order for individuals to have an authentic sense of themselves and the world (Groenewald, 2004; Schutz, 1973), as well as their role in relation to dominant culture (Freire, 2000), this study incorporated the gallery walk to give participants the opportunity to see and hear the experiences of other commuters. While one meeting for approximately 90 minutes is limited in its ability to help the participants to reach a fully conscious state, the gallery walk did serve as a starting point and initial awakening. The participants experienced various epiphanies during the gallery walks they realized that students took the bus; they agreed with the concept of the car as a second home; they noticed the heterogeneity of commuter students; they saw the significance of the Library; and they celebrated the fact that they were able to fit it all together and navigate the systems.

In addition, they raised my level of consciousness by disproving the assumption that leaving home and living on campus is a necessary rite of passage in becoming an independent adult (Alfond, 1998; Smith, 1989). For the participants meaning was made through their connection to home, as opposed to independence through separation from home. As noted in Chapter 2, institutions of higher education see the normative transition from high school to college as involving a move away from one's family, both physically and intellectually (Holdsworth, 2006; Torres, Gross 
\& Dadashova, 2010). However, the participants' narratives contradicted this assumption as they characterized their experience of commuting as requiring a higher level of maturity and independence. According to the participants, unlike their residential counterparts, they needed to put a lot of time and effort into preparing to come to campus each day as they could not easily return to their homes if they forgot a homework assignment, cell phone charger, or umbrella. In addition, they needed to time their commute very precisely - if they missed a bus, got into traffic, or could not find a parking space they risked missing class. A car breakdown could be devastating - requiring the arrangement of alternative means of transportation via the bus or getting dropped off by family members. Meals, off campus employment, time to complete and print homework assignments, and on campus event attendance all needed to be carefully scheduled. Aside from an occasional ride to campus when other transportation means failed, none of the participants mentioned their family members doing tasks for them (except for cooking the occasional meal) or coddling them in any way. More often than not, the participants were so busy with school, commuting, and working that they seemed to seldom see their families. Furthermore, half of the participants did not live with their families of origin, thus they did not need the experience of living on campus to give them the opportunity to live independently.

It is important to note that a commuter student's living arrangement can change throughout their time in college, even from semester to semester, or from week to week, depending on their finances, family situation, and other factors. Some of the study participants experienced at least two different living arrangements during their time in college - usually either moving out of their family's home or moving back into 
their family's home. So life could be a bit more unpredictable, which influenced a student's ability to successfully manage school and life responsibilities. The interplay between living arrangement, family commitments, employment, and schoolwork speaks to critical theory's concept of wholeness and the issue of compartmentalization (hooks, 1994). When higher education institutions see students as one-dimensional individuals whose only role is that of student, the ability of these institutions to promote student success is diminished. Furthermore, this view can serve to isolate students and devalue their breadth of life experience.

The findings also disproved the myth of commuter students as apathetic and not interested in campus activities (Jacoby, 1989; Rhatigan, 1985). The participants often mentioned the issue of inaccessibility of campus events as they often took place at times which were inconvenient for them or they were too tired after a long day on campus to stay and attend a program. Annie shared her frustration with a system that values certain types of activities, noting that

It's kind of ... frustrating sometimes you see ... scholarships that you want to apply for and [they want you to] show evidence of participating in ... two campus activities and you just want to be like this is a commuter campus ... if you're a student here you [only] have time for maybe ... one activity, but not multiple activities.

As Annie pointed out, the campus culture, through it scholarship criteria, legitimizes and values (Apple, 1995) involvement in particular types campus activities, despite the fact that it can be more difficult for commuter students to participate in those activities. This argument is not to say that campus activities are not worthy pursuits - 
as a Student Affairs professional I have a bias toward seeing these activities as very valuable - but it is to say that the current model seems to disadvantage students who do not live on campus and promotes a very narrow view of what activities are considered acceptable means for social integration and college success. Thus, commuter students were drawn into an internal conflict of whether to try to be like dorm students or to carve out an alternative existence, which can be isolating and risky (hooks, 1994) - like sitting in your car for many hours. Oftentimes the participants experienced both views simultaneously - they felt as if they were missing out on opportunities while, at the same time, they expressed satisfaction at being able to enjoy a more independent lifestyle.

\section{The Role of Space and Place}

In addition to exploring how commuter students make meaning of their college experience, this study sought to examine how these students describe the role of campus space and place. In finding a "second home" on campus participants seemed to be looking for a place to find some privacy, to store their things, and to interact with other students. The participants often spent long stretches of time on campus during which they would hang out in the Library, in their cars, at their on campus jobs, in the hallways of classroom buildings, and in academic workspaces.

In particular, the Library seemed to offer a home base for commuter students. One of the benefits of the Library was that it was a space that could be molded by students to fit their needs, as in the transactional relationship between the environment and individuals within the community described by Strange and Banning (2001) in campus ecology. While the institution may have constructed the Library with the 
intent of providing a place for students to access books and periodicals, do online research, and meet with peers to study and work on projects, students transformed the Library into a place for napping, snacking, charging electronic devices, working on papers, listening to music, and watching movies on Netflix. In a sense, the Library was a place that is akin to the concept of counterspaces (Guiffrida, 2003) in critical race theory, which offers students of color a space to feel welcomed, safe, and comfortable. The Library served as a space where you could "prop your feet up" and feel at home.

Despite this comfortable feeling, it is questionable if the Library truly provided a "second home" as there were no opportunities for "displays of self" or ways to really personalize the space and claim ownership. Unlike a residence hall room, students could not leave their things in the Library overnight or personalize their usual Library cubicle with a sign with their name and a dry erase board so friends could leave messages. The only space in which the participants could safely store items and over which they could claim ownership was their cars - for those participants who drove to campus. They could keep things in the trunk or backseat overnight, or longer, and could personalize the space with decorations to show that it was their space. Thus while spending time in the car could seem risky (hooks, 1994) as it does not conform with the accepted and expected behavior of leaving one's car when a destination is reached, it was sometimes seen by the participants as the only space of their own on campus.

In taking the analysis of campus place and space a bit further, one can see the themes of compartmentalization and consciousness-raising running through the findings, as was apparent in the discussion of commuter student meaning-making. In 
terms of compartmentalization, it appears that campus spaces are set up to isolate specific behaviors - the dining hall is for eating, the library is for studying, the student union is for events, etc. However, this separation does not reflect the actual habits of the participants. For example, Sarah used the Library for eating, studying, watching movies, charging electronic devices, and taking naps. Thus, there is a disconnect between the way that the institution envisions space usage and the needs of students. A much more integrated approach would incorporate a café, study cubicles, computer lab, lounge, multimedia rooms, and event space in the same building. The Library at State College comes closest to providing all of these elements, which may be related to why Sarah and other participants spent so much time there.

Taking compartmentalization to the next level, there is also a disconnect between students" "first home" - where they live off campus - and their "second home" on campus. The two homes do not run on the same schedule and are maintained for different purposes. Mealtimes do not match, thus students are often left to improvise with meals on the go or end up not eating at all. The family members and roommates sharing their "first homes" seem to be sleeping or working when the students return, which limits the amount of social interaction. To help carve out two distinct niches, the participants made an effort to do most or all of their schoolwork on campus in order to reserve their off campus time for family and work obligations, and other personal pursuits. If there was more fluidity between the students' first and second homes, their lifeworlds could be more unified and even mutually supportive, which could, in turn, decrease the stress of lifestyle and the need to work so hard to "fit it all in." 
The institution can play an important role in making this shift by taking students' habits into consideration when planning spaces and systems, as is recommended by Strange and Banning (2001) and further explored in the Recommendations section. However, Strange and Banning (2001) do not suggest that institutions just do whatever students want; there is also an element of intentionally creating spaces that further the educational mission. For example, while the participants repeatedly vocalized a desire for private spaces in which to "chill by yourself", their relative lack of collective consciousness and community calls for a need to construct gathering spaces for consciousness-raising and community building - in addition to places for privacy. Intentionally creating an environment for social interaction fosters self-awareness and an exchange of ideas, which furthers State College's goal of developing "an open and inquiring mind" (State College Mission \& Vision, 2013) and helps to break down the hegemony of dominant ideology (Apple, 1995).

\section{Reflections on Methodology}

Phenomenologically based interviewing and participant driven photo elicitation were chosen as the methodology for this study as they are appropriate qualitative methods for getting at the essence of an individual's experience, assisting in having the participants share their stories (Collier \& Collier, 1986; Carter \& Mankoff, 2005; Schwartz, 1989), empowering individuals who may not identify with the dominant group (Wang 1999; Noland, 2006; Van Auken, Frisvoll \& Stewart, 2010), and integrating the physical environment into the study. Using this combination of research strategies was especially useful as there was data that was not reflected in 
the photos, but was mentioned in the interviews, and vice versa. As a relatively new researcher, my comfort with the use of these methods is still developing. In addition, it is possible that the methods can be further modified and adapted for use in a broader range of studies - it appears that the methodology continues to redefine itself (Noland, 2006), especially with the advent of iPhones and other digital technologies. As such, there are a few aspects related to the implementation of the methodological strategies that warrant further discussion: use of digital cameras, timing of the study, and inclusion of other individuals in the photos.

\section{Use of Digital Cameras}

The focus of this study is not on recent developments in cellular and photographic technology, though these areas are related to participant driven photo elicitation. Within the last ten years we have seen a switch from the use of film cameras to digital cameras to cell phone cameras, which represents an important change in how research involving images continues to develop (pun intended). However, these changes can be difficult to reconcile with other research protocols, including safeguarding confidentiality and other ethical considerations. For example, this study used digital cameras, which were provided to the participants, as opposed to allowing the participants to take the photos on their cell phones and electronically transmit the photos to me. I made the decision to use digital cameras because I thought it would be the best way to ensure the confidentiality of the photos, i.e. having the participants email, instant message, or post their photos would somehow compromise the confidentiality of the images. Furthermore, having all of the participants use the same model of digital camera would ensure that they all had access to the same quality 
of photographic equipment. While all of the participants seemed to have cell phones, their type and quality varied - most had iPhones, but definitely not all of them.

While using the digital cameras worked in achieving a level of uniformity and equality, as well as safeguarding confidentiality through limiting the transmission of the photos, it might have sacrificed spontaneity and authenticity. Many of the participants noted forgetting to carry the camera around with them, thus they took all of the pictures over a span of one or two days in order to complete the assignment before the follow up interview. Sara in particular noted this issue, explaining that "a lot of these [pictures] I took in two days because I kept forgetting to bring the camera." It is possible that the photos would have been more representative of their experience if the participants had been able to use their cell phones to take the pictures, as most of them seemed to carry their cell phones with them at all times.

\section{Timing of the Study}

In addition to the type of device used to take the photographs, the amount of time given to gather the pictures seemed to hinder some of the participants from authentically representing their experience. Patrick commented on this issue:

It was interesting, with times. A lot of times I'm rushing to the bus stop in the morning and I get on the bus and the camera was in my pocket so there [were] things I wanted to take pictures of - and I forgot you know - I was just being constrained by the amount of time I'm not working or in class or studying. I don't want to sound like I didn't dedicate time to it because I did but ...

While one week was given to the participants in order to keep with the general timeline of phenomenologically based interviewing and trying to decrease the 
likelihood of participants not completing the study, it is possible that this strategy did not allow participants enough time to take all of their intended photos. I did try to address this issue by asking participants if there were any photos missing and to describe pictures that they would have taken, but were unable to capture.

In particular some participants mentioned wishing that the study had taken place over the course of the entire academic year, as opposed to just the spring semester, or even throughout their entire time in college. Victoria expressed this feeling when asked what kind of story her pictures conveyed:

... that I definitely had a . . . long run [at State College] in five years and that

I've achieved a lot . . there wasn't really a good way to show achievement with just pictures of going around and stuff but ... you know how like it would have been really cool to have started this freshman year to like this semester because then ... what I really would like to show is ... the progression over the years but ...

So it is possible that a longitudinal study would have captured a more accurate picture of the participants' college experience.

\section{Inclusion of Other Individuals in the Photos}

Along with providing more time to take the photos, editing the wording of the instructions for gathering photos (see Appendix E) might have helped participants to more accurately represent their experience. In an effort to safeguard privacy and confidentiality I included the following instructions regarding pictures of others:

"When taking pictures featuring other individuals, please ask for their permission. Please do not take pictures featuring other individuals without their knowledge and 
consent" (Appendix E). In reviewing this protocol, I would usually explain to the participants that I could blur the faces of any individuals in the photos upon request. I also discussed some of the caveats noted by Wang (1999) in terms of how to approach someone to take their picture.

With so much emphasis placed on cautioning participants about other individuals in photos, it is not surprising that very few of the pictures taken by the participants included others. Some of the participants noted wanting to take "safe" pictures or purposefully avoiding including people in their pictures. Marcela explained this intention in describing her picture of the bus (Figure 36):

I was trying to take a picture of the outside of the bus - this lousy shot there - I didn't like that shot anyway - and the bus driver, I said oh no - I can't take your picture - he said I don't care - I said really - he said well what are you doing it for? I told him and he said take a picture of the fare box [laughs] - so I took a picture of the fare box ... [and this picture has the] backs of some people [on the bus] - I think these are safe pictures. 


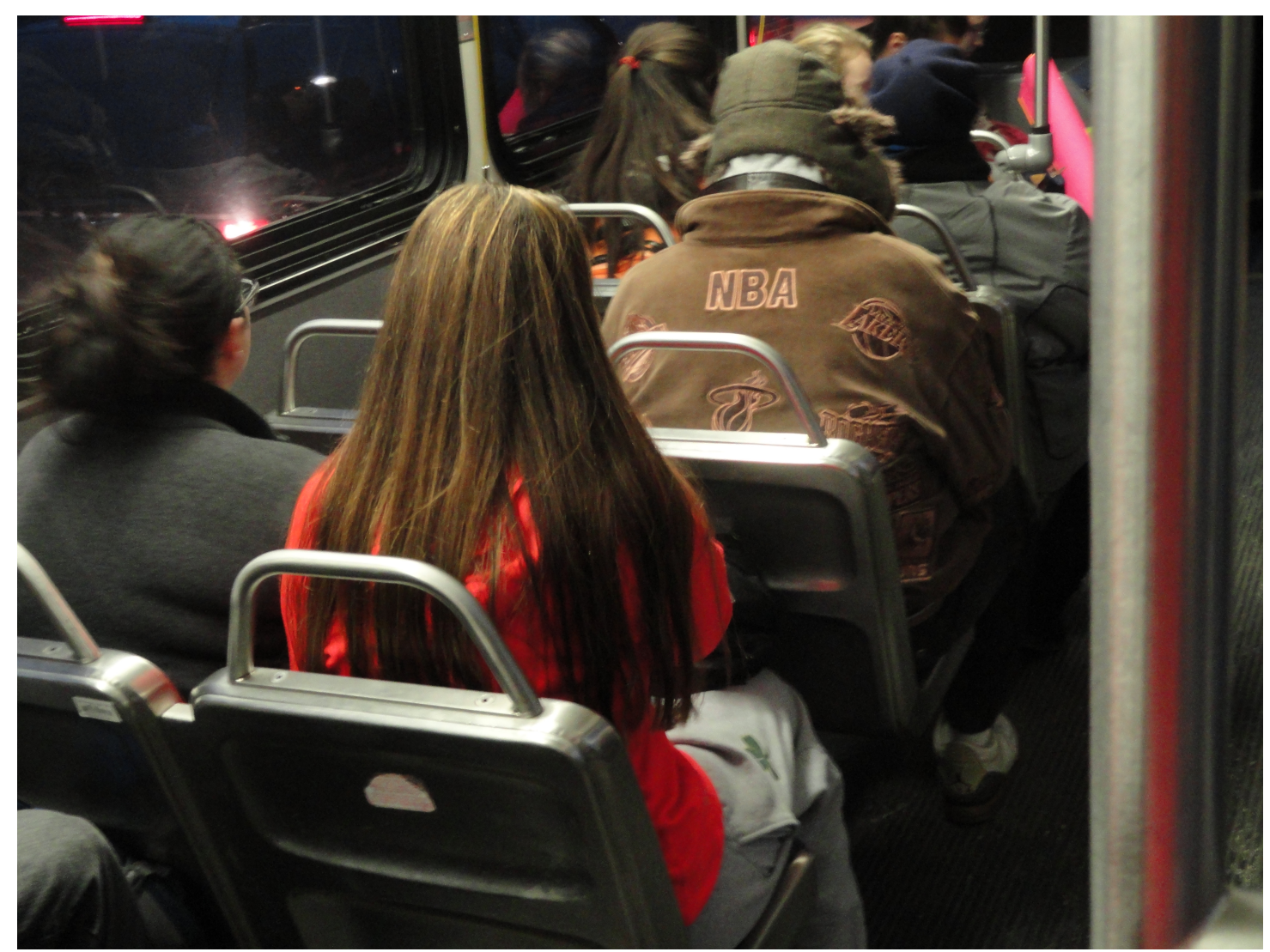

Figure 36. "Back view of people - getting off bus 2 home" - photo taken and titled by Marcela of people sitting in front of her on her ride home on the bus

Some participants addressed this issue by taking pictures of pictures. This method also helped with the timing restraints in that it allowed participants to include images that would have been impossible to gather during the week timeframe. Kara discussed her need to take this approach as "there's no way in a week that [my family is] getting together." Figure 37 is the picture she took of her family picture. 


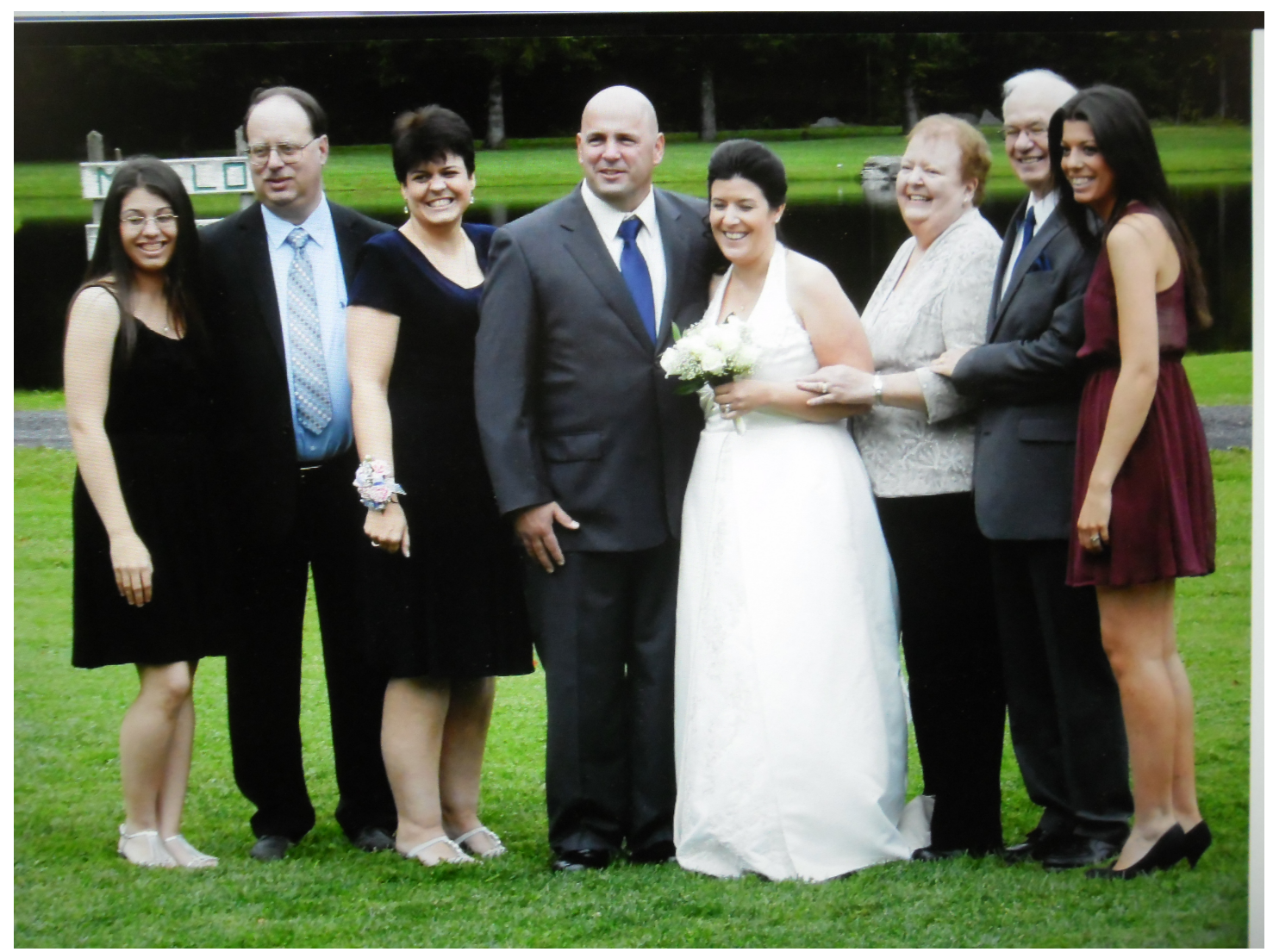

Figure 37. "Thank you" - photo taken and titled by Kara of her family at her Aunt's wedding

So reframing the instructions for taking photos of other individuals might have helped participants to feel more comfortable to include family, friends, and other significant people in their pictures.

\section{Value of the Study}

The overarching significance of this study is that it gives voice to the often ignored experience of commuter students (Jacoby, 1989; Dugan et al., 2008). Focusing on the commuter student narrative helps to broaden the narrow perception of college as a time when students who just graduated from high school come to live on campus, form independent identities from their families, attend full time, and focus all of their energies into getting involved with campus programs and activities (Pascarella, 2006). Adding the aforementioned phenomenological essence of the commuter student 
experience to the stories of college life has important implications for how faculty, student affairs professionals, and administrators approach the business of higher education and their interactions with students. Annie clearly explained the need for this type of approach in her assessment of the president of State College:

I think what this college could use is a president who . . is more [of] an activist or has a ... vision for ... the college and ... understands that it's a commuter college ... [The President of State College] is a nice person, but I

feel like a lot of her projects have been vested in the [Recreation Center] . . things that will attract more residential students here.

Furthermore, giving voice to these students empowers them to feel like "real college students" and validates their experiences. As individuals who are outside of the dominant group it is important for them to feel valued and included in the conceptualization of campus life (Giroux, 1989; Jacoby, 2000). In this sense, inclusion does not mean changing their experience so that it is more inline with the dominant residential experience, but instead refers to challenging the notion that a student needs to live on campus in order to truly experience college.

\section{Implications for Practice}

Challenging dominant ideology and the systems based on this ideology, informed by a new understanding of the phenomenon of commuting to college, is the basis for the below recommendations. As a student affairs practitioner at heart, I feel a deep obligation to offer ways that the findings from this study can be used to influence practice in relation to student support services. In addition, I offer implications for the work of faculty and higher education administrators, as they are the two other entities 
that govern colleges and universities. Lastly, I end with implications for students - the often forgotten partner in the educational process. As noted in the discussion of critical theory (Apple, 1995) and campus ecology (Strange \& Banning, 2001), education is a dialectical process in that students are not merely the receivers of information; they play an active role in adding knowledge to the conversation, rejecting information that they find inappropriate or irrelevant, and manipulating the environment to meet their needs. Therefore, they need to be included in the conceptualization of action steps for furthering issues related to commuter students.

The main, overarching implication is for individuals from all four of these groups to actively and intentionally seek out and listen to the stories of commuter students. The more that these stories are heard; the more that the narrow perception of the traditional or normal college experience will become broader. As commuter students are a highly heterogeneous group, it takes a concerted amount of effort to appreciate the plurality of their experience.

\section{Student Affairs Practitioners}

Specifically in regards to student affairs practitioners, the findings of this study call for us to examine the scope of campus involvement, integration of family, work, community, and school life, support for wellness, providing "second homes," and reinventing residential life. In regards to the scope of campus involvement, it appeared that the participants had internalized a very specific notion of what it means to be an involved, engaged student. Though most of them had found something to connect with on campus, such as on campus jobs, clubs, academic pursuits, and networks of friends, they still did not view themselves as very involved because they did not participate in 
the stereotypical activities of attending campus programs, going to college athletic events, joining a sorority, playing Frisbee, etc. Thus, I propose that student affairs practitioners make a concerted effort to broaden the definition of campus involvement to include on campus jobs, spending time in the library, participating in study groups basically any activity related to the college that students do in addition to attending class. As Tinto's (1987) theory of student departure notes, students need to feel connected to the campus community in order to persist. Therefore, we should embrace the full range of ways that students connect with the campus, as opposed to narrowly focusing on the traditional concepts of clubs and events that do not attract all students.

One way to foster connections is to create an environment in which the multiple life roles that students inhabit are acknowledged and valued. The first way to accomplish this goal is to lessen the focus placed on leaving home as a necessary rite of passage. We need to revise the tips given to new students to stop centering on homesickness, how to get along with roommates, and other topics that assume that students are no longer living at home. Instead we can be developing resources for how to help students to clarify their family role and responsibilities, care for ailing family members, access affordable childcare, serve as a role model for siblings, and to handle changes in their living arrangements.

Furthermore, while the traditional parent and family weekends are nice programs, they only recognize students' families for two days out of the year. To improve home-school integration we could include more family-friendly events in the programs that take place throughout the school year. We could also encourage students to bring their cousins, siblings, home friends, and significant others to attend 
campus events. These strategies may help family members and friends from home to understand the students' college experience. In addition, it acknowledges the important role that these individuals play in the lives of students.

Similarly, to appreciate the role that off campus employment plays in students' lives, we can work for form partnerships with students' employers by offering training programs and other resources. As with inviting family and friends to campus, this effort could help employers to understand the students' college experience, which could in turn help the employers to create work schedules that are more aligned with students' class schedules.

While lessening students' hectic schedules by better aligning their work and class commitments would be helpful, student affairs practitioners can also assist by supporting students in attaining a level of wellness. As the participants noted, finding time to eat and planning for meals could be challenging. Offering affordable meal plans for commuter students, partnering with local restaurants to provide discounts, supporting the use of Tupperware by selling these items on campus, allowing them to be used in the dining center, and identifying places where students can wash their Tupperware, and providing community refrigerators and microwaves throughout campus (not just in the dining center and student union) could help commuter students to eat meals. Furthermore, faculty could consider doing pot lucks meals during class to help students who are in class at mealtimes.

In addition to needing a place to eat meals, the participants discussed looking for a space that provided comfort, storage for their things, privacy, warmth, opportunities for social interaction, and a general sense of home. While the student 
union is typically seen as a lounge and home base for students, we need to embrace the hospitality of other campus spots - most notably the library. As commuter students often take advantage of their time on campus to complete homework assignments, they can spend a lot of time in the library. It could make sense to partner with the library to plan programs and offer resources.

The participants did not mention a commuter lounge, as one does not exist at State College, but many other colleges do offer this type of space. However, instead of merely recommending that each college have a commuter lounge, I would suggest that a lounge is not sufficient to provide the type of comfort mentioned by the participants. It could be more useful to have commuter students assigned to different "houses" or community centers that really did provide the amenities of a home away from home. Furthermore, being assigned to a community center would promote a feeling of ownership and belonging as opposed to a lounge where one is just a visitor. Students could decorate the community center as they like, set up a governing body, and jointly decide on the organization of the center. This type of environment would intentionally incorporate campus ecology's notion of students both shaping and being shaped by their surroundings (Strange \& Banning, 2001).

While I am not suggesting that commuter students should live on campus, the participants' perception of the residential experience as expensive, full of drama, and for younger students indicates that residential life may want to consider reinventing its image as a place where older students are welcomed and students can have a mature living experience. State College does not offer on campus apartments or options for family housing - these two living arrangements could be attractive to commuter 
students. In terms of cost, if prices cannot be lowered, a realistic comparison of the cost of living in a residence hall, renting an apartment, and living at home would help students to have a more accurate view of their housing options.

\section{Faculty}

Student affairs practitioners cannot change the campus culture alone; they need the support of faculty, higher education administrators, and students to make this shift. In terms of the faculty's role, they can embrace the conceptualization of the classroom as the "gateway to the campus" (Braxton, Milem \& Sullivan, 2000) and structure their classes in a way that appreciates commuter students' lives. As some of the participants noted, their life on campus mainly consisted of going to class and spending time in the library, with some time at on campus jobs mixed in. Thus, the classroom plays a crucial role in students' college experience - not just as a space for learning, but as a place to make friends, learn about campus resources, eat meals, charge electronic devices, and store their things. Embracing this expanded notion of classroom time and space can be a challenge to faculty who believe that it is not their job to know about students' lives or to serve as a campus resource - their main focus is to teach the students the academic material. However, if Tinto (1987) is correct and social and intellectual integration is central to student success, then it is incumbent upon faculty to assist with this integration.

A classroom that is a "gateway to the campus" can incorporate a lot of different elements, including a faculty member who knows his/her students (if they live on campus or commute, the length of their commute, the jobs they are working, their living arrangement, their family situation, etc.), time set aside for announcements 
about campus events and resources, activities designed intentionally for students to get to know each other and form friendships, and support for extending the relationships outside of the classroom through organization of study groups, intramural teams, coffee hours, and other activities. In short, the classroom is more than a "gateway to the campus"; it functions as it's own community, fostering comfort and a sense of belonging.

In order for these classroom communities to be successful students need to feel as if faculty care about them and have an appreciation for their life circumstances. To be specific, participants in the study mentioned issues with faculty members who posted assignments late and expected that students had constant access to email and the classroom management program. As commuter students often juggle multiple life roles and split their time between family responsibilities, jobs, friends, and school, they need to be able to plan ahead. Therefore, last minute changes to syllabi, late cancellations of classes, requesting that students attend programs not held during class

time, and delayed explanation of assignments can be difficult for commuter students to manage. To give students the greatest opportunity for success faculty need to ensure that things are planned in advance as much as possible.

\section{Higher Education Administrators}

Higher education administrators also need to mindful of commuter students' life circumstances when managing their institutions. More specifically, they need to account for commuter students' variability in their assessment and data collection measures, offer class scheduling that is predictable and convenient, and incorporate commuter students into the image of the institution. In terms of assessment and data 
collection, the measures used need to allow for the variability within the commuter student population. As seen with the participants, commuter students' living arrangements and modes of transportation often change over the course of their time in college, and even from semester to semester. Thus, the system through which students list their home addresses needs to be easily accessible, or the institution runs the risk of not having correct information on file.

Furthermore, the institution needs to ensure that it is collecting all of the relevant data it needs to effectively serve the students. For example, it could be helpful to collect information on marital/partner status, dependent children, and family member caretaking responsibilities to get a clearer picture of students' family lives. Currently State College collects information on marital status at the time of admission, but does not systematically update that information. While Financial Aid does have information on marital status and dependents, it is not typically available to staff who are planning programs.

As evinced by Sarah's mention of “the commuter's nightmare schedule," long breaks between classes can be very inconvenient for commuter students. Furthermore, as Annie noted, the unpredictability of the class schedule can make it very difficult to work an off campus job. Therefore, making the class schedule predictable and condensed into blocks can make the commuter student experience more seamless.

While listening to and appreciating the commuter student experience is necessary, it is not enough. This appreciation must then be incorporated into the institution's image. According to Annie, the president of State College does not seem to embrace the fact that it is a predominantly commuter college. When an institution 
does not display ownership of and pride in the type of students it attracts those students can feel marginalized. Using a tag line such as State College: Where Commuters Succeed, could go a long way in helping commuter students to see the College as their home.

\section{Students}

Students also have a role to play in shaping campus culture. This role can center on advocacy for commuter student concerns and support for their commuter student peers. Their efforts can help to reclaim the validity of the breadth of college experiences. Commuter students can advocate for appropriate resources such as predictable class schedules, community centers, and amenities in the library. In terms of support, commuter students can serve as peer mentors - helping new commuter students to find a "second home" on campus through specialized campus tours, to balance their multiple commitments by providing sample schedules incorporating commute times, on and off campus jobs, and family responsibilities, to establish reliable transportation and alternative routes for inclement weather through carpool message boards and bus information, and to keep updated with pertinent information by creating a commuter student blog, twitter account, text alerts, or e-newsletter.

Furthermore, commuter students can provide more personalized support by forming groups related to the various subsets of commuters. Commuters who transferred from the same community college could meet to discuss transfer credits and ways to connect the involvement experiences at the community college to those of the four year college. For example, members of the anime clubs from both institutions could hold joint meetings so when students transfer they have an automatic group of 
friends and a sense of continuity. Commuter students who live in their own homes or apartments could meet to discuss leases and rental insurance, personal finance, and neighborhood resources. The opportunities for these support groups are endless.

Resident students also have a role in these efforts by taking the time to gain an appreciation for the commuter student experience and advocating along side commuter students for these resources. Through this advocacy commuter students can reclaim the legitimacy of their college experience and encourage resident students, student affairs practitioners, faculty, and higher education administrators to respect their experience as a valid path through college.

\section{Implications for Further Study}

Along with practical applications, this study had implications for future research. I would recommend three directions for future research: methodological adjustments utilizing cell phones and a longitudinal framework, replication of the study at a variety of institutions, and investigation of the attitudes of student affairs practitioners, faculty, and higher education administrators regarding the commuter student experience. As mentioned in the Reflection on Methodology, the use of cell phones to capture pictures and administering the study over the course of a student's college experience could yield a more accurate and authentic representation of the experience of commuting.

As noted in Chapter 3, the purpose of qualitative research is not to generalize (Creswell, 2009); the goal is to gain a depth of understanding of a specific experience. Therefore, the findings of this study cannot be directly applied to commuter students at other institutions. Furthermore, as the commuter student population is highly 
heterogeneous, numerous studies need to be conducted in order to identify and explore the various subpopulations.

Lastly, as noted in the Implications for Practice, student affairs practitioners, faculty, and higher education administrators play an integral role in cultivating the campus culture. Therefore, it would be helpful to better understand their attitudes toward commuter students, as well as their living arrangements during their college careers.

\section{Summary and Concluding Thoughts}

This study both confirmed some of my prior notions and challenged my assumptions about the commuter student experience. I had expected to hear a lot about parking, traffic, the bus schedules, and the amount of effort it took to get to campus. However, I had not anticipated the focus on independence, maturity, resourcefulness, and responsibility expressed by the participants. I had not realized that I continued to cling to the stereotype of resident students as the independent ones as they were "on their own" as opposed to commuter students who "still" lived with their families. The amount of coordination that it takes to get to and from campus, work a job (or multiple jobs), handle family responsibilities, and do schoolwork is amazing.

I also learned how important on campus jobs can be for a student's connection to the college and sense of belonging. On campus jobs do not just help students earn money - they help them to make friends, learn about resources, and find a second home. These jobs definitely need to be better incorporated into the lexicon of campus involvement. 
In terms of my own development, the practice of bracketing taught me how difficult, but important, it is to be aware of one's own assumptions and to consciously set them aside in order to truly hear the voices of the participants. For example, participants repeatedly remarked on the amount of planning and level of responsibility necessary to commute to campus. I had always thought that living on campus was the more independent experience, as it represented a departure from family life and the need to fend for oneself. Instead, the participants framed the residential experience as a somewhat sheltered existence and easier lifestyle, as it did not take much effort for those students to roll out of bed and go to class. I also assumed that commuter students all secretly wished that they could live on campus, but that was not the case. Most of the participants had never even considered living on campus - due to age and life circumstances living on campus was never an option.

Another example of challenging my preconceived notions in order to attain a new understanding of the commuter experience centered on multiple participants sharing that "commuters don't wear sweatpants." This comment related to the overarching emerging theme that commuter students put in more effort than resident students to get to campus and attend college. This theme was a new discovery for me I had never really considered that commuter students would identify so strongly with a sense of responsibility and dedication. When I shared this theme with the other participants they agreed enthusiastically, often going on to share stories of how hard it is to get to campus.

In addition to learning to challenge my own assumptions, conducting this study helped me to challenge the biases of others. At the State College Graduate Student 
Symposium one of the faculty members asked why I had not also interviewed resident students to do a comparative study, to which I replied that as a phenomenological study, the purpose was to understand the essence of the experience of commuter students, not to explore the differences between commuters and residents.

Furthermore, the focus on commuter students is consistent with critical theory's notion of highlighting the lived experience (Giroux, 1989; hooks, 1994) of individuals in the non-dominant group; the commuter student experience does not need to be viewed in relation to the residential student experience in order to be considered valid.

Lastly, this study showed me how important it is to keep meeting with students, hearing their stories, and making appropriate changes to the programs that I coordinate in student activities. It would be easy for me to just keep doing the same thing and not to venture out and meet students who are not already involved in my programs, but that would not be ethical or interesting. The participants in this study showed me the need to keep information on trip ticket sales up-to-date as it is unfair to have a student drive all the way to campus just to find out that a trip is sold out. They showed me the Library truly is the heart of our campus, thus leading me to seek to increase the amount of collaboration with the Library staff. They showed me that time between classes is not seen as "free" time to attend events - it is "break" time spent doing homework, working, napping, running errands, meeting friends for lunch, or watching Netflix.

I still have not fully grasped all the ways that this study impacts my work with students. Hopefully as I share the findings with students and colleagues we can make 
sense of it together and I can effectively incorporate the findings into practice, while encouraging others to do the same. 


\section{APPENDICES}

Appendix A: Data Collection Timeline

Table A-1

Data Collection Timeline

\begin{tabular}{|c|c|}
\hline Date & Stage \\
\hline January 14, 2013 & Obtained IRB approval \\
\hline January 22, 2013 & Began recruitment of participants \\
\hline January 28, 2013 & Initial interview with Participant 1 \\
\hline January 29, 2013 & Initial interview with Participant 2 \\
\hline January 30, 2013 & Initial interview with Participant 3 \\
\hline February 5, 2013 & $\begin{array}{l}\text { Collected camera from Participants } 1 \& 2 \text { and printed } \\
\text { pictures } \\
\text { Follow up interviews with Participants } 1 \& 2\end{array}$ \\
\hline February 6, 2013 & $\begin{array}{l}\text { Collected camera from Participant } 3 \text { and printed pictures } \\
\text { Follow up interview with Participant } 3\end{array}$ \\
\hline February 14, 2013 & Initial interview with Participant 4 \\
\hline February 19, 2013 & Initial interview with Participant 5 \\
\hline February 20, 2013 & $\begin{array}{l}\text { Collected camera from Participant } 4 \text { and printed pictures } \\
\text { Follow up interview with Participant } 4\end{array}$ \\
\hline February 21, 2013 & Initial interviews with Participants 6, 7, $8 \& 9$ \\
\hline February 27, 2013 & Collected camera from Participant 9 and printed pictures \\
\hline February 28, 2013 & $\begin{array}{l}\text { Collected cameras from Participants 5, 6, } 7 \& 8 \text { and printed } \\
\text { pictures } \\
\text { Follow up interviews with Participants 5, 6, } 7 \& 8\end{array}$ \\
\hline March 1, 2013 & $\begin{array}{l}\text { Gallery Walk with Participants } 1,2 \& 3 \text { (Participant } 4 \text { was } \\
\text { also supposed to attend) }\end{array}$ \\
\hline March 5, 2013 & Follow up interview with Participant 9 \\
\hline March 22, 2013 & $\begin{array}{l}\text { Gallery Walk with Participants 4, 5, 6, } 8 \& 9 \text { (Participant } 7 \\
\text { was also supposed to attend) }\end{array}$ \\
\hline March 21, 2013 & Initial interview with Participant 10 \\
\hline March 28, 2013 & Collected camera from Participant 10 and printed pictures \\
\hline April 12, 2013 & Gallery Walk with Participants $7 \& 10$ \\
\hline
\end{tabular}




\section{Appendix B: Initial Interview Questions}

What is your major?

Where is your hometown?

How many semesters have you been at RIC?

What is your racial and ethnic background?

How did you decide to come to Rhode Island College?

How did you become a commuter student?

Take me through a typical day - describe in detail how you spend your time.

Please describe any key past experiences in your family, school, and work life that have shaped your current college life.

What about the commuter experience really works for you?

What aspects are challenging? 


\section{Appendix C: Recruitment Flyer}

\section{(1.) $\overline{\text { RHODE ISLAND }}$ COLLECE \\ RIC COMMUTER STUDENTS WANTED FOR PARTICIPATION IN A RESEARCH STUDY}

Who can participate in this study?

Rhode Island College undergraduate students over 18 years of age who do not live in College-owned housing (residence halls)

Why is this study being done?

To give commuter students the opportunity to describe their college experience in their own words and to reflect on the meaning of that experience.

What are the study procedures? What will I be asked to do?

If you agree to take part in this study, you will be asked to do the following tasks:

1. Participate in an initial one-on-one interview with the researcher lasting approximately one hour. This interview, which will take place at a location of your choosing (either on or off campus) entails a discussion of how you came to be a commuter student and a brief training on gathering photographs.

2. Take a series of around 10 photographs that represent your college experience. A digital camera will be provided for you to use.

3. Participate in a follow-up one-on-one interview in which you discuss the photographs you have taken. The interview will last approximately one hour and will take place at a location of your choosing.

4. Participate in a "gallery walk" in which a few of your photographs (chosen by you), as well as photos selected by other student participants, will be on display. After viewing the photographs you participate in a group discussion of the themes of the images. The gallery walk will take approximately two hours and is located on campus.

In total, participation will take approximately six to eight hours.

\section{Will I receive payment for participation?}

Participants who complete all parts of the study (two interviews, photo gathering, and gallery walk) can choose from the following gifts:

15-ride RIPTA bus pass (\$13 value with RIC discount; \$26 value without RIC discount)

$\$ 10$ Dunkin Donuts gift card

$\$ 15$ gas station card

Who do I contact if I would like to participate in the study or have questions about the study? Marissa Weiss

mweiss@ric.edu

(401) 456-8149

Principal Investigator: Annemarie Vaccaro, avaccaro@uri.edu, (401) 874-2270

Student Researcher: Marissa Weiss, mweiss@ric.edu, (401) 456-8149

Study Title: The College Experience of Commuter Students and the Concepts of Place and Space This study received approval from the Rhode Island College Institutional Review Board (IRB) on 1/14/13. 


\section{Appendix D: Demographic Questionnaire}

\begin{tabular}{|l|l|l|}
\hline \multicolumn{3}{|c|}{ GENERAL INFORMATION ABOUT YOU } \\
\hline \multicolumn{3}{|c|}{ THIS INFORMATION WILL BE KEPT CONFIDENTIAL. YOUR NAME WILL NOT BE } \\
ASSOCIATED WITH YOUR PARTICIPATION.
\end{tabular}




\section{Appendix E: Photo Gathering Protocol}

Instructions for study participants:

Thank you for participating in this study on the commuter student experience. Using the provided digital camera, please take at least 10 pictures (you can take more if you'd like) that represent your college life.

Please note that the pictures you take for this study are the property of the researcher and may be used during presentations and publications related to this research. Your signature on the consent form indicates your agreement with and understanding of this statement.

As you take the pictures please use the attached worksheet to record brief notes about each picture. Once you're done taking pictures, put the camera and your completed worksheet in the provided envelope and meet me at the following date, time, and location to drop off the items:

Date:

Time:

Location:

The follow up interview is scheduled for the following date, time, and location:

Date:

Time:

Location:

The interview will be focused on discussing your photos and why you selected them. 
Before taking the photos, let's consider the following questions in order to minimize any potential risks to you and anyone included in your pictures.

1. What is an acceptable way to approach someone to take his or her picture?

2. Should someone take pictures of other people without their knowledge?

3. To whom might you wish to give photographs, and what might be the implications?

4. Why would you not want to have your picture taken?

(Questions taken from Wang, 1999, p. 188)

Please review the below general guidelines for the photos.

When taking pictures featuring other individuals, please ask for their permission.

Please do not take pictures featuring other individuals without their knowledge and consent.

It is okay to delete photos you do not like, as long as you have at least 10 photos at the end of the week.

The photos will be used during the interview to prompt discussion. You will also select a few of your photos for inclusion in the Gallery Walk. In addition photos may be included in the researcher's dissertation and presentation of findings, but your name will not be associated with any of your pictures. Furthermore, you have the option to ask that the faces of any individuals pictured in the photos be blurred in order to protect their identities.

If pictures you take involve any activities that present a potential threat to you or to others the researcher may need to report the behavior to the appropriate authorities. 
Try to avoid taking photos of things that are exciting and look interesting, but are not related to your college life. Things that may seem ordinary to you might be new and different to someone else. 


\section{Appendix F: Annotation Worksheet}

Complete the following worksheet as you take the pictures.

\begin{tabular}{|l|l|l|l|l|}
\hline Picture \# & Date & Time & Location & Title \\
\hline Example & $10 / 26 / 12$ & $10: 00$ AM & $\begin{array}{l}\text { Kauffman } \\
\text { Center at State } \\
\text { College }\end{array}$ & $\begin{array}{l}\text { Important dissertation } \\
\text { proposal defense }\end{array}$ \\
\hline 1 & & & & \\
\hline 2 & & & & \\
\hline 3 & & & & \\
\hline 4 & & & & \\
\hline 5 & & & & \\
\hline 6 & & & & \\
\hline 7 & & & & \\
\hline 8 & & & & \\
\hline 10 & & & & \\
\hline
\end{tabular}


Appendix G: Photo Elicitation Interview Questions

As we look at the photos, consider these questions:

What do you see here?

What is happening here?

How does this image relate to your experience as a commuter?

What would you add, keep, or change about the situation depicted in the photo?

What would you like for others to know about this image?

(Questions based on Wang, 1999, p. 188)

Speak to me about this photo. What does it mean to you?

What was this process like for you?

Describe the process of gathering the photos. Did you plan it out or improvise?

Did you notice any overall themes in your pictures? If yes, please describe them.

Which two or three pictures are especially meaningful to you? Why are they

significant?

After looking through the photos, do you see anything that's missing? If yes, please explain.

Given what you have discovered through the gathering of photos and your comments about your past experiences in the initial interview, how do you understand your experience as a commuter student?

What does it mean to you to be a commuter student?

What about the commuter experience really works for you?

What aspects are challenging? 
Which five photos would you like to include in the Gallery Walk? What titles or short descriptions would you like to include for each picture?

What is your availability during the week of May 6 (finals week) to attend the Gallery Walk? 


\section{Appendix H: Gallery Walk Prompt Questions:}

As you view the displayed photographs, please consider the following questions:

What themes, or commonalities, do you see throughout the photos?

What images and ideas really stood out to you?

Are there any images that do not fit with your experience? If yes, how are they different?

After viewing the photos are there any pictures that you wish you would have taken? If so, what would be included in those pictures?

Are there any images missing?

In a sentence or a few words, summarize the feeling you get from looking at the photos.

What about the commuter experience really works for you?

What aspects are challenging?

What would you like for others to know about the commuter experience? 


\section{BIBLIOGRAPHY}

Adelman, C. (1998). Photocontext. In J. Prosser (Ed.), Image-Based Research (pp. 148-161). New York, NY: Routledge.

Alfond, S. M. (1998, Spring). The impact of inner-city values on student social adjustment in commuter colleges. NASPA Journal, 35(3), 225-233.

Apple, M. (1995). Education and power. New York, NY: Routledge. Assessment. (2012). http://www.ric.edu/assessment/list.php

Aud, S., Hussar, W., Planty, M., Snyder, T., Bianco, K., Fox, M., Frohlich, L., Kemp, J., and Drake, L. (2010). The Condition of Education 2010 (NCES 2010-028). National Center for Education Statistics, Institute of Education Sciences, U.S. Department of Education. Washington, DC. Retrieved from http://nces.ed.gov/pubs2010/2010028.pdf.

Aud, S., Hussar, W., Kena, G., Bianco, K., Frohlich, L., Kemp, J., and Tahan, K. (2011). The Condition of Education 2011 (NCES 2011-033). U.S. Department of Education, National Center for Education Statistics. Washington, DC: U.S. Government Printing Office. Retrieved from http://nces.ed.gov/pubs2011/2011033.pdf.

Aud, S., Hussar, W., Johnson, F., Kena, G., Roth, E., Manning, E., Wang, X., and Zhang, J. (2012). The Condition of Education 2012 (NCES 2012-045). U.S. Department of Education, National Center for Education Statistics. Washington, DC. Retrieved from http://nces.ed.gov/pubs2012/2012045.pdf.

Baker, C. N. (2008, August). Under-represented college students and extracurricular involvement: the effects of various student organizations on academic performance. Social Psychology Education,11(3), 273-298. 
Banks, M. (1998). Visual anthropology: Image, object, and interpretation. In J. Prosser (Ed.), Image-Based Research (pp. 9-23). New York, NY: Routledge.

Banning, J. H. \& Hughes, B. M. (1986, Summer). Designing the campus environment with commuter students. NASPA Journal, 24(1), pp. 17-24.

Banning. J. H., Middleton, V, \& Deniston, T. L. (2008). Using photographs to assess equity climate: A taxonomy. Multicultural Perspectives, 10(1), 41-46.

Bean, J. P. \& Metzner, B. S. (1985, Winter). A conceptual model of nontraditional undergraduate student attrition. Review of Educational Research, 55(4), 485540.

Becker, H. S. (1998). Visual sociology, documentary photography, and photojournalism: It's (almost) all a matter of context. In J. Prosser (Ed.), Image-Based Research (pp. 84-96). New York, NY: Routledge.

Boyatzis, R. E. (1998). Thematic analysis and code development: Transforming qualitative information. Thousand Oaks, CA: Sage Publications.

Brantlinger, E. (2001, March). Poverty, class, and disability: A historical, social, and political perspective. Focus on Exceptional Children, 33(7), 1-19.

Braxton, J. M., Hirschy, A. S., \& McClendon, S. A. (2004). Understanding and reducing college student departure: ASHE-ERIC report. San Francisco: Wiley.

Braxton, J. M., Milem, J. F. \& Sullivan, A. S. (2000, September/October). The influence of active learning on the college student departure process. The Journal of Higher Education, 71(5), 569-590.

Cabrera, A. F., Nora, A., Terenzini, P. T., Pascarella, E. \& Hagedorn, L. S. (1999, 
March-April). Campus racial climate and the adjustment of students to college: A comparison between White students and African-American students. The Journal of Higher Education, 70(2), 134-160.

Carnegie Foundation for the Advancement of Teaching (n.d.). Carnegie classifications: Size \& setting classification. Retrieved from http://classifications.carnegiefoundation.org/descriptions/size_setting.php.

Carnegie Foundation for the Advancement of Teaching (2010). Distribution of institutions and enrollments by classification category. Retrieved from http://classifications.carnegiefoundation.org/summary/size_setting.php.

Carnegie Foundation for the Advancement of Teaching. (2011). Methodology: Undergraduate profile classification. Retrieved from http://classifications.carnegiefoundation.org/methodology/ugrad_profile.php.

Carspecken, P. F. \& Apple, M. (1992). Critical qualitative research: Theory, methodology, and practice. In M. D. LeCompte, W. L. Millroy \& J. Preissle (Eds.), The Handbook of Qualitative Research in Education (pp. 507-553). New York: Academic Press.

Carter, S. \& Mankoff, J. (2005). When participants do the capturing: The role of media in diary studies. Human-Computer Interaction Institute. Paper 123. Retrieved from http://repository.cmu.edu/hcii/123

Chalfen, R. (1998). Interpreting family photography as pictorial communication. In J. Prosser (Ed.), Image-Based Research (pp. 214-233). New York, NY: Routledge.

Choy, S. (2002). Nontraditional Undergraduates (NCES 2002-012). U.S. Department 
of Education, National Center for Education Statistics. Washington, DC.

Retrieved from http://nces.ed.gov/pubs2002/2002012.pdf.

Collier, J. \& Collier, M. (1986). Visual Anthropology: Photography as a Research Method. Alburquerque: University of New Mexico Press.

Creswell, J. W. (2009). Research Design: Qualitative, Quantiative, and Mixed Methods Approaches. Los Angeles: Sage Publications.

D’Augelli, A. R. \& Hershberger, S. L. (1993, Winter). African American undergraduates on a predominantly white campus: Academic factors, social networks, and campus climate. The Journal of Negro Education, 62(1), 67-81.

Davies, T. G., Safarik, L., \& Banning, J. H. (2003). The deficit portrayal of underrepresented populations on community college campuses: A cross case analysis. Community College Journal of Research and Practice, 27, 843-858.

Dugan, J. P., Garland, J. L., Jacoby, B. \& Gasiorski, A. (2008). Understanding commuter student self-efficacy for leadership: A within-group analysis. NASPA Journal, 45(2), pp. 282-310).

du Toit, M. \& Gordon, J. (2007). The means to turn the social key: The South Durban Photography Project's workshops for first-time photographers (2002-2005). In N. de Lange, C. Mitchell \& J. Stuart (Eds.), Putting people in the picture: Visual methodologies for social change (pp. 257-273). Rotterdam, The Netherlands: Sense Publications.

Ehrich, L. (2005). Revisiting phenomenology: its potential for management research. 
In Proceedings Challenges or organisations in global markets, British Academy of Management Conference, pp. 1-13, Said Business School, Oxford University. Retrieved from http://eprints.qut.edu.au/2893/1/2893.pdf.

Epstein, I., Stevens, B., McKeever, P. \& Baruchel, S. (2006). Photo elicitation interview (PEI): Using photos to elicit children's perspectives. International Journal of Qualitative Methods, 5(3), 1-11.

Fraenkel, J. R. \& Wallen, N. E. (2010). How to design and evaluate research in education ( $7^{\text {th }}$ international ed.). Singapore: McGraw Hill.

Framingham State University Office of Housing and Residential Services. (2012). Guide to Residence Living 2011-2012. Retrieved from http://www.framingham.edu/residence-life/forms-and-publications/guide1112.pdf.

Freire, P. (2000). Pedagogy of the oppressed. New York, NY: Continuum.

Gibson, S. K. \& Hanes, L. A. (2003, June). The contribution of phenomenology to HRD research. Human Resource Development Review, 2(2), 181-205. Retrieved from http://www.hu.liu.se/cf/larc/utbildning-information/scientificmethodology/course-literature-and-links/1.253560/Phenomenology_4.pdf.

Gilardi, S. \& Guglielmetti, C. (2011, January/February). University life of nontraditional students: Engagement styles and impact on attrition. The Journal of Higher Education, 82(1), 33-53.

Giroux, H. (1989). Schooling for democracy: Critical pedagogy in the modern age. London: Routledge.

Groenewald, T. (2004, April). A phenomenological research design illustrated. 
International Journal of Qualitative Methods, 3(1). Retrieved from http://uir.unisa.ac.za/bitstream/handle/10500/2573/groenewald_IJQ..?sequence $=1$

Guiffrida, D. A. (2003, May/June). African American student organizations as agents of social integration. Journal of College Student Development, 44(3), 304-319.

Harper, D. (2002). Talking about pictures: A case for photo elicitation. Visual Studies, 17(1), 13-26).

Harper, S. R., \& Quaye, S. J. (2007). Student organizations as venues for Black identity expression and development among African American male student leaders. Journal of College Student Development, 48(2), 127-144.

Harris-Stowe State University. (n.d.). Residential Life: FAQs. Retrieved from: http://www.hssu.edu/sp_content.cfm?wID=57\&pID=557.

Holdsworth, C. (2006). "Don't you think you're missing out, living at home?" Student experiences and residential transitions. The Sociological Review, 54(3), 495517.

Hurtado, S. (1992, September-October). The campus racial climate: Contexts of conflict. The Journal of Higher Education, 63(5), 539-569.

Husserl, E. (1976). Ideas. (W. R. Boyce Gibson, Trans.). New York, NY: Humanities Press Inc. (Original work published 1913)

Inman, P. \& Pascarella, E. (1997). The impact of college residence on the development of critical thinking skills in college freshmen. Presented at ASHE '97: The Annual Meeting of the Association for the Study of Higher Education. Albuquerque. 
Jacoby, B. (1989). The student as commuter: Developing a comprehensive institutional response. ASHE-ERIC Higher Education Report No. 7. Washington, D.C.: School of Education and Human Development, The George Washington University.

Jacoby, B. (2000, Spring). Why involve commuter students in learning? New Directions for Higher Education, 109, pp. 3-12.

Johnson, D. R., Soldner, M., Brown Leonard, J., Alvarez, P., Kurotsuchi Inkelas, K., Rovan-Kenyon, H. T. \& Longerbean, S. D. (2007, September/October). Examining sense of belonging among first-year undergraduates from different racial/ethnic groups. Journal of College Student Development, 48(5), 525-542.

Jones, L., Castellanos, J. \& Cole, D. (2002, January). Examining the ethnic minority student experience at predominantly white institutions: A case study. Journal of Hispanic Higher Education, 1(1), 19-39.

Karlsson, J. (2007). The novice visual researcher. In N. de Lange, C. Mitchell \& J. Stuart (Eds.), Putting people in the picture: Visual methodologies for social change (pp. 185-201). Rotterdam, The Netherlands: Sense Publications.

Karp, M. M., Hughes, K. L. \& O'Gara, L. (2010-2011). An exploration of Tinto's integration framework for community college students. Journal of College Student Retention, 12(1), 69-85.

Keith. P. M. (2007, December). Barriers and nontraditional students' use of academic and social services. College Student Journal, 41(4), 1123-1127.

Koch, W. (1999, Spring). Integration and de facto segregation in campus housing: An 
analysis of campus housing policy. College Student Affairs Journal, 18(2), 3543.

Krause, K. D. (2007). Social involvement and commuter students: The first-year student voice. Journal of the First Year Experience \& Students in Transition, 19(1), 27-45.

Kuh, G. D., Gonyea, R. M., \& Palmer, M. (2001). The disengaged commuter student: Fact or fiction? Commuter Perspectives, 27 (1), 2-5.

Kuk, L., Banning, J. H. \& Amey, M. J. (2012). Positioning student affairs for sustainable change. Styllus: Sterling, VA.

Larking, J., Lombardo, C., Walker, L., Bahreini, R., Tharao, W., Mitchell, C. \& Dubazane, N. (2007). Taking it Global Xpress: Youth, photovoice and HIV \& AIDS. In N. de Lange, C. Mitchell \& J. Stuart (Eds.), Putting people in the picture: Visual methodologies for social change (pp. 31-43). Rotterdam, The Netherlands: Sense Publications.

Lewis, L., Farris, E. \& Greene, B. (1997). Campus Crime and Security at Postsecondary Education Institutions (NCES 97-402). U.S. Department of Education, National Center for Education Statistics. Washington, DC. Retrieved from http://nces.ed.gov/pubs/97402.pdf.

Likins, J. M. (1986, Summer). Developing the commuter perspective: The art of advocacy. NASPA Journal, 24(1), 11-16.

Locks, A. M., Hurtado, S., Bowman, N. A. \& Oseguera, L. (2008, Spring). Extending notions of campus climate and diversity to students' transition to college. The Review of Higher Education, 31(3), 257-285. 
Mason, M. (2010). Sample size and saturation in $\mathrm{PhD}$ studies using qualitative interviews. Forum: Qualitative Social Research, 11(3), article 8. Retrieved from http://www.qualitativeresearch.net/index.php/fqs/article/view/1428/3027.

Massachusetts College of Liberal Arts Residential Programs and Services. (2012). Campus Housing. Retrieved from: http://www.mcla.edu/Student_Life/campushousing/.

Maxwell, J. (1998). Designing a qualitative study. In Bickman, L \& Rog, D. (Eds.), Handbook of applied social research methods. (pp. 69-100). Thousand Oaks, CA: Sage Publications.

McLauren, P. (2003). Critical pedagogy: A look at major concepts. In A. Darder, M. Baltodano \& R.D. Torres (Eds.), The Critical Pedagogy Reader (pp.69-96). New York, NY: Routledge.

Museus, S. D. (2008, November/December). The role of ethnic student organizations in fostering African American and Asian American students' cultural adjustment and membership at predominantly white institutions. Journal of College Student Development, 49(6), 568-586.

Natanson, M. (1973). Introduction: Phenomenology and the social sciences. In M. Natanson (Ed.), Phenomenology and the Social Sciences: Volume 1 (pp. 3-44). Evanston, IL: Northwestern University Press.

Newbold, J. J., Mehta, S. S. \& Forbus, P. (2011). Commuter students: Involvement and identification with an institution of higher education. Academy of Educational Leadership Journal, 15(2), 141-153. 
Noland, C. M. (2006). Auto-photography as research practice: Identity and self-esteem research. Journal of Research Practice, 2(1), 1-16.

Nykiforuk, C. I. J., Vallianatos, H. \& Nieuwendyk, L. M. (2011). Photovoice as a method for revealing community perceptions of the built and social environment. International Journal of Qualitative Methods, 10(2), 103-124.

Office of Institutional Research and Planning. (2013). Information withheld to protect confidentiality.

Ogren, C. A. (2003, November/December). Rethinking the "nontraditional" student from a historical perspective: State normal schools in the late ninteenth and early twentieth centuries. The Journal of Higher Education, 74(6), 640-664.

Ortman, J. (1995). Commuter students in colleges and universities. U.S. Department of Education Report, ED 398779, HE 029376. Retrieved from Wilson Web online database.

Pascarella, E. T. (2006, September/October). How college affects students: Ten directions for future research. Journal of College Student Development, 47(5), pp. 508-520.

Patton, M. Q. (2002). Qualitative research \& evaluation methods. Los Angeles: Sage Publications.

Piedmont College. (2012). Residence Life and Housing: Frequently Asked Questions. Retrieved from: http://www.piedmont.edu/pc/index.php/dorm-faq.

Planty, M., Hussar, W., Snyder, T., Kena, G., KewalRamani, A., Kemp, J., Bianco, K., and Dinkes, R. (2009). The Condition of Education 2009 (NCES 2009-081). Center for Education Statistics, Institute of Education Sciences, U.S. 
Department of Education. Washington, DC. Retrieved from http://nces.ed.gov/pubs2009/2009081.pdf.

Pope, R.L., Mueller, J.A. \& Reynolds, A.L. (2009). Looking back and moving forward: Future directions for diversity research in student affairs. Journal of College Student Development, 50(6), 640-658.

Prosser, J. \& Schwartz, D. (1998). Photographs within the sociological research process. In J. Prosser (Ed.), Image-Based Research (pp. 115-130. New York, NY: Routledge.

Rankin, S. R. \& Reason, R. D. (2005, January/February). Differing perceptions: How students of color and White students perceive campus climate for underrepresented groups. Journal of College Student Development, 46(1), 4361.

Reid, L. D. \& Radhakrishnan, P. (2003). Race matters: The relation between race and general campus climate. Cultural Diversity and Ethnic Minority Psychology, 9(3), 263-275.

Rhatigan, J. J. (1986, Summer). Developing a campus profile of commuting students. NASPA Journal, 24(1), pp. 4-10.

Schratz, M. \& Steiner-Loffler, U. (1998). Pupils using photographs in school selfevaluation. In J. Prosser (Ed.), Image-Based Research (pp. 235-251). New York, NY: Routledge.

Schutz, A. (1973). On Phenomenology and Social Relations. H. R. Wagner (Ed.). Chicago, IL: The University of Chicago Press.

Schwartz, D. (1989). Visual ethnography: Using photography in qualitative research. 
Qualitative Sociology, 12(2), 119-154.

Seidman, I. (2006). Interviewing as Qualitative Research: A Guide for Researchers in Education and the Social Sciences. New York, NY: Teachers College Press.

Scheuer Senter, M. \& Senter, R. (1998, Summer). A comparative study of traditional and nontraditional students' identities and needs. NASPA Journal, 35(4), 270280.

Smith, B. M. (1989). The personal development of the commuter student: What is known from the comparisons with resident students? An ERIC review. Community College Review, 17(1), 47-56.

Snyder, T.D., and Dillow, S.A. (2012). Digest of Education Statistics 2011 (NCES 2012-001). National Center for Education Statistics, U.S. Department of Education. Washington, DC. Retrieved from http://nces.ed.gov/pubs2012/2012001.pdf.

Snyder, T.D., and Dillow, S.A. (2011). Digest of Education Statistics 2010 (NCES 2011-015). U.S. Department of Education, National Center for Education Statistics. Washington, DC. Retrieved from http://nces.ed.gov/pubs2011/2011015.pdf.

Strange, C. C. \& Banning, J. H. (2001). Educating by Design: Creating Campus Learning Environments that Work. San Francisco: Jossey-Bass.

State College (2012). Academic calendar. Retrieved from (website withheld due to anonymity).

State College Assessment. (2012). List of All Assessments. Retrieved from (website withheld due to anonymity). 
State College Mission \& Vision. (2013). Mission Statement. Retrieved from (website withheld due to anonymity).

State College Residential Life \& Housing. (2013). Applying for Housing. Retrieved from (website withheld due to anonymity).

Suarez-Balcazar, Y., Orellana-Damacela, L., Portillo, N., Rowan, J. M. \& AndrewsGuillen, C. (2003, July-August). Experiences of differential treatment among students of color. The Journal of Higher Education, 74(4), 428-444.

Tan, D. L. \& Pope, M. L. (2007, October). Participation in co-curricular activities: Nontraditional student perspectives. College \& University, 83(1), 2-11.

Thomas, D. R. (2006, June). A general inductive approach for analyzing qualitative evaluation data. American Journal of Evaluation, 27(2), 237-246.

Tinto, V. (1987). Leaving college: Rethinking the causes and cures of student attrition.

Torres, V., Gross, J. P. K. \& Dadashova, A. (2010-2011). Traditional-age students becoming at-risk: Does working threaten college students' academic success? Journal of College Student Retention, 12(1), 51-68.

Turley, R. N. L. (2009, April). College proximity: Mapping access to opportunity. Sociology of Education, 82, 126-146.

U.S. Department of Education, Integrated Postsecondary Education Data System. (n.d.). Glossary. Retrieved from http://nces.ed.gov/ipeds/glossary/?charindex=P.

U.S. Department of Education, National Center for Education Statistics. (2011). Fast 
facts: Graduation rates. Retrieved from

http://nces.ed.gov/fastfacts/display.asp?id=40.

U.S. Department of Education, National Center for Education Statistics. (2013). The condition of education 2013: Reference table supplement.

Retrieved from http://nces.ed.gov/pubs2013/2013037_sup.pdf.

University of Massachusetts - Lowell Office of Residence Life. (2009). Residence Hall Contract and Terms of Agreement. Retrieved from: http://www.uml.edu/docs/Housing\%20Contract_tcm18-1001.pdf.

Van Auken, P. M., Frisvoll, S. J. \& Stewart, S. I. (2010, April). Visualising community: Using participant-driven photo-elicitation for research and application. Local Environment, 15(4), 373-388.

Villalpando, O. (2003). Self-segregation or self-preservation? A critical race theory and Latina/o critical theory analysis of a study of Chicana/o college students. Qualitative Studies in Education, 16(5), 619-646.

Wang, C. C. (1999). Photovoice: A participatory action research strategy applied to women's health. Journal of Women's Health, 8(2), 185-192.

Weiss, M. L. (2009). "I'm not part of that whole on-campus college community": The commuter student experience at Rhode Island College. (Unpublished essay). University of Rhode Island, Kingston, RI.

Willis, P. (2001, April). The "things themselves" in phenomenology. Indo-Pacific Journal of Phenomenology, 1(1), 1-12.

Wilson, A. H. (2003, September-October). Serving the quiet majority: The Drexel commuter program. About Campus, pp. 23-25. 
Wolfe, J. (1993, September). Institutional integration, academic success, and persistence of first-year commuter and resident students. Journal of College Student Development, 34, 321-326.

Yosso, T. J., Smith, W. A., Ceja, M., \& Solórzano, D. G. (2009). Critical race theory, racial microaggressions, and campus racial climate for Latino/a undergraduates. Harvard Educational Review, 79(4), 659-786. 